Prof. Mg. Leandro Nicolás Marcó

\title{
Ambiente y Asma, ¿Qué hay más allá de la Alergia?
}

\author{
Estudio epidemiológico del asma infantil \\ en Concepción del Uruguay \\ Factores inespecíficos de riesgo
}

Tesis presentada en la carrera de Doctorado

Facultad de Ciencias Médicas

Universidad Nacional de La Plata

Director de Tesis: Prof. Dr. José María Paganini 
A Roque Jorge Marcó que me señaló un rumbo de compromiso con la Medicina y la Salud pública 


\section{Contenido}

Introducción

Capítulo 1.

Capítulo 2 Definición y diagnóstico de asma

Diagnóstico de Asma.

Caracterización del asma infantil.

Estudios epidemiológicos.

Factores de riesgo para el Asma bronquial.

Capítulo 3 Contaminación del aire.

Componentes naturales y contaminantes del aire

Aspectos especiales del aire interior.

Humo de tabaco

Hongos aerógenos

Formaldehido.

Insecticidas

Otros factores inespecíficos del aire interior.

Aspectos especiales del aire exterior

Partículas

Áreas inundables.

Diseño de la investigación y otros aspectos metodológicos

Capítulo 4 Proyecto de investigación.

Objetivos

Material y métodos.

Criterios y procedimientos para la aplicación de las encuestas

Plan de análisis 
Presentación y análisis de resultados.

Capítulo 5 Descripción de síntomas, severidad, antecedentes y tratamientos. 88

$\begin{array}{lr}\text { Síntomas. } & 88\end{array}$

$\begin{array}{ll}\text { Severidad } & 91\end{array}$

$\begin{array}{ll}\text { Hiperreactividad bronquial } & 91\end{array}$

$\begin{array}{ll}\text { Descripción de antecedentes } & 91\end{array}$

Descripción de tratamientos 95

Capítulo 6. Estudio de casos y controles 99

$\begin{array}{ll}\text { Unidad de análisis Niño (endógena) } & 100\end{array}$

$\begin{array}{ll}\text { Unidad de análisis vivienda y entorno próximo } & 105\end{array}$

$\begin{array}{ll}\text { Determinación de variables ambientales específicas } & 105\end{array}$

$\begin{array}{ll}\text { Capítulo } 7 & 108\end{array}$

Factores de riesgo inespecíficos según la percepción familiar 108

$\begin{array}{ll}\text { Factores inespecíficos del ambiente interior } & 111\end{array}$

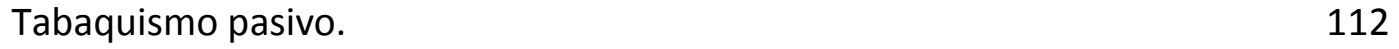

$\begin{array}{ll}\text { Hongos aerógenos } & 118\end{array}$

$\begin{array}{ll}\text { Formaldehido } & 125\end{array}$

$\begin{array}{ll}\text { Uso de insecticidas } & 129\end{array}$

$\begin{array}{ll}\text { Tipo de calefacción } & 135\end{array}$

$\begin{array}{ll}\text { Otros factores inespecíficos del aire interior. } & 139\end{array}$

$\begin{array}{ll}\text { Unidad de análisis ambiente exterior } & 143\end{array}$

Discusión de los resultados. 156

$\begin{array}{ll}\text { Tema 1. Factores de confusión. } & 156\end{array}$

$\begin{array}{ll}\text { Tema 2. Tabaquismo pasivo. } & 158\end{array}$

Tema 3. Hongos en el dormitorio no aumentan el riesgo 163

$\begin{array}{ll}\text { Tema 4. Formaldehido } & 165\end{array}$ 
Tema 5. Insecticidas

Tema 6. Sistemas de calefacción

Tema 7. Otros factores contribuyentes del aire interior

Tema 8. Contaminantes atmosféricos

Tema 9: zonas inundables

Conclusiones y propuestas

Aspectos más destacables de lo hallado

Propuesta de investigaciones complementarias

Recomendaciones sanitarias. 


\section{Introducción}

\section{Capítulo 1}

¿Es interesante estudiar la epidemiología del asma infantil en una ciudad mediana de la región mesopotámica argentina? ¿Está todo dicho sobre sus factores de riesgo, causales, predisponentes y desencadenantes? ¿Persisten algunas controversias al respecto? ¿Pueden surgir aportes de interés para la acción sanitaria y la atención clínica?

Estas y otras preguntas intentaré responder en el desarrollo de la Tesis, con la convicción de que los trabajos académicos médicos deben buscar una contribución en el esfuerzo preventivo y asistencial de enfermedades, que a pesar de su frecuencia y su exposición en numerosas publicaciones, no tienen una concepción compartida entre los distintos enfoques médicos (generalistas y familiares, pediatras, alergistas inmunólogos, neumólogos y sanitaristas). Estas diferentes miradas, la falta de actualización en algunos casos y la excesiva difusión de publicaciones muchas veces interesadas parecen favorecer un espectro demasiado amplio y desordenado de abordajes clínicos y sanitarios. La complejidad del asma, como punto de encuentro bronquial de la genética y la inmunología con el ambiente interior y exterior, justifican estudiar y actualizar permanentemente, tanto sobre los avances en el conocimiento de los aspectos endógenos involucrados, las alternativas terapéuticas como las realidades ambientales de cada región.

La calidad de vida de los niños asmáticos está muy condicionada por la resultante de la interacción entre los profesionales tratantes, las familias y los "opinadores" del entorno familiar o mediático. Es muy frecuente detectar una gran sumatoria de restricciones de todo tipo, que generalmente terminan afectando el goce cabal de la vida. No realizar ejercicios físicos normales, descartar las mascotas hogareñas y todos los juguetes, en particular los muñecos "peluches", evitar las actividades al aire libre, se suman a algunas recomendaciones como practicar intensamente natación en ámbitos climatizados, generalmente clorados sin control, confiar en que un par de dosis diarias de corticoides inhalados es suficiente como acción preventiva ${ }^{1}$, humectar u ozonizar el dormitorio del niño, entre tantas que he detectado en mi experiencia. Generalmente por 
opción personal o familiar, muchos pacientes han basado su tratamiento en el uso intensivo de $\beta$-adrenérgicos inhalados con efecto de corta duración, lo que ha sido fuertemente asociado a las dos epidemias de mortalidad de asma en población joven que se observaron en varios países ${ }^{2}$. El ausentismo escolar, el gran número de consultas ambulatorias y de emergencia, las internaciones y un costo importante en medicamentos son cuestiones de interés para la Salud pública y el bienestar social.

La estrategia global para el manejo y la prevención del Asma, propuesta por la Organización Mundial de la Salud, ha recomendado como necesidades de investigación, entre otras, las de identificar los factores que contribuyen al desarrollo del Asma y los alérgenos e irritantes para cada área geográfica ${ }^{3}$.

Existen evidencias de que la prevalencia está aumentando en todo el mundo, sobre todo en la población joven y con estilo de vida occidental ${ }^{4}$. En Estados Unidos de América ha aumentado un 33\% la prevalencia en adultos entre el 2000 y el $2009^{5}$. Los estudios para determinar posibles causas de este aumento o de las variaciones en la prevalencia entre los países son insuficientes, contándose con mayor información de la situación en los países más desarrollados de occidente, de los cuales provienen la mayor parte de las publicaciones. En una comparación internacional basada en el estudio cooperativo mundial denominado "The International Study of Asthma and Allergies in Chilhood" (ISAAC) 6 , la Argentina se ubica en un rango de prevalencia intermedia (10 a 20\%), con mayor valor a los 6 años de edad que a los 13 años. En el caso de la mortalidad por Asma, la Argentina presenta cifras 3 a 4 veces más elevadas que las de los países desarrollados.

En el Congreso Mundial de Asma realizado en Buenos Aires en 1999, el Prof. Dr. Jonathan Samet de la Johns Hopkins University, planteó las preguntas claves para la investigación epidemiológica7:

- “¿por qué la prevalencia varía marcadamente entre diferentes lugares del mundo?

- ¿ ¿por qué la ocurrencia de asma varía en el tiempo y qué está induciendo el actual incremento?

- ¿ ¿podrá la reducción de factores de riesgo afectar la ocurrencia del asma?

- ¿Cuál es el rol de los genes en la determinación del riesgo de asma? 
- ¿por qué la tasa de mortalidad varía en el tiempo y en los diferentes países?, ¿Cuál es el rol de los agentes terapéuticos en el riesgo de mortalidad?

- ¿puede ser modificada la historia natural del asma por los cambios ambientales o las intervenciones terapéuticas?

Responder a estas preguntas requiere un compromiso sustancial con la investigación y décadas de proyectos".

En su exposición, realizaba algunos aportes para orientar la búsqueda de respuestas, mencionando entre otros:

"La rapidez del aumento del asma solo puede ser explicada por cambios en las exposiciones ambientales. Numerosas especulaciones se han propuesto para resolver esta hipótesis:

$\checkmark$ Cambios en el hogar con incremento de la exposición a contaminantes del aire interior..."

Mencionaba a continuación otras relacionadas con la experiencia inmunológica modificada, la inactividad física y los cambios en la dieta. Otros autores ${ }^{8}$ también coinciden con esta posición.

Los factores ambientales pueden clasificarse, desde el punto de vista alergológico, en específicos e inespecíficos según el tipo de respuesta inmunitaria. Otra clasificación importante es según la localización doméstica o del aire interior, y la externa a los hogares y otros lugares cerrados, llamada del aire exterior.

Las respuestas específicas, mediadas por IgE, se manifiestan en general por alergia a ácaros, pólenes, esporas fúngicas, epitelios de animales y otras partículas alergénicas. Están determinadas genéticamente y la presencia de estos antígenos en el ambiente solo genera reacciones en quienes tienen la predisposición para aquella respuesta. En el caso de las mascotas hogareñas, por ejemplo, puede comprobarse que la presencia en la casa no es claramente un factor directo de riesgo y por el contrario hasta podría tener cierto efecto protector ${ }^{9}$. Entre otras razones, esto podría explicarse porque es relativamente baja la prevalencia de individuos con capacidad de responder con una IgE específica a los determinantes antigénicos propios de los epitelios. Solo serán un importante factor de 
riesgo cuando en el niño haya una sensibilidad inmediata tipo I a los mismos. Pueden estudiarse mediante pruebas cutáneas, provocaciones y determinaciones in-vitro, arribando generalmente a diagnósticos muy certeros.

Por otra parte, los factores inespecíficos actúan por otros mecanismos no mediados por IgE, generalmente produciendo irritaciones en la mucosa respiratoria que, según el variable umbral de irritabilidad de cada persona, en cada momento, podrán conducir a manifestaciones obstructivas, inflamatorias e hipersecretantes. Estos factores no pueden estudiarse mediante las pruebas cutáneas ni por la búsqueda in-vitro que detectan la presencia de IgE específica. En algunos casos podrían realizarse pruebas de provocación inhalatoria que deberían restringirse a casos muy especiales. Por lo tanto, aumenta la importancia del estudio epidemiológico para orientar las decisiones terapéuticas y preventivas de control ambiental tanto a nivel individual como colectivo.

Los desencadenantes o factores de riesgo inespecíficos pueden clasificarse en dos conjuntos importantes: físico/químicos y psicológicos.

\section{Factores físicos y químicos,}

Actúan principalmente como irritantes directos y como amplificadores de respuestas alérgicas específicas ${ }^{10}$ :

- Climáticos (frío excesivo, cambios bruscos de temperatura, corrientes de aire y humedad). En los niños con umbral bajo de excitabilidad de la mucosa bronquial (predisposición), la hiperventilación de aire frío y seco (factor climático) provoca broncoespasmo y tos seca.

- Contaminantes ambientales (humos, gases, partículas, olores intensos) tanto del ambiente interior como exterior.

\section{Factores psicológicos:}

En el marco de psiquismo infantil y su interrelación con la familia y el ambiente, se han propuesto varios cuadros vinculados con el asma:

- Aspectos de la personalidad: Mientras que en muchos casos la enfermedad es asumida con los cuidados adecuados a cada caso sin exageraciones ni 
sobreprotecciones ni medicalización excesiva, y no se detectan repercusiones psíquicas de importancia en el niño, se ha descripto en otros casos una "personalidad del niño asmático".

- "Seudoasma" o asma nerviosa11: desencadenada exclusivamente por impulsos psicológicos que pueden estar relacionados con el entorno familiar (personas con asma $\mathrm{u}$ otros cuadros respiratorios severos agregados a situaciones conflictivas) o con el entorno físico (se han descripto cuadros de disnea producidos en habitaciones con muchas manchas de humedad y hongos que se atribuyen a la sugestión, aunque en estos casos como en otros de lugares contaminados con olores o humos podrían actuar mecanismos irritativos sobre las mucosas respiratorias).

- Crisis de asma psicogénica. No pueden demostrarse otros factores etiológicos mientras que se detecta una clara vinculación con situaciones conflictivas del niño (entre otras en situaciones de rechazo del hijo por la madre). Muñoz López ${ }^{12}$ afirma que el factor psicológico que interviene en la crisis es exógeno, "nunca endógeno". "No hay una personalidad asmática previamente establecida, sino que ésta se moldea, como toda personalidad, sobre unos elementos intelectuales, somáticos, sensoriales, etc...". Es importante tener en cuenta que la hiperventilación producida por el llanto, la risa o una tensión nerviosa de causa exógena puede provocar en sujetos hiperirritables un cuadro de tos seca y sibilantes que ya no es psicogénico sino mediado por una serie de factores somáticos. 


\section{Capítulo 2}

\section{Definición y diagnóstico de asma}

La definición del Asma ha variado según los avances en el conocimiento de su fisiopatogenia, con la incorporación de conceptos que han modificado en forma importante los diversos enfoques sobre la misma. En el momento actual se considera al Asma como una enfermedad inflamatoria crónica de las vías respiratorias que se caracteriza por episodios de disnea sibilante e hiperreactividad bronquial. Desde el punto de vista fisiopatogénico ocurre un estrechamiento generalizado de las vías aéreas, debido a broncoespasmo (contracción del músculo liso bronquial), edema e infiltración de células en la pared bronquial, formación de tapones mucosos y remodelamiento de la pared bronquial, entre otros fenómenos, siendo variado el peso relativo de cada uno, el último de ellos en una etapa posterior del curso evolutivo.

Se manifiesta clínicamente por episodios recurrentes de disnea sibilante, tos seca o con escasa expectoración mucoide y opresión torácica. Se alternan períodos de exacerbación aguda con otros asintomáticos o de síntomas atenuados. Pueden revertirse en forma espontánea o mediante tratamiento específico, pero en la fase más tardía de la remodelación, se producen alteraciones poco o nada reversibles. Los casos más severos presentan síntomas permanentes y crisis con afectación importante y riesgo de vida.

La hiperirritabilidad bronquial es la respuesta exagerada de las vías aéreas a diversos estímulos físicos, químicos o farmacológicos que tiene un componente principal obstructivo, con aparición rápida de disnea sibilante y/o tos seca. No solo puede encontrarse en asmáticos sino también en otras enfermedades como las bronquitis crónicas, tabaquismo y fibrosis quística. En algunos niños se asocia a variantes de genes asociados con el asma y la exacerbación en la primera infancia. Como informan Bisgaard y colaboradores ${ }^{13}$ "una variación en el locus $17 q 12$ - q21 se asoció con aproximadamente doble riesgo de sibilancias recurrentes, exacerbaciones del asma e hiperreactividad bronquial desde la primera infancia hasta la edad escolar, pero sin conferir riesgo de eczema, rinitis, o sensibilización a alérgenos". Enrique Mathov ${ }^{14}$ describe tres componentes de la HRB: broncolabilidad, broncorreactividad y reflejos tusígenos 
broncoconstrictores. Los síntomas asociados son el broncoespasmo inducido por el esfuerzo, el aire frío y seco y la tos nocturna. Estaría inducida por un umbral bajo de reactividad de las vías aéreas.

La mayor prevalencia del asma es en la infancia y el pico de incidencia ocurre alrededor de los 10 años de edad, tendiendo a decaer luego hasta la adultez joven, donde se produce un nuevo incremento ${ }^{15}$. Como se describirá más adelante, hay fenotipos evolutivos diferentes principalmente condicionados por la presencia de atopía. Dos tercios de los niños con sibilantes remiten en la adolescencia y la juventud, pero quienes presentaban asma en la escuela primaria tienen alto riesgo de continuar con ella muchos años después (OR: 14 para asma 25 años después ${ }^{16}$ ). El tercio que no remite presenta en su mayoría cuadros leves intermitentes o persistentes leves y moderados. En la adultez son raras las remisiones completas, salvo cuadros leves con tratamientos tempranos bien ejecutados ${ }^{17}$. Las evoluciones con cuadros severos y progresivo empeoramiento, con remodelación de la vía aérea, pueden conducir a la muerte. La mortalidad por asma es relativamente baja, y luego de un incremento a nivel mundial unas décadas atrás, en los últimos veinte años ha tendido a disminuir, presumiblemente debido al mejor manejo en cuanto a diagnóstico y terapéuticas disponibles. En la Argentina la tasa observada en los años 80 era de 3,38 cada 100.000 habitantes y ajustada para el grupo etareo de 5 a 34 años de 0,68/100.000 ${ }^{18}$, que bajaron en 1997 a 2,8 y 0,43 respectivamente, valores intermedios para la realidad mundial y latinoamericana.

Profundizando en su estudio, el asma aparece como un síndrome complejo tanto en sus expresiones fenotípicas (observables), como en fisiopatogenia que reconoce diversos endotipos cuando se la estudia desde la Biología y la Química molecular. Estas subdisciplinas han aportado conocimientos que aportan a una mejor comprensión de la historia natural y de las implicancias genotípicas y clínicas. El hallazgo de biomarcadores endotípicos orienta en la selección de distintos enfoques terapéuticos ${ }^{19}$. La Epidemiología ha realizado también aportes de importancia.

\section{Diagnóstico de Asma.}

Para arribar al diagnóstico de Asma deben seguirse los siguientes procedimientos:

- Anamnesis. 
- Examen físico

- Mediciones objetivas de la obstrucción del flujo aéreo y su seguimiento para detectar variabilidad

- Pruebas de provocación bronquial para detectar hiperirritabilidad.

- Estudios alergológicos.

- Estudios de esputo inducido y fibrobroncoscopías para anatomía patológica

- Otras pruebas complementarias para diagnóstico diferencial.

La anamnesis orientada a detectar los episodios recurrentes de disnea sibilante, tos con nula o escasa expectoración blanquecina, opresión torácica, con señales de hiperirritabilidad de vías aéreas y desencadenantes de tipo irritativo o alergénico, la reversibilidad del cuadro ya sea espontáneamente o mediante tratamiento, junto a los datos negativos para otras patologías, pueden servir y son utilizados para diagnosticar Asma tanto a los fines clínicos como epidemiológicos. ${ }^{20}{ }^{21}$. Este interrogatorio es decisivo para el diagnóstico ya que tanto el examen físico como los estudios complementarios pueden dar falsos negativos. En esta afirmación se fundamentan la mayoría de los estudios epidemiológicos basados en un cuestionario, como el multicéntrico argentino (FUNDALER) ${ }^{22}$, o como el multicéntrico mundial ISAAC ${ }^{23}$, en los que he participado, como centro colaborador.

Si siempre "una buena anamnesis representa la mitad del diagnóstico"24, y "para el diagnóstico, una hora de cuidadoso interrogatorio vale más que diez horas de exploración" ${ }^{25}$, en el caso del Asma puede afirmarse que es mayor aún la importancia. Indudablemente que influyen sobre la calidad de la misma la formación y el entrenamiento previo del examinador y el diálogo que logre establecerse en la entrevista, aumentando la complicación en el caso de los niños menores cuando generalmente interviene la madre con su propia interpretación de los fenómenos.

El examen físico adquiere importancia cuando puede observarse al paciente en pleno episodio asmático pero carece de valor para descartar la enfermedad ya que puede ser completamente normal en las intercrisis, sobre todo en el Asma leve. Es útil para el diagnóstico diferencial y la detección de patologías agregadas de importancia.

Las mediciones de la función pulmonar, tanto espirométricas como los monitoreos de pico flujo, son decisivas para el diagnóstico, sobre todo si se puede hacer 
un seguimiento en el tiempo y registrar las variaciones que justamente son una de las características esenciales de esta patología. Una medición normal aislada no descarta la enfermedad.

Los estudios alergológicos (pruebas cutáneas, IgE total y específica, provocación con alérgenos, etc...) contribuyen a confirmar el diagnóstico en su componente fisiopatogénico, ya que más del $50 \%$ de los casos de asma tienen un fuerte componente alérgico, y se piensa que esta proporción puede aumentar en la medida que se perfeccionen los métodos de estudio. Los resultados negativos en estas pruebas no descartan el asma, pero se lo considera un factor de riesgo de padecerla. El concepto actual de atopía, ha variado desde el inicial postulado por Coca en 1920, hacia la propuesta de concebirla como la predisposición familiar para desarrollar una respuesta mediada por IgE frente a los alérgenos ambientales comunes, con bases genéticas importantes que se manifestará como Rinitis asociada o no con Conjuntivitis, Eccema y Asma. Se ha generalizado en la práctica no especializada el uso de la IgE total para catalogar esta susceptibilidad alérgica, aunque existen muchos casos en la que un nivel normal de esta inmunoglobulina acompaña a reactividades alérgicas específicas bien claras.

También se pueden usar las mediciones de la función pulmonar ya mencionadas, para ejecutar pruebas de provocación, que al detectar la hiperirritabilidad bronquial prácticamente confirman el diagnóstico cuando la historia es sugestiva. Son de mayor utilidad cuando la espirometría basal es normal pero se sospecha Asma. Cuatro alternativas para detectar y medir la hiperirritabilidad que son comúnmente usadas en investigaciones de este tipo son:

- Provocación con Histamina

- Provocación con Metacolina

- Provocación con esfuerzos físicos estandardizados y aire frío y seco.

- Provocación con esfuerzos físicos estandardizados

Se ha afirmado que para la comprobación definitiva de Asma actual, desde el punto de vista de la atención clínica individual pueden utilizarse las pruebas positivas de provocación mediante inhalación de histamina o metacolina o por la realización de esfuerzos físicos controlados, sumadas al registro de los síntomas durante el último año. 
En realidad, el resultado negativo de estas pruebas en un paciente con asma leve intermitente que esté correctamente tratado, no puede inducir a dejar de considerarlo asmático, por lo que la utilidad de las mismas podría reducirse a un primer momento de diagnóstico o como parte del seguimiento. La variabilidad del umbral de irritabilidad bronquial es amplia ya sea en su curso natural como en respuesta a los tratamientos.

Por estas y otras razones, los estudios epidemiológicos poblacionales, tienden a usar como parámetros principales las respuestas de los pacientes o sus familiares sobre la ocurrencia en los últimos 12 meses de episodios de sibilantes, tos seca, sin un cuadro compatible con resfrío u otra infección de vías aéreas, que se presenta frecuentemente por la noche o en situaciones de hiperventilación o esfuerzo físico. En algunos casos se interroga sobre el uso de corticoides inhalados 262728 .

Los estudios de esputo y la fibrobroncoscopia pueden proveer varios datos que orienten hacia el diagnóstico como el hallazgo de diversas señales de inflamación ya sea de tipo alérgico (eosinofilias, etc....) o no atópico (neutrofilias, etc...), así como para descartar otras etiologías del síndrome obstructivo.

En el mismo sentido, otros estudios (Radiografías de tórax, tomografías axiales computarizadas de senos paranasales, diversas determinaciones de laboratorio, etc...) pueden aportar para comprender mejor el caso particular, sus posibles enfermedades asociadas y sobre todo para profundizar en el diagnóstico diferencial.

Recientemente se está avanzando en la determinación de los transcriptomas extraídos de mucosa nasal, como alternativa menos invasiva para determinar subfenotipos de asma. Los transcriptomas, que representan al RNA, exponen los genes ligados a los endotipos de respuesta asmática Th 2 alto y Th 2 bajo que describiremos posteriormente. Pueden hallarse unas 70 expresiones genéticas entre las que cabe mencionar a los que codifican para IL13, IL5 y periostin (POSTN) ${ }^{29}$.

Para los estudios epidemiológicos pueden utilizarse, si están disponibles, diagnósticos clínicos de mayor certeza como los que aplican los procedimientos descriptos. Pero en los estudios poblacionales con muestras más grandes, de suma utilidad para medir con mayor aproximación y menores sesgos de selección la prevalencia y los factores asociados, se utilizan criterios abreviados, muchas veces basados en autocuestionarios a las propias personas o a sus familiares. La validez de esta 
aproximación diagnóstica, mediante el relevamiento de síntomas indicadores de asma, ha sido estudiada con resultados favorables ${ }^{30} 31$ y aplicada en muchos trabajos por grupos de primer nivel en el tema y publicados en las revistas científicas más calificadas ${ }^{32}$. 


\section{Caracterización del asma infantil.}

A efectos de esta Tesis, se denomina asma infantil a la presente durante los primeros 6 años de vida, considerando asma actual a la que presentó síntomas en los últimos doce meses o tiene diagnóstico médico de asma con el tratamiento respectivo. Esta edad es una de las más frecuentemente adoptadas por las investigaciones epidemiológicas para la infancia.

Según Fernando Martinez (1995) ${ }^{33}$, el 51\% de los niños no presenta sibilantes en los primeros 6 años de vida. Para el $49 \%$ restante, se han descripto tres fenotipos de niños sibilantes y sus probables frecuencias:

- Sibilantes muy tempranos transitorios (entre 0 a 3 años y asintomático a los 6 ) $\mathbf{2 0 \%}$

- Sibilantes tardíos (aparición de sibilantes después de los 3 años de edad) $\mathbf{1 5 \%}$

- Persistentes (sibilantes a los 3 y a los 6 años) $14 \%$.

A su vez estos tres fenotipos pueden agruparse en dos conjuntos ${ }^{34}$ :

\section{Asma temprana transitoria (no alérgica)}

Tos seca, sibilantes y disnea, generalmente durante la noche o primeras horas de la mañana, en episodios reiterados que comienzan generalmente durante los primeros meses de vida y ceden antes de los 6 años de edad, sin recidivas en el futuro, aunque puede persistir una hiperreactividad bronquial (HRB) leve algunos años más. Barker (1992), rastreando los orígenes fetales o infantiles de las enfermedades en el adulto, plantea que estos cuadros podrían estar relacionados con la proclividad a desarrollar enfermedad pulmonar obstructiva crónica en el adulto ${ }^{35}$. Puede presentarse solamente como tos recurrente nocturna o por hiperventilación generalmente bucal (esfuerzo, llanto, risa, etc...). Hay que estudiar alternativas diagnósticas como la fibrosis quística, la aspiración recurrente de leche, el reflujo gastroesofágico, la aspiración de cuerpo extraño, el síndrome de disquinesia ciliar primaria, inmunodeficiencias primarias, cardiopatías congénitas y estrechamiento congénito de las vías aéreas generalmente asociado a bajo peso al nacer, entre otros ${ }^{36}$. 
Estos niños tienen generalmente antecedentes de bronquiolitis y otras virosis respiratorias y no tienen antecedentes de alérgicos en la familia. No presentan eccemas ni rinitis de tipo alérgico. Fernando Martinez $(1991)^{37}$, un importante investigador de la Universidad de Arizona (USA), sugiere que la anomalía básica está más relacionada con el tamaño de las pequeñas vías aéreas que con la inflamación y tiende por lo tanto a normalizarse con el crecimiento. Las virosis respiratorias (principalmente rinovirus) ${ }^{38}$ serían un desencadenante frecuente de los episodios ${ }^{39}$.

\section{Asma alérgica}

Abarca dos fenotipos según el momento del inicio de los sibilantes.

El cuadro clínico típico del asma aparece luego de los tres años con un incremento progresivo de la incidencia con el pico mayor a los 10 años de edad. Presenta antecedentes de eccema y rinitis alérgica y pertenece a familias atópicas. Tiende a persistir luego de la infancia, habiéndose descripto una "marcha alérgica" que comienza con el eccema en los pliegues, sigue con la rinitis y termina con el cuadro de vías aéreas bajas. Puede presentarse solamente como tos recurrente nocturna o por hiperventilación (esfuerzo, llanto, risa, etc...), señal de hiperirritabilidad de las vías aéreas.

El fenotipo de sibilantes persistentes, niños que comienzan en los tres primeros años y continúan sintomáticos a los 6 y más años, tienen en general una etiología alérgica y antecedentes personales y familiares de atopia. La cohorte de Perth, mostró una reactividad bronquial aumentada a las 4 semanas de vida, en niños con padres atópicos, antes de que aparecieran síntomas de asma ${ }^{40}$. La Sociedad Argentina de Pediatría ha propuesto los siguientes criterios predictivos en casos de niños de 0 a 3 años, que hayan tenido tres o más episodios de obstrucción bronquial reversible y, al menos, un criterio mayor más dos de los criterios menores ${ }^{41}$ :

\begin{tabular}{|l|l|}
\hline \multicolumn{2}{|c|}{ Índice clínico predictivo de asma en el niño pequeño. SAP 2008.} \\
\hline \multicolumn{1}{|c|}{ Criterios mayores } & \multicolumn{1}{c|}{ Criterios menores } \\
\hline Diagnóstico de asma en los padres & Diagnóstico de rinitis alérgica \\
\hline Diagnóstico médico de eccema en el niño & Sibilancias fuera de los resfríos \\
\hline & Eosinofilia $>4 \%$ \\
\hline
\end{tabular}


Es interesante conectar esta clasificación del asma infantil con las diferentes formas de manifestarse la evolución en el adulto. Desde hace mucho se ha diferenciado un asma extrínseca en la que predomina la causalidad alérgica típica y de comienzo temprano, del asma intrínseca de comienzo en el adulto, en la que no puede demostrarse un alérgeno causal ni se detectan antecedentes personales y familiares típicos de la atopia $^{42}$. Se diferenciaban también por una serie de características que hoy pueden reconocerse en algunos de los fenotipos usados actualmente, aunque no coinciden estrictamente las categorías enunciadas.

En los últimos tiempos se ha propuesto una aproximación integradora multiescala, incorporando datos moleculares, celulares, estructurales, clínicos, epidemiológicos y de resultados terapéuticos ${ }^{43}$, que relacionan los genotipos, con los endotipos y los fenotipos, construcciones teóricas en plena elaboración que pretenden aportar a la comprensión de este tipo de patologías tan complejas. La principal utilidad está dada por la utilización más precisa de nuevos abordajes terapéuticos y por el pronóstico y seguimiento a largo plazo.

Las características endotípicas básicas que generan dos grandes categorías, se refieren a la presencia en las vías aéreas de inflamación eosinofílica y de una serie de citoquinas propias de los linfocitos Th 2, (Th 2 high) o un bajo nivel de los mismos (Th 2 low $)^{44}$. Fundamentalmente se basa en la alta o baja expresión de los genes inducibles para $\mathrm{IL}-13^{45}$. 


\begin{tabular}{|c|c|c|c|c|c|c|}
\hline & Fenotipo & Subtipo & Genotipo & Endotipo & Tipo epidemiológico & Terapéutica etiopatogénica \\
\hline \multirow{4}{*}{$\begin{array}{l}\text { Alérgica Extrínseca } \\
\text { (alérgica) }\end{array}$} & Infantil & \begin{tabular}{|c|}
$\begin{array}{c}\text { Comienzo muy temprano } \\
\text { (0 a } 2 \text { años) y persistente }\end{array}$ \\
$\begin{array}{c}\text { Comienzo en } 2^{\circ} \text { infancia } \\
\text { (5 a } 10 \text { años, persistente. }\end{array}$ \\
\end{tabular} & $\begin{array}{l}\text { Atopia autosómico } \\
\text { dominante }(\mathrm{Cr} 11) \text { 17q12; } \\
\text { genes inducibles para } \\
\text { IL/13 y } 5 \text {. Th2. genes } \\
\text { relacionados con } \\
\text { Periostin }\end{array}$ & \begin{tabular}{l}
\multicolumn{1}{c|}{ Perfil Th2 $^{[1]}$ alto } \\
Alergia I, IgE especifica elevada citoquinas Th2. \\
IL13, 4 y 5. \\
FeNO el evado. Inflamación eosinofílica vía aérea. \\
Leve engrosamiento de membrana basal \\
(remodelación) Ninguno es específico del endotipo
\end{tabular} & $\begin{array}{l}\text { Familia atópica } \\
\text { Rinitis y eccema. } \\
\text { Cuadros leves, moderados y } \\
\text { severos. HRB y AlE variables }\end{array}$ & $\begin{array}{l}\text { Inmunoterapia específica. Ac antilgE y } \\
\text { antilL-13 (leikrizumab) antagon IL-4 } \\
\text { (en modelos) Responde a corticoides } \\
\text { inhalados menos en asma crónica } \\
\text { con remodelación; Blanco en Th2 }\end{array}$ \\
\hline & Adultez & Comienzo entre $20 \mathrm{~s}$ a $40 \mathrm{~s}$ & $\begin{array}{l}\text { Escasa historia familiar. } \\
\text { Genes de respuesta Th2 }\end{array}$ & \begin{tabular}{l}
\multicolumn{1}{c}{ Perfil Th2 alto } \\
Alergia leve Esputo eosinofílico persistente (>2\%) \\
citoquinas Th2: IL-5 IL-13. lipoxigenasa 1 yácido \\
hydroxieicosaetetranoico, sintetasa de FeNO, \\
eotaxina-2, cisteinil leucotrieno urinario elevado \\
\end{tabular} & $\begin{array}{l}\text { Generalmente severa desde el } \\
\text { comienzo }\end{array}$ & $\begin{array}{l}\text { Respuesta anti- IL-5 y a modificadores } \\
\text { de leucotrienos; Eosinofilia con baja } \\
\text { respuesta a corticoides que deben ser } \\
\text { usados sistémicos para prevenir } \\
\text { exacerbaciones y reducir síntomas }\end{array}$ \\
\hline & & Comienzo tardío. & $\begin{array}{l}\text { Gen que expresa } \\
\text { periostin en pólipos } \\
\text { nasales }\end{array}$ & Subendotipo: AERD & $\begin{array}{l}\text { Inducido por AAS y AINE. } \\
\text { Rinosinusitis crónica }\end{array}$ & antiLeucotrienos \\
\hline & $\begin{array}{l}\text { Adultez. Niños y } \\
\text { adoles-centes, HRB }\end{array}$ & $\begin{array}{c}\text { Asma linducida por el } \\
\text { Esfuerzo }\end{array}$ & & $\begin{array}{l}\text { Activación de mastocitos; citoquinas Th2; } \\
\text { leucotrienos asociados con eosinofilia en esputo y } \\
\text { tejidos. Liberación de mediadores para neutrofilia. } \\
\text { Respuesta de receptores epiteliales y reflejo de } \\
\text { vasoconstricción con hiperemia reactiva } \\
\text { posterior }{ }^{[2]} \text {. }\end{array}$ & Deportistas; Leve intermitente & $\begin{array}{l}\text { Respuesta a beta agonistas, CGDS, } \\
\text { antileucotrienos y Ac antillL9 }\end{array}$ \\
\hline \multirow{4}{*}{$\begin{array}{l}\text { Intrínseca (no } \\
\text { alérgica) }\end{array}$} & Infantil & $\begin{array}{l}\begin{array}{l}\text { Temprano transitorio }(0 / 2 \\
\text { años) }\end{array} \\
\end{array}$ & Familia no atópica & Perfil Th2 bajo & Asociado a bronquiolitis y $\mathrm{VSR}^{[3]}$ & \\
\hline & \multirow{3}{*}{ Adultez } & $\begin{array}{l}\text { Obesidad en adultos ( } 40 \\
\text { años y más años) }\end{array}$ & $\begin{array}{l}\text { Familia no atópica. } \\
\text { Posible alteración } \\
\text { genómica para asma y } \\
\text { obesidad. Cr 16p11.2 }\end{array}$ & $\begin{array}{l}\text { Perfil Th2 bajo } \\
\text { (TNF) } \alpha \text {, IL-6 y leptinas, estrés oxidativo. >ADMA }{ }^{[4]} \text {. } \\
\text { Asociado con síndrome metabólico con aumento de } \\
\text { producción de citoquinas Th2 al bajar de peso. }\end{array}$ & $\begin{array}{l}\text { Asma severa pero escasa o leve } \\
\text { alergia, relación con obesidad, } \\
\text { generalmente mujeres, muy } \\
\text { sintomática. HRB }\end{array}$ & $\begin{array}{c}\text { Res puesta favorable a pérdida de } \\
\text { peso, (Cirugía bariátrica). } \\
\text { Antioxidantes y posibilidad de terapia } \\
\text { hormonal }\end{array}$ \\
\hline & & $\begin{array}{l}\text { Comienzo tardío, poca } \\
\text { reversibilidad }\end{array}$ & $\begin{array}{c}\text { (Cr 5) Expresión genética } \\
\text { en esputo a mplificadora } \\
\text { vía IL-1 y TNFa }{ }^{[5]} \\
\end{array}$ & \begin{tabular}{l}
\multicolumn{1}{c}{ Perfil Th2 bajo } \\
Neutrofilia en esputo, Amplificación de vía IL-1 y \\
TNF- $\alpha$ Th17; IL-8
\end{tabular} & $\begin{array}{l}\text { bajo FEV1, atrapamiento aéreo y } \\
\text { frecuente asma severa }\end{array}$ & $\begin{array}{l}\text { Posible respuesta a macrólidos } \\
\text { Corticoides poco efectivos }\end{array}$ \\
\hline & & $\begin{array}{l}\text { Fumador (no alérgico al } \\
\text { tabaco) }\end{array}$ & & $\begin{array}{l}\text { Perfil Th2 bajo } \\
\text { FeNO disminuída }\end{array}$ & $\begin{array}{l}\text { Fumador pasivo o activo bajo } \\
\text { FEV1 }\end{array}$ & $\begin{array}{l}\text { Posible respuesta a suspensión de } \\
\text { tabaquismo. Corticoides poco } \\
\text { efectivos }\end{array}$ \\
\hline
\end{tabular}

${ }^{[1]}$ Th2. T-helper type 2. Linfocitos timodependientes colaboradores de tipo

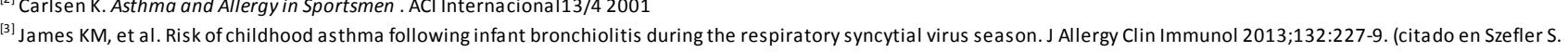

Advances in pediatric asthma in 2013: Coordinating asthma care J ALLERGY CLIN IMMUNOL MARCH 2014)

${ }^{(14)}$ ADMA: (inhibidor endógeno de iNOS)

${ }^{[3]}$ Baena-Cagnani C. y Gené R. Factores de riesgo. Módulo 3 del Curso de actualización a distancia en Asma.

Estrategia global para el manejo y la prevención del Asma. 1998-99. INTERASMA, GINA, Facultad de Ciencias médicas de la Universidad Nacional de Rosario. Argentina 


\section{Estudios epidemiológicos.}

La Epidemiología proporciona información de gran utilidad tanto de la morbilidad como de la mortalidad, para conocer la situación actual, la evolución y el impacto que determinadas acciones o situaciones pueden ocasionar. También es muy importante para identificar los factores de riesgo y de protección y orientar las medidas de prevención y atención así como para conocer aspectos de la fisiopatogenia y la historia natural de las enfermedades. En los últimos años se han realizado muchos estudios epidemiológicos del Asma, estimulados por la preocupación mundial ante el aumento de su prevalencia y su mortalidad, aunque esta última muestra una tendencia a mejorar en los últimos años, en algunos países ${ }^{46}$. En las poblaciones de edades semejantes a las de este proyecto se cuenta con la información relevada en dos oportunidades en Concepción del Uruguay (en sendas investigaciones concretadas por la Cátedra de Salud pública a mi cargo) que formaron parte de estudios cooperativos con otros grupos argentinos y extranjeros, realizados en $1993^{47}$ y 1995.

La prevalencia en la Argentina se ha estimado en el 15\% de los niños de 6 años y en los adolescentes en $10 \%$, pero se hallaron extremos como el caso de Concordia, Entre Ríos, con un 30,2\% y Balcarce (Bs. As) 5,6\% para el primer grupo y de $28,6 \%$ en Quilmes a 1,4\% en Comodoro Rivadavia para los de 11 años. ${ }^{48}$. En Concepción del Uruguay se ha determinado una prevalencia del $23,8 \%$, en base al estudio de corte transversal que se realizó en $2004^{49}$ y un resultado prácticamente similar obtenido 10 años antes $(23,7 \%)$. Existe gran variabilidad de prevalencias entre países y regiones. Los valores superiores a $20 \%$ en la población general se consideran muy elevados. El pico máximo de casos nuevos a nivel mundial se ha calculado a la edad de 10 años, produciéndose otro pico en la mediana edad (aproximadamente 40 años) ${ }^{50}$.

La prevalencia sigue elevada en el mundo, sin una tendencia clara hacia el descenso en los últimos 20 años, aunque se han reducido las consultas a servicios de emergencia, posiblemente por una mejor atención preventiva ${ }^{51}$.

Dado que intervienen numerosas variables endógenas y ambientales es de gran importancia determinar el peso relativo de cada una de ellas en los diversos grupos poblacionales. En este sentido, se pueden utilizar dos herramientas de gran utilidad en 
la Epidemiología analítica como son los estudios de casos y controles (retrospectivo) y estudios ambispectivos de cohorte ${ }^{52}$ con seguimiento durante 5 o más años. 


\section{Factores de riesgo para el Asma bronquial.}

Con el correr de los años se ha ido delimitando con más claridad este síndrome.

Se han detectado los factores de riesgo tanto endógenos como ambientales que permiten un enfoque terapéutico preventivo mejor fundado y se han sumado elementos propios de los cambios culturales y tecnológicos de los últimos 60 años.

\begin{tabular}{|l|l|}
\hline \multicolumn{2}{|c|}{ Tabla 2.2 Clasificación de factores de riesgo de asma infantil. ${ }^{53}$} \\
\hline \multicolumn{1}{|c|}{ Tipo de factor } & \multicolumn{1}{c|}{ Efecto } \\
\hline Factores predisponentes: & Mayor susceptibilidad \\
\hline Factores causales de asma alérgica & $\begin{array}{l}\text { Sensibilizan la vía aérea y provocan el inicio del asma a } \\
\text { través de reacciones específicas Ag-lgE }\end{array}$ \\
\hline Factores causales de asma no alérgica & Estructura bronquial reducida \\
\hline Factores contribuyentes & $\begin{array}{l}\text { aumentan la posibilidad de desarrollo o agravamiento del } \\
\text { curso del asma luego de la exposición a un factor causal } \\
\text { dependiendo del geno y endotipo }\end{array}$ \\
\hline Factores desencadenantes & crisis y exacerbaciones \\
\hline
\end{tabular}

A continuación se presenta un listado de estos factores a estudiar, clasificados según su rol y comentando su relación con factores ambientales inespecíficos:

\begin{tabular}{|c|c|c|}
\hline Nombre & Descripción y componentes & $\begin{array}{l}\text { Relación con factores ambientales } \\
\text { inespecíficos }\end{array}$ \\
\hline Atopía & $\begin{array}{l}\text { Propensión a producir eccema, rinitis no infecciosa } \\
\text { a repetición y asma mediados por IgE con } \\
\text { antecedentes familiares alérgicos tipo I. Se han } \\
\text { hallado reacciones específicas tipo I en fetos de } 22 \\
\text { semanas }^{55} \text { y en neonatos } \\
\end{array}$ & $\begin{array}{l}\text { Se han propuesto mecanismos de } \\
\text { amplificación de la respuesta alérgica, } \\
\text { aumento de la severidad y de la HRB. }\end{array}$ \\
\hline $\begin{array}{l}\text { Genética. } \\
\text { Herencia }\end{array}$ & 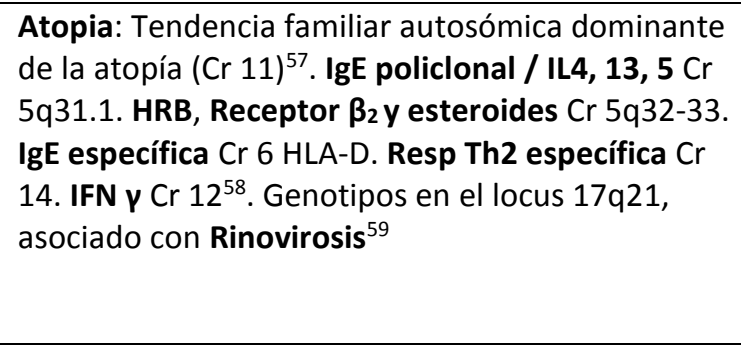 & $\begin{array}{l}\text { Tabaquismo materno induce } \\
\text { hipermetilación en el hijo con mayor riesgo } \\
\text { (asma o alergia) }^{60} \text {. El desarrollo de la } \\
\text { epigenética está demostrando una } \\
\text { interacción importante entre las cadenas } \\
\text { cromosómicas y el ambiente. Algunas } \\
\text { características genéticas modulan la } \\
\text { susceptibilidad a factores ambientales }{ }^{61} \text {. }\end{array}$ \\
\hline Sexo & $\begin{array}{l}\text { Masculino en primera infancia hasta la pubertad, } \\
\text { luego femenino }{ }^{62} \text {. (Lo mismo para atopia). Estaría } \\
\text { relacionado con un menor tamaño de las vías } \\
\text { aéreas que tiende a corregirse en la pubertad, por } \\
\text { lo que estaría vinculado a estímulos hormonales. }\end{array}$ & \\
\hline
\end{tabular}




\begin{tabular}{|c|c|c|c|}
\hline Nombre & Efecto & Descripción y componentes & Relación con factores ambientales inespecíficos \\
\hline \multirow{4}{*}{$\begin{array}{l}\text { Factores causales } \\
\text { de asma alérgica }\end{array}$} & $\begin{array}{l}\text { Alérgenos de interiores } \\
\text { domésticos }\end{array}$ & $\begin{array}{l}\text { ácaros del polvo doméstico, animales domésticos (gato, perro, otros) } \\
\text { cucarachas, hongos anemófilos, plumas, tabaco }{ }^{63} \text {, otros }\end{array}$ & $\begin{array}{l}\text { El tabaco actúa también y más frecuentemente } \\
\text { como irritante inespecífico }\end{array}$ \\
\hline & Alérgenos del aire exterior & Pólenes, hongos anemófilos, polvo de soja ${ }^{64}$, otros & $\begin{array}{l}\text { Se ha planteado la interacción en aire con las } \\
\text { partículas y gases atmosféricos }\end{array}$ \\
\hline & $\begin{array}{l}\text { Antígenos y otros } \\
\text { sensibilizadores } \\
\text { ocupacionales }\end{array}$ & $\begin{array}{l}\text { Tabaco, epitelio y orina de animales, mariscos, huevo, ácaros, hongos, } \\
\text { polvo de soja, harina, maderas, formaldehido, glutaraldehído, isocianatos } \\
\text { de tolueno, etc... }\end{array}$ & $\begin{array}{l}\text { Viviendas próximas a los ámbitos de producción y } \\
\text { depósito }\end{array}$ \\
\hline & Aspirina y otros AINE & Generalmente adultos con pólipos nasales y rinosinusitis. & \\
\hline $\begin{array}{l}\text { Factores causales } \\
\text { de asma no } \\
\text { alérgica }\end{array}$ & $\begin{array}{l}\text { Bajo peso al nacer y calibre } \\
\text { reducido de las pequeñas } \\
\text { vías aéreas }\end{array}$ & $\begin{array}{l}\text { Peso inferior a } 2.500 \text { g puede generar también mayor susceptibilidad a las } \\
\text { virosis por déficit inmunitario y causado por ellas mayor tendencia a HRB }\end{array}$ & $\begin{array}{l}\text { Tabaquismo materno. Pobreza. Control deficiente } \\
\text { del embarazo. }\end{array}$ \\
\hline \multirow[t]{3}{*}{$\begin{array}{l}\text { Factores } \\
\text { contribuyentes }\end{array}$} & Infecciones respiratorias & $\begin{array}{l}\text { Rinovirus }^{65} \text {, Parainfluenza virus } \\
\text { alérgica, mientras que otros parecen ejercer un efecto protector. } \\
\text { sincitial respiratorio } \\
\text { s8. Al menos el } 30 \% \text { de todos los niños tienen } \\
\text { sibilantes en el transcurso de infecciones virales respiratorias y son } \\
\text { asintomáticos interepisodios }\end{array}$ & $\begin{array}{l}\text { Ambientes poco ventilados favorecen el contagio a } \\
\text { través de las microgotas y su permanencia en aire } \\
\text { interior. }\end{array}$ \\
\hline & Obesidad & $\begin{array}{l}\text { Los adipocitos generan mediadores proinflamatorios que se asocian con } \\
\text { el asma infantil }{ }^{70} \text {. Otros estudios no hallan este resultado }\end{array}$ & \\
\hline & Dieta & Falta de lactancia materna & \\
\hline \multirow{6}{*}{$\begin{array}{l}\text { Factores } \\
\text { desencadenantes } \\
\text { de crisis y } \\
\text { exacerbaciones }\end{array}$} & $\begin{array}{l}\text { Contaminación del aire } \\
\text { exterior }\end{array}$ & $\begin{array}{l}\text { Neblumo industrial }\left(\mathrm{SO}_{2} \text {, Ozono, óxidos de } \mathrm{N} \text {, compuestos orgánicos }\right. \\
\text { volátiles, }\end{array}$ & $\begin{array}{l}\text { Fuentes industriales fijas y automóviles, basurales e } \\
\text { incineraciones, }\end{array}$ \\
\hline & $\begin{array}{l}\text { Contaminación del aire } \\
\text { interior }\end{array}$ & $\begin{array}{l}\text { Óxidos N y S, CO, formaldehido, endotoxinas, pesticidas, desodorantes, } \\
\text { sistemas de calefacción y cocina con hidrocarburos y maderas sin tiraje } \\
\text { balanceado }\end{array}$ & Edificios herméticos, hacinamiento \\
\hline & Humedad elevada & $\begin{array}{l}\text { Los terrenos inundables en nuestra zona generan ambientes más } \\
\text { húmedos y favorecen el desarrollo de los ácaros }\end{array}$ & $\begin{array}{l}\text { Cotas por debajo de los límites de creciente máxima } \\
\text { en zonas climáticas de alta humedad prevaleciente. }\end{array}$ \\
\hline & Humo de tabaco & Efecto alergénico en sensibilizados al tabaco e irritante en general. & $\begin{array}{l}\text { Bajo nivel de conciencia de los riesgos del } \\
\text { tabaquismo. Fumadores convivientes. }\end{array}$ \\
\hline & sociales & $\begin{array}{l}\text { Pobreza, raza (por discriminación), escasa accesibilidad a una correcta } \\
\text { atención sanitaria }\end{array}$ & $\begin{array}{l}\text { Utilización de medios de calefacción y cocción de } \\
\text { baja calidad ambiental. Dificultades terapéuticas. }\end{array}$ \\
\hline & $\begin{array}{l}\text { Aumento puntual de la } \\
\text { densidad de alérgenos }\end{array}$ & $\begin{array}{l}\text { Estaciones polínicas, espacios húmedos colonizados por hongos, } \\
\text { depósitos colonizados por ácaros }\end{array}$ & $\begin{array}{l}\text { Cercanía a empresas de procesamiento, transporte y } \\
\text { depósito de productos alergizantes (polvo de } \\
\text { cereales, etc...) }\end{array}$ \\
\hline
\end{tabular}




\begin{tabular}{|c|c|c|c|}
\hline \multirow{8}{*}{$\begin{array}{l}\text { Factores } \\
\text { desencadenantes } \\
\text { de crisis y } \\
\text { exacerbaciones }\end{array}$} & Infecciones respiratorias & $\begin{array}{l}\text { Virosis respiratorias con mayor riesgo para menores de } 10 \text { años. Rinovirus } \\
\text { el más importante. Se ha identificado una IgE específica antiVSR y } \\
\text { antiparainfluenza. }{ }^{72} \text { Rinosinusitis bacteriana }\end{array}$ & $\begin{array}{l}\text { Ambientes poco ventilados favorecen el contagio a } \\
\text { través de las microgotas y su permanencia en aire } \\
\text { interior. }\end{array}$ \\
\hline & $\begin{array}{l}\text { Actividades físicas e } \\
\text { hiperventilación }\end{array}$ & Aire frio y seco, nulo entrenamiento para control del AIE, & piscinas climatizadas hipercloradas \\
\hline & F actores climáticos & frío, humedad, vientos, inversiones térmicas & $\begin{array}{l}\text { Puede generar aumento de la densidad de } \\
\text { contaminantes a nivel de la respiración humana }\end{array}$ \\
\hline & Contaminantes químicos & $\begin{array}{l}\text { compuestos orgánicos volátiles, dióxido de azufre, formaldehído, } \\
\text { pesticidas, entre otros }\end{array}$ & $\begin{array}{l}\text { Son emitidos por diversos materiales y procesos } \\
\text { contaminando el aire interior y exterior. }\end{array}$ \\
\hline & $\begin{array}{l}\text { Alimentos, aditivos y } \\
\text { fármacos. }\end{array}$ & $\begin{array}{l}\text { Se han descripto efectos asmógenos por salicilatos, tartrazina, glutamato, } \\
\text { metabisulfitos (libera } \mathrm{SO}_{2} \text { ). AAS y AINE en adultos, rara vez en niños. } \\
\text { Betabloqueantes. }\end{array}$ & \\
\hline & $\begin{array}{l}\text { Trastornos emocionales } \\
\text { (entorno familiar, escolar y } \\
\text { otros). }\end{array}$ & $\begin{array}{l}\text { Estrés emocional que puede generar hiperventilación. Ataques de pánico. } \\
\text { Sobreprotección y discriminación }\end{array}$ & Familias conflictivas \\
\hline & Reflujo gastroesofágico & Irritación directa y por vía refleja de las vías aéreas & \\
\hline & $\begin{array}{l}\text { Variaciones hormonales } \\
\text { (sexo femenino). }\end{array}$ & $\begin{array}{l}\text { En la infancia influye en la falta de desarrollo torácico y pulmonar de } \\
\text { muchos varones. Postmenarca, se describen casos de aumento de } \\
\text { frecuencia de crisis premenstruales }{ }^{73}\end{array}$ & \\
\hline
\end{tabular}


La búsqueda de los genes ligados al desarrollo del asma se ha enfocado en cuatro áreas importantes ${ }^{74}$ :

- producción de anticuerpos IgE contra alérgenos (atopia);

- expresión de la hiperreactividad de la vía aérea;

- generación de mediadores proinflamatorios (citoquinas, quimioquinas) y de factores de crecimiento;

- determinación de la respuesta inmunitaria Th1 y Th2 (Esta modulación podría estar influenciada por el ambiente y los primeros contactos con diversos microbios según la hipótesis de la higiene y asma).

Se desarrollarán en particular los factores más vinculados a los objetivos de la Tesis, o sea los ambientales físicos de tipo inespecífico, clasificados en dos conjuntos según predominen en el aire interior (doméstico) o exterior (atmosférico). 


\section{Capítulo 3}

\section{Contaminación del aire.}

Los factores inespecíficos, por definición, no pueden confirmar su vinculación fisiopatogénica directa mediante pruebas cutáneas o in-vitro que demuestren la respuesta alérgica. Por razones éticas no es recomendable realizar pruebas de provocación en niños, salvo en situaciones muy particulares que lo justifiquen. Por lo tanto cobra mayor interés la posibilidad de relacionar con estudios epidemiológicos la presencia en el ambiente interior de determinado contaminante o de su fuente emisora con la mayor frecuencia o severidad del asma infantil y la HRB.

Componentes naturales y contaminantes del aire como riesgo para la salud humana.

Desde el punto de vista de la Epidemiología ambiental se pueden clasificar ${ }^{75}$ los posibles agentes causales en:

- Aerosoles ${ }^{76}$ : Partículas (sólidos) dispersas

- Orgánicas: polen, esporas fúngicas (2 a $30 \mu \mathrm{m}$ ), compuestos orgánicos volátiles (VOC), polvo de cereales, excrementos, bacterias, DEP (Diesel exhaust particles, 0,03 a 0,1 $\mu \mathrm{m}$ )

- Inorgánicas: sílice.

○ Mixtas (fitolitos)

- Fase líquida (nieblas)

- Vapores y gases (especies químicas, aunque debe notarse que los ácidos de azufre son partículas PM 2,5 $\mu \mathrm{m}$ ). Dióxidos de Nitrógeno y Azufre. Ozono. Monóxido de Carbono.

\section{Material particulado (PM)}

Las partículas suelen clasificarse por su tamaño en:

- Muy grandes $>10 \mu \mathrm{m}$ (quedan retenidas en las vías aéreas superiores)

- Grandes PM 10: < a $10 \mu \mathrm{m}$ (Ilegan a los alvéolos)

- Pequeñas PM 2,5: < a 2,5 $\mu \mathrm{m}$ (pueden ser absorbidas a nivel alveolar)

○ Muy pequeñas: PM 1 < a $1 \mu \mathrm{m}$ y Ultrafinas: PM < a 0,1 $\mu \mathrm{m}$ (más vinculadas a la mecánica inspiración-espiración, pueden ser expulsadas). 
Se denomina Fracción gruesa al conjunto de partículas entre PM 10 - PM 2,5. La deposición en el aparato respiratorio de las partículas respirables varía según el tamaño ${ }^{77}$, predominando el depósito central (grandes vías aéreas) de partículas con diámetro aerodinámico de 2,7 um y una deposición difusa (pequeñas vías aéreas) para las de 1,4 $\mu \mathrm{m}$. Estas últimas generan reacciones más duraderas postinhalación particularmente si se trata de alérgenos. Se ha planteado que el tamaño que favorece la fagocitosis es próximo a $1 \mu \mathrm{m}^{78}$. Las partículas muy pequeñas como las DEP se pueden observar adheridas en la superficie de los granos de polen ${ }^{79}$ y con cierta humedad podrían alterar los determinantes antigénicos. También estas partículas ultrafinas pueden provocar daños pulmonares agudos, con hemorragias y edema pulmonar. Los lavajes pulmonares en ratas, luego de unas $4 \mathrm{~h}$ de exposición de 10 a $50 \times 10^{5}$ partículas $/ \mathrm{cm}^{3}$, muestran aumento de polimorfonucleares, IL-1 $\beta$, IL-6, TNF $\alpha$ y sintetasa de óxido nítrico. Las partículas que llegan a los alvéolos, son fagocitadas por macrófagos y penetran en el epitelio, el intersticio y el endotelio, provocando daños y necrosis celular, con liberación de mediadores proinflamatorios, con un cuadro histológico de injuria pulmonar oxidativa ${ }^{80}$. Se ha hallado evidencia epidemiológica que los aumentos diarios de $\mathrm{PM}_{10}$ se asocian con el aumento del consumo de medicamentos en niños y adultos asmáticos ${ }^{81}$.

Tienen generalmente un núcleo de carbono al que se pueden adherir por fuerzas electrostáticas, minerales, VOC, alérgenos y otras moléculas de carbono haciendo conglomerados. Debido a esta capacidad de adherirse a múltiples sustancias irritativas y alérgenos, las partículas actúan como transportadores y adyuvantes de la inflamación en el tracto respiratorio superior e inferior. Aunque la respuesta inflamatoria puede ser Th1, se ha demostrado que pueden favorecer la producción de anticuerpos IgE policlonales, lo que aumenta el riesgo de sensibilizaciones y de desarrollar asma alérgica. Comparando exposiciones, el alérgeno unido a la partícula, aumenta 50 veces más la producción de IgE que la que se produciría con el alérgeno solo ${ }^{82}$.

\section{Gases y vapores.}

El $\mathrm{NO}_{2}$ parece asociarse con un mayor número de crisis de asma pero algunos trabajos no encuentran esta asociación. Según Caraballo (2012), "esta aparente 
contradicción en los resultados depende del diseño metodológico de los estudios y de la compleja relación que existe entre los factores del ambiente y las características de las personas estudiadas, porque variaciones genéticas que intervienen en los procesos de óxido-reducción, por ejemplo, la familia de la glutatión S transferasa, pueden favorecer o proteger contra el desarrollo de síntomas respiratorios inducidos por los contaminantes incluyendo los NOx. Se ha encontrado que en algunas poblaciones de Estados Unidos, México y otros países existe una alta proporción de polimorfismos en los genes de estas proteínas, que disminuyen su acción biológica y favorecen un efecto inflamatorio de resolución más lenta ante exposiciones a NOx". La inhalación de $\mathrm{NO}_{2}$ puede favorecer el aumento de neutrófilos y citoquinas proinflamatorias del perfil Th2 como la IL-5, IL-8, IL-13 que favorecen un estado proalérgico. "El Ozono y los NOx pueden aumentar la HRB y modificar la alergenicidad aumentándola o disminuyéndola" 83

Se ha observado que es más intenso y claro el efecto de la presencia simultánea de más de un contaminante gaseoso (por ejemplo $\mathrm{NO}_{2}$ y $\mathrm{SO}_{2}$ ). Los efectos más intensos de este tipo de gases requieren algunas horas de exposición y se presentan entre 24 y 48 horas después ${ }^{84}$. Se ha demostrado un efecto de DEP inhalado incrementando cuatro o cinco veces la lgE total medida en el lavaje nasal, 4 días después del desafío, lo que no se produce en las otras inmunoglobulinas. El aumento de la IgE específica es muy importante (20 a 25 veces) si se realiza una provocación nasal del alérgeno (Ambrosía) junto con DEP, detectándose en los niveles de linfoquinas un patrón de respuesta Th2. Estudios in vitro han demostrado que la acción del Diesel (DEP) estaría principalmente basada en los hidrocarburos aromáticos policíclicos $(\mathrm{PAH})^{85}$.

El $\mathrm{NO}_{2}$, generalmente emitido por vehículos, puede dar como resultado la formación de Ozono por reacciones fotoquímicas reversibles. El Ozono, en provocaciones de 6 horas con 200 ppb, no muestra cambios clínicos detectables en asmáticos y controles sanos, pero en los lavados alveolares realizados $18 \mathrm{~h}$ después, en los asmáticos, a diferencia de los controles, se pueden medir incrementos de producción de citoquinas y presencia de células proinflamatorias, lo que indicaría un riesgo aumentado de exacerbaciones e hiperirritabilidad bronquial frente a otros agentes en un período posterior inmediato ${ }^{86}$. Se ha demostrado un incremento de la ECP (proteína catiónica de los eosinófilos) frente a la inhalación de alérgenos a los que era sensible, 4 
$\mathrm{h}$ después de las provocaciones con $\mathrm{O}_{3}{ }^{87}$. El $\mathrm{NO}_{2}$ también tiene produce alteraciones proinflamatorias en los líquidos de lavado alveolar incluso en sujetos sanos no fumadores $^{88}$. La mucosa bronquial puede verse afectada, alterándose la depuración ciliar lo que facilita el contacto de los alérgenos inhalados con las células presentadoras de antígenos, promoviendo la sensibilización de las vías aéreas ${ }^{89}$.

Los asmáticos generalmente toleran menos las concentraciones de $\mathrm{CO}$ que les pueden causar crisis y aumento de la hiperreactividad bronquial ${ }^{90}$.

Se ha atribuido al tráfico automotor el $14 \%$ de los casos de asma infantil crónico ${ }^{91}$, especialmente para quienes habitan en cercanías de calles y rutas por las que transitan gran cantidad de vehículos.

\section{Aspectos especiales del aire interior.}

El Comité de evaluación sobre Asma y aire interior del Instituto de Medicina de Washington ${ }^{92}$, plantea en su reporte del año 2000 que la información sobre la exposición a sustancias químicas en el aire interior es inadecuada e insuficiente principalmente sobre pesticidas, compuestos orgánicos volátiles (VOC), formaldehido, fragancias y plastificadores. Jerarquiza la cuestión como un importante problema de salud pública que afecta diariamente al $10 \%$ de niños con asma.

Los compuestos orgánicos volátiles (VOC) tienen un punto de fusión cercano a la temperatura ambiente. Son emitidos por la quema de combustibles, como gas natural, kerosene, Diesel, madera, carbón y tabaco. Otras fuentes son los disolventes, pinturas, placas de madera reconstituida, repelentes de polillas, aromatizantes del aire, sustancias en aerosol, disolventes de grasa, productos de uso en autos, disolventes para lavado en seco y otros productos empleados y almacenados en la casa y el lugar de trabajo. Bello (2010) ${ }^{93}$ afirma que en las casas aseadas con detergentes, los VOC pueden permanecer varias horas en el aire, afectando no solo a las personas que los utilizaron sino también a los niños que regresan de la escuela un tiempo después. Como los VOC se adhieren a partículas flotantes en aire, penetran con ellas en las vías aéreas y las no inhaladas se depositan y vuelven a ser reflotadas desde el mobiliario y los pisos, dada su estabilidad y bajo peso. Este último mecanismo puede explicar la persistencia de efectos. Entre los VOC naturales puede mencionarse al isopreno, pineno y limoneno y 
entre los artificiales al benceno, tolueno, nitrobenceno, clorobenceno, xileno y acetona. En el caso del formaldehido hay formación natural y producción artificial. La asociación con otros VOC en algunos de los emisores de formaldehido, podrían potenciar los efectos hallados con esta molécula.

Pero no faltan trabajos contradictorios como el de Harving $(1991)^{94}$, que realizó un desafío controlado en una muestra randomizada de 11 personas con asma que fueron expuestos a una mezcla de 22 VOC que pueden hallarse comúnmente en el aire doméstico. Probó con una concentración de $25 \mathrm{mg} / \mathrm{m}^{3}$ considerada alta para un hogar, pero que puede ser encontrada sobre todo en construcciones que utilizaron materiales en boga en las últimas décadas (placas para pisos, paredes, cielorrasos y mobiliario, alfombras sintéticas, etc...). Estos asmáticos mostraron previamente un severo incremento de la reactividad de las vías aéreas, medida con la prueba de Metacolina (PC 20 para $\mathrm{VEF}_{1}$ con $0,2 \mathrm{mg} / \mathrm{ml}$ ). Suspendidos los broncodilatadores 4 horas antes en todos los casos, hubo dos que continuaron con el corticoide inhalado. La prueba consistió en una exposición a los VOC durante 85 minutos en una cámara especial. El resultado no fue diferente de la misma prueba realizada con aire fresco. Frente a este resultado considero que caben algunas posibles explicaciones etiopatogénicas, entre las que puede plantearse que el efecto "mezcla" de los compuestos orgánicos volátiles puede diluir a los que verdaderamente son causantes de reacciones bronquiales con otros que carezcan de ese efecto y de esta manera morigerar su potencialidad como nocivos.

Los principales contaminantes considerados en el estudio para esta Tesis son el humo del cigarrillo, las partículas de origen fúngico, el formaldehido y otros VOC emitidos por los sistemas de calefacción y otros elementos así como los insecticidas. Cada uno de ellos se profundiza en los siguientes títulos y se exponen en otro capítulo los resultados propios de esta investigación epidemiológica.

\section{Humo de tabaco}

Desde hace varias décadas se considera la inhalación de humo de tabaco como una de las principales causas prevenibles de morbilidad 95969798 . En Argentina el 33,4 \% de la población es fumador activo ${ }^{99}$, valor similar al hallado en España ${ }^{100}$. En Entre Ríos la prevalencia de tabaquismo es de $34,2 \%$ en varones y $29,4 \%$ en mujeres. 
El humo de cigarrillo genera el "aire contaminando con humo de tabaco" (ACHT) en los ambientes domésticos y ocupacionales, producto de la incineración progresiva del tabaco y de lo exhalado por fumadores (humo de segunda mano), de una interacción de ese humo con otros componentes del aire y de su depósito transitorio en objetos y personas que luego es reciclado al aire (humo de tercera mano). Permanece en el aire un tiempo variable según la ventilación, pero suficiente para poder ser nuevamente inhalado.

Sobre datos de una encuesta nacional, la estimación de fumadores pasivos en el hogar se calculó en 32,9\% (2004), cifra similar a la que se halló luego en 2012, pero el $57 \%$ de los entrerrianos adultos no fumadores entrevistados informó que fumaban cerca suyo en el hogar ${ }^{101}$. En encuestas nacionales de Estados Unidos de América, Gran Bretaña, España y China, los valores oscilaron cercanos a la mitad de la población ${ }^{102}$. En una encuesta realizada en Buenos Aires sobre tabaquismo entre los niños y adolescentes, el $60 \%$ de los que faltaron 7 o más veces (sobre 120 días de clase) a la escuela, por causas respiratorias, convivía con uno o más fumadores. El $74 \%$ de los asmáticos que faltaron estaba expuesto al tabaquismo pasivo ${ }^{103}$.

Durante el embarazo fumaron el $27,8 \%$ de las gestantes, cifra algo superior al 22 $\%$ de las madres que fuman durante el embarazo según una estimación norteamericana ${ }^{104}$, que suele tomarse como cifra estimativa para otros países, aunque ellos detectaban una menor proporción entre las mujeres inmigrantes de origen latinoamericano.

Tanto la corriente principal del humo (inhalada por el fumador) como la secundaria (que emite la punta del cigarrillo en combustión) tienen los mismos componentes, aunque el filtro incorporado al cigarrillo podría retener algunas partículas de la corriente principal. Se mencionan unos 7.000 componentes $^{105}$ entre los que vale destacar unos 70 de mayor riesgo para la salud, como 4-aminobifenoles, benceno, níquel y una amplia variedad de hidrocarburos policíclicos aromáticos y $\mathrm{N}$-nitrosaminas que tienen probables efectos carcinógenos. Además contiene gases irritantes como amoníaco, dióxido de nitrógeno, dióxido de azufre, monóxido de Carbono, partículas diversas y varios aldehídos, entre los que se destaca el formaldehido. Es destacable la nicotina, alcaloide con efectos estimulantes que provoca adicción. En la corriente secundaria y en el "aire de segunda mano" (humo exhalado por el fumador se puede 
generar mayor concentración de algunas de estas sustancias por tener menos temperatura ${ }^{106}$.

La exposición de los niños puede ocurrir en los hogares, las guarderías y otros espacios escolares y sociales y los medios de transporte. La concentración dependerá de la cantidad de fumadores, el tiempo en que mantengan encendidos los cigarrillos y la ventilación del local. La cotinina en sangre, orina y saliva sirve para detectar la incorporación al organismo, y se han determinado claras diferencias en niños y adultos comparando expuestos y no expuestos al tabaquismo pasivo ${ }^{107}$, con buena correlación con las respuestas a los autocuestionarios ${ }^{108}$. En una primera publicación (1997) de una serie de metanálisis realizados por Strachan y Cook, se detecta un riesgo débil pero consistente (OR 1,6), para el conjunto de patologías respiratorias bajas (incluyendo sibilantes, asma, bronquiolitis y neumonía) en los dos primeros años de vida con padres o convivientes fumadores ${ }^{109}$.

\section{Aspectos fisiopatogénicos}

En cuanto a la fisiopatogenia del efecto del humo del tabaco en la vía aérea y su relación con el asma infantil, la búsqueda de publicaciones relacionadas muestra hallazgos que reflejan, una vez más, la complejidad causal, genotípica, endotípica y fenotípica del asma y la alergia respiratoria en los niños.

El tabaco como alérgeno inhalatorio ha sido motivo de controversias. Estudiando en 1930 la naturaleza de la acción alergénica del polvo doméstico, Carlos Jiménez Díaz, de la importante Escuela de Clínica Médica española, la atribuye al tabaco en un caso sobre 39 muestras de polvo de viviendas de asmáticos ${ }^{110}$. En los últimos años se está planteando la importancia del "humo de tercera mano", producto de la interacción de componentes del humo de cigarrillos que se combina con otros elementos del aire, formando nitrosaminas y otros compuestos que precipitan en el polvillo de la habitación, en las ropas y otros objetos del ambiente en que se ha fumado, encontrándose incluso en el pelo de niños presentes en esos lugares ${ }^{111}$. Shahon (1941), de la escuela de uno de los precursores de la Alergología, Arthur Coca, afirma que "el tabaco raramente es causa de asma" y que "todavía no ha sido dilucidado si el humo del tabaco actúa simplemente como un irritante mecánico o si puede ser considerado como un alérgeno específico" ${ }^{112}$. Sin embargo, lo utiliza en su batería de antígenos, y 
recomienda prohibir a los asmáticos sensibles al tabaco el uso terapéutico de los cigarrillos antiasmáticos que combinan tabaco, estramonio y lobelia. El médico oriental Varela Fuentes $(1946)^{113}$ solo menciona al tabaco como posible componente alergógeno del polvillo doméstico y no lo incorpora a su batería rutinaria de antígenos para pruebas cutáneas. Unos años después, Urbach en una de los tratados clásicos sobre Alergia ${ }^{114}$, menciona que "raramente puede juzgarse que obra como alérgeno inhalatorio", argumentando sobre los millones de personas que lo fuman, aunque reconoce un papel importante como alérgeno ocupacional, en los trabajadores tabacaleros. Sin embargo, él mismo menciona su propia experiencia con una paciente asmática debida al tabaco. Le da mayor importancia a las partículas presentes en el humo del tabaco y refiere las casuísticas de Vaughan ${ }^{115}$ y de Pipes ${ }^{116}$. Este último describe en su casuística, un $9 \%$ de pacientes con síntomas desencadenados o agravados por el humo de tabaco y un $13 \%$ de pruebas intradérmicas positivas con un extracto específico. Especialistas de importancia en aquella época como Walker y Feinberg, también describen casos de asma por humo de tabaco o por trabajar en fábricas de cigarrillos ${ }^{117}$.

Enrique Mathov (1972) ${ }^{118}$, en Argentina, menciona al tabaco dentro de los alérgenos inhalantes, como productor de reacciones tanto en su presentación como cigarrillo, cigarro, habano y hebras para pipa. Plantea también la hipótesis del papel que envuelve al tabaco y de las sustancias mejoradoras. Otro argentino, Kurlat (1974) ${ }^{119}$, también lo incluye dentro de los alérgenos inhalantes con hallazgo frecuente de sensibilidad clínica. Lo plantea como un "tema sumamente controvertido" entre su potencialidad alergénica o irritante, ya que las pruebas cutáneas positivas podrían no ser específicas, provocadas por sustancias irritantes del extracto. En una recopilación norteamericana de $1982^{120}$ el tabaco no aparece en la enumeración alérgenos pero es mencionado como irritante de importancia. Recomiendan evitar el tabaquismo pasivo en los niños. En 1986 se publica en el Annals of Allergy ${ }^{121}$ una actualización sobre el tema, que plantea las siguientes cuestiones:

- Los atópicos, fumadores y no fumadores, presentan anticuerpos IgE específicos para los antígenos CIE 19, 23 y 30 de la hoja de tabaco pero no se han demostrado para antígenos del humo de tabaco.

- Los niveles de IgE específicas no correlacionan con los cuadros clínicos conocidos de sensibilidad al tabaquismo y no se pudo demostrar dicha 
sensibilidad en pruebas respiratorias aún para quienes percibían síntomas expuestos al humo. Recomiendan perfeccionar las pruebas de provocación respiratoria en cantidad y calidad para lograr conclusiones más sólidas.

- Sostienen por lo tanto, que no puede definirse a esa fecha, el tipo de expresión clínica asmática como respuesta de hipersensibilidad al tabaquismo.

Abate (1989), comentando una publicación de Cockcroft en el Annals of Allergy, clasifica como irritante inhalatorio (o sea como no alergénico) al humo de tabaco, que no genera aumento de la $\mathrm{HRB}^{122}$.

En los últimos años se ha retomado una línea de investigación que se orienta hacia las respuestas alérgicas tipo I (IgE dependientes) a partículas de tabaco. Por ejemplo, en 2001 se realiza una testificación con extracto de tabaco a 170 niños con una edad media de 7 años. Hallan $36 \%$ de pruebas positivas, todas en expuestos a tabaquismo pasivo, predominando en alérgicos con alguna otra prueba positiva a inhalantes comunes. Los autores informan que no logran verificar una capacidad predictiva significativa de síntomas vinculados al humo de tabaco en los niños con la prueba cutánea positiva ${ }^{123}$. Un trabajo español ${ }^{124}$ de un equipo integrado por especialistas en Alergia e Inmunología, Neumólogos y Pediatras de un Hospital universitario, abordan esta cuestión con un estudio de 120 casos de adultos con obstrucción bronquial (60 asmáticos polínicos, 20 con asma intrínseca, 20 con EPOC y 20 con carcinoma broncogénico) y 60 controles. Se realizaron varios estudios: prick con extracto de tabaco (positivo en el $18 \%$ pero ninguno en asma intrínseca y en controles); provocación bronquial (PB) con cigarrillo encendido, apagado y extracto de hoja fresca de tabaco; prueba epicutánea con extracto de tabaco y nicotina, IgE específica a tabaco por CAP y EAST, immunoblotting e inhibición de EAST. La positividad del prick y del parche no dependió del número de cigarrillos fumados ni del número de años de hábito tabáquico, pero la respuesta bronquial se asoció significativamente al índice tabáquico $(p<0,001)$. La respuesta dual en la provocación bronquial fue más frecuente en los pacientes con EPOC $(p<0,001)$ y podría vincularse con una hipersensibilidad de tipo IV 
(celular) que contribuya a la remodelación de las vías aéreas. Se halló reactividad cruzada con el polen de Lolium y una asociación con la ocupación como agricultores.

Se ha determinado en estudios experimentales con roedores que:

- Efecto no específico. La exposición inhalatoria de humo de tabaco durante 10 semanas después del nacimiento aumenta la hiperirritabilidad bronquial (HRB) en la descendencia, tanto en los ratones genéticamente predispuestos como en los no predispuestos a la alergia inhalatoria a ovalbúmina (OVA). Esa HRB no está asociada con eosinofilia en los tejidos pulmonares ni con la presencia de $\lg E$ específica antiOVA o sea que pareciera seguir una vía diferente a la conocida como alérgica tipo I. Más aún, en los animales alérgicos, si se compara la provocación con OVA inhalada y la mezcla de OVA y humo de tabaco, con esta última desciende la IgE total y las IgE e IgG antiOVA $^{125}$.

- ¿amortigua la reactividad bronquial? En el corto plazo (primeras 3 semanas de exposición al humo de tabaco), puede observarse una disminución del broncoespasmo provocado por OVA inhalada en los ratones alérgicos a ella, al igual que la respuesta a la metacolina comparados con los animales no expuestos. Este efecto se relaciona con una significativa disminución de los eosinófilos en el lavado broncoalveolar y en los tejidos pulmonares que explicaría aquella mejoría en la respuesta bronquial. Parece producirse también una alteración en la respuesta de los linfocitos $T$ (principalmente CD4) con modificación del balance Th1/Th2 que podría explicar el mecanismo amortiguador por la influencia que estos tienen sobre los eosinófilos. La diferencia en los CD4 no alcanzó un nivel significativo estadístico ni se pudo medir a las citoquinas de interés por su muy baja concentración. Tanto la inducción de una respuesta alérgica como la exposición al humo genera aumento considerable de macrófagos en los tejidos pulmonares. Sorprendentemente, en el caso de los ratones asmáticos por alergia a OVA se observó una disminución de la migración de macrófagos, aunque no una normalización ${ }^{126}$.

- Aumenta la inflamación. En el modelo de exposición subaguda de 30 días, se produce una amplificación de la activación mastocitaria inducida por antígenos en animales previamente alergizados, por la vía TGF- $\beta / S m a d$ produciendo 
inflamación y remodelización. Determinaron aumento de IgE específica antiOVA y reclutamiento de células proinflamatorias ${ }^{127}$.

- Fibrosis y depósitos de colágeno. En una exposición crónica (6 meses) se observa la activación de factores de crecimiento profibróticos y expresión de genes procolágeno (CTGF, TGF- $\beta_{1}$, PDGF-A y $-B$ ) con aumento de colágeno en los tejidos de las pequeñas vías aéreas, que intervendrían en la remodelación de la pequeña vía aérea $(S A R)^{128}$. En este experimento no evalúan la respuesta en ratones alérgicos o asmáticos.

En un estudio observacional ${ }^{129}$ en humanos asmáticos leves estables y en no asmáticos, se determinaron una serie de variables comparando a fumadores y no fumadores. Al contrario de lo hallado por Melgert ${ }^{130}$ en el modelo de ratones asmáticos, los eosinófilos están aumentados en el esputo de los asmáticos fumadores o no fumadores. Otros resultados son:

- El total de células en esputo es mayor en los asmáticos fumadores que en los no fumadores y los controles.

- El hábito de fumar se asocia a una neutrofilia y aumento de interleukina 8 (IL-8) en esputo tanto en asmáticos como no asmáticos

- La proteína catiónica de los eosinófilos (ECP) está elevada en el esputo de asmáticos fumadores y no fumadores.

- En los asmáticos fumadores hay una correlación negativa de la función pulmonar (FEV1) con IL-8 ( $r=-0.52)$ y la proporción de neutrófilos en esputo ( $r=-0.38)$, mientras que IL-8 en esputo correlaciona positivamente con la cantidad de paquetes de cigarrillo/año $(r=0.57)$ y la cuenta de neutrófilos en esputo $(r=$ $0.51)$.

Floreani y col. en 1999, postularon que el humo del tabaco estimula la inflamación de las vías aéreas con activación de células proinflamatorias, con alteraciones en las funciones y subtipos celulares y con liberación de mediadores inflamatorios, lo que ha sido reafirmado por algunos trabajos ya mencionados. También plantean una "inflamación neurogénica” y el estrés oxidativo ${ }^{131}$. 
Coincidente con esta última línea de investigación, un estudio reciente ${ }^{132}$ observó el efecto del tabaquismo pasivo en niños asmáticos severos refractarios al tratamiento. El estrés oxidativo que produce el humo del tabaco en los alvéolos afecta la enzima histona deacetilasa-2 (HDAC2) por la vía de activación de la fosfoinositide-3kinasa (PI3K/Akt) reduciendo su expresión en los macrófagos alveolares. Aumenta el recuento de neutrófilos en el líquido de lavado alveolar (BAL), baja la puntuación $\mathrm{ACT}^{133}$ y reduce la respuesta a corticoides, comparados con niños asmáticos severos no expuestos al tabaquismo pasivo.

Desde hace mucho tiempo se conocen los mecanismos adrenérgicos y colinérgicos con una importante influencia en el control neural sobre la tonicidad del músculo liso bronquial y otras respuestas a estímulos que penetran en la vía aérea. La inflamación neurogénica se produce por liberación de neuropéptidos proinflamatorios (sustancia $\mathrm{P}, \mathrm{K}$ y $\mathrm{CGRP}^{134}$ ) por las fibras $\mathrm{C}$ de las neuronas nociceptivas, primer escalón del sistema nervioso periférico. Estas fibras se clasifican como no adrenérgicas y no colinérgicas. La neurokinina A es secretada por células participantes del eje hipotalámico-pituitario-adrenal, entre ellas las neuronas nociceptivas. Al unirse a los receptores NKR-2 del músculo liso bronquial produce broncoconstricción y en la mucosa, aumento de las secreciones ${ }^{135}$. La endopeptidasa neutral (EPN) presente en la superficie de las células con receptores para estos neuropéptidos, los degrada e inactiva, modulando la respuesta. El balance entre la cantidad de neuropéptidos liberadores y la actividad de la enzima podría explicar las exacerbaciones o el mejor control endógeno de la irritabilidad de las vías aéreas. Se ha propuesto como uno de los principales mecanismos de acción de los irritantes inespecíficos la estimulación de los receptores sensoriales ${ }^{136}$.

\section{Aspectos epidemiológicos del tabaquismo pasivo}

En los estudios epidemiológicos, si bien predomina una tendencia a plantear que el tabaquismo pasivo es un factor claro de riesgo de asma infantilli37138139140 141, otros trabajos de este tipo no han hallado resultados significativos que confirmen tal enunciado. Eisner (2002) no encuentra aumento de la frecuencia de exacerbaciones asmáticas en niños. ${ }^{142}$ En un informe sobre la investigación ISAAC en 2001, sobre 38 países incluidos en el estudio, se determina una relación positiva para el grupo etareo 
adolescente (13-14 años), mientras que en el grupo de 6-7 años de edad (el de nuestra investigación) aparece una relación inversa entre sibilantes nocturnos con alteraciones del sueño y el antecedente de padres fumadores ${ }^{143}$. Collins $(1985)^{144}$ estudiando los efectos del tabaquismo materno en los pulmones del niño no encuentra relación con el asma. El mismo resultado aparece en el seguimiento de una cohorte en Australia ${ }^{145}$. Tampoco halla resultados positivos Plaschke $(2000)^{146}$, estudiando la aparición y la evolución del Asma y la Rinitis alérgica en relación con la atopía y el tabaquismo. Coincidentemente, en un interesante estudio sobre genética y ambiente en asma $\left(E_{G E A}{ }^{147}\right.$ ) realizado en Francia, y otro en España ${ }^{148}$ en la misma época, sobre tabaquismo y patología respiratoria, no encontraron una relación significativa entre ser fumador y la posibilidad de desarrollar asma, aunque sí pudo evidenciarse una fuerte relación con la mayor gravedad del asma. En este sentido también se expresaría un estudio de corte transversal realizado en 4.500 escolares de Buenos Aires. Para evaluar el asma como causa de ausentismo ${ }^{149}$ hallan un $74 \%$ de asmáticos expuestos al tabaquismo pasivo (más que los no asmáticos) siendo el asma la segunda causa de ausentismo en los niños de 8 a 9 años.

Se han propuesto tres momentos diferentes para la exposición infantil al $\mathrm{ACHT}^{150}$, en los cuales analizar el impacto respiratorio:

- Período de gestación o exposición intrauterina;

- los primeros 2 años de la vida, cuando la frecuencia ventilatoria es mayor, tiene lugar mayor número de infecciones que afectan al tracto respiratorio inferior y el tabaquismo materno tiene mayores efectos,

- los demás años de la infancia.

Integrando la serie "Health effects of passive smoking", en la que revisan un gran número de publicaciones, los Profesores de Epidemiología Cook y Strachan de la Universidad de Londres, publican en 1997 un metaanálisis interesante por su amplitud $^{151}$. Seleccionaron 60 estudios, luego de revisar más de 1000 resúmenes, en los que se abordaba, mediante investigaciones poblacionales, la relación entre tabaquismo pasivo y asma infantil. Los cuestionarios de los diversos trabajos se orientaban a identificar niños en diversas categorías tales como asma, sibilantes, tos crónica, catarro crónico o disnea. Las investigaciones procesadas fueron las que contenían información 
cuantitativa analizada estadísticamente, que les permitió procesar conjuntos de OR de cada uno de los grupos sintomáticos. Utilizando los intervalos de confianza de las OR y la prueba de $\chi^{2}$ para evaluar el significado estadístico de las OR representativas de los conjuntos ("pooled odds ratio") informan resultados, sobre los que planteo comentarios tanto de éste como de los otros informes de la serie mencionada:

- "El tabaquismo pasivo se asocia al asma, los sibilantes, la tos crónica, el catarro crónico y la disnea en la infancia". Puede notarse sin embargo que para asma y sibilantes el valor de conjunto de OR es relativamente bajo, (riesgo débil) ${ }^{152}$ y el intervalo de confianza abarcaba la unidad en la mayoría de los estudios, que evaluados con $\chi^{2}$ muestran una importante heterogeneidad en los resultados.

\begin{tabular}{|c|c|c|c|}
\hline Variable asociada con padres fumadores & OR & IC 95\% & $x^{2}$ \\
\hline asma infantil & 1,21 & $1,10-1,34$ & $49.6, p=0.00025$ \\
\hline \multicolumn{4}{|c|}{$\begin{array}{l}\text { En 16/21 estudios que tomaban el diagnóstico de asma, el IC } 95 \% \text { abarcaba el } 1 \text {. El alto valor de } \chi^{2} \text { muestra I } \\
\text { heterogeneidad del conjunto de OR. }\end{array}$} \\
\hline sibilancias & 1.23 & $1.11-1.37$ & $35.7, p=0.0019$ \\
\hline \multicolumn{4}{|c|}{$\begin{array}{l}\text { En } 17 / 30 \text { estudios que tomaban el diagnóstico de sibilantes, el IC } 95 \% \text { abarcaba el } 1 \text {. El alto valor de } \chi^{2} \text { muestra } \\
\text { la heterogeneidad del conjunto de OR. }\end{array}$} \\
\hline tos crónica & 1.47 & $1.27-1.70$ & $63.0, p<0.000001$ \\
\hline \multicolumn{4}{|c|}{$\begin{array}{l}\text { En } 12 / 30 \text { estudios que tomaban el diagnóstico de sibilantes, el IC } 95 \% \text { abarcaba el } 1 \text {. El alto valor de } \chi^{2} \text { muestra } \\
\text { la heterogeneidad del conjunto de OR. }\end{array}$} \\
\hline Catarro crónico & 1.35 & $1.13-1.62$ & $4.3, p=0.51$ \\
\hline \multicolumn{4}{|c|}{$\begin{array}{l}\text { En } 3 / 6 \text { estudios que tomaban el diagnóstico de sibilantes, el IC } 95 \% \text { abarcaba el } 1 . \chi^{2} \text { muestra un conjunto de } \\
\text { OR más homogéneo }\end{array}$} \\
\hline Disnea & 1.31 & $1.08-1.59$ & $4.6, p=0.47$ \\
\hline
\end{tabular}

- "Se percibe una disminución de la OR desde la edad preescolar hasta los 6 años de edad, tendencia que persiste hacia la adolescencia (1,9 a 1,07). En un estudio italiano de casos y controles ${ }^{153}$ las OR antes y después de los 6 años de edad fueron respectivamente: 1.13 (95\% $\mathrm{Cl} 0.71$ to 1.80$)$ y $0.83(95 \% \mathrm{Cl} 0.48$ to 1.44$)$. Otros autores ${ }^{154}$ no hallan este gradiente de riesgo. La mayor asociación con el tabaquismo pasivo se da en los dos primeros años de vida." Sorprendentemente, y reafirmando el gradiente, en la cohorte británica de 1958, los niños con sibilantes a los 7 años, tienen un riesgo menor de asma a los 11 y 23 años de edad si la madre fumaba ${ }^{155}$. 
- "Si bien el tabaquismo materno tiene mayor influencia que el paterno, los efectos de este último, por sí mismos, son claramente significativos, lo que induce a pensar que el efecto postnatal es importante". Sin embargo, los mismos autores informan las conclusiones de un estudio de cohorte británico que comienza en 1970, en el que si bien la incidencia a los 7 años es mayor si la madre fumó durante el embarazo, independientemente de otros factores, este antecedente no influye en la incidencia entre los 7 y 16 años de edad y que tampoco se asocia al tabaquismo de padre y madre.

- "No se halla asociación consistente entre padres fumadores antes o después del nacimiento y el riesgo de alergia en sus hijos (reacción cutánea positiva, IgE sérica aumentada, fiebre del heno o dermatitis atópica, excluyendo el asma)". Según un estudio de un grupo italiano ${ }^{156}$, el tabaquismo intenso ( $>20$ cigarrillos) de los padres disminuiría la reactividad alérgica a aeroalérgenos locales relevantes medida por la positividad de pruebas cutáneas (OR 0,54 IC 95\% 0.31/0.92). EI efecto es más atenuado y poco significativo con menor exposición. Estos resultados coinciden con el modelo experimental en ratones, expuesto anteriormente.

- "Un aumento de la hiperreactividad bronquial en hijos de madres fumadoras"157. Como ya se mencionó, una investigación experimental posterior demostró, en ratones, que se desarrollaba la hiperreactividad bronquial (HRB) sin activación de mecanismos alérgicos específicos tipo $\mathrm{I}^{158}$. Un estudio de 2001, encuentra inflamación neutrofílica de vías aéreas en fumadores asmáticos y no asmáticos pero no detectan aumento de la HRB en los asmáticos ${ }^{159}$. Coincidentemente, en fumadores activos adolescentes y adultos, se detecta aumento de síntomas y caída en los indicadores de funcionalidad respiratoria pero no aumento de $\mathrm{HRB}^{160}$.

- "La incidencia de sibilantes tempranos transitorios y de sibilantes persistentes se dobla en hijos de madres fumadoras de más de 10 cigarrillos por día". Un estudio posterior $^{161}$ con seguimiento durante los tres primeros años, hallan una significativa diferencia entre expuestos y no expuestos al tabaquismo para la aparición de asma en el primer año de vida (OR 1.88; 95\% Cl 1.14-3.12), no así 
para los dos años posteriores. La cotinina en sangre y en cordón es coincidente con el resultado del cuestionario sobre hábito tabáquico.

- "El exceso de incidencia de sibilancias a los 16 años generado por el tabaquismo aparece como ampliamente atribuible a "bronquitis sibilantes" en no atópicos con relativo buen pronóstico".

\begin{tabular}{|l|c|c|c|c|}
\hline $\begin{array}{l}\text { Asma o sibilancias a los 16 } \\
\text { años }\end{array}$ & \multicolumn{2}{|c|}{$\begin{array}{l}\text { Incidencia acumulada } \\
\text { tabaquismo durante el embarazo }\end{array}$} & OR & $95 \% \mathrm{Cl}$ \\
\hline & $\mathrm{Si}$ & no & & \\
\hline Sin antecedentes atópicos & $24,5 \%$ & $18,9 \%$ & 1,39 & 1.18 to 1.63 \\
\hline $\begin{array}{l}\text { antecedentes atópicos } \\
\text { positivos }\end{array}$ & 32.2 & 33.5 & 0.95 & 0.76 to 1.18 \\
\hline
\end{tabular}

Un hallazgo similar se da en la investigación de corte transversal en niños canadienses $^{163}$ que reportó una fuerte asociación entre el tabaquismo de los padres y asma reciente en niños sin historia de Alergia (OR 2.93, 95\% Cl $0.83 / 10.3$ ). En los niños alérgicos la OR fue inferior a la unidad 0.73, (¿efecto protector?) pero el intervalo de confianza del 95\% abarca la unidad: 0.37/1.46, por lo que no puede considerarse un resultado estadísticamente significativo. Por el contrario en un estudio clínico de pacientes alérgicos de 1 a 17 años de edad $^{164}$ con dermatitis atópica el tabaquismo materno se asoció con riesgo de asma (OR 3.42, 95\% Cl 1.60-7.30) mientras que en los que no tenían eccema la OR mostró un resultado indiferente $(0.93,95 \% \mathrm{Cl} 0.57 / 1.51)$. Debe tenerse en cuenta que el grupo estudiado está sesgado por la selección asistencial y no es comparable con los estudios de casos y controles o las cohortes con selección aleatoria.

- "En los niños atópicos con asma, el pronóstico es peor a largo plazo si los padres son fumadores. Esta aparente paradoja puede ser explicada si el humo de tabaco ambiental es considerado co-factor provocando ataques de sibilancias más que como causa subyacente de una tendencia asmática"165.

El efecto en los niños con asma podría explicarse por la amplificación de la respuesta mastocitaria a los alérgenos con un agravamiento en los niños alérgicos a otros antígenos (aunque podría ser también al tabaco) por el camino 
de la inflamación crónica y remodelación de las vías aéreas. Coincidentemente, otros autores ${ }^{166}$ han postulado que el humo del tabaco favorece la inflamación de la vía aérea al aumentar la activación de células proinflamatorias y favorecer la liberación de mediadores inflamatorios, la inflamación neurogénica y el estrés oxidativo.

- "Una revisión cualitativa de tres estudios de caso-control y 10 series de casos no controlados muestran un posible aumento de la severidad del asma en los expuestos a humo de tabaco, sobre todo en los concurrentes a servicios hospitalarios" ${ }^{167}$. Como contraprueba fáctica coherente con esta hipótesis, hay informes de casuísticas que describen una sensible mejoría en el grupo de niños cuyos padres dejaron de fumar comparados con los cuales no se logró el cambio de conducta ${ }^{168}$.

En un estudio de corte transversal realizado en México recientemente no hallan asociación entre tabaquismo pasivo y asma infantil ${ }^{169}$. Una investigación en China, publicada este año ${ }^{170}$, con el mismo método (ISAAC) de la que realizamos aquí, en una muestra mayor de 10.000 niños, halla un riesgo débil para el tabaquismo pasivo originado por el padre pero un resultado indiferente para el tabaquismo materno. Los autores no comentan este resultado que en principio no es muy congruente, y deberían buscarse algunas explicaciones en función de aspectos conductuales de las madres, que disminuyan la exposición de sus hijos.

En el marco de una importante investigación sobre Epidemiología del asma, se estudió la validez de las respuestas familiares en los autocuestionarios referidos a la exposición doméstica de los niños al tabaquismo pasivo, midiendo la nicotina en el aire de la vivienda, hallando una correspondencia muy buena ${ }^{171}$.

\section{Síntesis sobre tabaquismo pasivo y riesgo de asma infantil.}

Intentando una síntesis ante tanta información fisiopatogénica y epidemiológica con resultados muchas veces no coincidentes y hasta contradictorios, vale destacar:

- La gran complejidad del asma, tanto en sus aspectos genéticos, endotípicos, fenotípicos, clínicos, evolutivos y epidemiológicos, se expresa con toda claridad y amplitud en la infancia y adolescencia, en particular frente al tabaquismo pasivo 
como factor de riesgo. Mientras las investigaciones fisiopatogénicas muestran resultados diversos y contradictorios, las investigaciones de tipo epidemiológico tienden a coincidir en resultados poco concluyentes sobre la asociación entre tabaquismo pasivo y asma infantil, salvo durante el primer año de vida y la tendencia al agravamiento de los asmáticos persistentes.

- Debe tenerse en cuenta dos grandes líneas de investigación sobre la causalidad y sus respectivas derivaciones

- Respuesta Th2 alta

- Respuesta alérgica específica IgE antitabaco

- ¿Activación de respuesta Th2 (IL13, IL5, eosinofilia, etc...) sin IgE específica?

- Respuesta Th1 o Th2 baja, inflamación neurogénica y estrés oxidativo con neutrofilia, disminución de la fracción exhalada de óxido nítrico (FeON), resistencia a corticoides. ¿Efecto del formaldehido?

- La hipótesis causal de la reacción alérgica tipo I específica contra antígenos del tabaco afecta, como en todos los casos en que actúa dicho mecanismo, a quienes estén genéticamente predeterminados para dicha respuesta. Teniendo en cuenta algunas casuísticas abarcaría entre un $9 \%$ y un $18 \%$ de personas con patologías respiratorias alérgicas y hasta un $36 \%$ de niños pueden tener pruebas cutáneas positivas. La hoja de tabaco podría ser más alergógena que las partículas del humo. Este grupo de alérgicos al tabaco, habitualmente no tenido en cuenta, puede afectar las conclusiones epidemiológicas. Puede vincularse también a la exposición ambiental a la hoja en plantaciones y elaboradoras y a la reactividad cruzada con otros alérgenos. En los no alérgicos al tabaco, se ha encontrado tanto en ratones como en humanos una tendencia a menor reactividad frente a otros alérgenos en quienes respiran el $\mathrm{ACHT}$.

- La acción irritativa del humo del tabaco, podría ser causa del asma. Depende de la cantidad y frecuencia de la exposición, puede conducir a una inflamación de las vías aéreas afectando la funcionalidad, con o sin aumento de HRB, pero varias investigaciones experimentales y epidemiológicas poblacionales no demuestran efectos perniciosos y en otros la asociación es débil. La OR es más elevada en los primeros años de vida, descendiendo progresivamente hacia la adolescencia con 
valores de indiferencia, sobre todo en los que tienen antecedentes atópicos. En el mediano y largo plazo conduce a una remodelación con poca respuesta a los corticoides.

- Este efecto podría clasificarse como un factor contribuyente del asma, por la vía de mecanismos fisiopatogénicos irritantes y parece afectar más a los niños sin antecedentes alérgicos con el fenotipo de sibilantes transitorios de comienzo temprano y exacerbaciones en las virosis respiratorias, potenciando los efectos de éstas últimas en niños mayores ${ }^{172}$. Este mecanismo de provocación de episodios sería similar al observado para otros polutantes, sobre todo del aire exterior ${ }^{173} \mathrm{o}$ podría deberse al formaldehido u otras moléculas que componen el humo del tabaco.

- Mientras las evaluaciones de los efectos en las primeras semanas de exposición muestran resultados controvertidos hay mayor consenso en que la exposición crónica promueve la remodelación de la vía aérea. La OR levemente elevada para todo tipo de patologías respiratorias bajas en los primeros dos años de vida reforzaría la hipótesis de un efecto irritante o proinflamatorio inespecífico con deterioro de las respuestas defensivas de los tejidos pulmonares.

- En niños asmáticos persistentes aumenta la severidad del cuadro, actuando probablemente como co-factor por inflamación y remodelación exacerbadas pero no por agravamiento de su causalidad alérgica frente a los neumoalérgenos. 


\section{Hongos aerógenos}

Más de 20.000 especies de hongos anemófilos emiten esporas al aire a partir de sus formas vegetativas y pueden hallarse, tanto en el aire interior como exterior, gran cantidad de las mismas que son trasladadas por el viento. Suelen encontrarse en una proporción mil veces más abundante que los granos de polen. Son partículas con tamaños que oscilan entre 2 a $30 \mu \mathrm{m}$, por lo que muchas de ellas pueden llegar a los alvéolos pulmonares. Pueden detectarse algunos picos estacionales generalmente de verano y otoño ${ }^{174}$, aunque no tan marcados como los polínicos. La gran persistencia de las esporas en ambientes exteriores e interiores y su reflotamiento por las corrientes de aire y la movilización de objetos probablemente genere alternativas perennes de exposición aerógena, sobre todo cuando las concentraciones han sido abundantes previamente. Es interesante tener en cuenta una interacción descripta en el ambiente doméstico entre la presencia de gatos ( $>$ de 1) y el aumento en el nivel de esporas fúngicas en el aire ${ }^{175}$.

Los Basidiomicetes, entre los que están las setas y hongos con sombrero, son la clase más avanzada y aumentan su presencia en ambientes lluviosos y húmedos y han sido poco estudiados en su relación con la alergia, con la excepción de royas y ustílagos. Es probable que hayan influenciado en la difundida vinculación de los hongos con la humedad ambiente y la poca ventilación. Sin embargo, la clase Deuteromycetes (Fungi imperfecti) que es la más importante desde el punto de vista alergológico, destacándose en ella Cladosporium, Alternaria, Aspergillus y Penicillium, tiende a incrementar sus concentraciones de esporas con humedad ambiental disminuida y las corrientes de aire. Aumentan al mediodía, con máxima luz solar ${ }^{176}$. Para sus formas vegetativas (hifas y micelios) requieren sustratos con condiciones favorables de humedad y provisión de nutrientes. Pueden encontrarse concentraciones importantes de levaduras en humidificadores y acondicionadores de aire.

Se ha planteado que los niños que están en contacto con altas concentraciones de esporas fúngicas tendrán más probabilidades de ser asmáticos ${ }^{177}$ y presentar otros síntomas respiratorios nasales, faríngeos y bronquiales ${ }^{178}$.

Los mecanismos fisiopatogénicos propuestos pueden clasificarse en: 
- Alérgicos Específicos: respuesta IgE dependiente ${ }^{179}$. Se ha estimado que un $10 \%$ de la población general y un $40 \%$ de los asmáticos presentan alergia tipo I a antígenos micóticos ${ }^{180}$. En Santa Fe (ARG), detectan un 27\% de pruebas epicutáneas positivas para hongos anemófilos en asmáticos $^{181}$. Otro relevamiento en 380 niños alérgicos halla 3,6\% para Aspergillus y $3,9 \%$ para Alternaria ${ }^{182}$. Alternaria es el hongo más estudiado y probablemente el de mayor importancia para este tipo de reacciones. Tiende a aumentar en verano ${ }^{183}$ y contra lo que podría suponerse, varias publicaciones refieren que aumenta relativamente su importancia en zonas de clima más seco de Australia y USA. Se halla en mayor cantidad en el aire exterior, mientras que Penicillium y Aspergillus predominan en el aire interior. Las especies de Cladosporium se tienen un comportamiento mixto en este sentido ${ }^{184}$. En el marco de la Encuesta nacional de Salud en Estados Unidos en 1987, se halló una prevalencia de pruebas positivas para Alternaria del 3,6\% ${ }^{185}$ en la población general. En Escandinavia ${ }^{186}$ determinan una prevalencia del $4 \%$ de pruebas positivas en piel para alérgenos fúngicos en general. Se halló una correlación entre la severidad del asma infantil y el conteo de esporas con un aumento del puntaje de síntomas cada $1000 \mathrm{UFC} / \mathrm{m}^{3}$.

- Micosis broncopulmonar alérgica ${ }^{187}$. La más conocida es la Aspergilosis broncopulmonar alérgica, que se produce generalmente en asmáticos, con infiltrados pulmonares y bronquiectasias centrales debido a reacciones de hipersensibilidad posiblemente mediadas por la IgE e IgG específicas antiAspergillus. Puede evolucionar con episodios repetidos de exacerbaciones de un cuadro asmático e incluso progresar hacia una enfermedad fibrocavitaria crónica tipo TBC o hasta una destrucción fatal de los pulmones. Ha sido reportada en niños ${ }^{188}$.

- Infecciosos: el crecimiento de los hongos en el organismo humano está limitado por la temperatura corporal salvo para los termofílicos como el Aspergillus $^{189}$ que puede producir un cuadro pulmonar invasivo o un aspergiloma, generalmente en personas con inmunodeficiencias o 
expuestas a altas dosis de esporas. La menor temperatura en piel y uñas posibilita cuadros infecciosos localizados de otras especies.

- Inespecíficos "tóxicos" o inflamatorios (no hiperreactivos) ${ }^{190}$. Se ha descripto un síndrome en personas expuestas a ambientes contaminados con hongos que incluye cefalea, rinorrea, tos, disnea, epistaxis, náuseas, vómitos, pérdida de memoria, debilidad y cambios de conducta ${ }^{191}$. Las manifestaciones respiratorias podrían interpretarse como un cuadro de asma. Este síndrome puede asociarse al "síndrome del edificio que enferma"192 ("sick building syndrome"). Pero si bien hay algunos trabajos que aportan casuística en este sentido, otros han cuestionado esta asociación ${ }^{193}$. Se ha propuesto que podrían actuar micotoxinas y otros metabolitos fúngicos (Compuestos orgánicos volátiles de microbios, $M V O C)$, que se producen en las fases de crecimiento, por lo que no están relacionados con la concentración esporular. Las micotoxinas no se han vinculado con reacciones de tipo alérgico respiratorio. El $\beta(1-3) D$-glucan de la pared micótica activa mecanismos proinflamatorios uniéndose a los Linfocitos CD14 y los receptores toll-like 4, con producción de citoquinas e inflamación en las vías aéreas y otros sistemas. La activación de los receptores activados por proteasas y la inducción de inflamación eosinofílica por la quitina de los hongos se propusieron como mecanismos potenciales ${ }^{194}$.

- Irritativos: se consideran fenómenos inicialmente no inflamatorios, que no se deben a una hiperreactividad específica, aunque los asmáticos, como suele suceder con la mayoría de los irritantes, tienen mayor sensibilidad. Rylander $(1998)^{195}$, comparando dos escuelas, halla una prevalencia mayor de síntomas respiratorios en la que tenía problemas de contaminación fúngica y mayor concentración de glucanos en aire. Los síntomas respiratorios como tos seca o catarral y ronquera fueron más frecuentes entre los niños atópicos que los no atópicos en esa escuela mientras que en la escuela control no se halló esa diferencia. Se ha mencionado como agentes irritativos fúngicos a los compuestos orgánicos volátiles de origen microbiano (MVOC), a los glucanos y al 
ergosterol. La baja concentración de MVOC detectados en ambientes muy contaminados llevan a descartar una reacción tóxica y orientan hacia un fenómeno irritativo ya que tampoco se han demostrado respuestas inmunitarias específicas. Estas concentraciones generalmente no están correlacionadas con la concentración de esporas o alérgenos fúngicos en aire ${ }^{196}$.

- Psicológicos: se ha propuesto que tanto el olor como la observación de lugares cerrados muy contaminados por hongos podría inducir malestares tales como dolor de cabeza, mareos, náuseas, entre otros, de tipo psicosomático. Esta alternativa causal ha sido amplificada por la difusión en medios de comunicación de los efectos perniciosos en la Salud de la contaminación por hongos ${ }^{197}$ - 198. 


\section{Formaldehido.}

El formaldehido es un compuesto orgánico volátil de fórmula $\mathrm{H}_{2} \mathrm{C}=\mathrm{O}$ que en su fase gaseosa es muy soluble en agua por lo que irrita con facilidad las mucosas ocular y del tracto respiratorio ${ }^{199}$. En soluciones acuosas al $40 \%$ se lo conoce como formol.

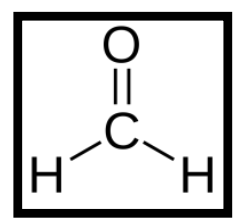

Es muy utilizado para elaborar tablas de madera reconstituida (MDF) destinadas a construir mobiliario, pisos y divisores de ambientes, tapicerías y cortinados, pegamentos, conservantes de pinturas, revestimientos, cosméticos, suavizadores de telas, acabados de papeles de envoltura, materiales aislantes, procesos médicos y de laboratorio, antisépticos, algunos líquidos para lavar platos y limpiadores de alfombras. Otras fuentes de liberación al aire son la quema de maderas (estufas hogareñas abiertas, salamandras y cocinas de leña con pérdidas de humos), combustión de kerosene y gas natural, automóviles con convertidores catalíticos o que usan naftas oxigenadas, cigarrillos y diversos procesos naturales. Puede hallarse en las capas bajas de la atmósfera cuando ocurre el fenómeno del "smog" o neblumo. Su ciclo biogeoquímico es breve en el agua y más breve aún en el suelo. En el aire, donde es más importante, se degrada durante el día, principalmente en ácido fórmico y monóxido de carbono. No parece acumularse en la biota aunque se han encontrado trazas en algunos alimentos ${ }^{200 \_201}$. Generalmente se encuentra en mayores concentraciones en el aire interior y más aún en viviendas de reciente construcción con materiales modernos.

Como se dice anteriormente tiene efectos irritantes, pero se han descripto también alergénicos y sensibilizantes, por lo que se le atribuye potencialidad agravante del asma infantil, (Krzyzanowski et al. 1990) ${ }^{202}$. En varios trabajos ${ }^{203}$ que han investigado la posibilidad de una reacción alérgica específica IgE dependiente como causa de asma en expuestos al formaldehido no se ha podido demostrar este hecho con evidencias contundentes, si bien se han hallado en muy pocos casos IgE antiformaldehido luego de exposición prolongada (Kramps et al. 1989) ${ }^{204}$. Una investigación de Wantke (1996) ${ }^{205}$, en escolares de 8 años de edad, que cursaban en aulas construidas con emisores de 
formaldehido (0,07 ppm de promedio), halló IgE específica en el 38\%, pero los niveles no se correlacionaban con la severidad y el número de síntomas, mientras que estos disminuyeron claramente al ser ubicadas en aulas con menores niveles de emisión. Otros trabajos ${ }^{206}$, intentando detectar la IgE específica en estudiantes de Anatomía y en personas que habitaban casillas rodantes o departamentos construidos con materiales emisores no lograron detectarla. Se supone como hipótesis para este trabajo que el mecanismo predominante es el irritativo y proinflamatorio inespecífico sin intervención de la lgE.

Este efecto puede producirse en el ambiente interior doméstico por la emisión de gases desde las tablas MDF, con una concentración que dependerá a su vez de la concentración utilizada en la tabla, la temperatura ambiente y la ventilación. La aplicación sobre la tabla de una cobertura impermeable podría disminuir la emisión ${ }^{207}$. El humo de cigarrillos $(0,02-0,04 \mathrm{mg} / \mathrm{unidad})$, las estufas de kerosene y gas natural (15 - $25 \mathrm{mg} /$ hora, equivalentes a 4,35 ppm acumulados en un dormitorio típico de $30 \mathrm{~m}^{3}$ ), los hogares a leña y las salamandras no herméticas son otras fuentes que deben tenerse en cuenta en el hogar. El uso invernal, con las ventilaciones cerradas agrava la situación. En el caso del humo de cigarrillos se han medido 40 ppm y se estima que 5 cigarrillos fumados en una habitación de $30 \mathrm{~m}^{3}$ genera una concentración de formaldehido de 0,23 $\mathrm{ppm}^{208}$.

\begin{tabular}{|l|l|}
\hline Tipo de emisión & Concentraciones en atmósfera \\
\hline Ambientes naturales & menos de $0,002 \mathrm{ppm}$ \\
\hline Ambientes suburbanos & 0,002 a $6.000 \mathrm{ppm}^{209}$ \\
\hline Ambientes urbanos densos o cercanía de algunas industrias & 10.000 a $20.000 \mathrm{ppm}^{210}$ \\
\hline
\end{tabular}

\begin{tabular}{|l|c|c|c|}
\hline \multicolumn{1}{|c|}{ Efecto } & tiempos de exposición & $\begin{array}{l}\text { Concentración en } \\
\text { aire interior }\end{array}$ & Equivalente $\mathbf{m g} / \mathbf{m}^{\mathbf{3}}$ \\
\hline irritante y alergénico & & Más de 0,10 ppm & \\
\hline Percepción olfativa. & & Entre 0,05 y 1 ppm & \\
\hline Nivel de mínimo riesgo agudo (MRL) & & $0,04 \mathrm{ppm}$ & 0,02454 \\
\hline Nivel de mínimo riesgo crónico & $30 / 40$ minutos & $0,02 \mathrm{ppm}$ & $0,2 \mathrm{ppm}$ \\
\hline $\begin{array}{l}\text { > Eosinófilos en lavaje nasal, } \\
\text { estornudos y picor }\end{array}$ & $30 / 40$ minutos & 0,1 a $2 \mathrm{ppm}$ & 0,123 a 2,454 \\
\hline $\begin{array}{l}\text { Obstrucción vías aéreas, Congestión } \\
\text { nasal }\end{array}$ & \multicolumn{2}{|c|}{ Fuente: Agencia para Sustancias Tóxicas y el Registro de Enfermedades, USA } \\
\hline
\end{tabular}


Es mencionado como cancerígeno (fundamentalmente ocupacional) del grupo 1 (confirmado nasofaríngeo y asociación fuerte pero no suficiente para leucemia) ${ }^{211}$ y tiene efectos tóxicos dosis-dependiente sobre los Linfocitos NK humanos ${ }^{212}$.

\begin{tabular}{|c|c|}
\hline \multicolumn{2}{|c|}{ Clasificación de calidad ambiental de los productos elaborados con formaldehido. } \\
Unión Europea.
\end{tabular}

Fuente: Eco informe Sector Muebles AIDIMA 2009

Los límites de la ecoetiqueta alemana "Ángel azul" para la categoría de productos de bajas emisiones plantean un valor final (a los 28 días) de 0.05 ppm.

\begin{tabular}{|l|l|l|}
\hline \multicolumn{3}{|l|}{ Tabla 3.2 Clases de emisión según Japanese Standards Association (JSA) } \\
\hline $\begin{array}{l}\text { clasificación de la emisión de } \\
\text { formaldehído valor medio (mg/l) }\end{array}$ & valor máximo (mg/l) & $\begin{array}{l}\text { restricciones para uso interior (para tasa de } \\
\text { circulación de aire en } 50 \% \text { hora) }\end{array}$ \\
\hline $\mathrm{F}^{* * * *}$ & $\leq 0,3 \leq 0,4$ & Sin restricciones \\
\hline $\mathrm{F}^{* * *}$ & $\leq 0,5 \leq 0,7$ & Cantidad de superficie restringida \\
\hline $\mathrm{F}^{* *}$ & $\leq 1,5 \leq 2,1$ & Cantidad de superficie restringida \\
\hline $\mathrm{F}^{*}$ & $\leq 5,0 \leq 7,0$ & Uso interior prohibido \\
\hline
\end{tabular}

Fuente: Eco informe Sector Muebles AIDIMA 2009.

Rumchev et al. (2002), en un estudio de casos y controles, observando la asociación entre niveles de formaldehido en el aire hogareño y consultas por asma en salas de emergencia, hallan una relación de 3\% de incremento de visitas de asma por cada $10 \mathrm{mg} / \mathrm{m}^{3}$ de aumento del formaldehido ${ }^{213}$. Para la Agencia toxicológica de los CDC norteamericanos, los síntomas observados por inhalación de formaldehido son fundamentalmente de ojos, nariz y garganta, con exposiciones en el rango de 0.4-3 ppm en un lapso de pocas horas $(<8 \mathrm{~h})$. Son poco convincentes las evidencias de manifestaciones en las vías aéreas bajas ${ }^{214}$. 


\section{Insecticidas}

Se presenta a continuación una tabla con los pesticidas aprobados por ANMAT que son los disponibles para el uso hogareño y que seguramente fueron los empleados por las familias incorporadas en esta investigación.

\begin{tabular}{|c|c|c|c|}
\hline \multicolumn{4}{|c|}{$\begin{array}{l}\text { Tabla 3.3. Listado de Insectic } \\
\text { Actualizado al } 31 / 10 / 2013\end{array}$} \\
\hline insecticida & Grupo químico & dispositivo & Efectos respiratorios \\
\hline $\begin{array}{l}\text { Tetrametrina } 0.40 \%,+ \\
\text { Permetrina } 0.10 \%\end{array}$ & piretroide & aerosol & \\
\hline Permetrina $0.25 \%$ & piretroide & aerosol & \\
\hline $\begin{array}{l}\text { Fenitrotión } 0,2905 \%,+ \\
\text { Tetrametrina 0,0664\% }\end{array}$ & $\begin{array}{l}\text { Fosforado + } \\
\text { piretroide }\end{array}$ & aerosol & $\begin{array}{l}\text { El fenitrotión es un inhibidor de } \\
\text { la colinesterasa, que en altas } \\
\text { dosis puede producir } \\
\text { broncoespasmos y broncorrea y } \\
\text { en un cuadro muy severo } \\
\text { parálisis respiratoria }\end{array}$ \\
\hline \multirow{2}{*}{$\begin{array}{l}\text { D-aletrina } 33,33 \% \text { y } \\
\text { Butóxido de piperonilo }\end{array}$} & Piretroide + & \multirow{2}{*}{$\begin{array}{l}\text { Eléctrico. Tabletas } \\
\text { termoevaporables }\end{array}$} & \\
\hline & Benzodioxol & & \\
\hline \multirow{2}{*}{$\begin{array}{l}\text { Esbiotrina } 20 \mathrm{mg} / \text { tableta } \\
2,438 \%,+ \text { Butóxido de } \\
\text { piperonilo } 20 \mathrm{mg} / \text { tableta } \\
2,438 \% \text {, Transflutrina } \\
3 \mathrm{mg} / \text { tableta } 0,366 \%\end{array}$} & Piretroides + & \multirow{2}{*}{$\begin{array}{l}\text { Tabletas } \\
\text { termoevaporables }\end{array}$} & \\
\hline & Benzodioxol & & \\
\hline $\begin{array}{l}\text { D-Aletrina } 4.675 \%,+ \\
\text { Butoxido de piperonilo } \\
0.104 \%\end{array}$ & $\begin{array}{l}\text { Piretroide }+ \\
\text { Benzodioxol }\end{array}$ & $\begin{array}{l}\text { Tabletas } \\
\text { termoevaporables }\end{array}$ & \\
\hline $\begin{array}{l}\text { Transflutrina } 3,49 \mathrm{~g} \% \text { (70 } \\
\text { mg por unidad) }\end{array}$ & Piretroide & $\begin{array}{l}\text { Tabletas } \\
\text { termoevaporables }\end{array}$ & \\
\hline $\begin{array}{l}\text { Aceite natural de } \\
\text { Lavanda } 94,9 \% \text {, } \\
\text { Permetrina } 0,1 \%\end{array}$ & Piretroide & $\begin{array}{l}\text { Blíster } \\
\text { termoformado con } \\
\text { dos burbujas por } \\
3 \mathrm{~g} \text { cada uno } \\
\end{array}$ & \\
\hline $\begin{array}{l}\text { D-aletrina } 0,12 \% \text { al } \\
0,2 \%\end{array}$ & Piretroide & Espirales & \\
\hline
\end{tabular}

Los aerosoles contienen generalmente piretroides en concentraciones variables por un total entre 650 y $1300 \mathrm{mg}$ por envase común de $360 \mathrm{~cm}^{3}$ disueltos en solventes, emulsionantes, antioxidantes, enmascarantes y propelentes (p.ej: isobutano/propano 80/20) que eventualmente pueden tener también efectos irritativos o alergénicos.

Las Tabletas termoevaporables tienen impregnado el principio activo en una base sólida de sílica y liquido indicador. Los espirales consisten en un compuesto sólido 
de lenta combustión que contiene aserrín, colorantes, fragancias y piretrinas ${ }^{216}$. La combustión del aserrín podría emitir formaldehido.

Como puede observarse en la tabla que sintetiza las múltiples presentaciones de insecticidas de venta libre para uso hogareño autorizadas en la Argentina, todos contienen derivados piretroides, aunque algunos agregan un sinergizante, el butóxido de piperonilo y otros agregan un organofosforado, el fenitrotión. Llama la atención que un componente de este grupo de importante toxicidad aguda esté disponible para venta libre en los supermercados y kioscos, en aerosoles de numerosas marcas comerciales ${ }^{217}$.

El fenitrotion se usa en agricultura, para el control de moscas, mosquitos y cucarachas en recintos cerrados (hogareños) y en programas de salud pública. Como todos los organofosforados es un potente inhibidor de la colinesterasa. Debe tenerse en cuenta que se han descripto variaciones genéticas en humanos que condicionan un nivel menor que el normal de acetilcolinesterasa sin previa exposición a los organofosforados, que los posiciona con mayor riesgo frente a un contacto ${ }^{218}$. Los síntomas más frecuentes de una intoxicación por inhalación son calambres abdominales, diarrea, vértigo, dolor de cabeza, náusea y pérdida de conocimiento. El cuadro respiratorio aparece en intoxicaciones más severas.

El piretro es una sustancia que se obtiene de las flores del crisantemo, que pertenece a la familia de las compositáceas. Varela Fuentes $(1946)^{219}$ menciona al piretro como uno de los inhalantes a tener en cuenta en los alérgicos asmáticos. Kurlat (1974) lo incluye en la lista de alérgenos inhalantes y menciona que puede tener reacciones cruzadas en alérgicos a los pólenes de compuestas. También afirma que "como en el caso del tabaco, muchas reacciones son inespecíficas, de irritación de las vías respiratorias" 220 . Según Feinberg 221 , su fracción alergénica la constituye una oleorresina que no tiene propiedad insecticida. Perez Lozano (1965) relata haber hallado 8 pruebas cutáneas positivas para piretro sobre 300 asmáticos adultos estudiados, que además eran sensibles a kapok, otra fibra de origen vegetal. Más recientemente (Mitchell 2006) publica el hallazgo de una prueba del parche 222 positiva para la piretrosina mientras que los demás componentes dieron negativos. Esta prueba del parche positiva es una reacción tardía (48 a 72 hs.) generalmente vinculada a la dermatitis atópica en la que también parece jugar un rol importante la IgE específica encontrada en la superficie de las células presentadoras de antígenos ${ }^{223}$. 
Del piretro se derivaron las piretrinas naturales y los sintéticos piretroides ofrecidos comercialmente como insecticidas de uso hogareño. La alergenicidad sería más pronunciada en las piretrinas naturales ${ }^{224}$. Los derivados semisintéticos o sintéticos del piretro pueden producir síntomas diversos, con efectos tanto sobre el SNC, el aparato digestivo, la piel y las vías respiratorias. Se ha atribuido a mecanismos alérgicos o irritativos la fisiopatogenia de los efectos en mucosas y piel, mencionando la mayor frecuencia de Rinitis, Conjuntivitis, Dermatitis y la exacerbación del Asma ${ }^{225}{ }^{226}$. Un estudio publicado en el Boletín de la OMS refiere síntomas en piel y respiratorios altos en fumigadores y habitantes de las viviendas fumigadas, de aparición rápida que ceden en un día ${ }^{227}$. Otro estudio, realizado en Nueva York, luego de una fumigación urbana con piretroides para combatir mosquitos, que monitoreó las consultas de emergencia por asma, no halló diferencias significativas ${ }^{228}$ entre los días previos y los inmediatos siguientes. Si bien esta investigación es muy interesante por sus características poblacionales en un universo de gran tamaño, que contempló además otras variables de confusión como las climáticas y de calidad de aire, surgen algunas observaciones:

- durante la fumigación nocturna se solicitó a la población que cerrara las ventanas, lo que podría haber disminuido en forma importante la exposición

- es posible que muchas personas con cuadros leves y moderados de exacerbación del asma o la rinitis no hayan concurrido a un sistema de emergencia.

- También algunos asmáticos pueden haber incrementado su medicación inhalada en momentos previos, dado el preaviso divulgado

- De todas maneras, desde el punto de vista sanitario, el balance costo-beneficio de la fumigación podría ser favorable, dada la peligrosidad de las enfermedades transmitidas por mosquitos y el aparente efecto leve en los asmáticos.

- $\quad$ El piretroide se hallaba potenciado por el butóxido de piperonilo.

Si bien se mencionan con más frecuencia los efectos irritativos, la posibilidad de que se produzcan reacciones alérgicas inmediatas se refuerza con el caso reportado recientemente de anafilaxia post-fumigación de un avión de pasajeros con piretroides ${ }^{229}$. La hipótesis que surge de la revisión de numerosas publicaciones es que la respuesta alérgica tipo I no ha sido claramente demostrada y, aunque posible, estaría limitada por una predisposición genética, siendo la irritación, acentuada en los 
hiperreactivos nasales o bronquiales la causa más común de síntomas. Los mecanismos de neurotoxicidad se atribuyen a la unión con los canales de Sodio, alterando la neurotransmisión, siendo los insectos mucho más sensibles que los mamíferos ${ }^{230}$. También se ha descripto la unión a los canales de Calcio, Cloro y a los receptores benzodiazepínicos ${ }^{231}$.

Analizando un registro de California sobre riesgo de enfermedad por pesticidas entre 2000 y $2008^{232}$, encuentran 4.974 casos relacionados con piretrinas y piretroides. La mayoría (85\%) fueron leves y un $34 \%$ se vinculó con el trabajo. El $48 \%$ de los casos eran respiratorios y se calcularon las OR para diversas fórmulas que oscilaron entre 1.79 (CI 95\%: 1.49-2.16) para piretrinas, hasta OR 2.99; (Cl 95\%: 2.33-3.84) para mezclas de piretrinas y piretroides.

Salome et al., (2000), estudiando pacientes que habían manifestado sensibilidad a insecticidas, efectuaron un estudio aleatorio doble ciego, controlado con placebo. Los pacientes, expuestos en una cámara especial con un máximo de $8.3 \mathrm{mg} / \mathrm{m} 3$ de piretro, registraron síntomas y caída significativa del FEV1 PC20 v. placebo $(p<0.05)^{233}$.

El butóxido de piperonilo es un benzodioxol derivado del safrol, que se utiliza como sinérgico de los piretroides y que está particularmente indicado para control ambiental en el caso de alérgicos a ácaros del polvillo doméstico en una fórmula que contiene Esbiol (piretroide) más el butóxido. Tiene una acción inhibidora del citocromo $\mathrm{P} 450^{234}$. Se evaluó en una muestra pequeña de 10 asmáticos y 5 controles el efecto en condiciones de exposición inhalatoria importante (local pequeño sin ventilar y pulverización durante 25 segundos con estancias repetidas de 5 minutos) con registro de síntomas y pruebas respiratorias. Diez de los quince expuestos presentaron irritación de garganta acompañada de tos en algunos casos. Tres de los 10 asmáticos presentaron caídas significativas del volumen espiratorio máximo en el primer segundo (VEF1) luego de 15 minutos de la inhalación que se fueron normalizando luego de los 40 minutos $^{235}$. Este efecto también fue detectado en otro estudio con asmáticos severos (Newton and Breslin 1983). Un estudio sobre las más de 17.000 denuncias recogidas por la American Association of Poison Control Centers (AAPCC) Toxic Exposure Surveillance System (TESS) ${ }^{236}$ en los años 2001 a 2003 hallaron 717 efectos moderados y 23 mayores en los usuarios de combinaciones de piretroides y butóxido de piperonilo. Reportan una mayor 
frecuencia de sensibilidad en los alérgicos a Ambrosia artemisifolia como anotaba Kurlat 30 años antes en Argentina.

En algunos productos también puede hallarse Metoprene, que es una hormona que actúa en el ciclo de desarrollo de los mosquitos interfiriendo con su transformación en adulto. Según el informe de $\operatorname{EPA}^{237}$ su toxicidad es muy leve e incluso se usa como aditivo en alimentos o aguas de consumo. No se refieren efectos por inhalación.

\section{Otros factores inespecíficos del aire interior.}

\section{Alfombras}

En relación con el asma, las alfombras pueden jugar principalmente a través de tres posibilidades:

- alergenicidad de sus propios tejidos,

- favoreciendo el crecimiento del número de ácaros del polvillo doméstico y por lo tanto aumentar el riesgo de episodios alérgicos en las personas sensibles a ácaros. La concentración media de ácaros es de 61 por gramo de polvo mientras que en un piso liso se cuentan 22 ácaros por gramo ${ }^{238}$.

- en los casos que sus materiales o pegamentos contengan compuestos orgánicos volátiles (algo muy frecuente), emitirlos llegando a concentraciones peligrosas en el aire interior en función de la temperatura y la ventilación del ambiente.

- Se ha descripto también una correlación entre el conteo de esporas fúngicas en aire y pisos alfombrados vs no alfombrados 239 .

- Podría plantearse una menor higiene del dormitorio alfombrado, con mayor probabilidad de desarrollo de hongos y bacterias que eventualmente, si se tuviera en cuenta la hipótesis de la falta de higiene como condicionante de una respuesta TH1 en niños, con menor riesgo de alergia, jugaría como un factor protector $^{240} 241$.

\section{Ventilación}

La ventilación adecuada es importante en un dormitorio desde varios puntos de vista, que incluyen el recambio de aire, la disminución de la humedad ambiente y por lo 
tanto de paredes, pisos, techos y mobiliario. Afectará el crecimiento de colonias fúngicas y de ácaros del polvillo doméstico así como bajará la concentración de contaminantes del aire que se estén emitiendo entre otros elementos determinantes de la calidad del ambiente. Pueden encontrarse diversos mecanismos para lograrla, siendo el mejor el de ventanas al exterior, aunque también se realiza a través de puertas (como única abertura del dormitorio), ventilaciones forzadas de aires acondicionados, pequeñas aberturas generalmente construidas por la reglamentación de las instalaciones de gas, etc... En el caso de los sistemas de aire acondicionado central se plantea el riesgo de contaminación de los conductos (microbiológica y química), que emitirán sus partículas al ser puestos en marcha. Por otra parte, los mecanismos de reducción de humedad y generación de frío de los diferentes aparatos acondicionadores pueden producir síntomas bronquiales en las personas con hiperirritabilidad de las vías aéreas.

Se ha propuesto un caudal de ventilación recomendable para dormitorios de 3,5 a $5 \mathrm{~L} / \mathrm{s}$ por persona ${ }^{242} 243$. Diversos factores influyen sobre la ventilación efectiva. Entre los principales se menciona el área de la abertura en relación con la superficie de la habitación o en otros trabajos ${ }^{244}$ en relación a la fachada de la habitación (20 a 30\%). También son importantes los vientos predominantes y su velocidad así como la relación de las aberturas de entrada y salida, la orientación y los obstáculos cercanos. Para calcular el factor de ventilación adecuada ${ }^{245}$ se ha tenido en cuenta la superficie de la ventana, su relación con la superficie de la habitación y el tipo de ventana, ya que las que tienen un mecanismo corredizo reducen generalmente a la mitad la superficie de ventilación. Se tomó como ventilación adecuada producida por una ventana, el valor igual o superior al $4 \%$ de la superficie de la habitación. Si bien la medición ideal sería sobre el volumen de la habitación, se carece del dato de la altura, aunque en las construcciones de la ciudad involucrada no se ha percibido una disparidad acentuada que haga presumir diferencias importantes. Finalmente la conducta de la familia en cuanto al tiempo y la proporción de la apertura efectiva, que muy probablemente sea muy reducida en los días fríos, introduce otro factor de incertidumbre. Para aplicar con mayor precisión este factor de ajuste de la contaminación en dormitorios debería contarse con la medición de la circulación real de aire y un registro de las costumbres familiares con respecto a apertura de las ventanas cotidianamente. 


\section{Manchas de humedad}

Se ha planteado la asociación entre ambientes interiores húmedos y efectos en la Salud ${ }^{246}$ aunque no han sido claramente establecidas las causas. Un factor asociado, que quizás tenga mayor importancia, es la falta de ventilación adecuada tanto en construcciones de bajo costo como en edificios que utilizan sistemas de climatización artificial que requieren hermeticidad. En este estudio, la problemática se refiere a construcciones hogareñas generalmente individuales, con ambientes ciegos o poco aireados que presentan además daños en los circuitos de agua, goteras o defectos en la aislación de los cimientos.

Las Ilamadas "manchas de humedad" en las paredes generalmente están acompañadas de cierta proliferación de colonias fúngicas ${ }^{247}$. Esto se produce cuando las condiciones de temperatura interior oscila entre 21 y $32{ }^{\circ} \mathrm{C}$, hay baja exposición solar y escasa ventilación que sumadas a la humedad ambiente propia de la región costera mesopotámica aumentan la posibilidad de que las esporas reproduzcan el micelio sobre el soporte de las paredes húmedas. Esta humedad es a veces acentuada por la costumbre de muchas familias de colocar algún sistema humidificador en los dormitorios, más aún cuando hay personas con síntomas respiratorios. A partir de los micelios son liberadas nuevas esporas reanudando el ciclo. Sin embargo, otros estudios describen un comportamiento del hongo Alternaria, probablemente el más importante desde el punto de vista alergológico, que tiende a aumentar en regiones de clima más $\operatorname{seco}^{248}$.

Por otra parte los ácaros del polvillo doméstico (Dermatofagoides, Blomia, Tirofagus, Acarus siro y otros) se reproducen mejor con una humedad relativa ambiente cercana al 75\% (Furumizo 1975), mientras que por debajo de 50\% mueren en muy pocos días (Arlian 1975). Vale destacar que en esta zona los ácaros son los más frecuentes causantes de alergia respiratoria ${ }^{249}$. Los hongos aportan a la alimentación de los ácaros (se han hallado esporas de hongos en el intestino de los ácaros (Van Bronswijk 1973), con lo que indirectamente aumentarían el número de los mismos, la cantidad de excrementos como complejo alergénico más importante y como consecuencia la frecuencia de sintomatología alérgica en las personas sensibles. Sin embargo, como suele suceder en los intrincados caminos ecológicos, un crecimiento mayor de hongos 
("escala de ataque") en los sustratos alimenticios va a limitar el crecimiento de los ácaros. Se ha sugerido que la ya mencionada humedad ambiente ideal para los ácaros es consecuencia de este equilibrio, que sería afectado con más humedad y más hongos ${ }^{250}$.

\section{Tipo de calefacción}

Desde el punto de vista de los posibles riesgos para asmáticos, los sistemas de calefacción pueden clasificarse en emisores o no emisores de partículas o gases.

Entre los no emisores están la mayoría de los aparatos eléctricos, la calefacción central por radiadores, los aires acondicionados tipo Split y las estufas de gas con tiro balanceado. Eventualmente sus sistemas de propulsión de corrientes de aire podrían arrastrar el polvillo depositado en su estructura, pero no está relacionado con los VOC y otras sustancias en los niveles de los otros aparatos.

Los sistemas con riesgo importante de emisión son ${ }^{251}$ :

- Kerosene

- Estufas de leña

- braseros

- Salamandras

- Gas sin tiro balanceado

- Aire acondicionado central

Generan gases y partículas respirables como el óxido nítrico, los óxidos del nitrógeno, el monóxido de carbono, el bióxido de carbono, el dióxido de sulfuro y nítricos biológicos que pueden actuar como endotoxinas 252253 . Tienen importancia también el formaldehido y otros VOC. El reporte de GINA $2006^{254}$, la "Iniciativa global para el asma", menciona como evidencia "D", "la eficacia de métodos para controlar o prevenir la exposición a estos agentes contaminadores, tales como los hornos al aire libre, y el mantener adecuadamente los sistemas de calentamiento, no se han evaluado y puede ser costosa". 


\section{Aire acondicionado}

Las posibles influencias sobre los cuadros respiratorios de los sistemas de aire acondicionado, se relacionan principalmente con la producción de frío y la deshumidificación, aunque hay aparatos mixtos con producción de calor y frío. Los sistemas centralizados tienen conductos que suman un importante riesgo de emisión de partículas contaminantes originadas en ellos del tipo compuestos orgánicos volátiles (VOC), bacterias, toxinas, esporas y alérgenos. El frío puede actuar como irritante bronquial, particularmente en los casos de hiperirritabilidad bronquial, sobre todo si es seco. Por el contrario se ha planteado que el efecto deshumidificador del ambiente disminuye la presencia de ácaros del polvo doméstico y de hongos aerógenos. En este sentido tendría un efecto protector, que es lo que se insinúa en esta muestra aunque las diferencias no son significativas.

\section{Método de limpieza del dormitorio}

Es posible que según el método que se aplique para limpiar influya en la densidad de alérgenos que se reciclan en el aire del dormitorio, dado que el uso de trapos húmedos puede retirar más eficazmente las pequeñas partículas, mientras que la escoba, el trapo seco o una aspiradora que generalmente no tiene filtros antiácaros eficientes, levantan una parte de las pequeñas partículas que persistirán en el aire de la habitación y que son las más importantes por su capacidad para penetrar en la vía respiratoria. El uso de productos químicos de limpieza sin ventilación adecuada puede incorporar al ambiente moléculas respirables que podrían tener efectos respiratorios como ya se ha mencionado.

\section{Desodorantes ambientales}

El uso muy difundido de desodorantes ambientales y otros productos del aseo, puede generar altas concentraciones de diversas sustancias, entre las que se pueden encontrar los compuestos orgánicos volátiles (VOC) ${ }^{255}$ como diclorobencenos y terpenos ${ }^{256}$. Los sahumerios y otros productos de combustión prolongada deberían ser 
estudiados en su composición y por un principio precautorio no deberían usarse en ambientes poco ventilados en que permanecen personas con problemas respiratorios hasta tanto no pueda comprobarse su inocuidad. 


\section{Aspectos especiales del aire exterior}

El aire exterior está compuesto por gases, vapores y partículas naturales en concentraciones a las que se ha adaptado el organismo humano, pero en determinadas condiciones climáticas, productivas y ambientales en general, se agrega la contaminación con gases, vapores y partículas naturales o artificiales que afectarán nocivamente el aparato respiratorio. Los asmáticos y los alérgicos pueden ser afectados por la propia respuesta alérgica específica a la que estén predispuestos (polen, esporas fúngicas, soja, otros cereales, por ejemplo), por la amplificación de la respuesta alérgica ${ }^{257}$ y por la acción irritante o proinflamatoria inespecífica que puedan provocar diversas moléculas. El bajo umbral de irritabilidad de las mucosas respiratorias aumentará este efecto, aún en concentraciones relativamente bajas. Por ejemplo, el $70 \%$ de los asmáticos responden a concentraciones más bajas del $\mathrm{NO}_{2},(0,05$ a 0,3 ppm versus $>1$ ppm en personas sanas) y además la exposición a 0,4 ppm de $\mathrm{NO}_{2}$ reduce la concentración necesaria de Dermatofagoides para provocar hiperreactividad bronquial ${ }^{258}$. También manifestarán síntomas respiratorios por irritación o inflamación inespecífica niños que no son asmáticos ni alérgicos, posiblemente en concentraciones mayores $^{259}$.

Muy recientemente se ha publicado ${ }^{260}$ un interesante meta-análisis de cinco importantes investigaciones europeas de cohortes desde nacimiento hasta los 10 años de edad, participantes del "Estudio europeo de cohortes para efectos de la polución en aire" (ESCAPE). El foco principal es la posible asociación de alergias específicas en los niños con la exposición a gases y material particulado, presentes en el aire exterior. Se efectuaron determinaciones de IgE específica para los alérgenos más comunes con técnicas in-vitro, se midieron las concentraciones de óxidos de nitrógeno y las partículas $\mathrm{PM}_{2,5}$, y $\mathrm{PM}_{10}$ y se estimaron densidades de tráfico en las cercanías y en la mayor avenida o ruta que estuvieran a unos $100 \mathrm{~m}$ de las respectivas viviendas. Si bien algunos de los estudios encontraban ciertas asociaciones, los resultados combinados no muestran una clara vinculación entre la contaminación estudiada y un aumento de alergias específicas, como si planteaban el trabajo mencionado de Diaz Sanchez y otras publicaciones. No detectaron tampoco interacciones estadísticamente significativas con las variables de control como sexo, historia familiar de asma o alergia y cambios de domicilio. No 
pudieron demostrar un efecto de la contaminación por tráfico vehicular, coincidiendo con el estudio de cohorte de Oslo (2007) $)^{261}$.

\section{Partículas originadas en depósitos, industrias y actividades de transporte portuario y terrestre.}

En el área urbana y suburbana de las ciudades entrerrianas, es frecuente encontrar molinos y depósitos de cereales y productos agropecuarios diversos. Son fuentes emisoras de polvos, material particulado de diverso tamaño, que en función de los vientos, la humedad, la temperatura y los movimientos productivos y de transporte, presentarán concentraciones diversas en la atmósfera. En los últimos años ha predominado fuertemente la soja.

\section{Polvo de soja}

En la década de 1980 ocurren 26 brotes epidémicos de asma en Barcelona y otras ciudades portuarias españolas relacionados con el movimiento de granos de soja, con gran número de personas afectadas, incluyendo cuadros severos de asma y 20 defunciones en Barcelona. Un estudio retrospectivo en New Orleans encuentra una asociación sospechosa en el mismo sentido, de los brotes epidémicos ocurridos entre 1957 y 1968. En consecuencia se profundizó el estudio alergológico y dos alérgenos mayores, Gly $\mathrm{m} 1$ y Gly $\mathrm{m} 2$, han sido identificados en el tegumento de la semilla. El alérgeno Gly $\mathrm{m} 1$ ha sido relacionado con las crisis epidémicas de asma en Cartagena y el alérgeno Gly m 2 con el asma epidémico en Barcelona ${ }^{262}$. En Rosario, Argentina un equipo encabezado por Ledit Ardusso y Carlos Crisci de la Universidad Nacional de Rosario, en colaboración con un grupo norteamericano, realiza un estudio epidemiológico ${ }^{263}$, dado el importante movimiento productivo sojero en la región de Rosario y la gran actividad exportadora en su puerto con el consiguiente acopio, traslado en camiones y carga con mangas a buques graneleros. Hallaron un $15.3 \%$ (56/365) de 
los pacientes con una respuesta cutánea positiva para soja (todos casos de asma y ningún control). El nivel de exposición, se asocia con una mayor prevalencia, siendo del $38.7 \%$ (12/31) para los pacientes con exposición directa (trabajadores rurales, de acopiadoras y transportistas), 20.3\% (27/133) para los que tenían una exposición indirecta (viviendas cercanas a fuentes) y $8.4 \%$ (17/201) para los que viven en zonas urbanas más alejadas de las mismas fuentes. Los casos con pruebas positivas también eran alérgicos a otros inhalantes comunes. Se ha descripto una asociación entre fenotipo asmático y alelos específicos del Complejo Mayor de Histocompatibilidad de clase II en individuos afectados por el asma epidémico en Barcelona, por lo que puede pensarse en la predisposición genética atópica. La densidad de partículas en el aire variará según los momentos productivos y las movilizaciones posteriores, pero dada la gran cantidad acumulada en depósitos durante períodos prolongados, es posible que dichos picos puedan ocurrir en cualquier momento del año. 


\section{Áreas inundables.}

La radicación de familias en áreas urbanas inundables se produce por varias motivaciones de tipo económico y social, generalmente ligadas a la pobreza, aunque también pueden hallarse cuestiones culturales, vinculadas a las costumbres y al estilo de vida ribereño. Generalmente, quienes se instalan en ellas no otorgan mucha importancia a las amenazas naturales ${ }^{264}$ y van generando, muchas veces con apoyo o al menos permisividad estatal de orientación populista, modificaciones no planificadas del entorno que agravan los riesgos de inundaciones y aluviones. Con cierta frecuencia la población se niega a trasladarse, aún con el beneficio de nuevas viviendas de tipo social. También se verifican nuevas ocupaciones de los espacios en los casos en que fue exitoso el plan de traslado. La cercanía a los lugares céntricos donde surgen oportunidades laborales también influye en la decisión de permanencia.

Desde hace mucho tiempo se ha planteado que las zonas bajas y húmedas, con abundante vegetación son inconvenientes para los asmáticos (Salter 1870). Algunos brotes de crisis asmáticas como el ocurrido en La Habana en 1963, se han atribuido a una humedad relativa ambiente muy alta ${ }^{265}$. Hay estudios epidemiológicos que han hallado una asociación entre la humedad ambiente y la altitud del terreno con el número de ácaros del polvillo. La mayor concentración de ácaros, que son muy alergénicos, se encuentra en las áreas de mayor humedad (Platts-Mills 1987), (Rijekaert 1981) ${ }^{266}$.

En Concepción del Uruguay, un territorio de suaves colinas o "cuchillas", los terrenos inundables corresponden a zonas con gran concentración de humedad, con cotas inferiores $a+8.25^{267}$, proximidad a desagües pluviales a cielo abierto y a los arroyos que cruzan o bordean la ciudad. La frecuencia de inundaciones es relativamente alta con una o más crecidas que generalmente duran varios días. Los procesos naturales son lentos aunque la construcción de grandes sistemas de defensa y bombeo de agua, aumentan el riesgo de crecidas rápidas en el caso de que fallaran los mecanismos artificiales de control ya que se ha obstruido el drenaje natural y ha aumentado la instalación de familias en lugares no aptos. El clima templado que está evolucionando hacia subtropical, con frecuentes momentos de alta humedad ambiental potencia las características de las zonas de planicies de inundación de los arroyos y del río. 


\title{
Diseño de la investigación y otros
}

\section{aspectos metodológicos}

\author{
Capítulo 4 \\ Proyecto de investigación.
}

\section{OBJETIVO GENERAL}

Estudiar los factores ambientales inespecíficos ${ }^{268}$ y su relación con las características clínico-epidemiológicas del asma en la población infantil de Concepción del Uruguay.

\section{OBJETIVOS ESPECIFICOS:}

1. Describir los síntomas, la severidad, los antecedentes y los tratamientos seguidos por los niños de 6 y 7 años de edad con síntomas compatibles con asma en Concepción del Uruguay,

2. Analizar la exposición a factores ambientales inespecíficos de riesgo o protección asociados al asma infantil en un grupo de casos y controles de 6 y 7 años de edad.

\section{Material y métodos.}

\section{1. Ámbito y duración del estudio}

La recolección de datos para la investigación se realizó en Concepción del Uruguay, Argentina, en el período 2005-2010. El procesamiento, análisis y elaboración de conclusiones se realizó entre 2009 y 2014. 


\section{Diseño metodológico}

Se inicia con un estudio poblacional de corte transversal, con diseño no experimental probabilístico. A partir de los casos hallados se seleccionan éstos y un grupo de controles para realizar una investigación de casos y controles con el fin de evaluar los factores de riesgo y protección, que pueden agruparse en tres unidades de análisis, como niveles interactuantes:

- Nivel 1: Niños

- Nivel 2: viviendas de cada uno de los niños estudiados

- Nivel 3: ambiente exterior

\section{Estudio de la Unidad de análisis endógena (Nivel 1: Niños)}

Para relevar los datos se utilizaron dos encuestas:

- el autocuestionario, denominado Encuesta 1, que se distribuyó a las familias de los niños seleccionados al azar a través de las respectivas Escuelas como parte del estudio de corte transversal ya mencionado.

- El cuestionario guiado, llamado Encuesta 2, para complementar datos relevados en la Encuesta 1, que se realizó en la muestra de casos y controles. Algunas de las variables estudiadas no se aplican a esta presentación.

\section{Encuesta I:}

Se aplicó a la muestra amplia para el estudio de corte transversal (ver plan de muestreo).

Las preguntas y las respectivas opciones de respuesta fueron diseñadas por un Comité internacional de expertos, especialmente conformado para el estudio colaborativo internacional denominado ISAAC. El Comité fue encabezado por el Profesor M.I. Asher del Departamento de Pediatría de la Universidad de Auckland y lo integraron entre otros el Prof. Keil del Instituto de Epidemiología y Medicina social de la Universidad de Münster (Alemania), y los Profesores de Salud pública de la Universidad de Londres, Strachan y Anderson. Fue aprobado en la reunión de Bochum, Alemania, en diciembre de $1991^{269}$.

El cuestionario es de estructura cerrada, con el formato y la redacción ya utilizado en el estudio ISAAC mencionado, donde se relevan datos sobre síntomas, 
antecedentes y desencadenantes, jerarquizando como decisivos tanto el diagnóstico establecido de asma como el antecedente de sibilantes en los últimos doce meses. En este caso, por ser niños de primer grado de escuela primaria (6-7 años), las preguntas son contestadas por los padres. Después del registro de los datos personales, comienza la serie de preguntas con las siguientes, para estimar la prevalencia y la incidencia acumulada en los primeros 5 años de vida.

\begin{tabular}{|c|c|c|}
\hline \multirow{2}{*}{1} & \multirow{2}{*}{$\begin{array}{l}\text { ¿Ha tenido alguna vez en el pasado chillidos o silbidos en el pecho? } \\
\text { Si la respuesta es "NO" pasar a la pregunta } 6 .\end{array}$} & SI \\
\hline & & NO \\
\hline 2 & $\begin{array}{l}\text { ¿Ha tenido en los últimos doce meses chillidos o silbidos en el pecho? } \\
\text { si la respuesta es "NO" pasar a la pregunta } 6 .\end{array}$ & $\mathrm{SI}$ \\
\hline 6 & ¿Ha tenido Asma alguna vez? & $\mathrm{SI}$ \\
\hline
\end{tabular}

La pregunta 6 intenta registrar la existencia de un diagnóstico médico de Asma.

Existen algunas preguntas que permiten evaluar la coherencia interna de las respuestas y otras que se refieren a enfermedades alérgicas asociadas (Rinitis y Dermatitis atópica). Esta metodología es muy práctica y se adapta particularmente para las encuestas poblacionales, que evitan a su vez el sesgo de selección de las muestras hospitalarias o de otros servicios de salud. Debe tenerse en cuenta que las respuestas pueden estar afectadas por un sesgo de información y por un sesgo de recuerdo. Las validaciones de esta modalidad investigativa 270271272 y del cuestionario ISAAC (International Study of Asthma and Allergies in Childhood) incluyen la versión en español que se aplica en esta investigación. Posteriormente ha continuado su utilización en numerosos trabajos publicados en todo el mundo durante más de 15 años. Se estima que los riesgos de errores por los sesgos mencionados se compensan ampliamente por la posibilidad de realizar estos estudios en muestras numerosas. En el anexo se agrega un ejemplar completo del cuestionario.

Un estudio español ${ }^{273}$ analizó la relación entre las variables de la encuesta ISAAC y la prevalencia acumulada de asma, realizando un estudio de provocación por esfuerzo y otras pruebas para diagnosticar clínicamente asma. Observaron una relación estadísticamente significativa entre la prevalencia actual de asma (respuesta a preguntas 2 y 6$)(p<0,001)$, con el diagnóstico de asma $(p<0,001)$, así como la 
prevalencia acumulada de rinitis $(p<0,001)$ con el diagnóstico de rinitis $(p<0,01)$. También comprueban una clara coincidencia entre la respuesta derivada del cuestionario para hallar la prevalencia acumulada de dermatitis $(p<0,001)$, con el diagnóstico de dermatitis $(p<0,001)$.

La prevalencia puede hallarse si la muestra fue diseñada y obtenida a través de métodos estadísticos adecuados.

Para evaluar la percepción familiar de algunos desencadenantes comunes de sibilancias, se formula la siguiente pregunta:

\begin{tabular}{|c|c|c|c|}
\hline \multirow{5}{*}{9} & \multicolumn{3}{|c|}{$\begin{array}{l}\text { ¿Ha tenido en el último año, chillidos en el pecho frente a algunos de estos } \\
\text { elementos? Marcar los que correspondan. }\end{array}$} \\
\hline & Polvo & Cambios de clima & Emociones \\
\hline & Pelos & Aire frío o refrigeración & Llanto \\
\hline & Plumas & Humo de cigarrillo & Risa \\
\hline & Pólenes, pastos & Olores fuertes, perfumes, y/o aerosoles & Resfrío \\
\hline
\end{tabular}

Las marcas en polvo, pelos, plumas, pólenes y pastos se consideran sospechosas de reacciones específicas a estos alérgenos. Los cambios de clima, las emociones, el aire frío o refrigeración, el llanto, el humo de cigarrillo, la risa y los olores fuertes son factores desencadenantes inespecíficos de episodios asmáticos. La respuesta a 'Resfrío' como desencadenante de sibilancias, se considera un indicador de presunta virosis respiratoria. Este conjunto de desencadenantes del asma integra el listado mencionado en la guía de GINA ${ }^{274}$, la iniciativa global para el asma. 


\section{Encuesta II}

Es un cuestionario estructurado, diseñado para realizarlo durante la visita domiciliaria, solo para el estudio de casos y controles y fue guiado por el encuestador. Releva una serie de datos complementarios, de los cuales se mencionan los utilizados finalmente en esta Tesis para completar lo planteado por el objetivo específico 1 (tratamientos):

\section{Atención médica.}

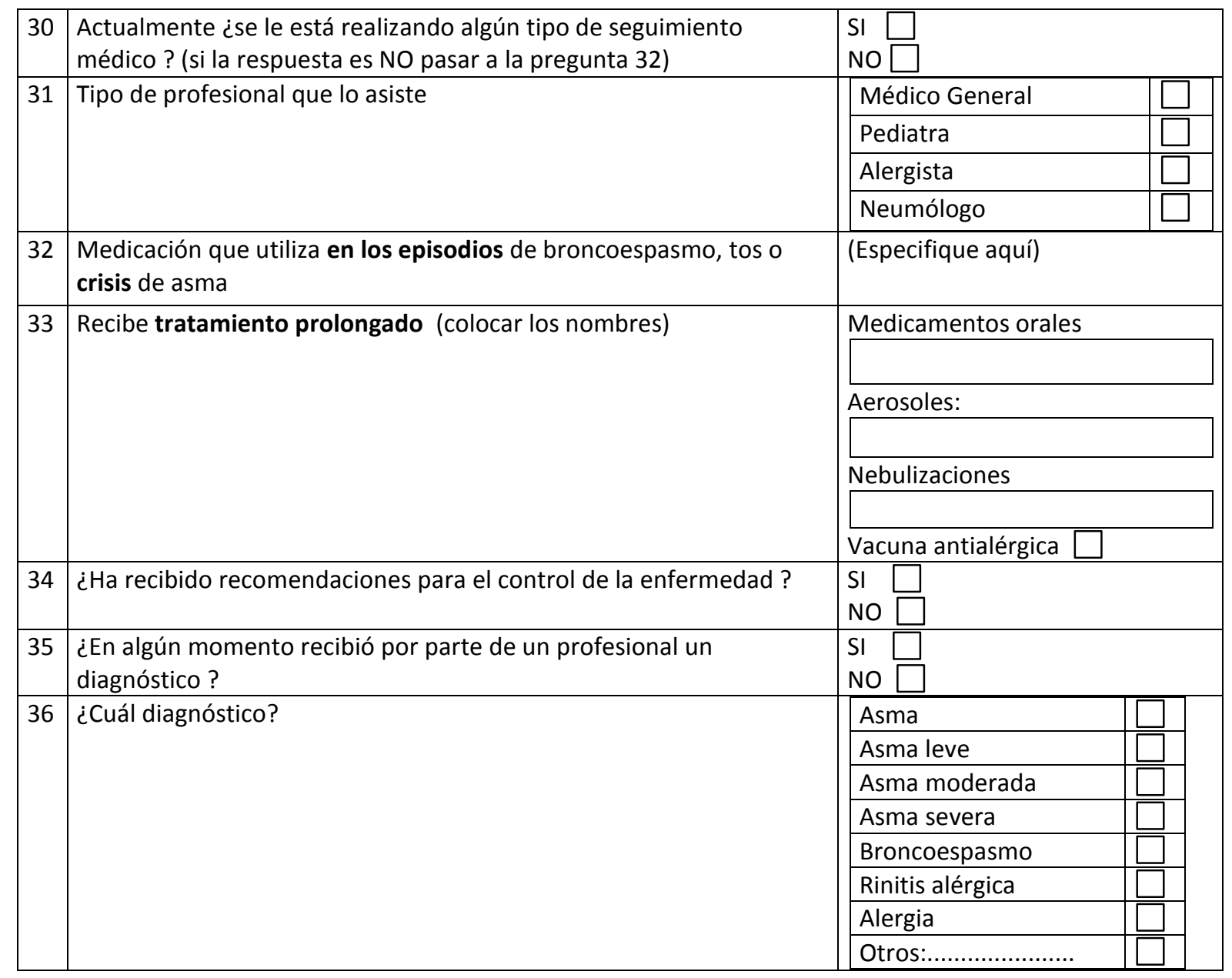


Estudio de la Unidad de análisis vivienda y entorno próximo (Nivel 2).

Registro de observaciones domiciliarias (con cuestionario estructurado)

- En el dormitorio del niño participante del estudio:

- Materiales emisores de formaldehido en paredes, pisos y mobiliario

- Alfombras

- Tipo de ventana (apertura completa o corrediza)

- Superficie en $\mathrm{m}^{2}$ de la ventana y superficie en $\mathrm{m}^{2}$ de la habitación

- Manchas de humedad

- Sistema de calefacción (kerosene, salamandra, brasero, gas con o sin tiro balanceado, eléctrica, otros)

- Aparatos para aire acondicionado

- Desodorantes ambientales (sahumerio, aerosol, aromatizador eléctrico, otros)

- Uso de insecticidas (aerosol, espiral, eléctrico, otros) Estación del año en que se utiliza con mayor frecuencia, periodicidad $(1,2,3$ y más de 3 veces por semana), mañana, tarde y noche.

- En la vivienda en general:

- Sistema de calefacción (kerosene, salamandra, brasero, gas con o sin tiro balanceado, eléctrica, otros)

- Talleres o depósitos lindantes

- Percepción familiar de partículas en suspensión

- Quema peridomiciliaria de residuos

\section{Captación, determinación y conteo de UFC micóticas}

La presencia de hongos en el dormitorio se estudió en forma directa a través una técnica no volumétrica de muestreo de aire. Se tomaron 6 muestras con cápsulas de Petri abiertas durante 10 minutos con caldo de cultivo específico (agar papa glucosada con cloranfenicol (100 mg/l) como antibiótico). Cuatro placas fueron ubicadas en el dormitorio del niño asmático o control (almohada, mesa de luz, cama, y 
ventana que contacta con el exterior), y otras dos en la cocina y en el comedor. También se midió la temperatura y humedad de los ambientes analizados con un termómetrohigrómetro.

Se observó si había manchas de humedad en las paredes del mismo y la posible asociación con las zonas inundables con mayor humedad ambiente.

Los hogares de los controles fueron seleccionados al azar dentro de los respectivos conglomerados en que se dividió la ciudad, intentando respetar la misma distribución de los casos. Se pudieron estudiar los que lo autorizaron mediante consentimiento informado.

Dado que no se halló una publicación sobre las categorías cuantitativas de hongos en aire y sus efectos sanitarios, medidos con esta técnica, se calcularon los cuartiles del grupo muestreado, estableciendo los respectivos puntos de corte y los intervalos, como puede verse en la siguiente tabla:

\begin{tabular}{|l|c|l|l|}
\hline \multicolumn{5}{|c|}{ Estimación de categorías según cantidad de UFC en la vivienda } \\
\hline cuartiles & punto de corte superior & categoría & intervalo \\
\hline primer & 40 & baja & 0 a 40 \\
\hline segundo & 59 & media & 41 a 59 \\
\hline tercer & 86,5 & alta & 60 a 86,5 \\
\hline cuarto & 120 & muy alta & 87 a 120 \\
\hline
\end{tabular}

\section{Indicador de exposición a formaldehido}

Se elaboró, con propósito exploratorio, un indicador de riesgo de inhalación de formaldehido gaseoso en el dormitorio de los niños estudiados. Las fuentes consultadas para introducir los supuestos de emisión y ventilación fueron:

- Division of Toxicology and Environmental Medicine Agencia para Sustancias Tóxicas y el Registro de Enfermedades , 4770 Buford Hwy NE, Atlanta, USA http://www.atsdr.cdc.gov/ September 2008

- Informe Técnico AIDIMA. España. http://www.xn--eco-diseo-s6a.net/ Ecoinforme Muebles 2009 
- Comunidad Valenciana, España. Norma HD 91 sobre ventilación de habitaciones.

Estimación de carga de formaldehido en aire de habitación $(30 \mathrm{m3})$ poco ventilada en invierno. 8 horas nocturnas.

\begin{tabular}{|c|c|c|c|}
\hline emisor & supuesto de emisión & ppm & puntaje de riesgo \\
\hline Placa MDF alta emisión 1 emisor (placard mediano 12,5 m²) & $8 \mathrm{~h} \times 5 \mathrm{mg} / \mathrm{hora}$ por $\mathrm{m}^{2} / 30 \mathrm{~m}^{3}$ & 16,6 & 16,6 \\
\hline tabaquismo frecuente. (5 o más cig/día en ambiente cerrado) & $5,7 \mathrm{mg}$ por cigarrillo & 0,23 & 0,23 \\
\hline kerosene y gas natural & 8 horas $\times 23 \mathrm{mg} / 30 \mathrm{~m} 3$ & 4,89 & 4,89 \\
\hline kerosene y gas natural fuera de dormitorio* & 8 horas $\times 23 \mathrm{mg} / 30 \mathrm{~m} 3 / 2$ & 2,445 & 2,445 \\
\hline braseros y salamandras fuera de dormitorio*** & 8 horas $\times 32,4 \mathrm{ppm} / 30 \mathrm{~m} 3 / 2$ & 4,32 & 4,32 \\
\hline
\end{tabular}

Para estimar los niveles de riesgo se aplicaron los valores propuestos por la Agencia para Sustancias Tóxicas y el Registro de Enfermedades de Estados Unidos de América, que se resumen en la siguiente tabla, en la que se agregó en la última columna de la derecha un nivel de riesgo para aplicar en esta investigación:

\begin{tabular}{|l|c|c|c|}
\hline \multicolumn{1}{|c|}{ Efecto } & $\begin{array}{l}\text { tiempos de } \\
\text { exposición }\end{array}$ & $\begin{array}{l}\text { Concentración en aire } \\
\text { interior }\end{array}$ & $\begin{array}{l}\text { Nivel de riesgo } \\
\text { propuesto en esta } \\
\text { Tesis }\end{array}$ \\
\hline irritante y alergénico & Más de $0,1 \mathrm{ppm}$ & alto \\
\hline $\begin{array}{l}\text { Obstrucción vías aéreas, } \\
\text { Congestión nasal }\end{array}$ & $\begin{array}{l}30 / 40 \\
\text { minutos }\end{array}$ & $0,1 \mathrm{a} 2 \mathrm{ppm}$ & alto \\
\hline $\begin{array}{l}\text { Nivel de mínimo riesgo } \\
\text { agudo (MRL) }\end{array}$ & & $0,04 \mathrm{ppm}$ & $\begin{array}{l}\geq \text { alto } \\
\text { bajo }\end{array}$ \\
\hline $\begin{array}{l}\text { Nivel de mínimo riesgo } \\
\text { crónico }\end{array}$ & $\begin{array}{l}\text { alto } \\
\text { > Eosinófilos en lavaje nasal, } \\
\text { estornudos y picor }\end{array}$ & $0,2 \mathrm{ppm}$ & alto \\
\hline Percepción olfativa. & & Entre $0,05 \mathrm{y} 1 \mathrm{ppm}$ & alto \\
\hline
\end{tabular}

Fuente: Agencia para Sustancias Tóxicas y el Registro de Enfermedades, USA

Sintetizando lo expuesto en la tabla anterior, el indicador diseñado para aportar al cumplimiento del objetivo de este trabajo, que toma el punto de corte del nivel mínimo de riesgo crónico según la información de la Agencia para Sustancias Tóxicas y el Registro de Enfermedades de Estados Unidos de América, genera una clasificación del riesgo en el dormitorio de los niños en dos niveles: 


\begin{tabular}{|l|c|}
\hline \multicolumn{2}{|c|}{ Indicador de riesgo de contaminación doméstica con formaldehido } \\
\hline Riesgo alto & $\geq 0,02 \mathrm{ppm}$ \\
\hline Riesgo bajo & Hasta $0,02 \mathrm{ppm}$ \\
\hline
\end{tabular}

Como ya se ha expuesto en el capítulo 3, es muy difícil evaluar la ventilación efectiva durante el invierno ya que aún pudiendo estimarse una superficie de ventilación adecuada, es posible que las ventanas no se abran en todo o gran parte del día. Con carácter exploratorio se analizó el posible efecto bajo el supuesto de que la capacidad de ventilación adecuada se realizara efectivamente, aplicando este ajuste en los valores de concentración de formaldehido:

\begin{tabular}{|l|l|c|}
\hline & Superficie de apertura de ventana & \\
\hline ventilación adecuada & $\geq 4 \%$ de superficie de habitación & $\Sigma / 2$ \\
\hline escasa ventilación & $<4 \%$ de superficie de habitación & $\Sigma \times 2$ \\
\hline
\end{tabular}

$\Sigma$ : sumatoria de los puntajes de riesgo por carga de formaldehido.

Posibles factores de confusión en la interpretación de este indicador:

- Debe tenerse en cuenta que las fuentes mencionadas de emisión de formaldehido son también emisoras de otros VOC, partículas y gases. Por ejemplo, la combustión del cigarrillo, maderas e hidrocarburos emiten numerosas sustancias que podrían potenciar el efecto en las vías aéreas.

- El invierno se relaciona con la menor ventilación y el uso más intenso de aparatos de calefacción emisores de formaldehido, pero también puede detectarse un aumento de la frecuencia de virosis respiratorias que también pueden influir desfavorablemente sobre el asma.

\section{Indicador para insecticidas}

También con propósito exploratorio se elaboró un indicador de riesgo de inhalar insecticidas en los dormitorios de los niños. Su valoración se basa en el cálculo de los cuartilos y se apoya en la experiencia clínica personal de 30 años de anamnesis de niños asmáticos y los efectos observados según las características del dispositivo utilizado: 


\begin{tabular}{|c|c|}
\hline Construcción exploratoria de un indicador de riesgo por insecticidas \\
\hline Variable & puntaje \\
\hline aerosol y espiral & 2 \\
\hline Eléctricos y otros & 1 \\
\hline no usan & 0 \\
\hline 2 o más veces por semana & 2 \\
\hline hasta 1 vez por semana & 0 \\
\hline Uso por la noche & 1 \\
\hline Otoño / primavera & 1 \\
\hline Invierno & 1 \\
\hline Verano & 1 \\
\hline
\end{tabular}

Para establecer las categorías a ser utilizadas en el análisis de este trabajo, los puntajes se agruparon en cuartiles en función de lo registrado en la muestra domiciliaria:

\begin{tabular}{|c|c|}
\hline $\begin{array}{c}\text { Clasificación de categorías de riesgo por } \\
\text { insecticidas }\end{array}$ & Puntaje \\
\hline riesgo muy alto (cuarto cuartil) & 7 y $8 \mathrm{p}$ \\
\hline Riesgo alto (tercer cuartil) & $6 \mathrm{p}$ \\
\hline Riesgo medio (segundo cuartil) & 1 a $5 \mathrm{p}$ \\
\hline riesgo bajo (primer cuartil) & $0 \mathrm{p}$ \\
\hline
\end{tabular}

Estos indicadores deberían ser validados con la medición de concentraciones de las substancias respectivas y de los efectos respiratorios en muestras representativas.

\section{Criterios para evaluar los sistemas de calefacción del dormitorio y el hogar.}

Se registran los sistemas utilizados tanto en la habitación donde duerme el niño como la utilizada en el hogar y se comparan las frecuencias y los riesgos para cada sistema en forma individual.

Se agruparon los sistemas de calefacción en función del riesgo de emisión de compuestos orgánicos volátiles (VOC), óxidos de Azufre y Nitrógeno, PM10 y otros irritantes respiratorios, en: 
- emisores: kerosene, gas sin tiro balanceado, estufas de leña, braseros y salamandras,

- no emisores: aparatos eléctricos, calderas con circuitos cerrados y gas con tiro balanceado. 
Estudio de la unidad de análisis ambiente exterior (Nivel 3).

Se consideraron dos tipos de áreas territoriales:

- Áreas con domicilios ubicados en cercanías de emisiones fijas de contaminantes atmosféricos, en los que se debe tener en cuenta a los vientos predominantes.

- Viviendas ubicadas en terrenos inundables con cotas inferiores $a+9^{275}$.

Para determinar las emisiones fijas se estudiaron varios trabajos realizados en la ciudad y la propia experiencia del equipo del Programa Salud para todos de la Facultad de Ciencias de la Salud bajo mi dirección que viene realizando relevamientos desde 1986.

Se consideraron fuentes de contaminantes atmosféricos las industrias de escala media y grande que realizan actividades productivas, secadoras de soja, almacenamiento, silos y carga de buques graneleros en el puerto.

Se revisaron como fuentes secundarias los trabajos publicados:

- Chichi Gabriel. Evaluación de Impacto Ambiental de la Empresa CALIMBOY S.A. C. del Uruguay E Ríos.

- PLANUR. Estudio de planificación urbana de la Municipalidad de Concepción del Uruguay. 1987.

- PECU. Plan estratégico de Concepción del Uruguay de la Municipalidad de Concepción del Uruguay. 2000 y revisión 2010.

- Carñel G, Costa Patricia y col. "Caracterización espacial por riesgo ambiental en la ciudad de Concepción del Uruguay con herramientas TIGs" Informe final PID-UNER 10053. 2013

Para las curvas de nivel de las cotas de inundación se contó con la información de la Municipalidad local. Está prohibida la construcción bajo esta cota por ser área inundable, según Ordenanza № 4110 del año 1996, mediante la cual declara "Zona de no innovar sujeta a expropiación", "al sector inundable ubicado al norte de la traza de la defensa hasta la curva de nivel cota $+8.25 \mathrm{~m}$ " (referida a la escala del puerto local). 


\section{Criterios y procedimientos para la aplicación de las encuestas}

Los criterios que se emplean aquí para relevar los casos de asma con fines epidemiológicos, han sido ampliamente aplicados en las investigaciones multicéntricas denominadas ISAAC (International Study of Asthma and Allergies in Childhood), con validaciones previas al lanzamiento 276277278 . Luego fueron utilizadas y validadas en otros estudios epidemiológicos, en particular PIAMA (Prevention and Prediction of Asthma and Mite Allergies) de Holanda, por ejemplo, que utiliza las mismas preguntas básicas.

A los fines de este estudio se construyeron una serie de puntajes que permitan analizar con objetividad, agrupando las respuestas a preguntas relacionadas $\mathrm{y}$ generando variables ordinales. Las bases conceptuales para establecer puntajes y categorías jerárquicas se apoyan en el Reporte del Consenso internacional sobre Diagnóstico y manejo del asma ${ }^{279}$ y en la experiencia clínica en el caso de las variables endógenas.

Por ejemplo, para categorizar la severidad se utiliza la Clasificación de severidad del asma, presentada en la página 4 del Reporte mencionado, con algunas modificaciones para facilitar la operacionalización. Se combinan la frecuencia de las crisis, la cantidad de despertares nocturnos y la dificultad para hablar, todas contabilizadas en los últimos doce meses.

Para valorizar la hiperreactividad bronquial se emplearon dos variables principales: la tos y el broncoespasmo postesfuerzo físico y la tos seca nocturna, que se incorporaron como preguntas al cuestionario ISAAC:

\begin{tabular}{|c|c|c|}
\hline \multirow{2}{*}{7} & \multirow{2}{*}{$\begin{array}{l}\text { En el último año ¿Ha tenido silbidos en el pecho durante o después del } \\
\text { ejercicio? }\end{array}$} & SI \\
\hline & & NO \\
\hline \multirow{2}{*}{8} & \multirow{2}{*}{$\begin{array}{l}\text { En el último año ¿Ha tenido tos seca en la noche, aparte de la tos por } \\
\text { infección respiratoria: resfrío, bronquitis, neumonía, etc.? }\end{array}$} & $S I$ \\
\hline & & NO \\
\hline
\end{tabular}

En la Tabla siguiente se expone para cada variable, la dimensión y el procedimiento aplicados. Debe tenerse en cuenta que es un estudio poblacional, con la potencialidad epidemiológica que tienen este tipo de investigaciones, pero que al realizarse fuera de los consultorios y hospitales carecen de algunas precisiones que pueden lograrse en un examen clínico completo y las pruebas complementarias específicas. 


\section{Tabla 4.1}

\begin{tabular}{|c|c|c|}
\hline \multicolumn{3}{|c|}{ Operacionalización de algunas de las principales variables endógenas (nivel niño). } \\
\hline Identificación & Dimensión & Procedimiento \\
\hline \multirow[t]{2}{*}{ casos de asma } & $\begin{array}{l}\text { presencia de disnea } \\
\text { sibilante en los últimos doce } \\
\text { meses }\end{array}$ & respuesta positiva a la pregunta 2 de cuestionarios I y II. \\
\hline & diagnóstico de asma & respuesta positiva a la pregunta 6 del cuestionario I y II. \\
\hline \multirow{6}{*}{ Severidad } & $\begin{array}{l}\text { Cantidad de ataques de } \\
\text { sibilantes en los últimos } \\
\text { doce meses }\end{array}$ & $\begin{array}{l}\text { Frecuencia evaluada según respuesta agrupada en cuatro } \\
\text { opciones: a. Ninguna (0), b. } 1 \text { a } 3 \text { (1), c. } 4 \text { a } 11 \text { (2), d. } \geq 12 \text { (4). }\end{array}$ \\
\hline & $\begin{array}{l}\text { Frecuencia de despertar } \\
\text { nocturno por sibilantes o tos } \\
\text { en los últimos doce meses }\end{array}$ & $\begin{array}{l}\text { Frecuencia evaluada según respuesta agrupada en cuatro } \\
\text { opciones: a. Ninguna: (0), b. menos de } 1 \text { vez semanal (1), c. } \\
1 \text { o más noches por semana (3). }\end{array}$ \\
\hline & $\begin{array}{l}\text { Dificultad para hablar por } \\
\text { disnea o tos }\end{array}$ & Respuesta por si (3) o no (0). \\
\hline & \multirow{3}{*}{$\begin{array}{l}\text { Fusión de los tres } \\
\text { anteriores: }\end{array}$} & Severa: 8 a 10 \\
\hline & & Moderada: 5 a 7 \\
\hline & & Leve: 0 a 4 \\
\hline \multirow{3}{*}{$\begin{array}{l}\text { Hiperreactividad } \\
\text { bronquial (HRB) }\end{array}$} & $\begin{array}{l}\text { Asma inducido por el } \\
\text { esfuerzo }\end{array}$ & $\begin{array}{l}\text { Respuesta por si o no a la pregunta: “'ha tenido en los } \\
\text { últimos doce meses silbidos en el pecho o tos después de } \\
\text { hacer ejercicio físico?" (1 punto) }\end{array}$ \\
\hline & Tos seca nocturna & $\begin{array}{l}\text { Respuesta por si o no a la pregunta: "¿ha tenido en los } \\
\text { últimos doce meses tos seca de noche sin padecer una } \\
\text { infección respiratoria (resfrío, bronquitis, neumonía, etc...?" } \\
\text { (1 punto) }\end{array}$ \\
\hline & Indicador conjunto & Baja: 0, media: 1 , alta: 2 \\
\hline Rinitis alérgica & $\begin{array}{l}\text { Presentar estornudos, picor } \\
\text { nasal, moqueo, nariz } \\
\text { tapada, sin estar resfriado. } \\
\text { Evolución y frecuencia. }\end{array}$ & $\begin{array}{l}\text { Se considera rinitis actual a la respuesta positiva para los } \\
\text { últimos } 12 \text { meses y antecedentes de Rinitis para los } \\
\text { síntomas detectados anteriormente. }\end{array}$ \\
\hline Eccema & $\begin{array}{l}\text { Erupción con picazón que } \\
\text { aparece y desaparece a lo } \\
\text { largo de por lo menos } 6 \\
\text { meses }\end{array}$ & $\begin{array}{l}\text { Respuesta por si o no a } 3 \text { preguntas relacionadas con } \\
\text { frecuencia, persistencia y severidad. (1 por cada una: } \\
\text { negativo (0), leve (1), moderado (2), severo (3)) }\end{array}$ \\
\hline $\begin{array}{l}\text { Historia familiar } \\
\text { de asma y /o } \\
\text { alergia }\end{array}$ & $\begin{array}{l}\text { Padres, abuelos o hermanos } \\
\text { con antecedentes de asma, } \\
\text { rinitis eccema y otras } \\
\text { manifestaciones alérgicas }\end{array}$ & $\begin{array}{l}\text { Respuesta por sí o por no a la pregunta: “¿hay en la familia } \\
\text { del niño antecedentes de personas asmáticas o alérgicas?" }\end{array}$ \\
\hline
\end{tabular}

Para la detección de atopía se tomará en cuenta la presencia de:

$\checkmark$ Datos hereditarios de cuadros compatibles con alergia tipo I y asma

$\checkmark$ Historia personal alérgica (destacándose la asociación eccema-asma, la rinitis alérgica típica, entre otras)

$\checkmark$ Para considerar atopia positiva: (1) deberán presentarse al menos dos antecedentes claros de las siguientes categorías: 
- Rinitis tipo alérgica

- Eccema

- Antecedentes familiares de alergia o asma

\begin{tabular}{|c|c|c|c|}
\hline Identificación & Dimensión & \multicolumn{2}{|c|}{ Procedimientos } \\
\hline $\begin{array}{l}\text { Tabaquismo } \\
\text { pasivo } \\
\text { (contacto con } \\
\text { fumadores) }\end{array}$ & frecuencia de exposición & \multicolumn{2}{|c|}{$\begin{array}{l}\text { Opciones de respuesta: } \\
\text { nunca, a veces, frecuente. }\end{array}$} \\
\hline \multirow{5}{*}{$\begin{array}{l}\text { Hongos } \\
\text { aerógenos en } \\
\text { el dormitorio }\end{array}$} & \multirow{5}{*}{ Esporas de hongos en el aire del dormitorio } & \multicolumn{2}{|c|}{$\begin{array}{l}\text { Número de UFC micóticas en } \\
\text { cápsulas abiertas } 10 \text { minutos } \\
\text { en el dormitorio. Categorías } \\
\text { según cantidad, por cuartiles }\end{array}$} \\
\hline & & baja & 0 a 40 \\
\hline & & media & 41 a 59 \\
\hline & & alta & 60 a 86,5 \\
\hline & & muy alta & 87 a 120 \\
\hline \multirow{5}{*}{$\begin{array}{l}\text { Exposición a } \\
\text { formaldehido }\end{array}$} & Placa MDF alta emisión (placard mediano 12,5 m²) 16,6 ppm & \multirow{5}{*}{\multicolumn{2}{|c|}{$\begin{array}{l}\text { Riesgo según ppm estimados } \\
\text { en invierno } \\
\text { Riesgo bajo: Hasta } 0,02 \mathrm{ppm} \\
\text { Riesgo alto: } \geq 0,02 \mathrm{ppm}\end{array}$}} \\
\hline & $\begin{array}{l}8 \text { horas de calefacción kerosene y gas sin tiro balanceado } \\
4,89 \mathrm{ppm} \text { (fuera del dormitorio: } 2,445 \mathrm{ppm} \text { ) }\end{array}$ & & \\
\hline & $\begin{array}{l}8 \text { horas de calefacción con braseros y salamandras: } 4,32 \\
\text { ppm (fuera del dormitorio) }\end{array}$ & & \\
\hline & índice de ventilación (inadecuado 1 ; adecuado: $\Sigma / 0,5$ ) & & \\
\hline & $\begin{array}{l}\text { aire contaminado con humo de tabaco. Tabaquismo } \\
\text { pasivo frecuente: } 0,23 \mathrm{ppm}\end{array}$ & & \\
\hline \multirow{5}{*}{$\begin{array}{l}\text { Uso de } \\
\text { insecticidas }\end{array}$} & tipo de insecticida & \multicolumn{2}{|c|}{$\begin{array}{l}\text { Aerosol/espiral: } 2 \text {; Eléctricos } \\
\quad \text { y otros: } 1 ; \text { ninguno: } 0\end{array}$} \\
\hline & Estación en que se lo utiliza con > frecuencia & \multicolumn{2}{|c|}{$\begin{array}{c}\text { Otoño/primavera: } 1 \text {; invierno } \\
1 \text {; verano: } 1\end{array}$} \\
\hline & Periodicidad en su uso & \multicolumn{2}{|c|}{$\begin{array}{c}1 \text { vez a la semana: } 1 ; 2 / 3 \\
\text { veces a la semana o más: } 2\end{array}$} \\
\hline & uso de insecticida a la noche & \multicolumn{2}{|c|}{ si: $1 ;$ no: 0} \\
\hline & $\begin{array}{l}\text { Puntaje sumatorio de las cuatro dimensiones, calculado } \\
\text { según cuartiles }\end{array}$ & \multicolumn{2}{|c|}{$\begin{array}{l}\text { 1: } 0 p \text { (riesgo bajo). 2: } 1 \text { a } 5 p \\
\text { (medio) 3: } 6 p \text { (alto). 4: 7-8 } \\
\text { (muy alto) }\end{array}$} \\
\hline
\end{tabular}




\begin{tabular}{|c|c|c|}
\hline Identificación & Dimensión & procedimientos \\
\hline $\begin{array}{l}\text { Exposición a polvo de } \\
\text { soja y otros cereales }\end{array}$ & $\begin{array}{l}\text { Distancia a fuentes de emisión } \\
\text { atmosférica de polvo de soja y } \\
\text { otros cereales }\end{array}$ & $\begin{array}{l}\text { cantidad de casos y controles en áreas crecientes } \\
\text { cada } 100 \text { metros de radio desde las principales } \\
\text { fuentes de emisión detectadas al domicilio de los } \\
\text { niños. }\end{array}$ \\
\hline $\begin{array}{l}\text { Exposición a diversas } \\
\text { fuentes polutantes del } \\
\text { aire urbano }\end{array}$ & $\begin{array}{l}\text { distancia a fuentes de emisión } \\
\text { atmosférica de polutantes } \\
\text { urbanos incluyendo los cereales, } \\
\text { fuentes industriales y basurales }\end{array}$ & $\begin{array}{l}\text { cantidad de casos y controles en áreas crecientes } \\
\text { cada } 100 \text { metros de radio desde las principales } \\
\text { fuentes de emisión detectadas al domicilio de los } \\
\text { niños. }\end{array}$ \\
\hline $\begin{array}{l}\text { áreas inundables de } \\
\text { mayor humedad } \\
\text { ambiental }\end{array}$ & áreas urbanas bajo la cota 9 & cantidad de casos y controles en ambas áreas \\
\hline
\end{tabular}

\section{Plan de muestreo}

\section{Estudio de corte transversal para encuesta 1.}

El universo elegido corresponde a los niños que concurren al 1음 año del EGB (nivel primario) en Concepción del Uruguay, Entre Ríos (ARG). Del total de 1175 niños se seleccionó una muestra inicial de 735 niños en forma aleatoria, agrupados en conglomerados siguiendo un criterio de distribución territorial proporcional a la distribución censal y tomando como base las escuelas públicas de cada zona. Este número, excede ampliamente al tamaño necesario para una muestra representativa de proporciones, ( $n$ : 272 ), calculado en base a una $P=0,23^{280}, Z=1,96$ y $E=0,05$. Se tomó esta decisión operativa para obtener una cantidad de casos y controles suficientes para abordar luego los estudios de cohorte y de casos y controles, teniendo en cuenta las dificultades de una encuesta poblacional donde la mayoría no presenta la enfermedad en estudio y por lo tanto disminuye su interés en colaborar.

Respondieron 532 niños ( $72 \%$ de la muestra) al formulario suministrado en las escuelas seleccionadas. Finalmente se incorporaron al procesamiento definitivo 529 niños ya que 3 de aquellos tenían errores insalvables en la confección del autocuestionario. Por lo tanto se logró un $45 \%$ del total de niños de 1 을 grado (aproximadamente 6 años de edad) y el doble del tamaño muestral mínimo recomendable estadísticamente. 
Por otra parte, se cumplió en 4 de las 5 fracciones censales estudiadas con su representatividad territorial, siendo relativamente diferente en una de estas fracciones (Fracción 4) debido al bajo nivel de respuesta de encuestas presentadas en esa zona (58\% de nivel de respuesta). (tabla 4.4 )

Tabla 4.4

\begin{tabular}{|c|c|c|c|c|c|}
\hline $\begin{array}{c}\text { Fracción } \\
\text { Censal }\end{array}$ & $\begin{array}{c}\text { Total de } \\
\text { Población por } \\
\text { Fracción Censal }\end{array}$ & $\begin{array}{c}\text { Total Niños de } \\
\mathbf{6} \text { años por } \\
\text { Fracción Censal }\end{array}$ & $\begin{array}{c}\text { Total } \\
\text { Muestreo } \\
\text { Territorial }\end{array}$ & $\begin{array}{c}\text { Distribución } \\
\text { Proporcional } \\
\text { Niños 6 años } \\
\text { por Fracción } \\
\text { Censal }\end{array}$ & $\begin{array}{c}\text { Total } \\
\text { Muestreo } \\
\text { Territorial }\end{array}$ \\
\hline 1 & 17260 & 305 & 141 & $26 \%$ & $26,6 \%$ \\
\hline 2 & 12381 & 223 & 113 & $19 \%$ & $21,3 \%$ \\
\hline 3 & 9128 & 98 & 54 & $8 \%$ & $10,2 \%$ \\
\hline 4 & 12064 & 173 & 61 & $15 \%$ & $11,5 \%$ \\
\hline 5 & 15931 & 376 & 160 & $32 \%$ & $30,2 \%$ \\
\hline Total & $\mathbf{6 6 7 6 4}$ & $\mathbf{1 1 7 5}$ & $\mathbf{5 2 9}$ & $\mathbf{1 0 0 \%}$ & $\mathbf{1 0 0 \%}$ \\
\hline
\end{tabular}

Fuente INDEC 2001 y elaboración propia

\section{Estudio poblacional de casos y controles.}

Para analizar los factores ambientales de riesgo o protección, se realizó un estudio poblacional de casos y controles. Se seleccionaron un total de 310 niños integrados por los 116 casos que aceptaron participar de esta etapa (116/126, 92\%) y un grupo control de 194 niños con distribución territorial similar, compuesto a su vez por un subgrupo que no tiene antecedentes de sibilantes y otro que si los presenta pero en los cuales todos los episodios han ocurrido antes de los últimos 12 meses. En todos los grupos se seleccionó una distribución por mitades de la variable sexo.

Los datos sobre la exposición se obtuvieron de las siguientes fuentes:

- dos cuestionarios (Encuestas 1 y 2 )

- informes de observaciones domiciliarias,

- relevamiento de factores contaminantes atmosféricos de la ciudad

- cotas de nivel de los domicilios,

- estudios de hongos aerógenos domiciliarios 


\section{Selección de los individuos: criterios de inclusión y exclusión. Consideraciones éticas.}

\begin{tabular}{|l|l|}
\hline Población & La población de referencia es el grupo etareo de 6-7 años de Concepción del Uruguay \\
\hline $\begin{array}{l}\text { Criterios de inclusión } \\
\text { como casos }\end{array}$ & $\begin{array}{l}\text { niños de ambos sexos, de 6-7 años de edad que concurrían al primer grado de las } \\
\text { escuelas de la ciudad en el año } 2005 \text { que hayan respondido en el cuestionario } 1 \text { en } \\
\text { forma positiva a las preguntas } 2 \text { ó } 6\end{array}$ \\
\hline $\begin{array}{l}\text { Criterios de inclusión } \\
\text { como controles }\end{array}$ & $\begin{array}{l}\text { niños de ambos sexos, de 6-7 años de edad que concurrían al primer grado de las } \\
\text { escuelas de la ciudad en el año } 2005 \text { que hayan respondido en forma negativa a la } \\
\text { pregunta 2 y } 6 \text { en el cuestionario } 1\end{array}$ \\
\hline Criterios de exclusión & $\begin{array}{l}\text { Negativa de los padres a participar en el estudio. Respuestas incoherentes al } \\
\text { cuestionario inicial. }\end{array}$ \\
\hline
\end{tabular}

\section{Consideraciones éticas:}

Con el propósito de respetar la autonomía de los sujetos de estudio, en este caso niños de 6 o 7 años que intervienen indirectamente, se inició el contacto con una información a los padres y a los maestros. Se solicita a los padres el consentimiento para responder a cuestionarios y toma de muestras de sus respectivos ambientes domésticos. En esa información escrita se describen las actividades y se abre una posibilidad de diálogo con los interesados en profundizar el conocimiento del proyecto.

Los resguardos éticos principales se sintetizan entonces en:
a) Consentimiento informado para participar
b) Secreto estadístico
c) Devolución de información personalizada

El protocolo fue aprobado por la Comisión provisoria de Ética de la Facultad de Ciencias de la Salud de la UNER. 


\section{Plan de análisis}

\section{Estudio de casos y controles}

Se aplica para analizar los factores ambientales inespecíficos de riesgo y protección. Se tienen en cuenta como factores de control el sexo y los antecedentes familiares y personales de asma y atopía. Se seleccionan todos los casos hallados y un conjunto de controles dividido en dos grupos, según la respuesta para los antecedentes de sibilancias antes de los últimos doce meses.

Preparación de la prueba de hipótesis.

\begin{tabular}{|c|c|c|}
\hline Hipótesis subyacentes & $\begin{array}{l}\text { Subhipótesis (consecuencias } \\
\text { empíricas de las hipótesis) }\end{array}$ & Comentarios, factores de confusión. \\
\hline $\begin{array}{l}\text { La mayor exposición a riesgos ambientales } \\
\text { domésticos inespecíficos (irritantes como } \\
\text { el humo del tabaco, emisores de } \\
\text { formaldehido, uso de insecticidas, etc....) } \\
\text { se correlaciona positivamente con la } \\
\text { severidad del asma }\end{array}$ & $\begin{array}{l}\text { Un indicador que combine los } \\
\text { riesgos por contaminación } \\
\text { fisicoquímica doméstica se } \\
\text { correlacionará positivamente } \\
\text { con el indicador de la severidad } \\
\text { del asma }\end{array}$ & $\begin{array}{l}\text { Riesgos ambientales domésticos específicos que solo se } \\
\text { expresan en los atópicos }\end{array}$ \\
\hline $\begin{array}{l}\text { La mayor exposición a hongos aerógenos } \\
\text { en el dormitorio se asocia con el riesgo de } \\
\text { asma }\end{array}$ & $\begin{array}{l}\text { La mayor cantidad de } \\
\text { UFC/cápsula abierta en las } \\
\text { respectivas habitaciones de } \\
\text { casos y controles se asocia } \\
\text { positivamente con el asma }\end{array}$ & $\begin{array}{l}\text { La presencia aumentada de esporas fúngicas es causa } \\
\text { de alergia solo en quienes tienen IgE específica contra } \\
\text { esos antígenos, que en función de la práctica clínica } \\
\text { local y de diversas publicaciones es de prevalencia } \\
\text { relativamente baja. Podrían producirse mecanismos } \\
\text { reactivos diferentes al tipo I o vincularse } \\
\text { indirectamente por la mayor humedad ambiente con el } \\
\text { aumento de ácaros y servir de alimento. }\end{array}$ \\
\hline $\begin{array}{l}\text { Las instalaciones portuarias y otras } \\
\text { vinculadas al depósito y secado de soja y } \\
\text { otras fuentes emisoras de contaminantes } \\
\text { atmosféricos generan un área de mayor } \\
\text { riesgo asociado con la distancia de } \\
\text { viviendas. }\end{array}$ & $\begin{array}{l}\text { La distancia de las viviendas con } \\
\text { las fuentes de emisión de } \\
\text { partículas se asocia con la } \\
\text { presencia y la severidad del } \\
\text { asma. }\end{array}$ & $\begin{array}{l}\text { Se debe estudiar la influencia de los vientos para } \\
\text { ponderar las distancias con factores de corrección. Las } \\
\text { fluctuaciones productivas pueden afectar en más o } \\
\text { menos la concentración atmosférica. Los procesos } \\
\text { utilizados para controlar las emisiones pueden } \\
\text { disminuir el riesgo por cercanía. }\end{array}$ \\
\hline $\begin{array}{l}\text { La ubicación de las viviendas en terrenos } \\
\text { de poca altura y aledaños a arroyos, con } \\
\text { mayor humedad relativa se asocia al } \\
\text { riesgo de asma }\end{array}$ & $\begin{array}{l}\text { Las viviendas ubicadas por } \\
\text { debajo de la cota } 9 \text {, se asocian a } \\
\text { mayor presencia de asmáticos. }\end{array}$ & $\begin{array}{l}\text { Se debe cruzar esta variable con la de colonias } \\
\text { fúngicas. La pobreza podría asociarse a estas } \\
\text { localizaciones }\end{array}$ \\
\hline
\end{tabular}




\section{Análisis e inferencias estadísticas}

Para calcular la Prevalencia de 12 meses se dividió el número de casos hallados por la encuesta 1 (n: 529, corte transversal), dividiéndolo por el número total de encuestados. Se estimó también la Incidencia acumulada de los primeros 5 años de vida, sumando todos los niños que presentaron sibilantes o fueron diagnosticados como asmáticos en ese período sobre el total del tamaño muestral logrado.

Los datos de las principales variables se agruparon para cuantificarlos en categorías nominales u ordinales, la mayoría de ellas dicotómicas. La significación estadística de las diferencias entre casos y controles y otras clasificaciones de las variables nominales se calculó por $\chi^{2}$ de Mantel-Haentzel, $P$ significativa $\leq 0,05$. Se estimaron además las respectivas odds-ratio (OR) con un intervalo de confianza (IC) del 95\% y la fracción atribuible para valorar el riesgo.

Para la interpretación de las odds-ratio se adapta una tabla planteada para el Riesgo Relativo por el Prof. Dr. Ramón Gálvez Vargas de la Universidad de Granada ${ }^{281}$ :

\begin{tabular}{|c|l|}
\hline Odds Ratio & \multicolumn{1}{|c|}{ Significado } \\
\hline$<0,4$ & Protección fuerte \\
\hline $0,4 / 0,56$ & Protección moderada \\
\hline $0,57 / 0,83$ & Protección débil \\
\hline $0,84 / 1,19$ & Indiferente \\
\hline $1,2 / 1,74$ & Riesgo débil \\
\hline $1,75 / 2,5$ & Riesgo moderado \\
\hline$.>2,5$ & Riesgo fuerte \\
\hline
\end{tabular}

El cálculo del Riesgo relativo se basó en la incidencia acumulada de los primeros 5 años de vida sumando a todos los casos más los controles con antecedentes de haber presentado sibilantes, en expuestos y no expuestos. Para el cálculo de la fracción de riesgo atribuible se adoptó como incidencia la acumulada durante los primeros 5 años de vida, utilizando la siguiente fórmula ${ }^{282}$ :

Incidencia expuestos - incidencia no expuestos $\underline{\text { Incidencia expuestos }}$ 
Para calcular el riesgo atribuible en toda la población se aplicó la fórmula de Levin 283 :

$$
\frac{P(r-1)}{P(r-1)+1}
$$

\section{Estimación de inferencias causales}

Para generar una inferencia causal sólida deben seguirse ciertas pautas como las que planteara el Comité de Expertos del Departamento de Salud de Estados Unidos de América ${ }^{284}$ para la cuestión del tabaquismo y la Salud. A partir de ella se han propuesto modificaciones y es útil el listado que propone Leon Gordis (2005) para analizar lo que se consideran resultados más relevantes de la presente investigación. El autor mencionado sugiere que no necesariamente deben satisfacerse todas las directrices para avanzar en la consolidación de una hipótesis causal basada en un juicio razonado.

Se utilizaron para procesamiento y análisis los paquetes informáticos Epi-Info 7 (CDC-WHO) y Microsoft Office Excel 2007@. 


\section{Presentación y análisis de resultados.}

\section{Capítulo 5}

Descripción de síntomas, severidad, antecedentes y tratamientos.

La encuesta I, realizada como estudio de corte transversal a una muestra de 529 niños, seleccionada al azar y representativa del total de la población de 6 años de edad, permitió realizar las siguientes observaciones (ver tabla 5.1) ${ }^{285}$ :

- La prevalencia del asma a los 6 años de edad es del 23,8\% en Concepción del Uruguay, Entre Ríos, estable en los últimos diez años comparando con un estudio anterior realizado con el mismo método ${ }^{286}$.

- El $38 \%$ de los niños presentó episodios compatibles con broncoespasmos alguna vez en los 5 primeros años de vida (incidencia acumulada para los primeros cinco años). Algo menos de la mitad (16\%) estaba asintomático a los 5 y 6 años de edad, y representarían el fenotipo de sibilantes muy tempranos transitorios. Ninguno de estos últimos había recibido el diagnóstico de asma.

- Un $21 \%$ tuvo episodios de broncoespasmos en los últimos doce meses, a los que se suma el 3\% de asmáticos tratados asintomáticos el último año para completar el $24 \%$ de asmáticos actuales.

- De los 126 casos hallados en esta muestra, solo 35 tenían el diagnóstico de Asma.

- El sexo masculino predomina en los casos (54\%) y se insinúa como un factor de riesgo débil: OR 1,44 (IC 0,96/2,15), $\chi^{2} 3,16$ P: 0,07.

\section{Síntomas.}

Los síntomas investigados se refieren a las manifestaciones propias del asma (disnea sibilante, tos seca nocturna 287 o por esfuerzo), de otras enfermedades alérgicas como Rinitis (estornudos, picor, rinorrea mucoide, oclusión), conjuntivitis (prurito y epifora) y dermatitis atópica infantil (erupción pruriginosa afebril generalmente en 
pliegues). La descripción clínica se completa con una estimación de la hiperreactividad bronquial y de las severidades del asma, la rinitis y el eccema.

- El 22\% presentó síntomas compatibles con asma inducido por el esfuerzo.

- El $28 \%$ tuvo episodios en el último año de tos seca nocturna, sin estar manifiestamente afectados por síntomas compatibles con infección del aparato respiratorio.

- La Rinitis tipo alérgica aparece en un $20 \%$ tomando todo el período estudiado, disminuyendo al $16 \%$ en el último año. Este porcentaje aumenta al 35\% si se tiene en cuenta la respuesta a la pregunta 19, sobre episodios estacionales compatibles con polinosis. En un $13 \%$ se acompañó de conjuntivitis.

- El síndrome compatible con eccema aparece en un $14 \%$ de los niños, respondiendo con una descripción más precisa el $11 \%$.

- El $16 \%$ de los casos presentó síntomas de asma severa, predominando en el sexo femenino, aunque sin diferencias significativas. (Tabla 2). El $65 \%$ del conjunto solo manifestaba síntomas leves.

\begin{tabular}{|c|c|c|}
\hline \multicolumn{3}{|c|}{ Comparación de fenotipos hallados. } \\
\hline fenotipo & Martinez (USA) & CDU \\
\hline - Comienzo muy temprano ( 0 a 3 a & & \\
\hline - Transitorio (no alérgico) & $20 \%$ & $16 \%$ \\
\hline •Persistente (alérgico) & $14 \%$ & $24 \%$ \\
\hline -Comienzo en $2^{\circ}$ infancia (5 a 10 a & & \\
\hline -Persistente (alérgico) & $15 \%$ & $9 \%$ \\
\hline
\end{tabular}

CDU: prevalencia hallada en esta investigación. 
Tabla 1. Sintomas según respuestas del autocuestionario. 529 niños de $1^{\circ}$ grado. Concepción del Uruguay, ARG. 2005

\begin{tabular}{|c|c|c|}
\hline & \multicolumn{2}{|c|}{ Frecuencia } \\
\hline Preguntas de Encuesta 1. & $\mathrm{Si}$ & $\%$ \\
\hline Pregunta 1. ¿Ha tenido alguna vez en el pasado silbidos o chillidos en el pecho?. & 204 & $39,23 \%$ \\
\hline Pregunta 2. ¿Ha tenido en el último año silbidos o chillidos en el pecho?. & 118 & $22,69 \%$ \\
\hline $\begin{array}{l}\text { Pregunta 7. En el último año, cha tenido silbidos en el pecho o tos durante o después de hacer ejercicio } \\
\text { física (correr, saltar, etc.) }\end{array}$ & 115 & $22,12 \%$ \\
\hline $\begin{array}{l}\text { Pregunta } 8 \text {. En el último año, ¿̇ha tenido tos seca en la noche, aparte de la tos por infección respiratoria: } \\
\text { resfrío, bronquitis, neumonía, etc.? }\end{array}$ & 145 & $27,88 \%$ \\
\hline \multicolumn{3}{|l|}{ Pregunta 14. ¿Ha tenido alguna vez sin estar resfriado } \\
\hline Moqueo? & 89 & $17,12 \%$ \\
\hline Estornudos? & 110 & $21,15 \%$ \\
\hline Nariz Tapada? & 110 & $21,15 \%$ \\
\hline Picazón de nariz? & 70 & $13,46 \%$ \\
\hline Ninguno? & 186 & $35,77 \%$ \\
\hline \multicolumn{3}{|l|}{ Pregunta 15. ¿Ha tenido en el último año sin estar resfriado? } \\
\hline Moqueo & 62 & $11,92 \%$ \\
\hline Estornudos & 85 & $16,35 \%$ \\
\hline Nariz Tapada & 87 & $16,73 \%$ \\
\hline Picazón de nariz & 55 & $10,58 \%$ \\
\hline Ninguno & 119 & $22,88 \%$ \\
\hline Pregunta 16. En el último año ¿Estos problemas nasales se acompañaron de picazón y lagrimeo ocular? & 70 & $13,46 \%$ \\
\hline Pregunta 19. ¿Ha tenido alguna vez resfríos alérgicos, de primavera y verano, o por pólenes? & 184 & $35,38 \%$ \\
\hline $\begin{array}{l}\text { Pregunta 20. ¿Ha Tenido alguna vez en el pasado, una erupción con picazón que apareciera y desapareciera a } \\
\text { lo largo de por lo menos } 6 \text { meses. }\end{array}$ & 74 & $14,23 \%$ \\
\hline Pregunta 21. ¿Ha tenido una erupción con picazón, en algún momento del último año? & 63 & $12,12 \%$ \\
\hline $\begin{array}{l}\text { Pregunta 22. ¿Ha afectado esta erupción con picazón algunos de los siguientes lugares? (Pliegue de codos, } \\
\text { detrás de las rodillas, delante de los tobillos, debajo de las nalgas, o alrededor del cuello, orejas u ojos) }\end{array}$ & 57 & $10,96 \%$ \\
\hline
\end{tabular}




\section{Severidad}

La severidad del asma en los casos se evaluó según las respuestas a las siguientes preguntas de la encuesta $1^{288}$ :

- Cantidad de ataques de sibilantes en los últimos doce meses

- Frecuencia de despertar nocturno por sibilantes o tos en los últimos doce meses

- Dificultad para hablar por disnea o tos en los últimos doce meses

\begin{tabular}{|c|c|c|c|c|}
\hline \multicolumn{5}{|c|}{ Tabla 5.2. Severidad del total de casos. Muestra de 529 niños } \\
\hline \multicolumn{1}{|c|}{ Sexo } & leve & moderada & severa & Total \\
\hline Femenino & 36 & 10 & 12 & 58 \\
\hline Fila \% & $62,07 \%$ & $17,24 \%$ & $20,69 \%$ & $100,00 \%$ \\
\hline Col\% & $43,90 \%$ & $41,67 \%$ & $60,00 \%$ & $46,03 \%$ \\
\hline Masculino & 46 & 14 & 8 & 68 \\
\hline Fila \% & $67,65 \%$ & $20,59 \%$ & $11,76 \%$ & $100,00 \%$ \\
\hline Col\% & $56,10 \%$ & $58,33 \%$ & $40,00 \%$ & $53,97 \%$ \\
\hline TOTAL & 82 & 24 & 20 & 126 \\
\hline Fila \% & $65,08 \%$ & $19,05 \%$ & $15,87 \%$ & $100,00 \%$ \\
\hline$\chi^{2}:$ & 1,9 & $\operatorname{Pr}<\chi^{2}:$ & 0,3859 & \\
\hline
\end{tabular}

Diferencia no significativa, aunque la proporción de casos severos es de casi el doble en el sexo femenino.

\section{Hiperreactividad bronquial}

Consideramos como síntomas indicadores de posible umbral bajo de irritabilidad bronquial a los sibilantes relacionados con los esfuerzos físicos, que presentó el $22 \%$ y a la tos nocturna que se registró en el $28 \%$.

\section{Descripción de antecedentes}

Los antecedentes familiares de asma o alergia son positivos en el $67 \%$ de los casos y en el $48 \%$ de los controles. De los 51 familiares que no saben sobre los antecedentes, 45 pertenecen al grupo de controles. (Tabla 5.3). 
Tabla 5.3 Antecedentes familiares de asma y alergia y asma infantil

\begin{tabular}{|c|c|c|c|}
\hline Antecedentes & casos & controles & Total \\
\hline SI & 84 & 194 & 278 \\
\hline fila \% & $30,22 \%$ & $69,78 \%$ & $100,00 \%$ \\
\hline Col\% & $66,67 \%$ & $48,14 \%$ & $52,55 \%$ \\
\hline NO & 36 & 164 & 200 \\
\hline fila $\%$ & $18,00 \%$ & $82,00 \%$ & $100,00 \%$ \\
\hline Col\% & $28,57 \%$ & $40,69 \%$ & $37,81 \%$ \\
\hline NO SABE & 6 & 45 & 51 \\
\hline fila $\%$ & $11,76 \%$ & $88,24 \%$ & $100,00 \%$ \\
\hline Col\% & $4,76 \%$ & $11,17 \%$ & $9,64 \%$ \\
\hline TOTAL & 126 & 403 & 529 \\
\hline fila $\%$ & $23,82 \%$ & $76,18 \%$ & $100,00 \%$ \\
\hline$\chi 2:$ & 14 & P: & 0,0009 \\
\hline
\end{tabular}

Los antecedentes familiares se hallan con mayor frecuencia en los niños con asma severa pero la diferencia no alcanza a ser estadísticamente significativa. (Tabla 5.4)

\begin{tabular}{|c|c|c|c|c|}
\hline \multicolumn{5}{|c|}{ casos. Muestra de 529 niños } \\
\hline Antecedentes familiares & leve & moderada & severa & Total \\
\hline SI & 52 & 18 & 14 & 84 \\
\hline Fila \% & $61,90 \%$ & $21,43 \%$ & $16,67 \%$ & $100,00 \%$ \\
\hline Col\% & $63,41 \%$ & $75,00 \%$ & $70,00 \%$ & $66,67 \%$ \\
\hline NO & 25 & 6 & 5 & 36 \\
\hline Fila $\%$ & $69,44 \%$ & $16,67 \%$ & $13,89 \%$ & $100,00 \%$ \\
\hline Col\% & $30,49 \%$ & $25,00 \%$ & $25,00 \%$ & $28,57 \%$ \\
\hline NO SABE & 5 & 0 & 1 & 6 \\
\hline Fila $\%$ & $83,33 \%$ & $0,00 \%$ & $16,67 \%$ & $100,00 \%$ \\
\hline Col\% & $6,10 \%$ & $0,00 \%$ & $5,00 \%$ & $4,76 \%$ \\
\hline TOTAL & 82 & 24 & 20 & 126 \\
\hline Fila $\%$ & $65,08 \%$ & $19,05 \%$ & $15,87 \%$ & $100,00 \%$ \\
\hline$\chi 2:$ & 2,1677 & $\operatorname{Pr}<\chi 2:$ & 0,7049 & \\
\hline
\end{tabular}

- Los antecedentes personales de sibilantes antes de los 5 años son positivos en el $95 \%$ de los casos y en el $25 \%$ de los controles, (Tabla 5.5 ) 


\begin{tabular}{|c|c|c|c|}
\hline \multicolumn{4}{|c|}{ Tabla 5.5 Antecedentes de sibilantes en los primeros 5 años de vida } \\
\hline sibilantes alguna vez & casos & controles & Total \\
\hline si & 114 & 87 & 201 \\
\hline fila \% & $56,72 \%$ & $43,28 \%$ & $100,00 \%$ \\
\hline Col\% & $95,00 \%$ & $24,79 \%$ & $42,68 \%$ \\
\hline no & 6 & 264 & 270 \\
\hline fila \% & $2,22 \%$ & $97,78 \%$ & $100,00 \%$ \\
\hline Col\% & $5,00 \%$ & $75,21 \%$ & $57,32 \%$ \\
\hline TOTAL & 120 & 351 & 471 \\
\hline fila\% & $25,48 \%$ & $74,52 \%$ & $100,00 \%$ \\
\hline & & $\chi 2: 180$ & $\operatorname{Pr}>\chi 2:<0,000000$ \\
\hline
\end{tabular}

El eccema se presentó en los primeros años de vida en el 30\% de los casos y en el 13\% de los controles. (Tabla 5.6).

\begin{tabular}{|c|c|c|c|}
\hline \multicolumn{4}{|c|}{ Tabla 5.6. Antecedentes de eccema en los primeros 5 años de vida } \\
\hline eccema alguna vez & casos & controles & Total \\
\hline si & 33 & 41 & 74 \\
\hline fila \% & $44,59 \%$ & $55,41 \%$ & $100,00 \%$ \\
\hline Col\% & $29,73 \%$ & $12,69 \%$ & $17,05 \%$ \\
\hline no & 78 & 282 & 360 \\
\hline fila \% & $21,67 \%$ & $78,33 \%$ & $100,00 \%$ \\
\hline Col\% & $70,27 \%$ & $87,31 \%$ & $82,95 \%$ \\
\hline TOTAL & 111 & 323 & 434 \\
\hline fila \% & $74,42 \%$ & $25,58 \%$ & $100,00 \%$ \\
\hline & & $\chi 2: 16,9$ & Pr $>\times 2:<0,00004$ \\
\hline
\end{tabular}

- La Rinitis alérgica tiene como síntomas principales el prurito nasal, los estornudos, la obstrucción y la secreción seromucoide. Pueden diferenciarse dos tipos, uno en el que predominan los estornudos y el prurito, que está más relacionado con las pruebas cutáneas positivas, la eosinofilia en secreción nasal y la respuesta positiva a los antihistamínicos ${ }^{289}$ y otro en el que la oclusión y la secreción son los síntomas más notorios, que puede estar vinculado a otros mecanismos fisiopatogénicos. Sobre todos estos síntomas se interrogó en la encuesta I, pero dada la posibilidad de confusión con resfríos de tipo viral o 
sintomatología nasal de tipo vasomotor se seleccionó como casos positivos de Rinitis alérgica a los que contestaban positivamente a la presencia de estornudos, prurito nasal y episodios de rinitis primaverales o estivales. Los antecedentes de Rinitis alérgica se hallan en el $44 \%$ de los casos y el $19 \%$ de los controles, mientras que la Rinitis actual (en los últimos doce meses) se presenta en el $34 \%$ de los casos y el $17 \%$ de los controles (ver tablas 5.7 y 5.8 ).

\begin{tabular}{|c|c|c|c|}
\hline \multicolumn{5}{|c|}{ Tabla 5.7. Antecedentes de rinitis en los primeros 5 años de vida } \\
\hline Antecedentes rinitis & casos & controles & Total \\
\hline si & 55 & 76 & 131 \\
\hline no & 72 & 326 & 398 \\
\hline TOTAL & 127 & 407 & 529 \\
\hline & & $\chi 2: 30$ & $\operatorname{Pr}>\times 2:<0,000000$ \\
\hline
\end{tabular}

\begin{tabular}{|c|c|c|c|}
\hline \multicolumn{4}{|c|}{ Tabla 5.8. Rinitis actual asociada al asma } \\
\hline Rinitis actual & casos & controles & Total \\
\hline si & $\mathbf{4 2}$ & $\mathbf{7 0}$ & 112 \\
\hline fila \% & $37,50 \%$ & $62,50 \%$ & $100,00 \%$ \\
\hline Col\% & $34,15 \%$ & $17,20 \%$ & $21,13 \%$ \\
\hline no & $\mathbf{8 1}$ & $\mathbf{3 3 7}$ & 418 \\
\hline fila $\%$ & $19,38 \%$ & $80,62 \%$ & $100,00 \%$ \\
\hline Col\% & $65,85 \%$ & $82,80 \%$ & $78,87 \%$ \\
\hline TOTAL & 123 & 407 & 530 \\
\hline fila $\%$ & $23,21 \%$ & $76,79 \%$ & $100,00 \%$ \\
\hline OR: 2,5 & IC: $1,5 / 3,9$ & $\chi 2: ~ 16,3$ & $\operatorname{Pr}>\chi 2:<0,00006$ \\
\hline
\end{tabular}




\section{Descripción de tratamientos ${ }^{290}$}

Médico tratante del asma actual: generalmente pediatras (65\%) seguidos por un $12 \%$ de alergistas y $6 \%$ de neumólogos. (Tabla 5.13).

\begin{tabular}{|l|c|c|}
\hline \multicolumn{3}{|c|}{ Tabla 5.13. Especialidad del médico tratante del asma } \\
\hline Pediatra & 43 & $65 \%$ \\
\hline Alergista * & 8 & $12 \%$ \\
\hline Neumólogo ** & 4 & $6 \%$ \\
\hline Medico general & 2 & $3 \%$ \\
\hline no registra médico que lo asiste & 18 & $27 \%$ \\
\hline$* 7$ en equipo con Pediatra & $* * 2$ en equipo con Pediatra \\
\hline
\end{tabular}

- Preguntados sobre diagnóstico médico, solo 46 casos recordaban que habían recibido uno, mayoritariamente "broncoespasmo" (33\%) mientras que el de "asma" se menciona en el 23\%. (Tabla 5.14). En 21 casos de Asma o broncoespasmo se mencionó además el Dx de Alergia.

Tabla 5.14. Diagnóstico médico percibido por la familia. 66 casos de muestra de 138 casos y controles.

\begin{tabular}{|c|c|c|}
\hline Asma & 15 & $23 \%$ \\
\hline Broncoespasmo $^{*} 22$ & $33 \%$ \\
\hline Alergia * & 5 & $6 \%$ \\
\hline Otros: & 4 & $70 \%$ \\
\hline total & 46 & $30 \%$ \\
\hline sin Dx & 20 & $6 \%$ como único Dx. En otros 21 casos de Asma o Broncoespasmo se mencionó además el Dx de Alergia \\
\hline
\end{tabular}

- De los 15 casos que tenían diagnóstico de asma, 7 presentaban sintomatología severa y 3 moderada, en función de respuestas al cuestionario de esta investigación. Cuatro casos severos tenían diagnóstico de "broncoespasmo", dos de ellos con Dx etiopatogénico de "alergia" pero sin tratamiento especializado. Otro niño era tratado también por un neumólogo y otro caso carecía de médico tratante y no seguía ninguna pauta de control.

- Observando algunas características del tratamiento médico en el grupo de 13 casos severos, pueden destacarse entre otras (ver tabla 5.15): 
- Solo la mitad de estos casos había recibido un diagnóstico médico de asma

- El 77\% estaba bajo control médico periódico, todos ellos con un Pediatra, asociado en dos casos con un Alergista y en uno con Neumólogo.

- En 3 sobre 10 casos bajo control médico, las familias no recordaban haber recibido instrucciones para el manejo de la enfermedad

- Todos recibían $\beta 2$ adrenérgicos inhalados y solo un 38\% tenían indicación de corticoides inhalados

- A pesar de que 8 sobre 13 tenían un diagnóstico etiopatogénico de Alergia, solo uno recibía inmunoterapia, que fue el único caso que no requirió atención de urgencia en los últimos doce meses.

- En los tres casos que requirieron atenciones de urgencia más frecuentemente en el último año $(8,4$ y 4$)$ hay una coincidencia en no asumir el asma como tal, ocultándolo a familiares y amigos.

- Si bien en 8 casos se reconocía el factor emocional como desencadenante de crisis, solo 2 recibían tratamiento psicológico.

\begin{tabular}{|c|c|c|c|c|c|}
\hline \multicolumn{6}{|c|}{ Tabla 5.15. Medicamentos de uso frecuente o prolongado. $n=138$} \\
\hline \multirow[b]{2}{*}{ casos según severidad } & \multirow[b]{2}{*}{ totales } & \multicolumn{2}{|c|}{ ß2 adrenérgicos inhalados } & \multicolumn{2}{|c|}{ corticoides inhalados } \\
\hline & & frecuencia & $\%$ & frecuencia & $\%$ \\
\hline leves & 43 & 19 & $44 \%$ & 16 & $37 \%$ \\
\hline moderados & 10 & 4 & $40 \%$ & 3 & $30 \%$ \\
\hline severa & 13 & 13 & $100 \%$ & 5 & $38 \%$ \\
\hline total & 66 & 36 & $55 \%$ & 24 & $36 \%$ \\
\hline \multicolumn{6}{|l|}{ controles según antecedentes } \\
\hline antecedentes sibilantes & 43 & 15 & $35 \%$ & 4 & $9 \%$ \\
\hline sin antecedentes & 29 & 0 & $0 \%$ & 0 & $0 \%$ \\
\hline total & 72 & 15 & $21 \%$ & 4 & $6 \%$ \\
\hline
\end{tabular}

Llaman la atención los cuatro controles con antecedentes de sibilantes antes del último año y sin diagnóstico de Asma que tienen tratamiento con corticoides y $\beta 2$ adrenérgicos inhalados, que podrían ser en realidad casos de asma leve muy bien 
controlada. Hay otros 11 controles con antecedentes que mencionan el uso de $\beta 2$ adrenérgicos inhalados y podrían también interpretarse de la misma manera.

\begin{tabular}{|c|c|c|c|}
\hline \multicolumn{4}{|c|}{ Tabla 5.16. Tratamientos de casos severos de la muestra para casos y controles } \\
\hline total de casos encuestados & 13 & $\%$ & comentarios \\
\hline HRB alta & 8 & $62 \%$ & \\
\hline HRB media & 4 & $31 \%$ & \\
\hline HRB baja & 1 & $8 \%$ & \\
\hline Dx asma & 7 & $54 \%$ & \\
\hline control médico & 10 & $77 \%$ & \\
\hline pediatra & 10 & $77 \%$ & \\
\hline pediatra + alergista & 2 & $15 \%$ & \\
\hline pediatra + neumólogo & 1 & $8 \%$ & \\
\hline sin control médico & 3 & $23 \%$ & \\
\hline desencadenantes emocionales & 8 & $62 \%$ & \\
\hline tratamiento psicológico & 2 & $15 \%$ & \\
\hline recomendaciones para control & 10 & $77 \%$ & $\begin{array}{l}\text { los } 3 \text { que no recibieron indicaciones refieren controles médicos de } \\
\text { rutina }\end{array}$ \\
\hline Trat. $\beta 2$ adrenérgicos inhalados & 13 & $100 \%$ & \\
\hline Trat. corticoides inhalados & 5 & $38 \%$ & \\
\hline Trat. corticoides orales & 5 & $38 \%$ & sólo dos también corticoides inhalados \\
\hline Trat. antihistamínicos & 1 & $8 \%$ & presenta rinitis y eccema \\
\hline inmunoterapia & 1 & $8 \%$ & es el único caso severo que no ha requerido tratamiento de urgencia \\
\hline requirió atención de urgencia & 12 & $92 \%$ & \\
\hline frecuencia de urgencias (> 3 anuales) & 3 & $23 \%$ & $\begin{array}{l}\text { en los } 3 \text { casos la familia no asume la enfermedad, ocultándola a otras } \\
\text { personas }\end{array}$ \\
\hline internaciones & 5 & $38 \%$ & \\
\hline
\end{tabular}

A manera de síntesis de lo descripto por el estudio de corte transversal, que sentó las bases de esta investigación, se puede afirmar que la prevalencia del asma infantil es alta $(23,8 \%)$ y que el $15 \%$ de los casos son severos entre los asmáticos a los 6 años de edad. De éstos, solo la mitad tiene un diagnóstico claro de Asma y un cuarto no tiene control médico rutinario. En general, el diagnóstico médico está presente en un tercio de los casos totales, que son tratados en su mayoría por pediatras. El $35 \%$ de los casos tiene además Rinitis alérgica y un $30 \%$ ha tenido manifestaciones eccemáticas. Los antecedentes familiares de alergia y asma, de Rinitis alérgica y eccema triplican el riesgo 
de asma a los 6 años. Los sibilantes en los primeros años de vida generan un alto riesgo de asma a esa edad. Por el contrario y contradiciendo una opinión muy frecuente, incluso en los médicos, el tabaquismo pasivo y la presencia de perros y gatos en el hogar no se asociaron significativamente con el asma infantil. Se observa una mayor frecuencia de casos en el radio de 500 a 1000 metros de fuentes emisoras de VOC.

Aparecen entonces con claridad, los factores endógenos, mientras que los factores ambientales, que generalmente son muy destacados en las recomendaciones de control, no muestran el mismo comportamiento.

Surgen algunas preguntas:

- ¿cuál es el comportamiento del tabaquismo pasivo como factor de riesgo de asma?

- ¿podrían tener mayor importancia otros factores como la cantidad de esporas fúngicas en el dormitorio como han afirmado algunos trabajos?

- ¿Son los materiales emisores de formaldehido un riesgo claro en el ambiente doméstico?

- ¿Qué papel juegan los insecticidas de uso hogareño?

- ¿ ¿tiene importancia la localización de los hogares en zonas inundables de alta humedad ambiente?

- ¿Qué impacto tienen las fuentes emisoras de contaminantes atmosféricos?

Para responder a estas y otras preguntas se diseñó el estudio de casos y controles, seleccionados ambos subgrupos en la base de datos generada en forma aleatoria y representativa de toda la ciudad, tal como se describió en el capítulo 4. 


\section{Capítulo 6}

\section{Estudio de casos y controles.}

De los 126 casos detectados por la encuesta 1 , se seleccionaron para esta muestra 116 con el criterio de equiparar por sexos y respetar la distribución por fracciones censales (2001) en forma aproximadamente proporcional al número de niños de 6 años en toda la ciudad. Con el mismo criterio se seleccionó al grupo de controles entre los integrantes de la muestra representativa de la población, que se incrementó por sobre los casos en una relación 1,7/1 para aumentar la potencia estadística, con la limitante del número de participantes en determinadas escuelas representativas de algunas fracciones censales.

Solo en 32 de estos casos seleccionados, la familia mencionó haber recibido el diagnóstico médico de "Asma" para el respectivo niño. La mayoría de los otros casos mencionaban diagnósticos tales como "broncoespasmos", "alergia bronquial", "bronquitis espasmódica", etc...

\begin{tabular}{|l|c|c|}
\hline \multicolumn{3}{|c|}{ Tabla 6.1 Muestra básica para casos y controles } \\
\hline \multicolumn{1}{|c|}{ Clasificación } & Frecuencia & $\%$ \\
\hline casos & 116 & $37 \%$ \\
\hline controles & 194 & $63 \%$ \\
\hline Total & 310 & $100 \%$ \\
\hline
\end{tabular}




\section{Unidad de análisis Niño (endógena)}

Caracterización de la muestra 2. Descripción de variables endógenas.

\section{Variables de control}

- Edad: por efecto de la selección de niños de primer grado de Escuela primaria, la edad fue en general de 6 años con un pequeño grupo de 7 años al momento de la encuesta.

- Sexo: se seleccionó por partes iguales tanto para los casos como para los controles y dentro de ellos a los controles con antecedentes de sibilantes en los primeros 4 años de vida:

\begin{tabular}{|c|c|c|c|c|c|}
\hline \multicolumn{7}{|c|}{ Tabla 6.2 Distribución según sexo en casos y controles } \\
\hline & casos & \multicolumn{2}{c|}{ controles } & & \\
\hline SEXO & & antecedentes de sibilantes & sin antecedentes & Frecuencia total & $\%$ \\
\hline Femenino & 58 & 33 & 64 & 155 & $50,00 \%$ \\
\hline Masculino & 58 & 33 & 64 & 155 & $50,00 \%$ \\
\hline Total & 116 & 66 & 128 & 310 & $100,00 \%$ \\
\hline
\end{tabular}

- Según tipos de control

\begin{tabular}{|l|c|c|}
\hline \multicolumn{3}{|c|}{ Tabla 6.3. Controles según antecedentes } \\
\hline \multicolumn{1}{|c|}{ tipo de control } & frecuencia & $\%$ \\
\hline antecedentes de sibilantes & 66 & $33,7 \%$ \\
\hline sin antecedentes & 128 & $66,3 \%$ \\
\hline Total & 194 & $100,00 \%$ \\
\hline
\end{tabular}

Como la severidad del asma se planteó para los últimos doce meses anteriores a la encuesta, por definición operativa solo podían hallarse los criterios aplicados en los 116 casos. En la tabla 4.1 de operacionalización de las variables se describe el procedimiento seguido. 


\begin{tabular}{|l|c|c|c|c|}
\hline \multicolumn{5}{|c|}{ Tabla 6.4 Severidad de los casos según sexo } \\
\hline \multicolumn{1}{|c|}{ SEXO } & leve & moderada & severa & Total \\
\hline Femenino & 35 & 11 & 12 & 58 \\
\hline Row\% & $60,34 \%$ & $18,97 \%$ & $20,69 \%$ & $100,00 \%$ \\
\hline Col\% & $46,05 \%$ & $55,00 \%$ & $60,00 \%$ & $50,00 \%$ \\
\hline Masculino & 41 & 9 & 8 & 58 \\
\hline Row\% & $70,69 \%$ & $15,52 \%$ & $13,79 \%$ & $100,00 \%$ \\
\hline Col\% & $53,95 \%$ & $45,00 \%$ & $40,00 \%$ & $50,00 \%$ \\
\hline TOTAL & 76 & 20 & 20 & 116 \\
\hline Row\% & $65,52 \%$ & $17,24 \%$ & $17,24 \%$ & $100,00 \%$ \\
\hline Col\% & $100,00 \%$ & $100,00 \%$ & $100,00 \%$ & $100,00 \%$ \\
\hline$X^{2}:$ & 1,47 & $P$ & 0,48 & \\
\hline
\end{tabular}

Si bien la severidad fue mayor en las niñas, la prueba estadística de homogeneidad da un valor superior a 0,10 por lo que se consideran no significativas las diferencias de severidad entre sexos.

La hiperreactividad bronquial, causada por un umbral bajo de excitabilidad que genera manifestaciones de tos seca, broncoespasmo y disnea sibilantes, puede darse en asmáticos y no asmáticos 291292 , pero predomina claramente en aquellos. Se registraron, como síntomas de hiperreactividad bronquial (HRB), a las manifestaciones de broncoespasmo o tos seca inducidas por el esfuerzo (AIE) y la tos seca nocturna en ausencia de un resfrío u otro cuadro respiratorio de tipo infeccioso ocurridas durante los últimos doce meses. Se categorizaron en 3 niveles:

- HRB alta: AIE + tos seca nocturna

- HRB media: solamente AIE o tos seca nocturna

- HRB baja: ninguna de aquellas manifestaciones

\begin{tabular}{|c|c|c|c|c|}
\hline Tabla 6.5 & ción de la $\mathrm{H}$ & $\begin{array}{l}\text { a totalidad } \\
\text { oles }\end{array}$ & muestrc & le casos \\
\hline HRB & Frecuencia & Porcentaje & IC & \\
\hline Alta & 55 & $17,74 \%$ & $13,75 \%$ & $22,56 \%$ \\
\hline Media & 55 & $17,74 \%$ & $13,75 \%$ & $22,56 \%$ \\
\hline Baja & 200 & $64,52 \%$ & $58,88 \%$ & $69,79 \%$ \\
\hline Total & 310 & $100,00 \%$ & & \\
\hline
\end{tabular}


Como es lógico, la HRB alta predomina claramente en los asmáticos pero 5 niños que tuvieron episodios de broncoespasmo antes de los 5 años pero actualmente no son considerados asmáticos por la familia ni por los médicos tratantes, también presentan una alta hiperreactividad.

\begin{tabular}{|l|c|c|c|c|}
\hline \multicolumn{5}{|c|}{ Tabla 6.5.1 Manifestaciones de HRB en los últimos 12 meses según casos $\boldsymbol{y}$} \\
controles
\end{tabular}

Llama la atención un control sin antecedentes de sibilantes, con HRB alta. NL es de sexo masculino, tiene antecedentes personales de eccema y rinitis leve alérgica, y antecedentes familiares de asma y alergia. Está expuesto con intensidad al tabaquismo pasivo y vive en un terreno no inundable, alejado de las principales fuentes de contaminantes atmosféricos. Es un alérgico que presenta episodios de tos nocturna y frente a determinados esfuerzos, que podría llegar a incluirse en un grupo de asmáticos alérgicos leves. Podría jugar como factor contribuyente importante en este caso el tabaquismo intenso a que se ve expuesto.

Los antecedentes eccemáticos o el eccema actual son un factor de riesgo moderado de asma a los 6 años de edad, lo que seguramente está vinculado con los mecanismos fisiopatogénicos compartidos por ambas patologías en muchos casos.

\begin{tabular}{|c|c|c|c|}
\hline Tabla 6.6 & \multicolumn{3}{|c|}{ Eccema como factor de riesgo de asma } \\
\hline ECCEMA & casos & controles & Total \\
\hline si & 50 & 57 & 107 \\
\hline no & 66 & 137 & 203 \\
\hline TOTAL & 116 & 194 & 310 \\
\hline OR: 1,8 & IC 95\%: 1,13/2,94 & $\chi^{2}: 6$ & $P: 0,01$ \\
\hline
\end{tabular}


Este hallazgo es coincidente con el score de riesgo PIAMA, que considera uno de los criterios mayores al eccema diagnosticado por el médico en los dos o tres primeros años de vida: OR, $4.6\left[95 \% \mathrm{Cl}, 3.1-6.8^{293}\right.$.

La Rinitis alérgica se asocia más claramente con el asma, duplicando el riesgo a los 6 años de edad.

\begin{tabular}{|c|c|c|c|}
\hline \multicolumn{4}{|c|}{ Tabla 6.7 Rinitis como riesgo de asma infantil } \\
\hline RINITIS & caso & control & Total \\
\hline si & 82 & 90 & 172 \\
\hline No & 34 & 104 & 138 \\
\hline TOTAL & 116 & 194 & 310 \\
\hline OR: 2,8 & IC $95 \%: 1,7 / 4,5$ & $\chi^{2}: 17$ & P: $<0,0001$ \\
\hline
\end{tabular}

Como ya se ha planteado en la introducción, las infecciones virales pueden afectar el curso del asma, desencadenando crisis y disminuyendo el umbral de irritabilidad, a veces en forma prolongada, por lo que es conveniente tenerlas en cuenta al evaluar los distintos factores involucrados. En este estudio se relevó en particular a los Resfríos como desencadenantes de sibilancias con un resultado claramente superior para los asmáticos pero también se presenta en niños no asmáticos. Debe tenerse en cuenta que algunos ruidos respiratorios que pueden manifestarse en estas infecciones podrían ser confundidos con sibilantes por los padres que responden el autocuestionario.

\begin{tabular}{|c|c|c|c|}
\hline \multicolumn{4}{|c|}{ Tabla 6.8 Resfríos tipo virosis como riesgo de sibilantes } \\
\hline Resfrios & casos & controles & Total \\
\hline Si & 44 & 14 & 58 \\
\hline No & 72 & 180 & 252 \\
\hline TOTAL & 116 & 194 & 310 \\
\hline OR: 7,8 & IC $95 \%: 4 / 15$ & $\chi 2: 45$ & P: $<0,00001$ \\
\hline
\end{tabular}

Los antecedentes familiares de asma y alergia son un riesgo moderado de asma a los 6 años de edad, como puede verse en la siguiente tabla: 


\begin{tabular}{|c|c|c|c|}
\hline \multicolumn{4}{|c|}{ Tabla 6.9 Antecedentes familiares como riesgo de asma } \\
\hline Antedentes fam & casos & controles & Total \\
\hline si & 76 & 98 & 174 \\
\hline no & 35 & 82 & 117 \\
\hline TOTAL & 111 & 180 & 291 \\
\hline OR: 1,8 & IC $95 \%: 1,1 / 2,9$ & $\chi 2: 5,6$ & P: 0,01 \\
\hline
\end{tabular}

Se consideró como atópicos, a los fines de este estudio, a los niños que presentaran al menos dos de las tres siguientes respuestas positivas:

- antecedentes personales de eccema o dermatitis atópica,

- rinitis tipo alérgica

- antecedentes familiares de asma y alergia

Como puede verse en la tabla siguiente, la atopia es un riesgo fuerte de asma a los 6 años de edad.

\begin{tabular}{|c|c|c|c|}
\hline \multicolumn{4}{|c|}{ Tabla 6.10 Atopia como riesgo de asma infantil } \\
\hline ATOPIA & casos & controles & Total \\
\hline si & 30 & 20 & 50 \\
\hline no & 86 & 174 & 260 \\
\hline TOTAL & 116 & 194 & 310 \\
\hline OR: 3 & IC 95\%: $1,6 / 5,6$ & $\chi 2: 13$ & $P<0,001$ \\
\hline
\end{tabular}




\section{Unidad de análisis vivienda y entorno próximo}

\section{Determinación de variables ambientales específicas}

En la encuesta 1 se interrogó sobre los desencadenantes de broncoespamo percibidos por la familia, compatibles con alergia (polvo, pelos, plumas, pólenes) resultando un riesgo fuerte para el asma:

\begin{tabular}{|c|c|c|c|}
\hline \multicolumn{4}{|c|}{ Tabla 6.13 Alérgenos como desencadenantes de sibilancias } \\
\hline ALERGENOS & casos & controles & Total \\
\hline si & 29 & 15 & 44 \\
\hline no & 87 & 179 & 266 \\
\hline TOTAL & 116 & 194 & 310 \\
\hline OR: 3 & IC 95\%: $2 / 7,8$ & $\mathrm{X} 2: 17$ & $\mathrm{P}<0,001$ \\
\hline
\end{tabular}

Más de la mitad de los 15 controles que refieren desencadenantes específicos (polvo, pelos, plumas, pólenes, pastos) son niños con antecedentes de sibilantes y 11 son atópicos.

Para verificar la sensibilidad manifestada frente a alérgenos, se cruzó este dato con el antecedente de Rinitis, demostrando una fuerte vinculación.

\begin{tabular}{|c|c|c|c|}
\hline \multicolumn{4}{|c|}{ Tabla 6.14. Sibilantes frente a alérgenos como factor de riesgo de asma en niños con } \\
Rinitis alérgica \\
\hline \multirow{2}{*}{ ALERGENOS } & caso & control & Total \\
\hline si & 25 & 9 & 34 \\
\hline no & 57 & 81 & 138 \\
\hline TOTAL & 82 & 90 & 172 \\
\hline OR: 3,9 & IC $95 \%: 1,7 / 9$ & $\chi 2: 11$ & $\mathrm{P}<0,001$ \\
\hline
\end{tabular}

Los niños con manifestaciones alérgicas (Rinitis tipo alérgica y sensibilidad frente a alérgenos), tienen casi cuatro veces más riesgo de desarrollar asma a los 6 años de edad. Con los antecedentes familiares de alergia y asma sucede algo similar. Tienen casi cuatro veces más posibilidades de presentar asma alérgica como puede verse en la tabla 6.14: 


\begin{tabular}{|c|c|c|c|}
\hline \multicolumn{4}{|c|}{ Tabla 6.15. Sibilantes frente a alérgenos como factor de riesgo de asma en niños con } \\
antecedentes familiares de alergia
\end{tabular}

Como se observó en la muestra general del estudio de corte, los perros y gatos en el hogar no parecen generar riesgo de asma en la infancia, aunque es posible que otras mascotas si lo provoquen.

\begin{tabular}{|c|c|c|c|c|}
\hline \multicolumn{5}{|c|}{ Tabla 6.16 Mascotas en el hogar como riesgo de asma } \\
\hline & OR & IC 95\% & X2 & P \\
\hline Perro & 0,8 & $0,5 / 1,4$ & 0,4 & 0,5 \\
\hline Gato & 1,3 & $0,7 / 2,3$ & 1,1 & 0,3 \\
\hline otros animales & 2,5 & $1,3 / 4,9$ & 8,4 & $<0,01$ \\
\hline
\end{tabular}

La Odds Ratio para presencia de perros es inferior a 1 pero no puede afirmarse un efecto protector ya que no hay diferencias significativas y el intervalo de confianza abarca el 1. Este resultado es similar al de varios estudios epidemiológicos incluyendo la amplia cohorte de nacimiento canadiense. ${ }^{294}$

La Odds Ratio del gato en el hogar es superior a la del perro y aunque la diferencia no es significativa, este resultado es compatible con la mayor potencia alergénica de Feld 1 y otros antígenos del gato ${ }^{295}$. La presencia de otros animales (no perros ni gatos) en el hogar duplica el riesgo de asma en la infancia. No se registró en la encuesta que tipo de animales son pero por otras observaciones domiciliarias que se han realizado en la zona es posible que la mayoría sean pájaros y en menor medida conejos y ratones.

Las variaciones estacionales de los síntomas pueden estar vinculadas con diversos factores causales, destacándose las polinosis desde agosto a abril, aunque puede haber concentraciones polínicas invernales, como el caso de algunas gramíneas y árboles. Como respuesta a las preguntas sobre los meses en que aparecen los síntomas 
se puede observar que: tanto la Rinitis como el Asma presentan una estacionalidad marcada, con un pico mayor hacia la época fría (mayo y junio) y un pico menor primaveral. En las Rinitis las diferencias son más marcadas y se insinúa otro pico de verano tardío y otoñal compatible con el aumento de los pólenes de compuestas y otras malezas.

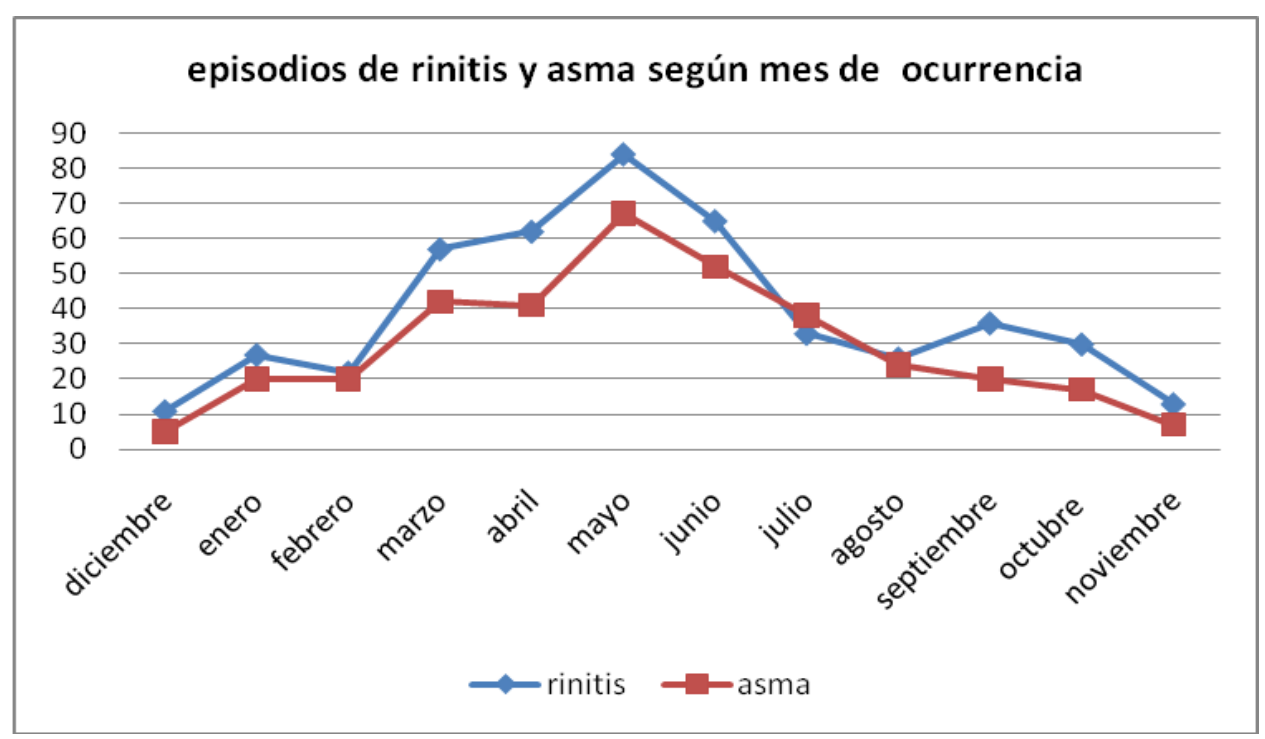




\section{Capítulo 7}

Factores de riesgo inespecíficos según la percepción familiar

Como una aproximación inicial al tema de fondo de la Tesis, se evaluó la percepción familiar de desencadenantes inespecíficos (cambios climáticos, aire frío o acondicionado, humo de cigarrillo, olores fuertes, perfumes y aerosoles varios, emociones, llantos y risa). En el capítulo 4 se presentaron las preguntas respectivas.

El resultado es una OR muy alta en una prueba estadística muy significativa.

\begin{tabular}{|c|c|c|c|}
\hline \multicolumn{4}{|c|}{ Tabla 7.1 Percepción familiar de desencadenantes inespecíficos como } \\
factor de riesgo de asma \\
\hline Factores inespecíficos & casos & controles & Total \\
\hline si & 88 & 49 & 137 \\
\hline no & 28 & 145 & 173 \\
\hline TOTAL & 116 & 194 & 310 \\
\hline OR: 9 & IC 95\%: $5 / 15$ & $\chi 2: 75$ & $\mathrm{P}<0,0001$ \\
\hline
\end{tabular}

Comparando la percepción familiar con los otros conjuntos de factores desencadenantes consultados, los inespecíficos son considerados más frecuentemente:

\begin{tabular}{|c|c|c|}
\hline Conjunto de factores & OR & IC 95\% \\
\hline Inespecíficos & 9 & $5 / 15$ \\
\hline Probables virosis & 7 & $3,6 / 13,5$ \\
\hline alérgenos & 4,31 & $2 / 8$ \\
\hline
\end{tabular}

Si se evalúa el efecto en los controles, los desencadenantes inespecíficos generan casi el triple de riesgo de sibilantes en niños con antecedentes de broncoespasmos en los primeros 5 años de vida, frente a los controles sin ese antecedente (Tabla 7.2). 


\begin{tabular}{|c|c|c|c|}
\hline \multicolumn{4}{|c|}{$\begin{array}{c}\text { Tabla 7.2 Percepción familiar de desencadenantes inespecíficos como factor de } \\
\text { riesgo de sibilantes según tipo de control }\end{array}$} \\
\hline INESPECIFICOS & $\begin{array}{c}\text { antecedentes } \\
\text { de sibilantes }\end{array}$ & $\begin{array}{c}\text { controles sin } \\
\text { antec. }\end{array}$ & Total \\
\hline si & 26 & 23 & 49 \\
\hline no & 40 & 105 & 145 \\
\hline TOTAL & 66 & 128 & 194 \\
\hline OR: $\mathbf{2 , 9}$ & IC $95 \%: 1,5 / 5,8$ & $\chi 2: 10$ & $\mathrm{P}<0,01$ \\
\hline
\end{tabular}

El resultado anterior podría deberse a un umbral de irritabilidad más bajo persistente, lo que puede inducirse de los resultados de la tabla 7.3, que muestra una distribución con porcentajes más altos para la HRB alta y media en los controles con antecedentes y una diferencia significativa de los niveles de hiperreactividad bronquial entre ellos.

\begin{tabular}{|c|c|c|c|c|c|}
\hline \multicolumn{7}{|c|}{ Tabla 7.3. HRB y tipo de control } \\
\hline HRB & Antecedentes de sibilantes & Controles sin antecedentes & Total \\
\hline & $\mathrm{n}$ & $\%$ de columna & $\mathrm{n}$ & $\%$ de columna & $\mathrm{n}$ \\
\hline alta & 5 & 8 & 1 & 1 & 6 \\
\hline media & 13 & 20 & 6 & 4 & 19 \\
\hline baja & 48 & 72 & 121 & 95 & 169 \\
\hline TOTAL & 66 & & 128 & & 194 \\
\hline$\chi^{2}$ & 51,2231 & & \multicolumn{5}{|c|}{$\operatorname{Pr}>\chi^{2}: 0,0001$} & \\
\hline
\end{tabular}

Como puede verse en la tabla 7.4, el $83 \%$ de los niños con HRB alta manifiestan sibilantes frente a factores inespecíficos mientras que solo el $27 \%$ de quienes tienen HRB baja responden con broncoespasmo expuestos a los mismos factores.

\begin{tabular}{|c|c|c|c|}
\hline \multicolumn{5}{|c|}{ Tabla 7.4 HRB como generadora de sibilantes frente a factores inespecificos } \\
\hline HRB & si & no & Total \\
\hline alta & 46 & 9 & 55 \\
\hline media & 36 & 19 & 55 \\
\hline baja & 55 & 145 & 200 \\
\hline TOTAL & 137 & 173 & 310 \\
\hline$\chi 2$ & 67,3734 & P & $<0,0001$ \\
\hline
\end{tabular}


Otro enfoque relacionado es analizar la distribución de la HRB entre los 137 niños (casos y controles) sensibles a los factores inespecíficos:

Tabla 7.5. Hiperreactividad bronquial en niños sensibles a desencadenantes inespecíficos como factor de riesgo de sibilantes

\begin{tabular}{|c|c|c|c|}
\hline HRB & casos & controles & Total \\
\hline alta & 42 & 4 & 46 \\
\hline media & 27 & 9 & 36 \\
\hline baja & 19 & 36 & 55 \\
\hline TOTAL & 88 & 49 & 137 \\
\hline \multicolumn{4}{|c|}{$\chi^{2}: 37$} \\
\hline
\end{tabular}

Tabla 7.6. Desencadenantes inespecíficos como factor de riesgo de sibilantes según HRB. OR.

\begin{tabular}{|l|c|c|cr|}
\hline \multicolumn{1}{|c|}{ HRB } & casos & controles & \multicolumn{2}{c|}{ totales } \\
\hline alta y media & 69 & 13 & & 52 \\
\hline baja & 19 & 36 & 137 \\
\hline totales & 88 & 49 & & \\
\hline \multicolumn{1}{|c|}{ OR: 10} & IC $95 \%: 4 / 22$ & $\chi 2: 35$ & $P<0,0001$ & \\
\hline
\end{tabular}

Los niños con HRB alta o media, evaluada según los antecedentes de AIE y tos nocturna sin infección respiratoria, tienen diez veces más riesgo de presentar sibilantes frente a desencadenantes inespecíficos.

Los familiares perciben a los resfríos tipo virosis como desencadenantes de episodios de broncoespasmo:

Tabla 7.7 Percepción familiar de resfríos tipo virosis como desencadenante de sibilantes

\begin{tabular}{|c|c|c|c|}
\hline Resfríos & casos & controles & Total \\
\hline si & 42 & 15 & 57 \\
\hline no & 72 & 181 & 253 \\
\hline OR: 7 & IC $3,6 / 13,5$ & $X 2: 40$ & P: $<0,00001$ \\
\hline
\end{tabular}




\section{Factores inespecíficos del ambiente interior}

Los factores inespecíficos de riesgo considerados fueron:

- Tabaquismo pasivo

- Hongos aerógenos

- Formaldehido

- Uso frecuente de insecticidas

- Sistemas de calefacción

- Otros factores del aire interior:
- Alfombras
- Dimensiones de ventanas en función de la superficie de la habitación (capacidad de ventilación)
- Aire acondicionado
- Métodos de limpieza
- Uso frecuente de desodorantes ambientales 
Tabaquismo pasivo.

El tabaquismo pasivo se evaluó en función de la respuesta familiar al autocuestionario con opciones cerradas de respuesta, en el que se preguntó: “¿con qué frecuencia tiene contacto con fumadores o humo de cigarrillo?", siendo las opciones: "frecuente", "a veces" y "nunca". Se interroga en general el contacto o exposición y no solamente si los padres fuman ya que se ha demostrado la importancia de terceros, familiares o no, que quedan muchas horas al cuidado de los niños ${ }^{296}$ y es posible que algunos padres eviten fumar en el hogar.

\begin{tabular}{|l|c|c|c|}
\hline \multicolumn{4}{|c|}{ Tabla 7.8. Tabaquismo pasivo como factor de riesgo de asma } \\
\hline Tabaquismo pasivo & casos & controles & Total \\
\hline frecuente & 42 & 71 & 113 \\
\hline Fila \% & $37,17 \%$ & $62,83 \%$ & $100,00 \%$ \\
\hline Col \% & $37,84 \%$ & $37,17 \%$ & $37,42 \%$ \\
\hline a veces & 42 & 79 & 121 \\
\hline Fila \% & $34,71 \%$ & $65,29 \%$ & $100,00 \%$ \\
\hline Col \% & $37,84 \%$ & $41,36 \%$ & $40,07 \%$ \\
\hline nunca & 27 & 41 & 68 \\
\hline Fila \% & $39,71 \%$ & $60,29 \%$ & $100,00 \%$ \\
\hline Col \% & $24,32 \%$ & $21,47 \%$ & $22,52 \%$ \\
\hline TOTAL & 111 & 191 & 302 \\
\hline Fila \% & $36,75 \%$ & $63,25 \%$ & $100,00 \%$ \\
\hline & 0,4805 & Pr & 0,7864 \\
\hline
\end{tabular}

No hay diferencias significativas.

Agrupando los niños en "expuestos" (frecuente y a veces) y "no expuestos" (nunca) para calcular la OR de exposición, tampoco aparece una diferencia significativa.

\begin{tabular}{|l|c|c|c|}
\hline \multicolumn{4}{|c|}{ Tabla 7.9 Tabaquismo pasivo } \\
\hline \multicolumn{1}{|c|}{ CONTACTO } & casos & controles & Total \\
\hline Expuestos & $\mathbf{8 4}$ & $\mathbf{1 5 0}$ & 234 \\
\hline no expuestos & 30 & 38 & 68 \\
\hline TOTAL & 114 & 188 & 302 \\
\hline \multicolumn{1}{|c|}{ OR: 0,71} & $\mathrm{IC} 0,41 / 1,22$ & $\chi^{2}: 1,51$ & $\mathrm{Pr}<\chi^{2}: 0,21$ \\
\hline
\end{tabular}


La OR presenta un intervalo de confianza que incluye al 1 por lo que no se manifiesta con claridad un posible efecto, que en todo caso tiende a ser protector. La distribución por sexos no presenta tampoco diferencias significativas:

\begin{tabular}{|c|c|c|c|c|}
\hline & \multicolumn{2}{|c|}{ casos } & \multicolumn{2}{|c|}{ controles } \\
\hline & fem & masc & fem & masc \\
\hline frecuente & 22 & 21 & 36 & 35 \\
\hline a veces & 22 & 19 & 42 & 37 \\
\hline \multirow[t]{3}{*}{ nunca } & 12 & 15 & 18 & 23 \\
\hline & femenino & $\chi 2: 0,3255$ & $\operatorname{Pr}<x^{2}$ & 0,8498 \\
\hline & masculino & $x 2: 0,3265$ & $\operatorname{Pr}<x^{2}$ & 0,8494 \\
\hline \multicolumn{5}{|c|}{ no hay diferencias significativas } \\
\hline
\end{tabular}

Tabla 7.11 Tabaquismo pasivo según sexo en casos y controles

\begin{tabular}{|c|c|c|c|c|}
\hline & \multicolumn{2}{|c|}{ casos } & \multicolumn{2}{|c|}{ controles } \\
\hline & fem & masc & fem & masc \\
\hline expuesto & 44 & 40 & 78 & 72 \\
\hline no expuesto & 12 & 15 & 18 & 23 \\
\hline$x 2: 0,3$ &, 85 & y difer & s signit & as \\
\hline
\end{tabular}

Tampoco hay diferencias significativas si solo se estudia el efecto del tabaquismo pasivo en niños con antecedentes familiares de asma o alergia $\left(\chi^{2}: 0,25 ; \operatorname{Pr}>\chi^{2} 0,9\right)$.

\begin{tabular}{|l|c|c|c|c|c|}
\hline \multicolumn{7}{|c|}{ Tabla 7.12} & \multicolumn{1}{c|}{ Tabaquismo pasivo y severidad del asma } \\
\hline TAB PASIVO & severa & moderada & leve & controles & Total \\
\hline frecuente & 5 & 12 & 25 & 71 & 113 \\
\hline Fila \% & $4,42 \%$ & $10,62 \%$ & $22,12 \%$ & $62,83 \%$ & $100,00 \%$ \\
\hline Col\% & $27,78 \%$ & $57,14 \%$ & $34,72 \%$ & $37,17 \%$ & $37,42 \%$ \\
\hline a veces & 7 & 7 & 28 & 79 & 121 \\
\hline Fila \% & $5,79 \%$ & $5,79 \%$ & $23,14 \%$ & $65,29 \%$ & $100,00 \%$ \\
\hline Col\% & $38,89 \%$ & $33,33 \%$ & $38,89 \%$ & $41,36 \%$ & $40,07 \%$ \\
\hline nunca & 6 & 2 & 19 & 41 & 68 \\
\hline Fila \% & $8,82 \%$ & $2,94 \%$ & $27,94 \%$ & $60,29 \%$ & $100,00 \%$ \\
\hline Col\% & $33,33 \%$ & $9,52 \%$ & $26,39 \%$ & $21,47 \%$ & $22,52 \%$ \\
\hline TOTAL & 18 & 21 & 72 & 191 & 302 \\
\hline Row\% & $5,96 \%$ & $6,95 \%$ & $23,84 \%$ & $63,25 \%$ & $100,00 \%$ \\
\hline & 6,2 & $\operatorname{Pr}$ & 0,4006 & & \\
\hline
\end{tabular}

No hay diferencias significativas. 


\begin{tabular}{|l|c|c|c|} 
& severa/moderada & leve & \\
\hline expuestos & 31 & 53 & \\
\hline no expuestos & 8 & 19 & \\
\hline OR: 1,4 & IC: $0,5 / 3,5$ & $\chi 2: 0,5$ & $\operatorname{Pr}: 0,5$ \\
\hline
\end{tabular}

Agrupando la exposición y el efecto en solo dos categorías lógicas tampoco hay diferencias significativas. EI IC 95\% de la OR involucra la unidad por lo que no puede afirmarse con certeza el riesgo débil que se insinúa: OR: 1,4.

\section{Relación con la hiperreactividad bronquial.}

Tabla 7.14 Tabaquismo pasivo como factor de riesgo de hiperirritabilidad bronquial

\begin{tabular}{|l|r|r|r|r|}
\hline \multicolumn{1}{|c|}{ TAB PASIVO } & \multicolumn{1}{c|}{ alta } & \multicolumn{1}{c|}{ media } & \multicolumn{1}{c|}{ baja } & \multicolumn{1}{c|}{ Total } \\
\hline frecuente & 21 & 19 & 73 & $130,00 \%$ \\
\hline Fila \% & $18,58 \%$ & $16,81 \%$ & $64,60 \%$ & $37,42 \%$ \\
\hline Col\% & $38,18 \%$ & $34,55 \%$ & $38,02 \%$ & 121 \\
\hline a veces & 18 & 22 & 81 & $100,00 \%$ \\
\hline Fila \% & $14,88 \%$ & $18,18 \%$ & $66,94 \%$ & $40,07 \%$ \\
\hline Col\% & $32,73 \%$ & $40,00 \%$ & $42,19 \%$ & 68 \\
\hline nunca & 16 & 14 & 38 & $100,00 \%$ \\
\hline Fila \% & $23,53 \%$ & $20,59 \%$ & $55,88 \%$ & $22,52 \%$ \\
\hline Col\% & $29,09 \%$ & $25,45 \%$ & $19,79 \%$ & 302 \\
\hline TOTAL & 55 & 55 & 192 & $100,00 \%$ \\
\hline Fila \% & $18,21 \%$ & $18,21 \%$ & $63,58 \%$ & \\
\hline & 3,0033 & Pr $\chi 2:$ & 0,5573 & \\
\hline
\end{tabular}

En los 7 controles sin antecedentes de sibilantes que presentan HRB, se destaca la exposición al tabaquismo en 6 de ellos. La excepción es una niña con antecedentes personales y familiares de alergia. 
Tabaquismo pasivo, atopia y asma.

Si se revisa el efecto del tabaquismo según la condición de atópico o no atópico de los niños, sin haber resultados estadísticamente significativos se insinúa un efecto protector en los no atópicos y una OR elevada en los niños alérgicos.

\begin{tabular}{|c|c|c|}
\hline \multicolumn{3}{|c|}{ Tabla 7.15 } \\
\hline tabaquismo pasivo como riesgo en no atópicos \\
\hline si & Casos no atópicos & Controles no atópicos \\
\hline no & 60 & 134 \\
\hline TOTAL & 23 & 36 \\
\hline OR 0,7 & 83 & 170 \\
\hline
\end{tabular}

\begin{tabular}{|c|c|c|c|}
\hline \multicolumn{3}{|c|}{ Tabla 7.16 tabaquismo pasivo como riesgo en atópicos } \\
\hline EXP TAB & Casos atópicos & \multicolumn{2}{c|}{ Controles atópicos } \\
\hline si & 24 & \multicolumn{2}{|c|}{15} \\
\hline no & 4 & \multicolumn{2}{|c|}{6} \\
\hline TOTAL & 28 & \multicolumn{2}{|c|}{21} \\
\hline OR 2,4 & IC $0,58 / 9,9$ & $\chi^{2}: 1,5$ & $\operatorname{Pr}<\chi 2: 0,22$ \\
\hline
\end{tabular}

\begin{tabular}{|c|c|c|c|}
\hline \multicolumn{4}{|c|}{ Tabla 7.17 Tabaquismo pasivo y alergia atópica } \\
\hline Exposición a Tabaquismo pasivo & atópico & no atópico & Total \\
\hline si & 39 & 194 & 233 \\
\hline no & 10 & 59 & 69 \\
\hline TOTAL & 49 & 253 & 302 \\
\hline OR 1,18 & $0,55 / 2,52$ & & \\
\hline X2 & 0,1975 & $\mathrm{P}$ & 0,66 \\
\hline
\end{tabular}

El tabaquismo pasivo no parece influir en el riesgo de presentar síntomas de atopia, pero en el $17 \%$ de atópicos expuestos que evolucionaron como casos de asma es posible que haya una proporción importante de alérgicos al tabaco. 
Observando por separado el efecto según los antecedentes familiares de asma o alergia no se detectan resultados significativos:

\begin{tabular}{|l|c|c|c|c|c|}
\hline \multicolumn{6}{|c|}{ Tabla 7.18 Tabaquismo pasivo como factor de riesgo según antecedentes } \\
familiares de asma y alergia \\
\hline & OR & IC 95\% & $X^{2}$ & P & Significado \\
\hline Antecedentes positivos & 1,05 & $0,5 / 2,18$ & 0,02 & 0,89 & NS \\
\hline Sin antecedentes & 0,58 & $0,22 / 1,46$ & 1,36 & 0,24 & NS \\
\hline
\end{tabular}

En la muestra grande del corte transversal se observó que entre las 41 familias que reconocían al humo de cigarrillo como desencadenante de sibilancias en el niño, solo el $10 \%$ evitaba la exposición y el $46 \%$ manifestaba que era frecuente, lo que generalmente se relaciona con fumadores en los convivientes.

\begin{tabular}{|c|c|c|c|c|}
\hline \multicolumn{5}{|c|}{ Tabla 7.19 Percepción como desencadenante y Tabaquismo pasivo } \\
\hline & \multicolumn{3}{|c|}{ Tabaquismo pasivo } & \multirow[b]{2}{*}{ Total } \\
\hline $\begin{array}{l}\text { Humo de cigarrillo como } \\
\text { desencadenante }\end{array}$ & Frecuente & A veces & Nunca & \\
\hline si & 19 & 18 & 4 & 41 \\
\hline fila $\%$ & $46,34 \%$ & $43,90 \%$ & $9,76 \%$ & $100,00 \%$ \\
\hline Col\% & $10,73 \%$ & $8,18 \%$ & $3,33 \%$ & $7,93 \%$ \\
\hline No & 158 & 202 & 116 & 476 \\
\hline fila $\%$ & $33,19 \%$ & $42,44 \%$ & $24,37 \%$ & $100,00 \%$ \\
\hline Col\% & $89,27 \%$ & $91,82 \%$ & $96,67 \%$ & $92,07 \%$ \\
\hline TOTAL & 177 & 220 & 120 & 517 \\
\hline fila $\%$ & $34,24 \%$ & $42,55 \%$ & $23,21 \%$ & $100,00 \%$ \\
\hline$x^{2}$ & 5,3927 & $\operatorname{Pr}<\chi 2$ & 0,0675 & \\
\hline
\end{tabular}

\section{Riesgo atribuible al tabaquismo pasivo}

El riesgo atribuible a la exposición al tabaquismo pasivo del grupo expuesto en el hogar es del $6 \%$ calculado en base a la incidencia acumulada de asma en los primeros 5 años de vida, aplicando la fórmula propuesta por Gordis ${ }^{297}$. 


\section{Incidencia expuestos $82 \%$ - incidencia no expuestos $77 \%=6 \%$ Incidencia expuestos $82 \%$}

Aplicando la fórmula de Levin ${ }^{298}$ para calcular el riesgo atribuible en toda la población el resultado es $2 \%$. La hipótesis es que si se lograra reducir fuertemente la exposición al tabaquismo pasivo podría disminuir hasta un 2 \% la incidencia de casos en los primeros 5 años de vida. 


\section{Hongos aerógenos}

La presencia de hongos en el dormitorio se estudió en forma directa a través de la toma de muestras y en forma indirecta observando manchas de humedad en las paredes del mismo. Las placas situadas en las ventanas de los dormitorios presentaban un $75 \%$ más de unidades formadoras de colonias (UFC) que las situadas en la cama y éstas eran superiores a la de la cocina o comedor. Es posible que en el aire exterior de nuestra ciudad haya mayor concentración de esporas que en el interior de las viviendas. En general fue múltiple la presencia de géneros micóticos con la excepción de una vivienda que presentaba solo Penicillium y en concentración elevada. Las temperaturas de los dormitorios oscilaron entre los 21,9 y $32{ }^{\circ} \mathrm{C}$ y la humedad ambiente entre el 48 y el $67 \%$.

El conteo y tipificación de las unidades formadoras de colonias (UFC) ${ }^{299}$ demostró la presencia de abundantes y variados géneros y especies de hongos anemófilos pero no pudo hallarse una relación clara con su posible rol como factor de riesgo de asma.

\begin{tabular}{|l|c|}
\hline \multicolumn{2}{|c|}{ Tabla 7.20 Conteo y tipificación de hongos en dormitorios de casos y controles } \\
\hline \multicolumn{1}{|c|}{ Género } & $\%$ UFC totales \\
\hline Cladosporium sp. (deuteromicetes) & $60,2 \%$ \\
\hline Penicillium sp. (deuteromicetes) & $9,3 \%$ \\
\hline Alternaria sp. (deuteromicetes) & $5,6 \%$ \\
\hline Mycelia Sterilia (deuteromicetes) & $4,6 \%$ \\
\hline Pseudotorula sp. (ascomicetes) & $3,6 \%$ \\
\hline Levadura (ascomicetes o basidiomicetes) & $2,3 \%$ \\
\hline Aspergillus sp. (deuteromicetes) & $<2 \%$ \\
\hline Dreschlera sp. & $<2 \%$ \\
\hline Fusarium sp. & $<2 \%$ \\
\hline Humicola sp. & $<2 \%$ \\
\hline Rhizopus sp. (phycomicetes) & $<2 \%$ \\
\hline Stemphilum sp. & $<2 \%$ \\
\hline Ceratosporium sp. & $<2 \%$ \\
\hline Nigrospora sp. & $<\%$ \\
\hline
\end{tabular}


La cantidad de UFC por placa presentó un gradiente de mayor a menor: ventana, dormitorio, cocina, pero guardando una proporcionalidad para cada vivienda.

\begin{tabular}{|c|c|c|c|c|}
\hline \multicolumn{5}{|c|}{$\begin{array}{c}\text { Tabla 7.21 Recuento de UFC Hongos en la vivienda según casos y } \\
\text { controles }\end{array}$} \\
\hline cuartil & CATEG CANT & casos & controles & Total \\
\hline \multirow{3}{*}{ cuarto } & muy alta & 10 & 8 & 18 \\
\hline & Row\% & $55,56 \%$ & $44,44 \%$ & $100,00 \%$ \\
\hline & Col\% & $58,82 \%$ & $42,11 \%$ & $50,00 \%$ \\
\hline \multirow{3}{*}{ tercero } & alta & 2 & 4 & 6 \\
\hline & Row\% & $33,33 \%$ & $66,67 \%$ & $100,00 \%$ \\
\hline & Col\% & $11,76 \%$ & $21,05 \%$ & $16,67 \%$ \\
\hline \multirow{3}{*}{ segundo } & media & 3 & 3 & 6 \\
\hline & Row\% & $50,00 \%$ & $50,00 \%$ & $100,00 \%$ \\
\hline & Col\% & $17,65 \%$ & $15,79 \%$ & $16,67 \%$ \\
\hline \multirow{7}{*}{ primero } & baja & 2 & 4 & 6 \\
\hline & Row\% & $33,33 \%$ & $66,67 \%$ & $100,00 \%$ \\
\hline & Col\% & $11,76 \%$ & $21,05 \%$ & $16,67 \%$ \\
\hline & TOTAL & 17 & 19 & 36 \\
\hline & Row\% & $47,22 \%$ & $52,78 \%$ & $100,00 \%$ \\
\hline & Col\% & $100,00 \%$ & $100,00 \%$ & $100,00 \%$ \\
\hline & $x 2: 1,45$ & df3 & $P: 0,69$ & \\
\hline
\end{tabular}

No hay diferencias significativas

Si bien la prueba sobre la distribución no muestra diferencias estadísticamente significativas, puede observarse, en cuanto a la proporción de las categorías según casos y controles, que en aquellos la categoría más alta presenta una diferencia mayor (59\% a $12 \%$ ) que en los controles ( $42 \%$ a $21 \%$ ), insinuando una posible implicancia causal.

Para explorar esta hipótesis se agrupan las categorías de los cuartiles 3 y 4 (alta y muy alta) y por otra parte la de los cuartiles 1 y 2 (media y baja), para calcular la odds ratio:

\begin{tabular}{|l|c|c|c|}
\hline \multicolumn{5}{|c|}{ Tabla 7.22 Cantidad de UFC en vivienda y riesgo de asma } \\
\hline & casos & controles & totales \\
\hline muy alta y alta & 12 & 12 & 24 \\
\hline media y baja & 5 & 7 & 12 \\
\hline totales & 17 & 19 & 36 \\
\hline OR: 1,4 & IC $95 \%: 0,34 / 5,6$ & $\mathrm{X} 2: 0,22$ & P: 0,63 \\
\hline
\end{tabular}


Si bien la OR de 1,4 para alta densidad de esporas insinúa un riesgo leve, el amplio rango del IC 95\% y la prueba de $\chi^{2}$ permiten afirmar que no hay diferencias significativas entre las viviendas de los casos y los controles. Comparando los cuartiles extremos aumenta la OR $(2,5)$ pero el intervalo de confianza y el test de $\chi^{2}$ no permiten plantear conclusiones firmes.

\begin{tabular}{|c|c|c|c|c|c|}
\hline MANCHAS HUMEDAD & muy alta & alta & media & baja & Total \\
\hline Si & 7 & 0 & 1 & 0 & 8 \\
\hline Row\% & $87,50 \%$ & $0,00 \%$ & $12,50 \%$ & $0,00 \%$ & $100,00 \%$ \\
\hline Col\% & $41,18 \%$ & $0,00 \%$ & $20,00 \%$ & $0,00 \%$ & $26,67 \%$ \\
\hline No & 10 & 4 & 4 & 4 & 22 \\
\hline Row\% & $45,45 \%$ & $18,18 \%$ & $18,18 \%$ & $18,18 \%$ & $100,00 \%$ \\
\hline Col\% & $58,82 \%$ & $100,00 \%$ & $80,00 \%$ & $100,00 \%$ & $73,33 \%$ \\
\hline TOTAL & 17 & 4 & 5 & 4 & 30 \\
\hline Row\% & $56,67 \%$ & $13,33 \%$ & $16,67 \%$ & $13,33 \%$ & $100,00 \%$ \\
\hline Col\% & $100,00 \%$ & $100,00 \%$ & $100,00 \%$ & $100,00 \%$ & $100,00 \%$ \\
\hline$X 2: 4,85$ & df3 & $P: 0,18$ & & & \\
\hline
\end{tabular}

Si bien la OR para alta densidad de esporas marca una asociación fuerte en los dormitorios con manchas de humedad, la amplitud del IC y la prueba de $\chi^{2}$ no permiten confirmar lo significativo de esta relación:

Tabla 7.24 Riesgo de esporas en aire por manchas de humedad

\begin{tabular}{|c|c|c|c|}
\hline Manchas de humedad & muy alta y alta & media y baja & total \\
\hline si & 7 & 1 & 8 \\
\hline no & 14 & 8 & 22 \\
\hline total & 21 & 9 & 30 \\
\hline OR: 4 & IC $95 \%: 0,4 / 38$ & X2: 1,6 & P: 0,2 \\
\hline
\end{tabular}

En las áreas inundables se determinó la presencia de hongos aerógenos en cuatro niños cuyas familias accedieron a realizar el estudio. El resultado mostró que 3 de ellas tenían niveles muy elevados de UFC por cápsula y baja en el otro. Dos eran casos. 


\begin{tabular}{|c|c|c|c|c|c|}
\hline \multirow[b]{2}{*}{ TERRENO INUNDABLE } & \multicolumn{4}{|c|}{ categ cant hongos } & \multirow[b]{2}{*}{ Total } \\
\hline & muy alta & alta & media & baja & \\
\hline si & 3 & 0 & 0 & 1 & 4 \\
\hline Row\% & $75,00 \%$ & $0,00 \%$ & $0,00 \%$ & $25,00 \%$ & $100,00 \%$ \\
\hline Col\% & $16,67 \%$ & $0,00 \%$ & $0,00 \%$ & $16,67 \%$ & $11,11 \%$ \\
\hline no & 15 & 6 & 6 & 5 & 32 \\
\hline Row\% & $46,88 \%$ & $18,75 \%$ & $18,75 \%$ & $15,63 \%$ & $100,00 \%$ \\
\hline Col\% & $83,33 \%$ & $100,00 \%$ & $100,00 \%$ & $83,33 \%$ & $88,89 \%$ \\
\hline TOTAL & 18 & 6 & 6 & 6 & 36 \\
\hline Row\% & $50,00 \%$ & $16,67 \%$ & $16,67 \%$ & $16,67 \%$ & $100,00 \%$ \\
\hline \multirow[t]{2}{*}{ Col\% } & $100,00 \%$ & $100,00 \%$ & $100,00 \%$ & $100,00 \%$ & $100,00 \%$ \\
\hline & $x 2: 3,6$ & 3 & $P: 0,31$ & & \\
\hline
\end{tabular}

\begin{tabular}{|c|c|c|c|}
\hline \multicolumn{4}{|c|}{ Tabla 26. Riesgo de hongos en aire en terrenos inundables } \\
\hline & alta/muy alta & media/baja & total \\
\hline si & 3 & 1 & 4 \\
\hline no & 21 & 11 & 32 \\
\hline total & 24 & 12 & 36 \\
\hline OR 1,54 & IC 95\%: 0,14/17 & X2: 0,14 & P: 0,7 \\
\hline
\end{tabular}

En Concepción del Uruguay, dada la predominancia del perro como mascota hogareña, es menos probable hallar hogares con gatos en su interior. Dado que en algunas observaciones se los ha relacionado con mayor cantidad de hongos en el ambiente doméstico, se calculó este dato. En este estudio, aunque la cantidad de hogares con gatos en que se pudo realizar el estudio de hongos fue relativamente pequeño, se observa una coincidencia con aquella relación (83\%) y en una sola casa con gato se halló una cantidad media/baja de UFC. La OR para cantidad de esporas es del triple en presencia de los felinos, pero la amplitud del IC $95 \%$ y el cálculo de $\chi^{2}$ no 
permiten sacar conclusiones significativas, probablemente por el tamaño de muestra acotado.

\begin{tabular}{|c|c|c|c|c|c|}
\hline \multirow[b]{2}{*}{ GATO } & & categ cant & ngos & & \\
\hline & muy alta & alta & media & baja & Total \\
\hline si & 6 & 0 & 2 & 0 & 8 \\
\hline Row\% & $75,00 \%$ & $0,00 \%$ & $25,00 \%$ & $0,00 \%$ & $100,00 \%$ \\
\hline Col\% & $33,33 \%$ & $0,00 \%$ & $33,33 \%$ & $0,00 \%$ & $22,22 \%$ \\
\hline no & 12 & 6 & 4 & 6 & 28 \\
\hline Row\% & $42,86 \%$ & $21,43 \%$ & $14,29 \%$ & $21,43 \%$ & $100,00 \%$ \\
\hline Col\% & $66,67 \%$ & $100,00 \%$ & $66,67 \%$ & $100,00 \%$ & $77,78 \%$ \\
\hline TOTAL & 18 & 6 & 6 & 6 & 36 \\
\hline Row\% & $50,00 \%$ & $16,67 \%$ & $16,67 \%$ & $16,67 \%$ & $100,00 \%$ \\
\hline Col\% & $100,00 \%$ & $100,00 \%$ & $100,00 \%$ & $100,00 \%$ & $100,00 \%$ \\
\hline$\chi 2: 5,424$ & 3 & $P: 0,14$ & & & \\
\hline
\end{tabular}

\begin{tabular}{|c|c|c|c|}
\hline \multicolumn{5}{|c|}{ Tabla 7.28 } & Gatos como factor de aumento de esporas fúngicas \\
\hline gato & muy alta/alta & media/baja & total \\
\hline si & 6 & 2 & 8 \\
\hline no & 18 & 10 & 28 \\
\hline total & 24 & 12 & 36 \\
\hline OR: 1,67 & IC $95 \%: 0.28 / 9,8$ & $\mathrm{X} 2: 0,32$ & P: 0,57 \\
\hline
\end{tabular}

Como puede verse en la tabla siguiente, no hay diferencias significativas en los dormitorios alfombrados en cuanto a la presencia de hongos.

Tabla 7.29 Alfombras como factor de aumento de esporas fúngicas

\begin{tabular}{|c|c|c|c|}
\hline ALFOMBRA & Muy alta/alta & media/baja & Total \\
\hline si & 4 & 4 & 8 \\
\hline Fila \% & $50,00 \%$ & $50,00 \%$ & $100,00 \%$ \\
\hline Col\% & $20,00 \%$ & $40,00 \%$ & $26,67 \%$ \\
\hline no & 16 & 6 & 22 \\
\hline Fila \% & $72,73 \%$ & $27,27 \%$ & $100,00 \%$ \\
\hline Col\% & $80,00 \%$ & $60,00 \%$ & $73,33 \%$ \\
\hline TOTAL & 20 & 10 & 30 \\
\hline Fila \% & $66,67 \%$ & $33,33 \%$ & $100,00 \%$ \\
\hline OR & 0,37 & IC 95\% 0,07 / 2 & \\
\hline$\chi^{2}$ & 1,36 & $\operatorname{Pr}<\chi^{2}$ & 0,24 \\
\hline
\end{tabular}


En las tablas siguientes se presentan los datos de la posible asociación entre hongos y otras enfermedades alérgicas. No pudo demostrarse una asociación entre la cantidad de UFC y las manifestaciones de Rinitis y dermatitis atópica.

\begin{tabular}{|c|c|c|c|}
\hline Tabla 7.30 Esporas $f$ & is como ri & yo de Rinitis & érgica \\
\hline \multirow[b]{2}{*}{ CATEG CANT HONGOS } & \multicolumn{2}{|c|}{ rinitis } & \multirow[b]{2}{*}{ Total } \\
\hline & si & no & \\
\hline muy alta & 9 & 9 & 18 \\
\hline Row\% & $50,00 \%$ & $50,00 \%$ & $100,00 \%$ \\
\hline Col\% & $42,86 \%$ & $60,00 \%$ & $50,00 \%$ \\
\hline alta & 4 & 2 & 6 \\
\hline Row\% & $66,67 \%$ & $33,33 \%$ & $100,00 \%$ \\
\hline Col\% & $19,05 \%$ & $13,33 \%$ & $16,67 \%$ \\
\hline media & 5 & 1 & 6 \\
\hline Row\% & $83,33 \%$ & $16,67 \%$ & $100,00 \%$ \\
\hline Col\% & $23,81 \%$ & $6,67 \%$ & $16,67 \%$ \\
\hline baja & 3 & 3 & 6 \\
\hline Row\% & $50,00 \%$ & $50,00 \%$ & $100,00 \%$ \\
\hline Col\% & $14,29 \%$ & $20,00 \%$ & $16,67 \%$ \\
\hline TOTAL & 21 & 15 & 36 \\
\hline Row\% & $58,33 \%$ & $41,67 \%$ & $100,00 \%$ \\
\hline Col\% & $100,00 \%$ & $100,00 \%$ & $100,00 \%$ \\
\hline$x 2: 2,4$ & 3 & $P: 0,49$ & \\
\hline
\end{tabular}

\begin{tabular}{|c|c|c|c|}
\hline \multirow[b]{2}{*}{$\overline{\text { CATEG CANT HONGOS }}$} & \multicolumn{2}{|c|}{ eccema } & \multirow[b]{2}{*}{ Total } \\
\hline & si & no & \\
\hline muy alta & 9 & 9 & 18 \\
\hline Row\% & $50,00 \%$ & $50,00 \%$ & $100,00 \%$ \\
\hline Col\% & $56,25 \%$ & $45,00 \%$ & $50,00 \%$ \\
\hline alta & 4 & 2 & 6 \\
\hline Row\% & $66,67 \%$ & $33,33 \%$ & $100,00 \%$ \\
\hline Col\% & $25,00 \%$ & $10,00 \%$ & $16,67 \%$ \\
\hline media & 1 & 5 & 6 \\
\hline Row\% & $16,67 \%$ & $83,33 \%$ & $100,00 \%$ \\
\hline Col\% & $6,25 \%$ & $25,00 \%$ & $16,67 \%$ \\
\hline baja & 2 & 4 & 6 \\
\hline Row\% & $33,33 \%$ & $66,67 \%$ & $100,00 \%$ \\
\hline Col\% & $12,50 \%$ & $20,00 \%$ & $16,67 \%$ \\
\hline TOTAL & 16 & 20 & 36 \\
\hline Row\% & $44,44 \%$ & $55,56 \%$ & $100,00 \%$ \\
\hline Col\% & $100,00 \%$ & $100,00 \%$ & $100,00 \%$ \\
\hline$X 2: 3,6$ & 3 & $P: 0,31$ & \\
\hline
\end{tabular}




\begin{tabular}{|c|c|c|c|}
\hline Tabla 7.32 & Hongos en dorm & orio y atopia & \\
\hline CANT HONGOS & atópicos & no atópicos & Total \\
\hline muy alta & 3 & 15 & 18 \\
\hline alta & 0 & 5 & 5 \\
\hline media & 1 & 9 & 10 \\
\hline baja & 0 & 2 & 2 \\
\hline TOTAL & 4 & 31 & 35 \\
\hline X2 1,41 & & $\operatorname{Pr} 0,70$ & \\
\hline
\end{tabular}

\begin{tabular}{|l|c|c|c|}
\hline \multicolumn{5}{|c|}{ Tabla 7.33 Hongos en dormitorio y atopia. Cálculo de OR } \\
\hline Cantidad de hongos & atópicos & no atópicos & \\
\hline Elevada (muy alta y alta) & 3 & 20 & 23 \\
\hline media y baja & 1 & 11 & 12 \\
\hline & 4 & 31 & 35 \\
\hline OR 1,65 & IC $0,15 / 17,8$ & X 0,17 & Pr 0,68 \\
\hline
\end{tabular}

Hiperreactividad y esporas fúngicas.

La hiperreactividad bronquial tiende a ser más frecuente en presencia de mayor cantidad de hongos en el aire interior y la OR es elevada pero el intervalo de confianza no es concluyente en cuanto a la repetibilidad de este resultado.

\begin{tabular}{|c|c|c|c|c|}
\hline \multicolumn{5}{|c|}{ Esporas fúngicas como riesgo de HRB } \\
\hline CANT HONGOS & alta & media & baja & Total \\
\hline Alta y muy alta & 6 & 5 & 12 & 23 \\
\hline media/baja & 0 & 3 & 10 & 13 \\
\hline TOTAL & 6 & 8 & 22 & 36 \\
\hline$x 24,23$ & & $\operatorname{Pr} 0,12$ & & \\
\hline
\end{tabular}

\begin{tabular}{|c|c|c|}
\hline \multicolumn{3}{|c|}{ Tabla 7.35 Esporas fúngicas como riesgo de HRB Odds Ratio } \\
\hline CANT HONGOS & alta/media & baja \\
\hline Alta y muy alta & 11 & 12 \\
\hline media/baja & 3 & 10 \\
\hline OR 3 & IC 0,66/14 & \\
\hline X2 2,14 & Pr 0,14 & \\
\hline
\end{tabular}




\section{Formaldehido}

En función de este estudio, para evaluar en conjunto las posibles fuentes de emisión de formaldehido en el aire interior doméstico, se elaboró un indicador que se expone en el capítulo de Material y Métodos.

Aplicando este puntaje de riesgo a los casos y controles en los que se pudo realizar la observación y encuesta domiciliaria, surge una diferencia estadísticamente significativa entre los diferentes niveles de exposición y un fuerte riesgo de asma en los niños expuestos, tanto si se realiza el cálculo sin contemplar la ventilación como cuando se ajusta por ella.

Tabla 7.36 Riesgo de asma por niveles de concentración potencial de formaldehido en aire de dormitorios en función de los emisores presentes

\begin{tabular}{|c|c|c|c|}
\hline $\begin{array}{c}\text { concentración de } \\
\text { formaldehido }\end{array}$ & casos & controles & Total \\
\hline alto & 56 & 47 & 103 \\
\hline bajo & 12 & 25 & 37 \\
\hline TOTAL & 68 & 72 & 140 \\
\hline OR: 2,5 & IC 95\%: $1,1 / 5,4$ & $\chi 2: 5,2$ & P: 0,02 \\
\hline
\end{tabular}

Diferencias significativas

Con propósito exploratorio se planteó una hipotética reducción o aumento de la concentración de formaldehido según la ventilación observada de los dormitorios.

Tabla 7.37 Corrección por ventilación en dormitorio

\begin{tabular}{|c|c|c|}
\hline ventilación adecuada & $\geq 4 \%$ de sup.hab & $\Sigma / 2$ \\
\hline sin ventilación & $<4 \%$ de sup.hab & $\Sigma \times 2$ \\
\hline
\end{tabular}

El resultado es idéntico al cálculo realizado sin tener en cuenta la potencial ventilación evaluada según la relación:

\begin{tabular}{|c|c|c|c|}
\hline \multicolumn{4}{|c|}{$\begin{array}{c}\text { Tabla } 7.38 \\
\text { Riesgo de asma por niveles de concentración de formaldehido en aire de } \\
\text { dormitorios. Ajuste por ventilación potencial }\end{array}$} \\
\hline RIESGO FORMALD CON VENT & casos & controles & Total \\
\hline alto & 56 & 47 & 103 \\
\hline bajo & 12 & 25 & 37 \\
\hline TOTAL & 68 & 72 & 140 \\
\hline OR: 2,5 & IC $95 \%: 1,1 / 5,4$ & $\chi 2: 5,2$ & P: 0,02 \\
\hline
\end{tabular}


Esta corrección podría estar afectada por las conductas de uso de la ventilación en los días fríos, ya que es posible que en algunos casos se abra para ventilar y en otros se mantenga totalmente cerrada la habitación.

También se comparó la OR según los antecedentes de atopia:

\begin{tabular}{|c|c|c|c|}
\hline \multicolumn{5}{|c|}{$\begin{array}{c}\text { Riesgo de asma por exposición al formaldehido según antecedentes atópicos y no } \\
\text { atópicos }\end{array}$} \\
\hline & \multicolumn{3}{|c|}{ no atópicos } \\
\hline FORMALDEHIDO & caso & control & Total \\
\hline alto & 20 & 23 & 43 \\
\hline bajo & 1 & 10 & 11 \\
\hline TOTAL & 21 & 33 & 54 \\
\hline OR 8,7 & IC $1 / 74$ & $\chi 2: 5,16$ & P: 0,02 \\
\hline & & atópicos & \\
\hline alto & 36 & 24 & 60 \\
\hline bajo & 11 & 15 & 26 \\
\hline TOTAL & 47 & 39 & 86 \\
\hline OR 2 & IC $0,8 / 5$ & $\chi 2: 2,3$ & P: 0,13 \\
\hline
\end{tabular}

\section{Severidad}

Por el contrario, si bien hay diferencias en cuanto a la distribución de la severidad, el cálculo de OR, que resulta por debajo de la unidad, no es estadísticamente significativo, tanto si se tiene en cuenta la ventilación o solamente los posibles emisores.

Tabla 7.39 Riesgo de severidad en los casos por exposición a formaldehido

\begin{tabular}{|c|c|c|c|c|c|}
\hline & \multicolumn{3}{|c|}{ severidad casos } & \multicolumn{2}{|l|}{ controles } \\
\hline Exposición & severa & moderada & leve & no & Total \\
\hline alta & 11 & 9 & 35 & 48 & 103 \\
\hline baja & 5 & 1 & 6 & 25 & 37 \\
\hline TOTAL & 16 & 10 & 41 & 72 & 140 \\
\hline$x 2: 6,8$ & & $P 0,078$ & & & \\
\hline
\end{tabular}

Diferencias significativas

Tabla 7.40 Riesgo de severidad en los casos por exposición a formaldehido

\begin{tabular}{|c|c|c|}
\hline Exposición & severa/moderada & leve \\
\hline alta & 20 & 35 \\
\hline baja & 6 & 6 \\
\hline OR: 0,57 & IC $95 \%: 0,16 / 2$ & $\chi 2: 0,77$ P: 0,38 \\
\hline
\end{tabular}

Diferencias no significativas 
Hiperreactividad bronquial y aire contaminado con formaldehido

La hiperirritabilidad bronquial (HRB) no aparece asociada a la exposición al formaldehido en este estudio.

\begin{tabular}{|c|c|c|c|c|}
\hline \multicolumn{5}{|c|}{ Tabla 7.41 Riesgo de HRB por exposición a formaldehido } \\
\hline & \multicolumn{4}{|c|}{ HRB } \\
\hline Exposición & alta & media & baja & Total \\
\hline alta & 21 & 31 & 51 & 103 \\
\hline baja & 9 & 8 & 20 & 37 \\
\hline TOTAL & 30 & 39 & 71 & 140 \\
\hline X2: 1,01 & & P: 0,60 & & \\
\hline
\end{tabular}

Diferencias no significativas

Tabla 7.42 Riesgo de HRB en los casos por exposición a formaldehido. OR.

\begin{tabular}{|c|c|c|c|}
\hline & \multicolumn{3}{|c|}{ HRB } \\
\hline Exposición & alta/media & baja & total \\
\hline alta & 52 & 51 & 103 \\
\hline baja & 17 & 20 & 31 \\
\hline total & 69 & 71 & 140 \\
\hline OR: 1,2 & IC $95 \%: 0,56 / 2,54$ & $\chi 2: 0,22$ P: 0,63 & \\
\hline
\end{tabular}

Diferencias no significativas

Efecto particular de las tablas MDF

Si solo se evaluara el formaldehido a partir de presencia de tablas de madera reconstituida los resultados son poco concluyentes:

\begin{tabular}{|c|c|c|c|}
\hline \multicolumn{1}{|c|}{ Tabla 7.43 Exposición a tablas emisoras de formaldehido según casos y controles } \\
\hline & casos & controles & totales \\
\hline expuestos & 24 & 20 & 44 \\
\hline no expuestos & 39 & 46 & 85 \\
\hline total & 63 & 66 & 129 \\
\hline OR 1.42 IC 95\% $0.64<O R<3.14$ & $\dot{X}^{2}=0.87$ & P: 0,35 & \\
\hline
\end{tabular}


Impacto sanitario.

El riesgo atribuible a la exposición con formaldehido en el hogar es del 10\%, calculado en base a la incidencia acumulada de asma en los primeros 5 años de vida, aplicando la fórmula propuesta por Gordis ${ }^{300}$.

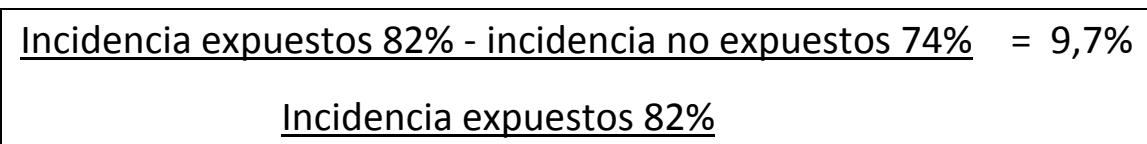

Si se lograra reducir fuertemente la exposición a formaldehido podría disminuir hasta un $10 \%$ la incidencia de casos en los primeros 5 años de vida.

La prioridad en la acción sanitaria, tanto educativa como de promoción y facilitación del mejoramiento del ambiente doméstico, debería enfocarse en los dispositivos para calefacción o cocina que emiten kerosene o gas sin un salida tipo tiro balanceado que sea eficiente. 


\section{Uso de insecticidas}

Predomina el uso de dispositivos emisores tipo aerosol (45\%) con un porcentaje algo superior en las familias de los casos que en la de los controles. Es posible que estos dispositivos generen mayor concentración de múltiples irritantes y alérgenos, lo probablemente suceda también en el caso de los espirales.

\begin{tabular}{|c|c|c|c|}
\hline TIPO & casos & controles & Total \\
\hline Aerosol & 34 & 29 & 63 \\
\hline Row\% & $53,97 \%$ & $46,03 \%$ & $100,00 \%$ \\
\hline Col\% & $50,00 \%$ & $40,28 \%$ & $45,00 \%$ \\
\hline Eléctricos & 12 & 11 & 23 \\
\hline Row\% & $52,17 \%$ & $47,83 \%$ & $100,00 \%$ \\
\hline Col\% & $17,65 \%$ & $15,28 \%$ & $16,43 \%$ \\
\hline Espiral & 6 & 8 & 14 \\
\hline Row\% & $42,86 \%$ & $57,14 \%$ & $100,00 \%$ \\
\hline Col\% & $8,82 \%$ & $11,11 \%$ & $10,00 \%$ \\
\hline Otros & 2 & 2 & 4 \\
\hline Row\% & $50,00 \%$ & $50,00 \%$ & $100,00 \%$ \\
\hline Col\% & $2,94 \%$ & $2,78 \%$ & $2,86 \%$ \\
\hline No usan & 14 & 22 & 36 \\
\hline Row\% & $38,89 \%$ & $61,11 \%$ & $100,00 \%$ \\
\hline Col\% & $20,59 \%$ & $30,56 \%$ & $25,71 \%$ \\
\hline TOTAL & 68 & 72 & 140 \\
\hline Row\% & $48,57 \%$ & $51,43 \%$ & $100,00 \%$ \\
\hline$\chi 2: 2,4$ & & $P: 0,66$ & \\
\hline
\end{tabular}

Se calcula la Odds Ratio para los dispositivos considerados de riesgo (aerosoles, espirales y eléctricos) y no se tienen en cuenta para este cálculo los 4 registros de "otros".

Tabla 7.45 Dispositivos para emitir insecticidas en el dormitorio como factor de riesgo

\begin{tabular}{|c|c|c|c|}
\hline emisores & casos & controles & total \\
\hline expuestos & 52 & 48 & 100 \\
\hline No expuestos & 14 & 22 & 36 \\
\hline total & 66 & 70 & 136 \\
\hline OR: 1,7 & IC $95 \%: 0,7 / 3,7$ & $\chi 2: 1,8$ & P: 0,17 \\
\hline
\end{tabular}


Si bien se insinúa un riesgo débil, no hay diferencias significativas. Tampoco hay diferencias en la frecuencia de uso diario y semanal ni en el estacional.

Tabla 7.46 Distribución del uso en el dormitorio durante el día

\begin{tabular}{|l|c|c|c|}
\hline \multicolumn{1}{|c|}{ USO EN EL DÍA } & casos & controles & Total \\
\hline Mañana & 6 & 3 & 9 \\
\hline Mañana - Tarde & 1 & 1 & 2 \\
\hline Tarde & 11 & 12 & 23 \\
\hline Tarde - Noche & 2 & 1 & 3 \\
\hline Noche & 30 & 29 & 59 \\
\hline Todo el día & 4 & 2 & 6 \\
\hline no usa & 6 & 16 & 22 \\
\hline TOTAL & 60 & 64 & 124 \\
\hline \multicolumn{1}{|c|}{$\chi 2: 6,48$} & & P: 0,37 & \\
\hline
\end{tabular}

No hay diferencias significativas

El $60 \%$ los usa en el dormitorio durante la noche, que probablemente sea el momento del día con mayor permanencia del niño en ese lugar.

Tabla 7.47 Periodicidad del uso de insecticidas como riesgo de asma

\begin{tabular}{|l|c|c|c|}
\hline \multicolumn{1}{|c|}{ PERIODICIDAD USO } & casos & controles & Total \\
\hline 1 vez por semana & 1 & 3 & 4 \\
\hline 2 veces por semana & 5 & 2 & 7 \\
\hline 3 veces por semana & 11 & 13 & 24 \\
\hline Más de 3 veces por semana & 37 & 31 & 68 \\
\hline no usa & 14 & 23 & 37 \\
\hline TOTAL & 68 & 72 & 140 \\
\hline \multicolumn{1}{|c|}{$\chi 2: 5$} & $\mathrm{df:} 4$ & P: 0,28 & \\
\hline
\end{tabular}

Tabla 7.48 Periodicidad del uso de insecticidas como riesgo de asma

\begin{tabular}{|c|c|c|c|}
\hline PERIODICIDAD & casos & controles & Total \\
\hline 3 o más veces por semana & 48 & 44 & 92 \\
\hline hasta 2 veces por semana & 20 & 28 & 48 \\
\hline TOTAL & 68 & 72 & 140 \\
\hline OR 1,52 & IC $0,75 / 3$ & X2 1,39 & P 0,23 \\
\hline
\end{tabular}




\begin{tabular}{|c|c|c|c|}
\hline Tabla 7.49 Períodc & so de insect & las según es & del año \\
\hline USO & casos & controles & Total \\
\hline Primavera - Verano & 6 & 3 & 9 \\
\hline Row\% & $66,67 \%$ & $33,33 \%$ & $100,00 \%$ \\
\hline Col\% & $8,82 \%$ & $4,17 \%$ & $6,43 \%$ \\
\hline Verano & 40 & 36 & 76 \\
\hline Row\% & $52,63 \%$ & $47,37 \%$ & $100,00 \%$ \\
\hline Col\% & $58,82 \%$ & $50,00 \%$ & $54,29 \%$ \\
\hline Todas & 8 & 11 & 19 \\
\hline Row\% & $42,11 \%$ & $57,89 \%$ & $100,00 \%$ \\
\hline Col\% & $11,76 \%$ & $15,28 \%$ & $13,57 \%$ \\
\hline no usa & 14 & 22 & 36 \\
\hline Row\% & $38,89 \%$ & $61,11 \%$ & $100,00 \%$ \\
\hline Col\% & $20,59 \%$ & $30,56 \%$ & $25,71 \%$ \\
\hline TOTAL & 68 & 72 & 140 \\
\hline Row\% & $48,57 \%$ & $51,43 \%$ & $100,00 \%$ \\
\hline$x 2: 3,35$ & & P 0,34 & \\
\hline
\end{tabular}

Aplicando el puntaje de riesgo elaborado para esta Tesis, que unifica en un solo indicador uso, frecuencia y estacionalidad, (ver en Cap. 4 Material y métodos), los resultados no muestran diferencias significativas y la odds ratio es cercana a la unidad.

\begin{tabular}{|l|c|c|c|c|}
\hline \multicolumn{5}{|c|}{ Tabla 7.50 Riesgo de asma según utilización de insecticidas en el dormitorio } \\
\hline CUARTILES & Puntaje de riesgo. Puntos de corte & casos & controles & Total \\
\hline cuarto & 7 y 8 & 10 & 9 & 19 \\
\hline tercero & 6 & 24 & 20 & 44 \\
\hline segundo & 1 a 5 & 13 & 18 & 31 \\
\hline primero & 0 & 21 & 25 & 46 \\
\hline TOTAL & & 68 & 72 & 140 \\
\hline & & $\chi 2: 1,45$ & P: 0,69 & \\
\hline
\end{tabular}

Tabla 7.51 Riesgo de asma según utilización de insecticidas en el dormitorio. OR

\begin{tabular}{|c|c|c|c|}
\hline riesgo & casos & controles & totales \\
\hline elevado & 34 & 29 & 63 \\
\hline bajo & 34 & 43 & 77 \\
\hline totales & 68 & 72 & 140 \\
\hline OR: 1,48 & IC $95 \%:$ & $0,7-2,9$ & X2: $1,33 \quad$ P: 0,25 \\
\hline
\end{tabular}




\begin{tabular}{|l|c|c|r|}
\hline \multicolumn{5}{|c|}{ Tabla 7.52. Riesgo de asma según utilización de insecticidas en el dormitorio. } \\
OR de cuartiles extremos
\end{tabular}

Severidad e hiperreactividad bronquial y exposición a insecticidas en el hogar.

La severidad de los casos no parece asociarse al uso de insecticidas.

Tabla 7.53 Relación entre cuartiles de emisión de insecticidas y severidad del asma

\begin{tabular}{|c|c|c|c|c|c|}
\hline CUART INSEC & leve & moderada & severa & no & Total \\
\hline primer & 11 & 3 & 3 & 20 & 37 \\
\hline Row\% & $29,73 \%$ & $8,11 \%$ & $8,11 \%$ & $54,05 \%$ & $100,00 \%$ \\
\hline Col\% & $27,50 \%$ & $30,00 \%$ & $18,75 \%$ & $27,40 \%$ & $26,62 \%$ \\
\hline segundo & 13 & 4 & 3 & 23 & 43 \\
\hline Row\% & $30,23 \%$ & $9,30 \%$ & $6,98 \%$ & $53,49 \%$ & $100,00 \%$ \\
\hline Col\% & $32,50 \%$ & $40,00 \%$ & $18,75 \%$ & $31,51 \%$ & $30,94 \%$ \\
\hline tercer & 10 & 2 & 4 & 22 & 38 \\
\hline Row\% & $26,32 \%$ & $5,26 \%$ & $10,53 \%$ & $57,89 \%$ & $100,00 \%$ \\
\hline Col\% & $25,00 \%$ & $20,00 \%$ & $25,00 \%$ & $30,14 \%$ & $27,34 \%$ \\
\hline cuarto & 6 & 1 & 6 & 8 & 21 \\
\hline Row\% & $28,57 \%$ & $4,76 \%$ & $28,57 \%$ & $38,10 \%$ & $100,00 \%$ \\
\hline Col\% & $15,00 \%$ & $10,00 \%$ & $37,50 \%$ & $10,96 \%$ & $15,11 \%$ \\
\hline TOTAL & 40 & 10 & 16 & 73 & 139 \\
\hline Row\% & $28,78 \%$ & $7,19 \%$ & $11,51 \%$ & $52,52 \%$ & $100,00 \%$ \\
\hline Col\% & $100,00 \%$ & $100,00 \%$ & $100,00 \%$ & $100,00 \%$ & $100,00 \%$ \\
\hline X2: 8,3494 & & $P: 0,4994$ & & & \\
\hline
\end{tabular}

Por el contrario, el riesgo de hiperreactividad bronquial parece aumentado sobre todo si se comparan los dos cuartiles de mayor puntaje con los dos menores: 


\begin{tabular}{|c|c|c|c|c|}
\hline Tabla 7.54 & Relación entı & emisión de & ecticidas & $R B$ \\
\hline CUART INSEC & baja & media & alta & Total \\
\hline primer & 22 & 9 & 6 & 37 \\
\hline Row\% & $59,46 \%$ & $24,32 \%$ & $16,22 \%$ & $100,00 \%$ \\
\hline Col\% & $30,99 \%$ & $23,08 \%$ & $20,69 \%$ & $26,62 \%$ \\
\hline segundo & 21 & 17 & 5 & 43 \\
\hline Row\% & $48,84 \%$ & $39,53 \%$ & $11,63 \%$ & $100,00 \%$ \\
\hline Col\% & $29,58 \%$ & $43,59 \%$ & $17,24 \%$ & $30,94 \%$ \\
\hline tercer & 20 & 8 & 10 & 38 \\
\hline Row\% & $52,63 \%$ & $21,05 \%$ & $26,32 \%$ & $100,00 \%$ \\
\hline Col\% & $28,17 \%$ & $20,51 \%$ & $34,48 \%$ & $27,34 \%$ \\
\hline cuarto & 8 & 5 & 8 & 21 \\
\hline Row\% & $38,10 \%$ & $23,81 \%$ & $38,10 \%$ & $100,00 \%$ \\
\hline Col\% & $11,27 \%$ & $12,82 \%$ & $27,59 \%$ & $15,11 \%$ \\
\hline TOTAL & 71 & 39 & 29 & 139 \\
\hline Row\% & $51,08 \%$ & $28,06 \%$ & $20,86 \%$ & $100,00 \%$ \\
\hline Col\% & $100,00 \%$ & $100,00 \%$ & $100,00 \%$ & $100,00 \%$ \\
\hline X2: 9,9355 & P: 0,127 & & & \\
\hline
\end{tabular}

\begin{tabular}{|l|c|c|c|}
\hline \multicolumn{4}{|c|}{$\begin{array}{c}\text { Tabla 7.55 Puntaje de insecticidas e Hiperreactividad bronquial. OR de } \\
\text { exposición muy alta }\end{array}$} \\
\hline & \multicolumn{3}{|c|}{ HRB } \\
\hline nivel riesgo insecticidas & alta & baja & Total \\
\hline Cuartil 4 muy alto & 8 & 8 & 16 \\
\hline Cuartil 1 bajo & 6 & 22 & 28 \\
\hline TOTAL & 14 & 30 & 44 \\
\hline \multicolumn{1}{|c|}{ OR 3.67 } & IC $0,97 / 13$ & $\chi^{2}: 3,8$ & P 0,05 \\
\hline
\end{tabular}

\begin{tabular}{|c|c|c|c|}
\hline $\begin{array}{c}\text { Tabla 7.56 Puntaje de insecticidas e Hiperreactividad bronquial. OR de } \\
\text { exposición muy alta y alta }\end{array}$ \\
\hline & \multicolumn{3}{|c|}{ HRB } \\
\hline nivel riesgo insecticidas & alta & baja & Total \\
\hline Cuartil 4 y 3 muy alto y alto & 18 & 28 & 46 \\
\hline Cuartil 2 y 1 medio y bajo & 11 & 43 & 54 \\
\hline TOTAL & 29 & 71 & 100 \\
\hline \multicolumn{1}{|c|}{ OR 2,5 } & IC $1,03 / 13$ & $\chi^{2}: 4,2$ & P 0,04 \\
\hline
\end{tabular}

No se observa un patrón de uso claramente diferente entre los casos y controles tanto en la consideración de la mayor utilización (factor de riesgo) como de una 
conducta preventiva que pudieran seguir en las familias de los casos. Por ejemplo no se asocia en las familias de atópicos con el uso de insecticidas en forma reducida.

\begin{tabular}{|c|c|c|r|r|}
\hline \multicolumn{5}{|c|}{ Tabla 7.57 Conducta de uso de insecticidas en familias de atópicos } \\
\hline & \multicolumn{2}{|c|}{ nivel riesgo exposición a insecticidas } \\
\hline \multicolumn{2}{|c|}{ ATÓPICOS } & bajo & alto/medio & Total \\
\hline si & 8 & 22 & 102 \\
\hline \multicolumn{2}{|c|}{ no } & 35 & 75 & 132 \\
\hline TOTAL & $\chi^{2}: 0,0005$ & 97 & P: 0,98 & \\
\hline OR: 1,01 & IC $0,4 / 2,5$ & & & \\
\hline
\end{tabular}

La fracción de riesgo atribuible en base a la incidencia acumulada durante los 5 primeros años de vida:

\section{Tabla 58 Incidencia acumulada y RR de asma y exposición a insecticidas}

\begin{tabular}{|c|c|c|c|}
\hline & IC Asma (5 años) & controles & totales \\
\hline expuestos & 80 & 24 & 104 \\
\hline No expuestos & 28 & 8 & 36 \\
\hline totales & 108 & 32 & 140 \\
\hline RR: 0,99 & IC 95\%: 0,80/1,21 & & \\
\hline$\chi^{2}$ & 0,01 & $\operatorname{Pr}<\chi^{2}$ & 0,92 \\
\hline
\end{tabular}

Para la incidencia acumulada (IC) de 5 años no hay riesgo relativo en la exposición a los insecticidas, dado que es prácticamente el valor de indiferencia $(0,99)$. No puede atribuirse un riesgo entre los asmáticos expuestos ya que la incidencia es similar entre los expuestos y los no expuestos, o ligeramente superior en todo caso.

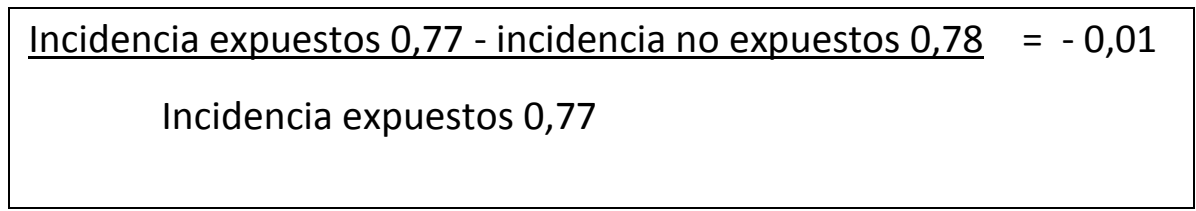

La exposición alta a insecticidas en el dormitorio no parece asociarse al asma pero aumentaría el riesgo de hiperirritabilidad bronquial. 


\section{Tipo de calefacción}

Puede destacarse que dos tercios de los aparatos eléctricos utilizados se dieron en los casos y que el kerosene por el contrario predominó entre los controles (3/4). Son 8 las familias que usan sistemas de calefacción con riesgo de emisión de contaminantes, distribuidas en forma aproximadamente pareja entre los casos (3) y los controles (4).

No se hallaron diferencias significativas para la evaluación del riesgo entre los aparatos emisores de COV, partículas y otros irritantes respiratorios con los no emisores.

\begin{tabular}{|c|c|c|c|}
\hline \multicolumn{4}{|c|}{$\begin{array}{c}\text { Tabla 7.59 Frecuencia de tipos de calefacción en el } \\
\text { dormitorio de los niños }\end{array}$} \\
\hline TIPOCALEFACCIÓN & casos & controles & Total \\
\hline Eléctrica & 17 & 8 & 25 \\
\hline Row\% & $68,00 \%$ & $32,00 \%$ & $100,00 \%$ \\
\hline Col\% & $25,00 \%$ & $11,11 \%$ & $17,86 \%$ \\
\hline Gas con tiro balanceado & 2 & 2 & 4 \\
\hline Row\% & $50,00 \%$ & $50,00 \%$ & $100,00 \%$ \\
\hline Col\% & $2,94 \%$ & $2,78 \%$ & $2,86 \%$ \\
\hline No usan & 44 & 57 & 101 \\
\hline Row\% & $43,56 \%$ & $56,44 \%$ & $100,00 \%$ \\
\hline Col\% & $64,71 \%$ & $79,17 \%$ & $72,14 \%$ \\
\hline Gas sin tiro balanceado & 2 & 0 & 2 \\
\hline Row\% & $100,00 \%$ & $0,00 \%$ & $100,00 \%$ \\
\hline Col\% & $2,94 \%$ & $0,00 \%$ & $1,43 \%$ \\
\hline kerosene & 1 & 3 & 4 \\
\hline Row\% & $25,00 \%$ & $75,00 \%$ & $100,00 \%$ \\
\hline Col\% & $1,47 \%$ & $4,17 \%$ & $2,86 \%$ \\
\hline salamandra & 0 & 1 & 1 \\
\hline Row\% & $0,00 \%$ & $100,00 \%$ & $100,00 \%$ \\
\hline Col\% & $0,00 \%$ & $1,39 \%$ & $0,71 \%$ \\
\hline Otros & 2 & 1 & 3 \\
\hline Row\% & $66,67 \%$ & $33,33 \%$ & $100,00 \%$ \\
\hline Col\% & $2,94 \%$ & $1,39 \%$ & $2,14 \%$ \\
\hline TOTAL & 68 & 72 & 140 \\
\hline Row\% & $48,57 \%$ & $51,43 \%$ & $100,00 \%$ \\
\hline$\chi 2: 9,1398$ & P: 0,1659 & $\begin{array}{r}\text { An expected va } \\
\text { may not }\end{array}$ & $\begin{array}{l}\text { 5. Chi-squared } \\
\text { lid test. }\end{array}$ \\
\hline
\end{tabular}

Tabla 7.60 . Frecuencia de tipos de calefacción en la vivienda de los niños

\begin{tabular}{|l|l|l|l|}
\hline TIPO CALEFACCIÓN VIVIENDA & casos & controles & Total \\
\hline
\end{tabular}




\begin{tabular}{|c|c|c|c|}
\hline Eléctrico & 15 & 12 & 27 \\
\hline Row\% & $55,56 \%$ & $44,44 \%$ & $100,00 \%$ \\
\hline Col\% & $22,06 \%$ & $16,67 \%$ & $19,29 \%$ \\
\hline Gas con tiro balanceado & 3 & 6 & 9 \\
\hline Row\% & $33,33 \%$ & $66,67 \%$ & $100,00 \%$ \\
\hline Col\% & $4,41 \%$ & $8,33 \%$ & $6,43 \%$ \\
\hline no & 28 & 34 & 62 \\
\hline Row\% & $45,16 \%$ & $54,84 \%$ & $100,00 \%$ \\
\hline Col\% & $41,18 \%$ & $47,22 \%$ & $44,29 \%$ \\
\hline Gas sin tiro balanceado & 6 & 2 & 8 \\
\hline Row\% & $75,00 \%$ & $25,00 \%$ & $100,00 \%$ \\
\hline Col\% & $8,82 \%$ & $2,78 \%$ & $5,71 \%$ \\
\hline Kerosene & 4 & 5 & 9 \\
\hline Row\% & $44,44 \%$ & $55,56 \%$ & $100,00 \%$ \\
\hline Col\% & $5,88 \%$ & $6,94 \%$ & $6,43 \%$ \\
\hline Salamandra & 6 & 5 & 11 \\
\hline Row\% & $54,55 \%$ & $45,45 \%$ & $100,00 \%$ \\
\hline Col\% & $8,82 \%$ & $6,94 \%$ & $7,86 \%$ \\
\hline Brasero & 5 & 6 & 11 \\
\hline Row\% & $45,45 \%$ & $54,55 \%$ & $100,00 \%$ \\
\hline Col\% & $7,35 \%$ & $8,33 \%$ & $7,86 \%$ \\
\hline Otros & 1 & 2 & 3 \\
\hline Row\% & $33,33 \%$ & $66,67 \%$ & $100,00 \%$ \\
\hline Col\% & $1,47 \%$ & $2,78 \%$ & $2,14 \%$ \\
\hline TOTAL & 68 & 72 & 140 \\
\hline Row\% & $48,57 \%$ & $51,43 \%$ & $100,00 \%$ \\
\hline Col\% & $100,00 \%$ & $100,00 \%$ & $100,00 \%$ \\
\hline$x 2: 4,4296$ & $P: 0,73$ & \multicolumn{2}{|c|}{$\begin{array}{l}\text { An expected value is }<5 \text {. Chi-squared } \\
\text { may not be a valid test. }\end{array}$} \\
\hline
\end{tabular}

Tabla 7.61 Cálculo de riesgo según potencialidad emisora de los sistemas de calefacción en el dormitorio.

\begin{tabular}{|l|c|c|c|c|c|c|}
\hline \multicolumn{1}{|c|}{ sistemas de calefacción } & casos & controles & OR & IC 95\% & $\chi 2$ & P \\
\hline Emisores & 3 & 4 & 0,8 & $0,17 / 3,7$ & 0,08 & \multirow{2}{*}{0,77} \\
\hline No emisores & 63 & 67 & & & \\
\hline
\end{tabular}

Tabla 7.62 Cálculo de riesgo según potencialidad emisora de los sistemas de calefacción en la vivienda.

\begin{tabular}{|l|c|c|c|c|c|c|}
\hline \multicolumn{1}{|c|}{ sistemas de calefacción } & casos & controles & OR & IC 95\% & $\chi 2$ & P \\
\hline Emisores & 21 & 18 & \multirow{2}{*}{1,3} & \multirow{2}{*}{$0,6 / 2,7$} & \multirow{2}{*}{0,5} & \multirow{2}{*}{0,46} \\
\hline No emisores & 46 & 52 & & & \\
\hline
\end{tabular}




\begin{tabular}{|c|c|c|c|}
\hline $\begin{array}{l}\text { CALEFACCIÓN CAT POR } \\
\text { CUARTILES }\end{array}$ & casos & controles & Total \\
\hline 1 y 2 & 40 & 40 & 80 \\
\hline Row\% & $50,00 \%$ & $50,00 \%$ & $100,00 \%$ \\
\hline Col\% & $62,50 \%$ & $64,52 \%$ & $63,49 \%$ \\
\hline 3 & 8 & 6 & 14 \\
\hline Row\% & $57,14 \%$ & $42,86 \%$ & $100,00 \%$ \\
\hline Col\% & $12,50 \%$ & $9,68 \%$ & $11,11 \%$ \\
\hline 4 & 16 & 16 & 32 \\
\hline Row\% & $50,00 \%$ & $50,00 \%$ & $100,00 \%$ \\
\hline Col\% & $25,00 \%$ & $25,81 \%$ & $25,40 \%$ \\
\hline TOTAL & 64 & 62 & 126 \\
\hline Row\% & $50,79 \%$ & $49,21 \%$ & $100,00 \%$ \\
\hline Col\% & $100,00 \%$ & $100,00 \%$ & $100,00 \%$ \\
\hline$\chi 2: 0,254$ & & $P: 0,88$ & \\
\hline
\end{tabular}

La distribución entre casos y controles es prácticamente idéntica tanto si se clasifican según la potencialidad emisora planteada o en función de los cuartiles de la emisión de formaldehido en ppm. La OR entre los dos cuartiles superiores con los dos inferiores es 1,09 (IC 95\% 0,5/2,25) con una prueba de $\chi^{2}$ no significativa. Ocurre lo mismo al solo computar el cuartilo 4 con el 1 .

No parece asociarse la severidad con los tipos de calefacción. En todo caso es posible que se manifieste una conducta preventiva en el uso familiar ya que el $87 \%$ de los casos severos no usan sistemas emisores de contaminantes para la calefacción de los dormitorios. OR y $\chi^{2}$ no significativas.

\begin{tabular}{|c|c|c|c|c|}
\hline $\begin{array}{l}\text { CALEFACCIÓN CAT POR } \\
\text { CUARTIL }\end{array}$ & severa & moderada & leve & Total \\
\hline 4 & 2 & 2 & 12 & 16 \\
\hline Col\% & $13,33 \%$ & $22,22 \%$ & $30,77 \%$ & $25,40 \%$ \\
\hline 3 & 0 & 1 & 6 & 7 \\
\hline Col\% & $0,00 \%$ & $11,11 \%$ & $15,38 \%$ & $11,11 \%$ \\
\hline 1 y 2 & 13 & 6 & 21 & 40 \\
\hline Col\% & $86,67 \%$ & $66,67 \%$ & $53,85 \%$ & $63,49 \%$ \\
\hline TOTAL & 15 & 9 & 39 & 63 \\
\hline
\end{tabular}


Tampoco aparecen diferencias significativas para la distribución de la hiperreactividad bronquial, aún explorando diversas formas de agrupar los cuartiles o los niveles de HRB.

\begin{tabular}{|c|c|c|c|c|}
\hline \multicolumn{5}{|c|}{$\begin{array}{c}\text { calefacción como factor de riesgo de HRB, según cuartiles del puntaje por } \\
\text { dispositivo }\end{array}$} \\
\hline $\begin{array}{l}\text { CALEFACCIÓN CAT POR } \\
\text { CUARTIL }\end{array}$ & alta & media & baja & Total \\
\hline 4 & 5 & 13 & 14 & 32 \\
\hline Row\% & $15,63 \%$ & $40,63 \%$ & $43,75 \%$ & $100,00 \%$ \\
\hline Col\% & $17,86 \%$ & $37,14 \%$ & $22,22 \%$ & $25,40 \%$ \\
\hline 3 & 1 & 3 & 10 & 14 \\
\hline Row\% & $7,14 \%$ & $21,43 \%$ & $71,43 \%$ & $100,00 \%$ \\
\hline Col\% & $3,57 \%$ & $8,57 \%$ & $15,87 \%$ & $11,11 \%$ \\
\hline 1 y 2 & 22 & 19 & 39 & 80 \\
\hline Row\% & $27,50 \%$ & $23,75 \%$ & $48,75 \%$ & $100,00 \%$ \\
\hline Col\% & $78,57 \%$ & $54,29 \%$ & $61,90 \%$ & $63,49 \%$ \\
\hline TOTAL & 28 & 35 & 63 & 126 \\
\hline Row\% & $22,22 \%$ & $27,78 \%$ & $50,00 \%$ & $100,00 \%$ \\
\hline Col\% & $100,00 \%$ & $100,00 \%$ & $100,00 \%$ & $100,00 \%$ \\
\hline$x 2: 7,1946$ & $P: 0,126$ & An expected va & $\begin{array}{l}\text { is }<5 \text {. Chi-so } \\
\text { a valid test. }\end{array}$ & may not be \\
\hline
\end{tabular}

\begin{tabular}{|l|l|l|}
\hline \multicolumn{2}{|c|}{ Estimación de OR para HRB según diferentes agrupamientos de la distribución } \\
\hline cuartil 4/cuartiles 1y 2 & para HRB alta vs. baja & \\
\hline OR: 0,6 IC $95 \% 0,2 / 1,99$ & $\chi 2: 0,6$ & P: 0,43 \\
\hline & & \\
\hline cuartil 4/cuartiles 1y 2 & para HRB alta/media vs. baja & \\
\hline OR: 1,2 IC 95\% 0,5/2,8 & $\chi 2: 0,23$ & P: 0,63 \\
\hline & & \\
\hline cuartil 4/cuartiles 1y 2 & para HRB alta vs media/baja & \\
\hline OR: 0,5 IC $95 \% 0,16 / 1,42$ & $\chi 2: 1,76$ & P: 0,18 \\
\hline
\end{tabular}


Otros factores inespecíficos del aire interior.

Mediante visitas a los domicilios de casos y controles, se logró relevar una serie de datos sobre elementos que podrían vincularse con la calidad del aire interior (ver tablas de operacionalización de variables en el capítulo 4). Se enfocó principalmente el dormitorio del niño, aunque también se tomaron datos generales de la vivienda en cuanto a sistema de calefacción y vegetales en el interior, y del entorno próximo como talleres y depósitos lindantes, percepción de partículas en suspensión y quema de residuos.

Debe tenerse en cuenta que en muchas familias donde hay antecedentes alérgicos de los padres, se toman algunas medidas de control ambiental, entre las que pueden destacarse el menor uso de alfombras ${ }^{301}$, la disminución del tabaquismo en el hogar y de la presencia de gatos. En nuestra experiencia clínica también se observa la tendencia a disminuir el uso de insecticidas.

En la tabla 7.64 se exponen los principales factores y su distribución en los casos y controles, calculando la Odds Ratio en las dicotómicas.

\begin{tabular}{|c|c|c|c|c|c|c|c|}
\hline \multicolumn{8}{|c|}{ Otros factores de riesgo inespecíficos en el dormitorio } \\
\hline factor & clases & casos & controles & OR & IC 95\% & $\chi 2$ & $\operatorname{Pr}<\chi^{2}$ \\
\hline \multirow{2}{*}{ alfombra } & si & 10 & 18 & \multirow{2}{*}{0,49} & \multirow[t]{2}{*}{$0,2 / 1,17$} & \multirow{2}{*}{2,65} & \multirow{2}{*}{0,10} \\
\hline & no & 48 & 42 & & & & \\
\hline \multirow[b]{2}{*}{ ventilación } & inadecuada & 11 & 10 & \multirow[b]{2}{*}{1,12} & \multirow[b]{2}{*}{$0,43 / 2,90$} & \multirow[b]{2}{*}{0,06} & \multirow[b]{2}{*}{0,80} \\
\hline & adecuada & 46 & 47 & & & & \\
\hline \multirow{2}{*}{ manchas de humedad } & si & 26 & 21 & \multirow[b]{2}{*}{0,66} & \multirow{2}{*}{$\begin{array}{l}0,31 \\
/ 1,39\end{array}$} & \multirow{2}{*}{1,21} & \multirow{2}{*}{0,27} \\
\hline & no & 31 & 38 & & & & \\
\hline \multirow{2}{*}{ aire acondicionado } & $\mathrm{Si}$ & 2 & 6 & \multirow[b]{2}{*}{0.32} & \multirow[b]{2}{*}{$0,06 / 1,66$} & \multirow{2}{*}{2} & \multirow{2}{*}{0,16} \\
\hline & No & 55 & 53 & & & & \\
\hline \multirow{2}{*}{$\begin{array}{l}\text { método de limpieza } \\
\text { dormitorio }\end{array}$} & $\begin{array}{l}\text { Escoba, plumero y } \\
\text { aspiradora común }\end{array}$ & 51 & 46 & 2,4 & $0,8 / 6,8$ & \multirow[t]{2}{*}{2,8} & \multirow[t]{2}{*}{0,09} \\
\hline & trapo húmedo & 6 & 13 & & & & \\
\hline \multirow{2}{*}{$\begin{array}{l}\text { desodorantes } \\
\text { ambientales }\end{array}$} & Sahumerios y aerosoles & 28 & 27 & \multirow[b]{2}{*}{1,14} & \multirow[b]{2}{*}{$0,55 / 2,35$} & \multirow{2}{*}{0,13} & \multirow{2}{*}{0,72} \\
\hline & No usan u otros & 30 & 33 & & & & \\
\hline \multirow{2}{*}{$\begin{array}{l}\text { Quema de podas en el } \\
\text { entorno del domicilio }\end{array}$} & Expuesto & 39 & 32 & \multirow{2}{*}{1,89} & \multirow{2}{*}{$0,89 / 4$} & \multirow{2}{*}{2,79} & \multirow{2}{*}{0,09} \\
\hline & No expuesto & 18 & 28 & & & & \\
\hline \multirow{2}{*}{$\begin{array}{l}\text { Partículas en } \\
\text { suspensión en las } \\
\text { cercanías de la } \\
\text { vivienda }\end{array}$} & Expuesto & 36 & 39 & \multirow{2}{*}{0,92} & $0,43 /$ & & \\
\hline & No expuesto & 21 & 21 & & & 0,04 & 0,83 \\
\hline
\end{tabular}




\begin{tabular}{|c|c|c|c|c|c|c|c|}
\hline \multicolumn{8}{|c|}{ everidad de los casos. Otros factores de riesgo inespecíficos en el dormitorio } \\
\hline factor & clases & $\begin{array}{c}\text { severa / } \\
\text { moderada }\end{array}$ & leve & OR & IC $95 \%$ & $\chi^{2}$ & $\operatorname{Pr}<\chi^{2}$ \\
\hline \multirow{2}{*}{ alfombra } & si & 2 & 8 & \multirow{2}{*}{0,38} & \multirow{2}{*}{$0,07 / 1,99$} & \multirow{2}{*}{1,37} & \multirow{2}{*}{0,24} \\
\hline & no & 19 & 29 & & & & \\
\hline \multirow{2}{*}{ ventilación } & inadecuada & 3 & 8 & \multirow{2}{*}{0,64} & \multirow{2}{*}{$0,15 / 2,74$} & \multirow{2}{*}{0,36} & \multirow{2}{*}{0,54} \\
\hline & adecuada & 17 & 29 & & & & \\
\hline
\end{tabular}

\begin{tabular}{|c|c|c|c|c|c|c|c|}
\hline \multicolumn{8}{|c|}{ Hiperreactividad bronquial. Otros factores de riesgo inespecíficos en el dormitorio } \\
\hline factor & clases & $\begin{array}{c}\text { severa / } \\
\text { moderada }\end{array}$ & leve & OR & IC 95\% & $x^{2}$ & $\operatorname{Pr}<x_{2}$ \\
\hline \multirow{2}{*}{ alfombra } & si & 11 & 17 & \multirow{2}{*}{0,43} & \multirow{2}{*}{$0,18 / 1,02$} & \multirow{2}{*}{3,7} & \multirow{2}{*}{0,24} \\
\hline & no & 54 & 36 & & & & \\
\hline \multirow{2}{*}{ ventilación } & inadecuada & 14 & 7 & \multirow{2}{*}{1,87} & \multirow{2}{*}{$0,7 / 5$} & \multirow{2}{*}{1,56} & \multirow{2}{*}{0,21} \\
\hline & adecuada & 48 & 45 & & & & \\
\hline
\end{tabular}

\section{Alfombras}

Las familias de atópicos tienen una fuerte tendencia a evitar el uso de alfombras en el dormitorio de los niños.

\begin{tabular}{|c|c|c|c|}
\hline \multicolumn{5}{|c|}{ Tabla 7.67 Evitación de alfombra en dormitorio según antecedentes de atopia } \\
\hline ATOPIA & No posee alfombra & Si posee alfombra & Total \\
\hline si & 58 & 12 & 70 \\
\hline no & 29 & 15 & 44 \\
\hline TOTAL & 87 & 27 & 114 \\
\hline OR: $\mathbf{2 , 5}$ & IC $95 \%: 1,03 / 6$ & X2: 4,29 & P: 0,04 \\
\hline
\end{tabular}


Alfombras y hongos en el aire interior.

Como puede verse en la tabla siguiente, no hay diferencias claramente significativas en los dormitorios alfombrados en cuanto a la presencia de hongos, pero si se comparan los cuartiles extremos aparece un efecto protector.

\begin{tabular}{|c|c|c|c|c|c|}
\hline \multicolumn{6}{|c|}{ Tabla 7.68 alfombras como factor de aumento de esporas fúngicas } \\
\hline \multirow[b]{2}{*}{ POSEE ALFOMBRA } & \multicolumn{5}{|c|}{ Cantidad de UFC por cápsula } \\
\hline & muy alta & alta & media & baja & Total \\
\hline Si & 3 & 1 & 1 & 3 & 8 \\
\hline Row\% & $37,50 \%$ & $12,50 \%$ & $12,50 \%$ & $37,50 \%$ & $100,00 \%$ \\
\hline Col\% & $17,65 \%$ & $25,00 \%$ & $20,00 \%$ & $75,00 \%$ & $26,67 \%$ \\
\hline No & 14 & 3 & 4 & 1 & 22 \\
\hline Row\% & $63,64 \%$ & $13,64 \%$ & $18,18 \%$ & $4,55 \%$ & $100,00 \%$ \\
\hline Col\% & $82,35 \%$ & $75,00 \%$ & $80,00 \%$ & $25,00 \%$ & $73,33 \%$ \\
\hline TOTAL & 17 & 4 & 5 & 4 & 30 \\
\hline Row\% & $56,67 \%$ & $13,33 \%$ & $16,67 \%$ & $13,33 \%$ & $100,00 \%$ \\
\hline \multirow[t]{2}{*}{ Col\% } & $100,00 \%$ & $100,00 \%$ & $100,00 \%$ & $100,00 \%$ & $100,00 \%$ \\
\hline & & & & $\chi^{2}: 5,6$ & $P: 0,13$ \\
\hline Comparación "muy alta" con "baja" & OR: 0,07 & \multicolumn{2}{|c|}{ IC $95 \%: 0,005 / 0,94$} & & \\
\hline
\end{tabular}

Manchas de humedad

\begin{tabular}{|c|c|c|c|c|c|}
\hline \multicolumn{6}{|c|}{$\begin{array}{c}\text { Tabla } 7.69 \text { Manchas de humedad en las paredes y Recuento de UFC } \\
\text { Hongos en el dormitorio }\end{array}$} \\
\hline MANCHAS HUMEDAD & muy alta & alta & media & baja & Total \\
\hline Si & 7 & 0 & 1 & 0 & 8 \\
\hline Row\% & $87,50 \%$ & $0,00 \%$ & $12,50 \%$ & $0,00 \%$ & $100,00 \%$ \\
\hline Col\% & $41,18 \%$ & $0,00 \%$ & $20,00 \%$ & $0,00 \%$ & $26,67 \%$ \\
\hline No & 10 & 4 & 4 & 4 & 22 \\
\hline Row\% & $45,45 \%$ & $18,18 \%$ & $18,18 \%$ & $18,18 \%$ & $100,00 \%$ \\
\hline Col\% & $58,82 \%$ & $100,00 \%$ & $80,00 \%$ & $100,00 \%$ & $73,33 \%$ \\
\hline TOTAL & 17 & 4 & 5 & 4 & 30 \\
\hline Row\% & $56,67 \%$ & $13,33 \%$ & $16,67 \%$ & $13,33 \%$ & $100,00 \%$ \\
\hline Col\% & $100,00 \%$ & $100,00 \%$ & $100,00 \%$ & $100,00 \%$ & $100,00 \%$ \\
\hline$\chi 2: 4,85$ & & P: 0,18 & & & \\
\hline
\end{tabular}


Como se observa en la tabla anterior, se ha encontrado una clara diferencia en la frecuencia de conteos representativos de la presencia de hongos en el aire de los dormitorios si hay manchas de humedad aunque la conclusión no es totalmente significativa desde el punto de vista estadístico.

\section{$\underline{\text { Aire acondicionado }}$}

En esta investigación no había ningún sistema central y solo 8 sobre 118 encuestas hogareñas registraron aparatos en los dormitorios de los niños, lo que limita la potencia estadística de esta comparación.

La OR 0.32 muestra un efecto protector pero el intervalo de confianza del 95\%: $0,06 / 1,66$ y la prueba de $X^{2} 2, P: 0,16$ le restan significado estadístico.

\section{Método de limpieza}

El uso del trapo húmedo como método de limpieza se insinúa como un factor protector (OR 0,41 IC 95\%: 0,15/1,18) con una distribución estadísticamente significativa $\chi^{2}: 2,8 \operatorname{Pr}<\chi^{2}: 0,09$.

\section{Combinación de variables y riesgo}

En función de la hipótesis inicial del proyecto, en una primera etapa de la investigación se exploró en profundidad la bibliografía relacionada con los factores de riesgo seleccionados, llegando a la conclusión que no tenía sustento teórico la vinculación en general de todos ellos en un solo indicador sin contar con datos cuantitativos que asocien concentración en aire y efectos en las vías aéreas. Por el contrario se pudo construir como ya fue mencionado el indicador de formaldehido que relaciona distintos materiales y procesos emisores. 


\section{Unidad de análisis ambiente exterior}

Factores inespecíficos del ambiente exterior.

Salvo picos excepcionales, no es una situación habitual que la población uruguayense se vea expuesta a una fuerte contaminación atmosférica originada en fuentes móviles. La superficie ligeramente ondulada del territorio permite la dispersión. La autopista con tráfico más intenso corre a unos $2 \mathrm{~km}$ por fuera del área suburbana. Teniendo en cuenta las características de la ciudad en cuanto a factores del ambiente físico exterior, se consideran dos categorías o áreas territoriales:

1. Áreas con domicilios ubicados en cercanías de emisiones fijas de contaminantes atmosféricos, en los que se debe tener en cuenta a los vientos predominantes. En esta zona no hay una predominancia estacional fuerte, pero pueden destacarse como más frecuentes los procedentes del este, seguidos del sudeste, norte y por último del noreste. En ocasiones sopla con fuerza el "pampero" del sudoeste y pueden observarse también vientos del oeste. Por lo tanto, en una evaluación epidemiológica poblacional por un período anual como la que se desarrolla para esta Tesis, no pareciera afectar demasiado la forma del área de riesgo según distancias a la fuente, porque en el año se habrán presentado todas las posibilidades.

2. Viviendas ubicadas en terrenos inundables. Los terrenos inundables corresponden a zonas con gran concentración de humedad, con cotas inferiores $a+8.25^{302}$, proximidad a desagües pluviales a cielo abierto y a los arroyos que cruzan o bordean la ciudad. 
Área de influencia de industrias y basural municipal como fuentes fijas de contaminantes atmosféricos.

En las 19.000 ha. del ejido municipal de Concepción del Uruguay, se ha producido un crecimiento desordenado en el que predomina el asentamiento de usos industriales en contextos residenciales, como asimismo la localización de nuevas viviendas en cercanía de las industrias. Esta situación aumenta el riesgo de exposición de los habitantes a contaminantes atmosféricos.

Las actividades productivas más importantes están relacionadas con la elaboración de productos alimenticios, ya sea procesamiento y conservación de carnes de aves y vacuna, procesamiento de arroz, secado de soja, almacenamiento de diversos granos, principalmente soja en los últimos años y fabricación de alimentos balanceados.

Dado el gran crecimiento del cultivo de la soja en esta región, pueden detectarse varias fuentes potenciales de emisión de partículas de la cáscara del grano de soja en la ciudad y aledaños. Son destacables los campos al momento de la cosecha, los transportes en camiones, los silos y la carga en los buques graneleros en el puerto, que tiene también grandes elevadores y galpones que son utilizados como depósito. También hay secadoras de soja en la zona portuaria y fábricas de alimentos balanceados en varios puntos de la ciudad.

1.1 En el sector Noroeste se encuentran ubicadas las empresas:

- eXtrusora DEL LITORAL, Acopio de granos (14),

- FEPASA. Procesadora de aves (6)

- SANTA ROSA, Alimentos balanceados (7),

- Corporación General de Alimentos balanceados (5),

- PIENSOS-CARGILL. (Tres Arroyos). Alimentos balanceados (8),

- Cabaña avícola CAMPICHUELO. (FEPASA).

Las principales emisiones de partículas de diferentes tamaños son debidas al polvillo que acompaña a los granos utilizados y a su procesamiento. También son liberados vapores, gases y olores como consecuencia del proceso de cocción y elaboración de los alimentos balanceados. Próximo a este sector se encuentra ubicado 
un basural municipal ${ }^{303}$, ocasionando emanaciones de fuertes olores y humos debido a la quema de residuos espontánea o provocada.

Dada su ubicación, la contaminación ambiental proveniente de ese sector no ocasionaría un impacto importante o severo sobre la planta urbanizada de Concepción del Uruguay, aunque ocasiona molestias a los habitantes de sus alrededores.

1.2 En el sector Este, Sureste se encuentran ubicadas las empresas:

- Alimentos San Patricio. Elaboración de Harina (10),

- CAlimBOY. Acopio y secado de soja (11). Si en el momento de secado de la soja hay vientos fuertes del este o sureste, se producirá un aumento en atmósfera del polvo producto del proceso, que también será producido por desperfectos en la maquinaria secadora de grano. La dimensión del impacto abarcará un radio importante de la ciudad,

- REPSOL- YPF (13). Depósitos de combustibles. Debe tenerse en cuenta la posibilidad de un impacto como el que puede ocasionar la emisión de gases de los grandes tanques de combustibles y su mezcla con el polvo de secado de los granos. (mezcla estequiométrica entre el polvo, el combustible y el aire) ${ }^{304}$.

- Puerto: se encuentran los galpones y silos de acopios de granos destinados a los buques ultramarinos, transporte por camiones y ferroviario. Además se encuentran micro-vertederos, ubicados en terrenos baldíos en terrenos privados y en la vía pública.

Por lo tanto en este sector la dispersión del contaminante es muy significativo, principalmente por la turbulencia que se formarían con las temperaturas elevadas y la rugosidad de los edificios y viviendas. Son los responsables de la dispersión del contaminante abarcando importantes sectores de la ciudad.

1.3. En el cuadrante sudoeste se ubican los grandes frigoríficos procesadores de aves, vacunos y porcinos y, algo más alejado de la ciudad, el parque industrial.

Sus emisiones atmosféricas principales se deben a la combustión de hidrocarburos producido en las calderas y motores, tanto gases (COx, SOx y NOx) como partículas $\left(\mathrm{PM}_{10}\right)$ típicos de estos procesos, al intenso tránsito de camiones con emisión 
de compuestos orgánicos volátiles (VOC) y la emisión de olores originados en las piletas de efluentes líquidos. 
Evaluación epidemiológica de la exposición.

El único hallazgo positivo es la OR elevada y las diferencias significativas encontradas en la zona ubicada entre los 500 m y los 1000 de distancia de los frigoríficos. La OR para el sector cercano al basural es alta pero el intervalo de confianza y la prueba de $\chi^{2}$ restan significado estadísticamente válido.

\begin{tabular}{|c|c|c|c|c|c|c|c|}
\hline fuente & exposición & casos & controles & $O R$ & IC $95 \%$ & $\chi^{2}$ & $\operatorname{Pr}$ \\
\hline \multirow{2}{*}{$\begin{array}{l}\text { molinos, depósitos y secadoras } \\
\text { del puerto distancia } 500 \mathrm{~m}\end{array}$} & expuestos & 1 & 4 & \multirow{2}{*}{0,42} & \multirow{2}{*}{$0,05 / 3,85$} & \multirow{2}{*}{0,61} & \multirow{2}{*}{0,43} \\
\hline & no expuestos & 113 & 192 & & & & \\
\hline \multirow{2}{*}{$\begin{array}{l}\text { molinos, depósitos y secadoras } \\
\text { puerto distancia } 1000 \mathrm{~m} \text { sin área } \\
500\end{array}$} & expuestos & 1 & 6 & \multirow{2}{*}{0,28} & \multirow{2}{*}{$0,03 / 2,36$} & \multirow{2}{*}{1,56} & \multirow{2}{*}{0,21} \\
\hline & no expuestos & 113 & 190 & & & & \\
\hline \multirow{2}{*}{$\begin{array}{c}\text { molinos, depósitos y secadoras } \\
\text { puerto distancia hasta } 2000 \mathrm{~m} \\
\text { por viento E sin } 500\end{array}$} & expuestos & 3 & 6 & \multirow{2}{*}{0,86} & \multirow{2}{*}{$0,21 / 3,5$} & \multirow{2}{*}{0,05} & \multirow{2}{*}{0,83} \\
\hline & no expuestos & 111 & 190 & & & & \\
\hline \multirow{2}{*}{ planta YPF $500 \mathrm{~m}$} & expuestos & 1 & 3 & \multirow{2}{*}{0,57} & \multirow{2}{*}{$0,06 / 5,54$} & \multirow{2}{*}{0,24} & \multirow{2}{*}{0,62} \\
\hline & no expuestos & 113 & 193 & & & & \\
\hline \multirow{2}{*}{ planta YPF $1000 \mathrm{~m} \mathrm{~s} / 500$} & xpuestos & 3 & 5 & \multirow{2}{*}{1,03} & \multirow{2}{*}{$0,24 / 4,4$} & \multirow{2}{*}{0,002} & \multirow{2}{*}{0,96} \\
\hline & no expuestos & 111 & 191 & & & & \\
\hline \multirow{2}{*}{$\begin{array}{c}\text { planta YPF hasta } 2000 \mathrm{~m} \text { por } \\
\text { viento } \mathrm{E}\end{array}$} & expuestos & 3 & 3 & \multirow{2}{*}{1,74} & \multirow{2}{*}{$0,34 / 8,76$} & \multirow{2}{*}{0,46} & \multirow{2}{*}{0,5} \\
\hline & no expuestos & 111 & 193 & & & & \\
\hline \multirow{2}{*}{ frigoríficos A de la China $500 \mathrm{~m}$} & expuestos & 2 & 6 & \multirow{2}{*}{0,56} & $011 / 285$ & 05 & 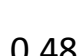 \\
\hline & no expuestos & 112 & 190 & & $0,11 / 2,03$ & & \\
\hline frigoríficos A de la China 1000 m & expuestos & 13 & 10 & 21 & $101 / 565$ & 17 & 004 \\
\hline $\sin$ & no expuestos & 101 & 186 & $2, \mathbf{4}$ & , & 4,17 & 0,04 \\
\hline Basural camino Puente de Fierro & expuestos & 2 & 1 & 3.48 & $031 / 388$ & 116 & 0.28 \\
\hline $500 \mathrm{~m}$ & no expuestos & 112 & 195 & & & & \\
\hline Basural camino Puente de Fierro & expuestos & 1 & 1 & 173 & $011 / 278$ & 015 & 07 \\
\hline $1000 \mathrm{~m}$ sin área 5 & no expuestos & 113 & 195 & $1,1,1$ & & & \\
\hline Arrocera Gallo $500 \mathrm{~m}$ & expuestos & 12 & 14 & 152 & $060 / 212$ & 107 & 03 \\
\hline Alrocerd Gdilo sou mim & no expuestos & 102 & 182 & 1,53 & $0,00 / 3,45$ & 1,07 & 0,3 \\
\hline 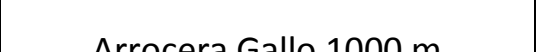 & expuestos & 30 & 45 & $12+3$ & $07 / 2$ & 011 & 05 \\
\hline Alrocerd udilo lovo im & no expuestos & 84 & 151 & 1,2 & $0,1 / 2$ & 0,44 & U, כ \\
\hline Arrocera Gallo 1000 m sin área & expuestos & 18 & 31 & 1 & $053 / 188$ & $<0001$ & 1 \\
\hline 500 & no expuestos & 96 & 165 & 1 & ט, /, / כנ, & $-\infty, 001$ & \\
\hline
\end{tabular}

Si se compara el efecto entre los niños atópicos y no atópicos no aparecen diferencias significativas. 


\begin{tabular}{|c|c|c|c|}
\hline \multicolumn{5}{|c|}{ Tabla 7.71 Riesgo de asma en no atópicos por cercanía a } \\
contaminantes \\
\hline TOTAL ÁREA 1000 m & casos & controles & Total \\
\hline si & 53 & 104 & 157 \\
\hline no & 32 & 71 & 103 \\
\hline TOTAL & 85 & 175 & 260 \\
\hline OR: 1,13 & $0,66 / 1,92$ & $\mathrm{X} 2: 0,2$ & P: 0,65 \\
\hline
\end{tabular}

\begin{tabular}{|c|c|c|c|}
\hline \multicolumn{5}{|c|}{ Tabla 7.72 Riesgo de asma en atópicos por cercanía a } \\
contaminantes \\
\hline TOTAL ÁREA $1000 \mathrm{~m}$ & casos & controles & Total \\
\hline si & 16 & 12 & 28 \\
\hline no & 13 & 9 & 22 \\
\hline TOTAL & 29 & 21 & 50 \\
\hline OR: 0,9 & IC: $0,3 / 2,9$ & X2: 0,02 & P: 0,9 \\
\hline
\end{tabular}

\section{Evaluación de efectos en la severidad de los casos.}

Algo menos de la mitad de la muestra de casos y controles vive en áreas relativamente cercanas a las fuentes más importantes como emisoras de contaminantes atmosféricos. Se evaluaron los posibles efectos sobre la severidad del asma que se informan en tabla 7.73:

\begin{tabular}{|l|c|c|c|c|c|c|}
\hline \multicolumn{7}{|c|}{ Tabla 7.73 Severidad del asma según cercanía a fuentes emisoras de contaminantes } \\
atmosféricos \\
\hline fuentes & leve & moderada & severa & total casos & controles & Total \\
\hline Arrocera G $500 \mathrm{~m}$ & 7 & 3 & 2 & 12 & 14 & 26 \\
\hline Arrocera G $1000 \mathrm{~m}$ & 10 & 3 & 5 & 18 & 31 & 49 \\
\hline Basural $500 \mathrm{~m}$ & 1 & 1 & 0 & 2 & 1 & 3 \\
\hline Basural $1000 \mathrm{~m}$ & 1 & 0 & 0 & 1 & 1 & 2 \\
\hline Frigoríficos $500 \mathrm{~m}$ & 2 & 0 & 0 & 2 & 6 & 8 \\
\hline Frigoríficos $1000 \mathrm{~m}$ & 11 & 1 & 1 & 13 & 11 & 24 \\
\hline Puerto $500 \mathrm{~m}$ & 0 & 0 & 1 & 1 & 4 & 5 \\
\hline Puerto $1000 \mathrm{~m}$ & 0 & 1 & 0 & 1 & 6 & 7 \\
\hline Puerto $2000 \mathrm{~m}$ & 2 & 1 & 0 & 3 & 6 & 9 \\
\hline YPF $500 \mathrm{~m}$ & 0 & 0 & 1 & 1 & 3 & 4 \\
\hline YPF $1000 \mathrm{~m}$ & 2 & 1 & 0 & 3 & 5 & 8 \\
\hline YPF $2000 \mathrm{~m}$ & 2 & 1 & 0 & 3 & 3 & 6 \\
\hline
\end{tabular}


Para posibilitar el análisis estadístico (suprimiendo casilleros en 0 ) se agrupa en solo dos categorías la severidad:

\begin{tabular}{|l|c|c|c|c|c|c|}
\hline \multicolumn{6}{|c|}{$\begin{array}{c}\text { Tabla 7.74 OR de severidad del asma según cercanía a fuentes emisoras de } \\
\text { contaminantes atmosféricos. }\end{array}$ Clasificación en 2 categorías. } \\
\hline fuente / distancia & $\begin{array}{c}\text { Sev/mo } \\
\text { d }\end{array}$ & leve & OR & IC 95\% & X2 & Pr \\
\hline Frigoríficos 500 m & 0 & 2 & $*$ & & 1,24 & 0,54 \\
\hline Frigoríficos 1000 m & 2 & 11 & 0,3 & $0,06 / 1,43$ & 2,50 & 0,11 \\
\hline $\begin{array}{l}\text { Frigoríficos } \\
\text { 500+1000 }\end{array}$ & 2 & 13 & 0,25 & $0,05 / 1,15$ & 3,59 & 0,06 \\
\hline Arrocera G 500 & 5 & 7 & 1,37 & $0,4 / 4,6$ & 0,25 & 0,61 \\
\hline Arrocera G 1000 & 8 & 10 & 1,6 & $0,57 / 4,44$ & 0,82 & 0,36 \\
\hline Arroc 500+1000 & 13 & 17 & 1,61 & $0,68 / 3,8$ & 1,21 & 0,27 \\
\hline Basural 500 & 1 & 1 & 1,87 & $0,11 / 30$ & 0,2 & 0,65 \\
\hline Basural 1000 & 0 & 1 & $*$ & & 0,89 & 0,64 \\
\hline Basural 500+1000 & 1 & 2 & 0,92 & $0,08 / 10$ & 0,004 & 0,95 \\
\hline Puerto 500 & 1 & 0 & $*$ & & 1,6207 & 0,4447 \\
\hline Puerto 1000 & 1 & 0 & $*$ & & 2,293 & 0,3177 \\
\hline Puerto viento 2000 & 1 & 2 & 0,92 & $0,08 / 10$ & 0,004 & 0,95 \\
\hline Puerto (500+1000) & 2 & 2 & 1,89 & $0,26 / 13,9$ & 0,4 & 0,52 \\
\hline Depósito YPF 500 & 1 & 0 & $*$ & & 1,51 & 0,47 \\
\hline Depósito YPF 1000 & 1 & 2 & 0,92 & $0,08 / 10$ & 0,004 & 0,95 \\
\hline $\begin{array}{l}\text { Dep. YPF viento } \\
\text { 2000 }\end{array}$ & 1 & 2 & 0,92 & $0,08 / 10$ & 0,004 & 0,95 \\
\hline Dep. YPF (suma) & 2 & 3 & 1,24 & $0,2 / 7,8$ & 0,05 & 0,81 \\
\hline * no se puede calcular & & & & & \\
\hline
\end{tabular}

No hay OR ni diferencias significativas en la severidad entre quienes viven en las áreas consideradas de mayor exposición a contaminación atmosférica.

\section{Relación con la hiperreactividad bronquial (HRB).}

Con respecto a la posible relación entre la exposición a contaminantes atmosféricos y la HRB, no pudo demostrarse un comportamiento estadísticamente claro, ya que incluso en el caso del pequeño número de niños habitando en las cercanías de un gran basural municipal, con una OR de 3,7 , tanto el intervalo de confianza como la evaluación de diferencias significativas con $\chi^{2}$ son determinantes para descartarlas. 
Tabla 7.75 HRB según cercanía a fuentes emisoras de contaminantes atmosféricos.

\begin{tabular}{|l|c|c|c|c|c|c|c|}
\hline \multicolumn{1}{|c|}{ fuente / distancia } & alta/media & baja & Total & OR & IC 95\% & X2 & Pr \\
\hline Frigoríficos 500 & 2 & 6 & 8 & 0,6 & $0,11 / 3$ & 0,4 & 0,53 \\
\hline Frigoríficos 1000 & 7 & 17 & 24 & 0,7 & $0,3 / 1,8$ & 0,45 & 0,50 \\
\hline Frig. 500+1000 & 9 & 23 & 32 & 0,7 & $0,3 / 1,5$ & 0,8 & 0,36 \\
\hline Arrocera G 500 & 11 & 15 & 26 & 1,4 & $0,6 / 3$ & 0,6 & 0,45 \\
\hline Arrocera G 1000 & 14 & 35 & 49 & 0,7 & 0,3 & 1,3 & 0,27 \\
\hline Arroc. 500+1000 & 25 & 50 & 75 & 0,9 & $0,5 / 1,5$ & 0,2 & 0,65 \\
\hline Basural 500 & 2 & 1 & 3 & $\mathbf{3 , 7}$ & $0,3 / 41$ & 1,3 & 0,26 \\
\hline Basural 1000 & 1 & 1 & 2 & $\mathbf{1 , 8}$ & $0,1 / 29$ & 0,2 & 0,67 \\
\hline Basural 500+1000 & 3 & 2 & 5 & $\mathbf{2 , 8}$ & $0,4 / 16$ & 1,3 & 0,25 \\
\hline Puerto 500 & 2 & 3 & 5 & 1,2 & $0,2 / 7$ & 0,04 & 0,83 \\
\hline Puerto 1000 & 2 & 5 & 7 & 0,7 & $0,13 / 3,8$ & 0,15 & 0,7 \\
\hline Puerto viento 2000 & 3 & 6 & 9 & 0,9 & $0,2 / 3,7$ & 0,02 & 0,9 \\
\hline Puerto (suma del área) & 5 & 10 & 15 & 0,9 & $0,3 / 2,7$ & 0,03 & 0,8 \\
\hline Dep. YPF 500 & 2 & 2 & 4 & $\mathbf{1 , 8}$ & $0,2 / 13$ & 0,4 & 0,5 \\
\hline Dep. YPF 1000 & 3 & 5 & 8 & 1,1 & $0,2 / 4,7$ & 0,01 & 0,9 \\
\hline Dep. YPF viento 2000 & 1 & 5 & 6 & 0,3 & $0,04 / 3$ & 0,9 & 0,33 \\
\hline Dep. YPF (suma del área) & 5 & 10 & 15 & 0,9 & $0,3 / 2,7$ & 0,3 & 0,8 \\
\hline
\end{tabular}

\section{Efectos sinérgicos}

Podría haber un efecto sinérgico en la exposición a contaminantes, cuando los externos penetran en el aire interior y en este sentido se ha hallado que los niños que viven a menos de $1000 \mathrm{~m}$ de una fuente contaminante del aire exterior y están expuestos al humo de tabaco, otras emisiones de formaldehido y contaminaciones del aire interior presentan más del doble de riesgo de asma (OR 2,24 IC 1 a 5; $\chi^{2}=4.95$ $\left.\operatorname{Pr}>\chi^{2}=0.03\right)$. 


\section{Viviendas ubicadas en terrenos inundables}

Concepción del Uruguay, como toda la provincia de Entre Ríos, está surcada y rodeada por números ríos, arroyos y cañadas, que periódicamente presentan crecidas de variable magnitud. Al este, la ciudad limita con el arroyo Molino, afluente del río Uruguay, que penetra por el mismo en las grandes crecientes. También este arroyo forma el límite geográfico norte. El arroyo de la China forma el límite sur y recibe descargas industriales en gran parte de su trayecto inferior. Hay además dos cuencas intraurbanas: el arroyo de las Ánimas y el arroyo El gato.

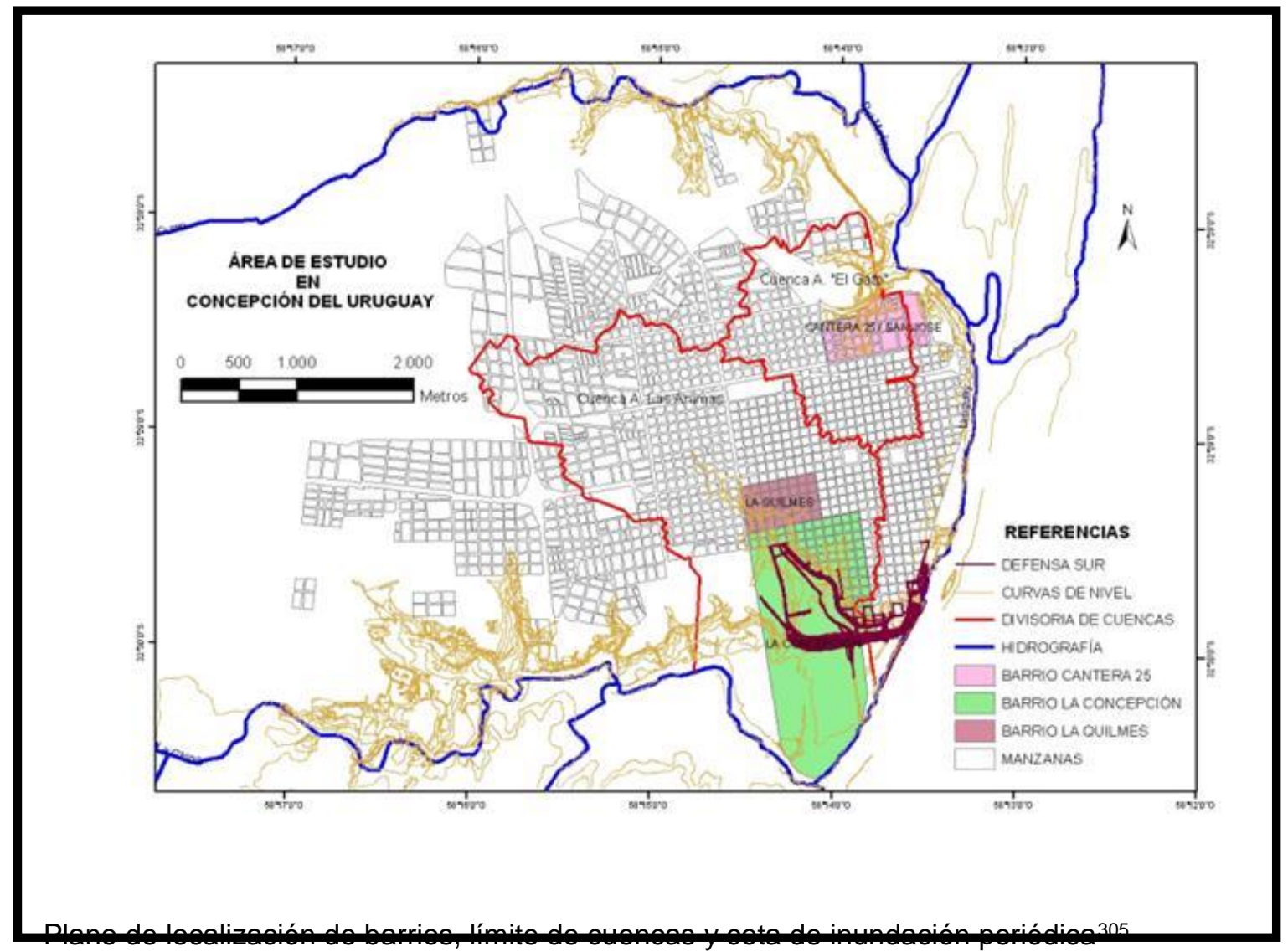

Las lluvias rondan los $1.100 \mathrm{~mm}$ anuales y contribuyen al anegamiento de estas zonas aunque no haya crecidas del río Uruguay. 
Pueden diferenciarse tres áreas:

\section{1.Área 1}

Corresponde a los barrios La Concepción (4.035 hab.) y Quilmes (1.684 hab.), situados en la subcuenca del Arroyo Las Ánimas, correspondiente a la Cuenca del Arroyo La China. Existen calles que actúan como canales de este sistema pluvial. Las calles Alem entre 25 de Agosto y Dra. Ratto, Víctor Etcheverry entre Alem y 21 de Noviembre, Piedras entre Henri y Suipacha y San Lorenzo entre Ereño y 25 de Agosto están canalizadas a cielo abierto, sin mantenimiento, con presencia de malezas, residuos y proliferación de vectores. Estas calles canales tienen agua en forma permanente lo que provoca una mayor concentración de humedad en el ambiente.

\section{2.Área 2}

Corresponde al barrio Cantera 25. Pertenece a la Subcuenca del Arroyo El Gato, afluente de la Cuenca del Arroyo Molino, con una superficie de captación de 250 Has.

Los barrios Cantera 25 y San José tienen aproximadamente 2.830 habitantes $^{306}$, de los cuales aproximadamente un $30 \%$ presentan un nivel de necesidades básicas insatisfechas (NBI). Este sector tiene características diferenciadas, por su localización en una ex-cantera, por lo cual se encuentra casi completamente bajo la cota $+8,25$.

El $43 \%$ de las viviendas, muestra en general un buen estado de conservación, sus materiales son aptos y han sido adaptadas a las necesidades de las familias que las habitan. Un 31 \% de ellas están construidas con materiales de baja calidad y no han sido adaptadas a las necesidades de las familias que las habitan. El $17 \%$ se ha calificado como precaria en función de que los materiales son de baja calidad, muestra un pronunciado deterioro y no se adapta a las necesidades de las familias que las habitan. El $9 \%$ se ha calificado como rancho, y se refiere especialmente a las viviendas construidas con materiales no aptos, en general no separan ambientes y están construidas en terrenos fiscales. La mitad de las viviendas se ha inundado por lo menos una vez en los últimos años ${ }^{307}$. 


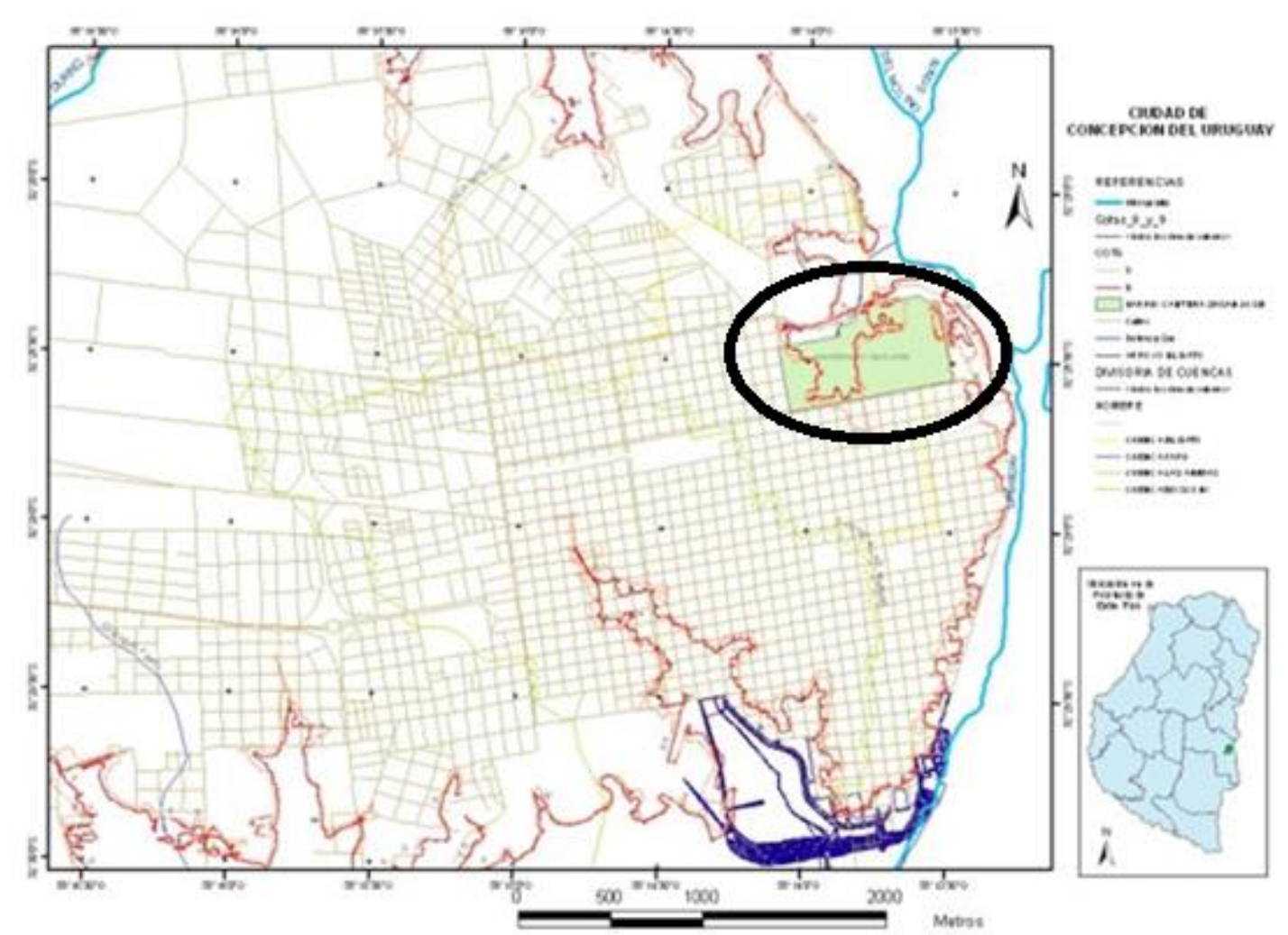

Mapa 1: Localización de los barrios Cantera 25 y San Josée 308.

\section{3. Área 3: Barrio San Vicente}

Este sector pertenece a la Subcuenca del Arroyo Las Ánimas. El Arroyo se encuentra entubado en los límites del área (Bvd. Díaz Vélez) y canalizado a cielo abierto en su recorrido, definiendo áreas húmedas con presencia constante de agua.

Tiene $3973^{309}$ habitantes, de los cuales 452 (12\%) presentan necesidades básicas insatisfechas (NBI). La falta de mantenimiento y arrojo de residuos a la vía pública obstruye el canal y produce un embalse del arroyo los días de lluvia con la consecuente inundación. Como consecuencias de las obras de entubamiento en Bvd. Díaz Vélez se produce estancamiento de aguas pluviales e inundación de las viviendas por levantamiento de la cota de las calles. 
En la siguiente tabla se muestra el conjunto de las tres áreas:

\begin{tabular}{|c|c|c|c|}
\hline \multicolumn{4}{|c|}{ Tabla 7.76. Vivienda en terreno inundable como factor de riesgo de asma } \\
( $n: 310$ casos y controles) \\
\hline cota $\leq 9 \mathrm{~m}$ & casos & controles & Total \\
\hline si & 7 & 3 & 10 \\
\hline fila \% & $70,00 \%$ & $30,00 \%$ & $100,00 \%$ \\
\hline Col\% & $6,36 \%$ & $1,50 \%$ & $3,23 \%$ \\
\hline no & 103 & 197 & 300 \\
\hline fila \% & $34,33 \%$ & $65,67 \%$ & $100,00 \%$ \\
\hline Col\% & $93,64 \%$ & $98,50 \%$ & $96,77 \%$ \\
\hline TOTAL & 110 & 200 & 310 \\
\hline fila $\%$ & $35,48 \%$ & $64,52 \%$ & $100,00 \%$ \\
\hline OR: 4,46 & IC $1,13 / 17,62$ & $\chi^{2}: 5,38$ & $\operatorname{Pr}>\chi^{2} 0,02$ \\
\hline
\end{tabular}

Vivir en una zona inundable cuadruplica el riesgo de asma infantil.

\section{Cambio de vivienda}

\begin{tabular}{|l|c|c|c|}
\hline \multicolumn{5}{|c|}{ Tabla 7.77 Efecto protector del cambio de vivienda y evolución de asma y } \\
rinitis
\end{tabular}

El cambio fue beneficioso tanto para los casos como para los controles que mejoran las rinitis pero las diferencias no son significativas específicamente en cuanto a síntomas indicadores de asma. En el $86 \%$ de los cambios la nueva vivienda fue menos húmeda, ubicada en zonas más altas de la ciudad. Uno de los niños que empeoró se había trasladado desde Neuquén (con menor humedad ambiental) hacia esta ciudad y el otro es un caso que se mudó desde Buenos Aires (se desconoce localización) a un barrio ubicado en la zona inundable. 
Para determinar la fracción de riesgo atribuible a vivir en zonas inundables, se adoptó como proxy la proporción expuesta en la muestra grande de 529 familias, que como se dijo fue seleccionada al azar pero respetando estratos de distribución territorial según el censo nacional. Los datos obtenidos son:

\begin{tabular}{|l|c|c|c|c|}
\hline Radicación & Casos incidentes 5 años & Controles & Totales & \% del total \\
\hline Inundable & 22 & 31 & 53 & 10 \\
\hline No inundable & 190 & 286 & 476 & 90 \\
\hline Totales & 212 & 317 & 529 & 100 \\
\hline
\end{tabular}

- Incidencia acumulada de 5 años en niños expuestos: $41 \%$

- Incidencia acumulada de 5 años en niños no expuestos: 22\% (incidencia de fondo)

- Incidencia acumulada de 5 años en la población total de niños: $40 \%$

- Riesgo relativo para los primeros cinco años: 1,86

- Proporción de riesgo atribuible en los expuestos de la muestra: $46 \%$

- Proporción de riesgo atribuible en la población: 8\% 


\section{Discusión de los resultados.}

Se consideraron 9 temas para discutir en función de los resultados analizados:

\section{Tema 1. Factores de confusión.}

\section{Conductas preventivas familiares}

Es posible que las familias con conocimientos sobre los riesgos reales o supuestos de asma y alergia modifiquen su entorno doméstico, tanto en la exposición al aire contaminado con humo de tabaco, como tratando las manchas de humedad, disminuyendo el uso de insecticidas y mejorando los sistemas de calefacción, así como con la evitación de alfombras. Precisamente en esta investigación se percibe con claridad que en las familias de atópicos hay una fuerte probabilidad de no hallar alfombras (OR 2,5). Esta conducta preventiva, demostrada en varios trabajos, en particular el PIAMA ${ }^{310}$ ya mencionado, puede afectar la interpretación epidemiológica y debería por lo tanto incorporarse a las encuestas alguna pregunta al respecto.

Otra alternativa de confusión es la asociación de alguno de estos posibles factores inespecíficos con otro factor causal que realmente está generando el aumento o la disminución de la prevalencia. Se ha mencionado el ejemplo del uso de pisos lisos plásticos como reemplazo de una alfombra dada la alergia a los ácaros detectada. Algún observador podría encontrar relación directa entre aquellos pisos y el asma y mencionarlo como factor de riesgo, pero la frecuente sensibilidad a ácaros del polvillo que promovió el cambio de alfombra por piso liso como se ha visto en muchos hogares de asmáticos o alérgicos, sería el factor de confusión en este caso ${ }^{311}$. Pero a su vez los pegamentos utilizados en algunas coberturas de pisos podrían ser emisores de compuestos orgánicos volátiles.

También los ácaros, importantes factores causales que proliferan en ambientes húmedos, podrían ser la causa del fuerte riesgo de asma en esos ambientes generalmente ubicados en terrenos más bajos, inundables, que actuarían como factores contribuyentes para la presencia de los alérgenos. 
No se observa un patrón de uso de insecticidas claramente diferente entre los casos y controles. No se percibe un uso más reducido en las familias de atópicos. Los casos severos tienden a usar dispositivos eléctricos de calefacción en el dormitorio asociando un efecto a la posible conducta preventiva.

Sesgos de recuerdo.

En las familias con antecedentes de alérgicos y la presencia de un hijo asmático y alérgico se puede producir el sesgo del recuerdo (recall bias) en el que los casos recuerden una exposición pasada mejor que los controles, sobre todo si saben que la misma se asocia a la enfermedad en estudio. Por el contrario, puede darse un recuerdo incompleto o impreciso en el reporte de la información en el grupo control ${ }^{312}$.

\section{Nivel de análisis "Ambiente exterior"}

La distancia a una fuente emisora de contaminantes aéreos es un elemento importante en la exposición respiratoria pero está condicionada por los vientos y otras variables meteorológicas, los horarios de emisión, la intensidad de la actividad productiva, los sistemas de depuración de efluentes que posea el emisor y la trayectoria en las capas de aire de las partículas o gases. Para lograr conclusiones más sólidas deben tenerse en cuenta todas estas variables y realizar mediciones de los principales componentes tanto gaseosos como particulados. También podría haber un efecto sinérgico ya mencionado en la exposición a contaminantes externos e internos. 


\section{Tema 2. Tabaquismo pasivo.}

No es un claro factor de riesgo de asma en la infancia temprana.

Según los resultados de esta investigación, el tabaquismo pasivo, durante los primeros 5 años de vida, no aparece como claro factor de riesgo de asma a los 6 años de edad, si se toma como un factor individual. Tampoco se asocia a un aumento de la hiperirritabilidad bronquial (HRB) en el conjunto de casos y controles ni a la severidad en los casos.

Sin embargo, 7 de los 8 niños que, sin presentar asma tuvieron síntomas compatibles con hiperreactividad bronquial, tienen el antecedente de tabaquismo pasivo, 5 de ellos sin antecedentes atópicos. Tanto en investigaciones experimentales como epidemiológicas poblacionales ya descriptas, sobre los riesgos del aire contaminado con humo de tabaco, se plantea un fenotipo de hiperreactividad bronquial sin asma en ratones y humanos. El patrón endotípico incluye la respuesta neurogénica ( $P, K$ y CGRP aumentadas) y la liberación mastocitaria de mediadores (entre otros $P_{2} \alpha$, LCT $E_{4}$ y ECP) sin aumento o incluso disminución de IgE total, (y específica en los experimentos con ratones alérgicos a Ovalbúmina). Podrían corresponder al fenotipo de asma infantil muy temprana transitoria, intrínseca con Perfil Th2 bajo.

No hay diferencias entre ambos sexos. Tampoco hay diferencias significativas si solo se estudia el efecto del tabaquismo pasivo en niños con antecedentes familiares de asma o alergia $\left(\chi^{2}: 0,25 ; \operatorname{Pr}>\chi^{2} 0,9\right)$.

El informe general sobre la investigación cooperativa ISAAC realizado sobre 38 países en 2001, en los que se utilizó la misma encuesta poblacional al empleado en esta Tesis, llega a una conclusión similar en niños de 6 a 8 años de edad en los que no encuentran ninguna relación significativa del asma y la hiperreactividad bronquial con el antecedente de tabaquismo durante el embarazo ni, luego del nacimiento, en el hogar. Son coincidentes también las investigaciones ya citadas (Collin 1985, Plashke 2000, cohorte australiana 2000, EGEA Francia 2000, Galván 2000, Huesca en España $2001^{313} 314$, Eisner 2002 y Bedolla 2013, entre otras). Este resultado es similar en la amplia cohorte de nacimiento canadiense, que publica sus resultados en el American Journal of Epidemiology en $2009^{315}$ y en el recientemente estudio longitudinal realizado en Cuba ${ }^{316}$. 
Por el contrario, un número importante de publicaciones también citadas anteriormente, afirma lo contrario (Larsson 1995, Cook y Strachan 1997 y 1998, Heraud 2002, Gilliland 2002, entre otras), aunque en general las OR son relativamente bajas (< 1,74), salvo en el estudio de Murray, que no es poblacional sino sobre pacientes ambulatorios (posible sesgo asistencial) que calcula un 3,88 para niños con eccema entre 1 y 17 años de edad.

Una investigación propia, siguiendo durante 5 años a una cohorte de controles desde los 6 años en adelante, el tabaquismo pasivo presenta un Riesgo Relativo fuerte: 2,86 (IC 95\%: 1,06/7,76) y una OR también elevada: 3,27 (IC 1,05/11,37). La incidencia acumulada fue descendiente desde $48 \%$ a los 9 años hasta un $34 \%$ a los 11 años de edad $^{317}$. Este efecto en la segunda infancia debería investigarse en función de varias hipótesis causales, entre otras las que van desde la respuesta alérgica al tabaco, la irritación como contribuyente a un asma desencadenado por otros alérgenos o su efecto sumativo como emisor de formaldehido para el que hubiera mayor exposición en esta etapa vital en la que podrían debilitarse los cuidados familiares.

\section{Efectos sobre alérgicos.}

El tabaquismo pasivo no parece influir en el riesgo de presentar síntomas de atopia. Este resultado es coherente con la mayoría de los hallazgos relevados, tanto experimentales como epidemiológicos. Vale destacar sin embargo que es posible que haya una proporción importante de alérgicos al tabaco en el $17 \%$ de atópicos expuestos que evolucionaron como casos de asma. Esa proporción es similar a la hallada en la investigación de Armentia y col. (2005) en la que comprobaron esa reactividad mediante testificación.

Si se revisa el efecto del tabaquismo según la condición de atópico o no atópico de los niños, sin haber resultados estadísticamente significativos, se observa en los niños alérgicos una OR elevada $(2,4)$ de asma pero con un IC que abarca el resultado indiferente. Este hallazgo fue también demostrado en forma experimental en la exposición subaguda de ratones alergizados (Dae 2011). Hay que tener en cuenta la posibilidad de que un porcentaje de los alérgicos lo sean también a los antígenos de tabaco como se verifica en el estudio epidemiológico español ${ }^{318}$ y por lo tanto la exposición al humo genera la aparición del asma. Puede plantearse entonces la hipótesis 
de que el riesgo de asma a los 6 años de edad está aumentado principalmente para los alérgicos al tabaco expuestos a su humo, por un mecanismo alérgico tipo I, con endotipo Th2 alto y genotipo atópico.

\section{Sesgo de información.}

Evaluando los posibles sesgos que podrían afectar este tipo de investigaciones, vale destacar que en el estudio PIAMA ${ }^{319}$, midiendo la conducta familiar en los meses inmediatos posteriores al nacimiento, encuentran que si ambos padres tienen antecedentes familiares de alergia o asma, baja significativamente el hábito de fumar en el hogar, mientras que si solo la madre tiene antecedentes, se mantiene el tabaquismo incluso durante el embarazo y el $15 \%$ de las madres sigue fumando. Este posible sesgo generado por un cambio de conducta familiar para evitar el riesgo podría afectar el resultado. Sin embargo, en la encuesta propia, la percepción del humo de tabaco como desencadenante de asma no modificó significativamente la exposición, ya que solo el $10 \%$ lo evitó completamente y el $46 \%$ continuaba exponiendo frecuentemente a su hijo. Este resultado también descarta en la muestra un sesgo de información importante, que podría inclinar a falsear la respuesta. 


\section{Perfiles endotípicos, tabaquismo y asma.}

Planteo como hipótesis a comprobar en investigaciones complementarias que, en el caso del tabaquismo y posiblemente de la mayoría de los factores llamados inespecíficos, las investigaciones epidemiológicas deben diferenciar a los casos e incluso a los controles según sus diferentes genotipos y endotipos, para poder hallar resultados más claros. Por ejemplo, para el tabaquismo pasivo:

\begin{tabular}{|c|c|c|c|}
\hline \multicolumn{4}{|c|}{$\begin{array}{l}\text { Tabla } 8.1 \text { Enfoque según genotipos, fenotipos y endotipos de la asociación entre tabaquismo pasivo } \\
\text { y asma. }\end{array}$} \\
\hline grupo & $\begin{array}{l}\text { Implicancias } \\
\text { epidemiológicas }\end{array}$ & $\begin{array}{l}\text { Efectos del tabaquismo } \\
\text { pasivo }\end{array}$ & $\begin{array}{l}\text { Implicancias } \\
\text { terapéuticas }\end{array}$ \\
\hline $\begin{array}{l}\text { Fenotipo infantil muy } \\
\text { temprano transitorio, } \\
\text { genotipo no atópico, } \\
\text { endotipo Th } 2 \text { bajo } \\
\text { (intrínseco) }\end{array}$ & $\begin{array}{l}\text { Comienzo } 0 \text { años, } \\
\text { asociado a } \\
\text { bronquiolitis, cede } \\
\text { aprox. antes de los } 5 \\
\text { años. Generalmente } \\
\text { leve. Posible } \\
\text { reaparición como } \\
\text { EPOC en el adulto }\end{array}$ & $\begin{array}{l}\text { Mayores efectos durante } \\
\text { la gestación en madres } \\
\text { fumadoras. Dosis } \\
\text { dependiente. Aumento } \\
\text { de la HRB persistente }\end{array}$ & $\begin{array}{l}\text { Evitación del } \\
\text { tabaquismo pasivo. } \\
\text { Tratamiento } \\
\text { sintomático inhalado. }\end{array}$ \\
\hline $\begin{array}{l}\text { Fenotipo infantil muy } \\
\text { temprano persistente, } \\
\text { genotipo atópico, } \\
\text { endotipo Th } 2 \text { alto }\end{array}$ & $\begin{array}{l}\text { Comienzo entre } 0 \text { y } 2 \\
\text { años, persistente. } \\
\text { Cuadros leves, } \\
\text { moderados y severos }\end{array}$ & \multirow{2}{*}{$\begin{array}{l}\text { Dos alternativas: } \\
\text { - Alergia específica tipo I } \\
\text { al tabaco } \\
\text { - No alérgicos al tabaco } \\
\text { En ambas alternativas, } \\
\text { aunque se puede agravar la } \\
\text { evolución con mayor } \\
\text { severidad se ha descripto un } \\
\text { descenso de la OR entre } 0 \text { y } \\
14 \text { años. Posible disminución } \\
\text { de reactividad frente a otros } \\
\text { alérgenos }\end{array}$} & $\begin{array}{l}\text { Evitación del } \\
\text { tabaquismo pasivo. } \\
\text { Inmunoterapia } \\
\text { específica. Ac antilgE y } \\
\text { antill-13 (leikrizumab) } \\
\text { antagonista IL-4 (en } \\
\text { modelos) Responde a } \\
\text { corticoides inhalados menos } \\
\text { en asma crónica con } \\
\text { remodelación; }\end{array}$ \\
\hline $\begin{array}{l}\text { Fenotipo de comienzo } \\
\text { en segunda infancia } \\
\text { persistente, genotipo } \\
\text { atópico, endotipo Th } 2 \\
\text { alto }\end{array}$ & $\begin{array}{l}\text { Comienzo entre } 5 \text { y } \\
10 \text { años, Cuadros } \\
\text { leves, moderados y } \\
\text { severos }\end{array}$ & & $\begin{array}{l}\text { Evitación del } \\
\text { tabaquismo pasivo. } \\
\text { antagonista IL-4 (en } \\
\text { modelos) Responde a } \\
\text { corticoides inhalados menos } \\
\text { en asma crónica con } \\
\text { remodelación; }\end{array}$ \\
\hline $\begin{array}{l}\text { Fenotipo de comienzo } \\
\text { en adultez, } \\
\text { persistente, genotipo } \\
\text { no atópico, endotipo } \\
\text { Th } 2 \text { alto }\end{array}$ & $\begin{array}{l}\text { Comienzo entre } 20 \text { y } \\
40 \text { años, } \\
\text { generalmente severa } \\
\text { Escasa historia familiar. } \\
\text { Esputo eosinofílico } \\
\text { persistente (>2\%) } \\
\text { ¿Exposición laboral } \\
\text { con respuesta } \\
\text { alérgica? }\end{array}$ & $\begin{array}{l}\text { Eosinofilia y neutrofilia en } \\
\text { esputo y BAL. > IL8 } \\
\text { correlacionada con < } \\
\text { función pulmonar. } \\
\text { Inflamación neurogénica } \\
\text { y estrés oxidativo }\end{array}$ & $\begin{array}{l}\text { Evitación del } \\
\text { tabaquismo. Respuesta a } \\
\text { Ac anti- IL-5 y a } \\
\text { modificadores de } \\
\text { leucotrienos; Eosinofilia con } \\
\text { baja respuesta a corticoides } \\
\text { que deben ser usados en } \\
\text { forma sistémica para } \\
\text { prevenir exacerbaciones y } \\
\text { reducir síntomas }\end{array}$ \\
\hline $\begin{array}{l}\text { Fenotipo de comienzo } \\
\text { en adolescencia o } \\
\text { adultez persistente. } \\
\text { Genotipo no atópico, } \\
\text { endotipo Th } 2 \text { bajo } \\
\text { FeNO disminuida }\end{array}$ & $\begin{array}{l}\text { Comienzo con el } \\
\text { hábito tabáquico o } \\
\text { alta exposición a } \\
\text { ACHT. ¿Exposición } \\
\text { laboral con } \\
\text { respuesta Th2 baja? }\end{array}$ & $\begin{array}{l}\text { Neutrofilia en esputo, } \\
\text { Amplificación de vía IL-1 y TNF- } \\
\text { a Th17; IL-8 }\end{array}$ & $\begin{array}{l}\text { Evitación del } \\
\text { tabaquismo. } \\
\text { Medicación } \\
\text { sintomática. }\end{array}$ \\
\hline
\end{tabular}


Para explorar esta propuesta probablemente deban utilizarse muestras más grandes que la utilizada en este estudio a efectos de lograr resultados estadísticamente significativos.

Es posible que algunos resultados poco claros en el estudio epidemiológico del tabaquismo pasivo y su relación con el asma se deban a que los casos generados por alergia específica al tabaco sean neutralizados parcialmente por los otros atópicos en general, expuestos al humo, que al disminuir su reactividad solo manifiestan Rinitis o Eccema y HRB, como se ha visto en estudios experimentales, pero no presentan las condiciones para ser considerados casos.

\section{El humo de tabaco como emisión de formaldehido.}

Si se incorpora el tabaquismo pasivo a un conjunto de agentes contaminantes intradomiciliarios que tienen como característica común emitir formaldehido, aparece asociado a un fuerte riesgo de asma infantil. El efecto que aislado no alcanza a producir en los no alérgicos, podría lograrlo potenciado en un conjunto de emisores, situación que altera los resultados de la encuesta si no se tiene en cuenta esta perspectiva. En este rol fisiopatogénico y en su asociación con mayor severidad a edades más avanzadas para los asmáticos alérgicos es que puede asentarse la afirmación surgida de la Iniciativa global para el asma (GINA 2006): "La medida más importante para controlar los contaminantes intradomiciliarios del aire es evitar el tabaquismo pasivo y activo. El tabaquismo pasivo o indirecto aumenta la frecuencia y la severidad de síntomas en niños con asma. Los padres de niños con asma deben ser aconsejados no fumar y no permitir el fumar en cuartos de su uso de los niños. Además de síntomas de aumento del asma y de causar limitaciones a largo plazo en la función de pulmón, el tabaquismo activo reduce la eficacia los glucocorticosteroides inhalados y sistémicos (evidencia B) y la eliminación del tabaquismo debe ser vigorosamente recomendado a todos los pacientes con asma que fumen" 320 . 


\section{Tema 3. Hongos en el dormitorio no aumentan el riesgo}

Los géneros de hongos determinados responden aproximadamente al patrón de hallazgos en el aire interior de los trabajos consultados. El recuento fue mayor en la placa colocada en la ventana abierta, lo que hace pensar en una mayor concentración en el aire exterior, aunque con una composición similar, como se ha encontrado en otro estudio nacional ${ }^{321}$. La fuerte predominancia de Cladosporium, podría deberse a una de las actividades de mayor desarrollo en la ciudad como son los molinos y depósitos de granos, tal como se ha comprobado en otras investigaciones ${ }^{322}$. Como era esperable, se detectó mayor cantidad de colonias fúngicas en los ambientes con manchas de humedad en las paredes y en las viviendas ubicadas en zonas inundables. Como han hallado otros autores, la presencia de gatos aumenta claramente la OR para alta cantidad de esporas en el aire del dormitorio pero el intervalo de confianza incluye la unidad, por lo que se generan dudas en cuanto a su significado estadístico. Las alfombras no parecen asociarse al número de esporas en el aire. Se hallaron mayor cantidad de UFC en las placas colocadas en el dormitorio que en las otras habitaciones. Por el contrario, Li y Kendrick ${ }^{323}$ hallaron mayor cantidad de esporas en el living y en la cocina que en el dormitorio y un aumento relacionado con manchas de humedad y alfombras y disminución en las habitaciones que utilizaban aire acondicionado. Otro grupo en Taiwan $^{324}$ no encuentra relación entre humedad y mayor conteo de esporas.

No se pudo demostrar que la presencia de mayor cantidad de esporas fúngicas se relacione con un aumento del riesgo de asma infantil. Este resultado es concurrente con el estudio realizado por un grupo francés (Hulin et al (INSERM, Paris, France) ) $^{325}$, que si bien halló una asociación de hongos y asma en las viviendas rurales (OR: 2.95), no encontró diferencias significativas en las viviendas urbanas y periurbanas. Una cohorte canadiense estudiando 79 casos y 87 controles encuentra una OR indiferente para la presencia de hongos en el dormitorio ${ }^{326}$. En la investigación de Edmonson en USA ${ }^{327}$, cuyo objetivo fue caracterizar la posible etiología de los síntomas en asmáticos y alérgicos que los atribuían a la exposición a hongos, concluyeron que la mayoría podían atribuirse a alergias específicas tipo I a las esporas. Para relacionarlos con mecanismos tóxicos se requieren más estudios que vinculen con certeza los elementos aerobiológicos y fisiopatogénicos involucrados. Otro estudio ${ }^{328}$ realizado en Finlandia 
encontró una correlación entre las manchas de humedad, el conteo de esporas fúngicas y síntomas de irritabilidad ocular y aumento de frecuencia de infecciones respiratorias.

Puede plantearse la hipótesis que entre los atópicos con concentraciones elevadas de esporas fúngicas en el aire de sus dormitorios se incluyan los alérgicos a hongos, con síntomas de rinitis y/o asma como sucede con 11 niños en cuyos hogares se pudo efectuar la recolección.

Hay otra alternativa de detección de esporas y alérgenos fúngicos midiendo su presencia en el polvo doméstico, que no se efectuó en esta oportunidad por limitaciones en los recursos disponibles. Para completar una búsqueda de asociación de tipo I, debería realizarse en las mismas viviendas una detección de IgE específica antimicótica en sus habitantes y un estudio clínico especializado, confirmando lo que parece ser el más importante mecanismo fisiopatogénico, que vincula el asma infantil con las esporas fúngicas. 


\section{Tema 4. Formaldehido}

Necesidad de un indicador complejo de emisión.

Por ser emitido en diversos procesos y desde múltiples materiales, la posibilidad de evaluar la exposición al formaldehido, debe construirse con indicadores complejos, que los tengan en cuenta según sus respectivas potencialidades emisoras. Además de las tablas de madera reconstituida, tipo MDF, con las que actualmente se hacen casi todos los mobiliarios domésticos, la combustión de kerosene, gas, maderas y tabaco son fuentes importantes. La ventilación es el factor que puede corregir los riesgos de mayor concentración, pero es habitual que en las épocas frías se tienda a cerrar las ventanas y puertas que la posibilitan. El incremento de la temperatura interior aumenta la emisión por parte de las tablas MDF.

Como se explica en el capítulo 4 (Material y métodos) he construido una tabla para calcular indirectamente el riesgo, para los casos en que no pueda recurrirse a técnicas de medición directa del formaldehido en el aire interior. Esta aproximación, que se basa en datos publicados de mediciones realizadas por otros investigadores ${ }^{329}$, tiene el propósito de contribuir a una evaluación simple indirecta que pueda ser de utilidad en el primer nivel de atención sanitaria y orientar en la prevención del asma y otras patologías relacionadas con el formaldehido. Debería verificarse con un estudio combinado de esta evaluación con las respectivas mediciones directas para poder ajustarla a parámetros más certeros.

Aplicándola en la muestra, detecta un riesgo importante de asma en los niños expuestos. No parece asociarse al grado de severidad ni a la hiperirritabilidad bronquial. Esto último es coincidente con el estudio de Harving ${ }^{330}$ que no halla cambios en la prueba inhalatoria con Metacolina, postinhalación de dosis domésticas de formaldehido $(0,008,0,12$ y $0,85 \mathrm{mg} / \mathrm{m} 3$ en $90 \mathrm{~min})$. El ajuste en función de la ventilación no modifica sustancialmente los resultados, pero debe tenerse en cuenta que los elementos de mayor riesgo, que se refieren a la calefacción solo se usan en invierno, aunque en muchos hogares se utiliza el gas para cocina y calefón, durante todo el año.

Coincidentemente, autores norteamericanos ${ }^{331}$ han propuesto que la mezcla de polutantes producto de la combustión de diversos materiales, tiene como efecto el incremento de la morbilidad respiratoria en adultos asmáticos. Una hipótesis podría ser 
que hubiera moléculas comunes entre esos materiales, que generalmente son compuestos orgánicos volátiles (VOC), que al incrementarse por la sumatoria de emisiones produzca el efecto hallado, siendo el formaldehido una de ellas con impactos conocidos.

\section{Impacto parcial de las tablas MDF}

Si solo se evaluara el formaldehido a partir de presencia de tablas de madera reconstituida los resultados son poco concluyentes. Si bien se insinúa como factor de riesgo (OR 1,42) no es significativo el hallazgo con el intervalo de confianza planteado. No debería registrarse solo la presencia de este tipo de emisor para estudiar el riesgo por formaldehido.

\section{Hipótesis del efecto del formaldehido}

Pueden plantearse dos hipótesis fisiopatogénicas:

- Endotipo Th 2 alto con respuesta IgE específica (Wantke $(1996)^{332}$ ) aunque otros trabajos ${ }^{333}$ no han podido demostrarla.

- Fenómeno irritativo / inflamatorio inespecífico con respuesta endotípica Th 2 baja. La falta de asociación con un aumento de la HRB genera ciertas dudas sobre el mecanismo involucrado. En su presentación sobre la relevancia para la Salud pública, la Agencia para Sustancias Tóxicas y el Registro de Enfermedades norteamericana ${ }^{334}$ afirma que si bien es un metabolito intermediario normal en la biosíntesis de purinas, timidina y otros aminoácidos por las células, es una molécula muy reactiva que puede irritar en forma directa los tejidos al contactar con ellos en cantidades mayores. Mencionan reportes sobre reacciones alérgicas en piel, vías aéreas altas pero que la evidencia sobre el tracto respiratorio es poco convincente.

Las dificultades para reforzar desde el punto de vista experimental los hallazgos observacionales epidemiológicos, podrían deberse a la necesidad de muestras grandes y prolongados períodos de observación que son más dificultosas en las investigaciones experimentales. Por otra parte, las observaciones epidemiológicas podrían estar sesgadas por algún factor de confusión asociado ${ }^{335}$. 


\section{Inferencia causal}

Si bien para la Agencia toxicológica de los CDC norteamericanos (2008), los síntomas observados por inhalación de formaldehido son poco convincentes en cuanto a evidencias de manifestaciones en las vías aéreas bajas ${ }^{336}$, considero que revisando los trabajos previos detectados y construyendo un indicador de exposición que englobe una parte importante de los emisores puede afirmarse que existe una asociación causal con el asma infantil. A continuación expongo los argumentos para sostener esta hipótesis.

Directrices para considerar si una asociación es causal. Formaldehido y asma infantil.

\begin{tabular}{|c|c|c|}
\hline Directriz & $\begin{array}{l}\text { Información sobre formaldehido y asma } \\
\text { infantil }\end{array}$ & $\begin{array}{c}\text { Investigaciones complementarias } \\
\text { a realizar }\end{array}$ \\
\hline Relación temporal & $\begin{array}{l}\text { La encuesta sobre exposición a los } \\
\text { factores emisores, al realizarse en el } \\
\text { período inicial de la vida supone que es } \\
\text { previa o al menos contemporánea con la } \\
\text { aparición de los síntomas }\end{array}$ & \multirow[t]{2}{*}{$\begin{array}{l}\text { Estudio de cohorte desde el } \\
\text { período perinatal con seguimiento } \\
\text { clínico y evaluación ambiental de } \\
\text { emisores con determinaciones en } \\
\text { aire doméstico }\end{array}$} \\
\hline Fuerza de la asociación & Riesgo fuerte $^{337}$ : OR 2,56 IC 1,22/5,35 & \\
\hline $\begin{array}{l}\text { Relación dosis } \\
\text { respuesta }\end{array}$ & $\begin{array}{l}\text { Si se evalúan por separado los emisores, } \\
\text { la OR es claramente menor en todos los } \\
\text { casos, }\end{array}$ & $\begin{array}{l}\text { Determinación directa de la } \\
\text { molécula en el aire doméstico en } \\
\text { casos y controles y las } \\
\text { modificaciones en síntomas y } \\
\text { registros de función pulmonar. }\end{array}$ \\
\hline $\begin{array}{l}\text { Reproducción de las } \\
\text { observaciones }\end{array}$ & $\begin{array}{l}\text { Krzyzanowski (1990). Kramps (1989). } \\
\text { Wantke (1996) }\end{array}$ & $\begin{array}{l}\text { Estudio de casos y controles con } \\
\text { diferentes niveles de exposición y } \\
\text { ventilación }\end{array}$ \\
\hline Plausibilidad biológica & $\begin{array}{l}\text { fase gaseosa muy soluble en agua por lo } \\
\text { que irrita y penetra con facilidad las } \\
\text { mucosas del tracto respiratorio. Efecto } \\
\text { pulmonar en experimentaciones con } \\
\text { disminución de las funciones y aumento } \\
\text { de respuestas alérgicas a partir de } 0,1 \\
\text { ppm en aire }\end{array}$ & $\begin{array}{l}\text { Estudio experimental para } \\
\text { observar el endotipo de respuesta } \\
\text { patogénica frente al ingreso de } \\
\text { formaldehido en la mucosa } \\
\text { respiratoria }\end{array}$ \\
\hline $\begin{array}{l}\text { Consideración de } \\
\text { explicaciones } \\
\text { alternativas }\end{array}$ & Respuesta IgE específica dudosa & $\begin{array}{l}\text { Estudio de biología molecular en } \\
\text { animales o humanos con perfil } \\
\text { endotípico Th } 2 \text { alto. }\end{array}$ \\
\hline $\begin{array}{l}\text { Suspensión de la } \\
\text { exposición }\end{array}$ & Wantke (1996), ambientes escolares & $\begin{array}{l}\text { Estudiar el impacto de la supresión } \\
\text { en hogares muy expuestos }\end{array}$ \\
\hline $\begin{array}{l}\text { Coexistencia con otro } \\
\text { conocimiento }\end{array}$ & $\begin{array}{l}\text { Exposición laboral y efectos } \\
\text { respiratorios. Asma ocupacional }{ }^{339}\end{array}$ & \\
\hline
\end{tabular}




\section{Tema 5. Insecticidas}

\section{Patrones de uso de insecticidas}

El uso de insecticidas durante todo el año es bastante elevado (18\%) para el total de familias, siendo un poco menor para los casos (13\%). Los aerosoles y espirales, considerados de mayor riesgo, son usados por el 57\%. Un estudio español de una cohorte desde el embarazo 340 encuentra un $4 \%$ de uso de insecticidas en el dormitorio durante todo el año, predominando el empleo estacional (77\%) de aparatos eléctricos (75\%) y aerosoles $(26 \%)$.

No se observa un patrón de uso claramente diferente entre los casos y controles tanto en la consideración de la mayor utilización (factor de riesgo) como de una conducta preventiva que pudieran seguir en las familias de los casos. Por ejemplo no se asocia en las familias de atópicos con el uso de insecticidas en forma reducida.

\section{No es un claro factor de riesgo de asma infantil.}

La OR para el uso de insecticidas en el dormitorio se insinúa como un factor débil $(1,7)$ pero como el intervalo de confianza abarca la unidad y la prueba de $\chi^{2}$ no es significativa, no pueden plantearse una conclusión clara. Esta OR es similar a la hallada en el amplio y prolongado estudio californiano para el riesgo con piretrinas, donde registraban todo tipo de síntomas pero predominaban los respiratorios.

El uso intenso de insecticidas duplicaría el riesgo de hiperirritabilidad bronquial. 


\section{Tema 6. Sistemas de calefacción}

Los sistemas de calefacción, en forma particular, no se asocian significativamente con el riesgo, pero parece haber una conducta preventiva (sesgo de información) en las familias de los casos que los lleva a utilizar aparatos eléctricos de baja o nula emisión o simplemente no colocar aparatos en el dormitorio.

La distribución entre casos y controles es prácticamente idéntica tanto si se clasifican según la potencialidad emisora planteada o en función de los cuartiles de la emisión de formaldehido en ppm. Asociados en el indicador de formaldehido que he propuesto, las estufas de gas, kerosene o leña sin tiro balanceado y las cocinas de gas o leña, son un importante factor de riesgo. La diferencia en este resultado que si da claramente positivo está en que el aporte en ppm de los otros emisores alcanza para sobrepasar también el punto de corte (que tiene poca diferencia entre las dos comparaciones), para considerar la categoría de riesgo, sumando más casos que controles en esta situación.

Sorprendentemente, un amplio estudio de cohorte canadiense halla un efecto protector en las estufas de leña ${ }^{341}$. Citando a Volkmer ${ }^{342}$ suponen que la chimenea puede generar una ventilación adecuada. También mencionan la hipótesis de Levesque ${ }^{343}$ de que se produce una disminución de la humedad con la consiguiente disminución de hongos anemófilos. 
Tema 7. Otros factores contribuyentes del aire interior

\section{Alfombras:}

Las OR bajas orientan hacia algún posible efecto protector para la aparición del asma, el aumento de la severidad y la hiperirritabilidad bronquial, aunque los IC 95\% y las pruebas de $\chi^{2}$ no son significativas para las dos últimas.

Este resultado, se contrapone con la probabilidad de mayor desarrollo de colonias de ácaros y su efecto en los niños alérgicos a ellos, que en esta ciudad son la mayoría entre los atópicos según la propia experiencia clínica. Por el contrario podría explicarse por la controvertida hipótesis higiénica que favorece la respuesta endotípica Th 1 disminuyendo el riesgo de alergia.

Otra explicación del predominio entre los casos del no uso de alfombras podría adjudicarse a una conducta preventiva familiar bastante difundida sobre todo en familias de asmáticos y alérgicos. Esta hipótesis se refuerza con el resultado del cruce entre niños atópicos y evitación de alfombra en el dormitorio, con una fuerte asociación, estadísticamente muy significativa.

\section{Manchas de humedad:}

Las manchas de humedad en el dormitorio no aumentan el riesgo de asma. Esto es coincidente con el resultado de la evaluación del riesgo frente a las esporas fúngicas, que no es significativo estadísticamente. Se asocian a mayor presencia de esporas fúngicas en el aire pero el resultado no es significativo. Un estudio ${ }^{344}$ realizado en Finlandia encontró una correlación entre las manchas de humedad, el conteo de esporas fúngicas y síntomas de irritabilidad ocular y aumento de frecuencia de infecciones respiratorias. Debe tenerse en cuenta en estos resultados que hay una cierta proporción de alérgicos tipo I que puede variar en diferentes países y etnias.

\section{Aire acondicionado}

En la muestra estudiada no se detectó ningún aparato de aire acondicionado central que es excepcional en esta ciudad para viviendas. Si bien el aire frío y seco puede actuar como irritante bronquial, particularmente en los casos de hiperirritabilidad bronquial (HRB), se ha planteado que el efecto deshumidificador y filtrante del ambiente de los acondicionadores de aire de ventana o tipo "Split", disminuye la presencia de 
ácaros del polvo doméstico y de hongos aerógenos. En este sentido tendrían un efecto protector, que es lo que se insinúa en esta muestra aunque las diferencias no son significativas. 


\section{Tema 8. Contaminantes atmosféricos}

No pudo confirmarse el hallazgo del estudio de corte transversal realizado para una muestra más grande de 529 niños (126 casos y 403 controles). El riesgo era significativo para quienes vivían en las cercanías de los grandes frigoríficos del sur de la ciudad y en la de dos arroceras. En el estudio de casos y controles que presento para profundizar en la valoración del hipotético riesgo hallado, el único sector de los seleccionados en toda la ciudad que muestra una OR elevada $(2,4$ IC 1,01 / 5,65) y estadísticamente significativa $\left(\chi^{2} 4,17 \mathrm{P} 0,04\right)$ es el que rodea al semicírculo norte, entre los $500 \mathrm{~m}$ y $1000 \mathrm{~m}$ de distancia de los frigoríficos de la costa del arroyo de la China. El semicírculo sur, del otro lado del arroyo está prácticamente despoblado. El hecho de que los niños que viven más cerca (a menos de $500 \mathrm{~m}$ ) no presenten este riesgo (OR 0,56 IC $0,11 / 2,85)$ genera dudas sobre la relación de los efluentes atmosféricos de estas industrias con el aumento de la prevalencia del asma. Para el aumento la frecuencia de casos en quienes viven en una franja que se sitúa entre los $500 \mathrm{~m}$ y 1.000 podrían proponerse algunas hipótesis, que deberían comprobarse con mediciones de partículas y gases en terreno. Por ejemplo, podría ser que la emisión desde las chimeneas y aereadores emitiera a cierta altura las partículas, que luego se precipitarían realizando una curva, que superara los 500m y recién se concentraran a nivel de la respiración humana entre los $500 \mathrm{~m}$ y $1000 \mathrm{~m}$.

En ninguno de los sectores, incluido el mencionado anteriormente, se halló una OR que pueda expresar un riesgo o protección frente a la severidad del asma o la hiperreactividad bronquial.

Para confirmar estos hallazgos deberían realizarse estudios complementarios con determinaciones cuantitativas de contaminantes aéreos mediante monitoreos vinculados a los diferentes momentos de la actividad productiva.

Este resultado, aunque con métodos diferentes, coincide con las conclusiones del meta-análisis “ESCAPE” que describiéramos en el capítulo 3. 


\section{Tema 9: zonas inundables}

El riesgo de asma infantil se cuadruplica en los niños que viven en una zona inundable y con mayor nivel de humedad ambiente. En principio podrían diferenciarse dos posibles conjuntos de factores de riesgo, no excluyentes entre sí que podrían explicar este resultado:

- los relacionados con aspectos físicos y biológicos propios del hábitat

- la posible vinculación con carencias socioeconómicas.

\section{Aspectos relacionados con el hábitat.}

En un estudio de casas inundadas en New Orleans, USA, se hallan altos niveles de esporas fúngicas y endotoxinas, similares a los de ámbitos rurales ${ }^{345}$. Como se expuso en el tema 3 sobre hongos, no se pudo demostrar una asociación clara entre conteo de esporas y prevalencia de asma, por lo que debería profundizarse el estudio de las endotoxinas y una cuantificación en volúmenes de aire para evaluar si existe algún efecto sobre el riesgo de asma infantil. Las endotoxinas se consideran factores contribuyentes del asma (ver Tabla 2.3).

El contenido de humedad en el aire afecta las mucosas respiratorias, considerándose que es el aire más seco el que genera irritación de las vías aéreas. En este sentido la probable mayor humedad predominante en las áreas inundables estudiadas actuaría como efecto protector.

Por otra parte, es sabido que los ácaros se ven favorecidos por los ambientes húmedos (70 a $80 \%$ de humedad relativa ambiente). La humedad de equilibrio crítico para el mayor desarrollo de las hembras de Dermatofagoides farinae es de $70 \%$ a $25{ }^{\circ} \mathrm{C}^{346}{ }^{347}$. Humedades superiores al $85 \%$ pueden generar competencia de colonias de hongos y bacterias. Como son una causa muy frecuente de asma alérgico, podrían ser la explicación más importante como parte de una asociación causal (humedad + ácaros + predisposición alérgica a ácaros). Para confirmarla deberían realizarse las pruebas alergológicas in-vivo o in-vitro para confirmar o descartar su relación causal así como determinar la densidad acarológica en esos ambientes. 
Áreas degradadas, pobreza y asma.

Estas viviendas, ubicadas a la vera de los pequeños arroyos, cañadas y zanjones intraurbanos, son en general precarias o muy precarias, y los peridomicilios pueden clasificarse como áreas ambientalmente degradadas, por lo que debe tenerse en cuenta a la pobreza como un posible factor contribuyente agregado 348349 . Por ejemplo, un estudio reciente en la isla de Madagascar planteó una relación entre la disminución funcional pulmonar en niños y la pobreza ${ }^{350}$.

La determinación de los ingresos familiares en nuestra investigación, sin embargo, mostró que solo el $50 \%$ de las familias que vive en estas zonas se hallaba bajo el nivel de pobreza, aunque la proporción es superior a la muestra general (39\%). Como puede verse en un mapa a continuación, las zonas inundables corresponden a familias con un índice de vulnerabilidad social (IVS) alto e incluso muy alto (Flechas blancas que señalan las tres áreas principales). Este índice de vulnerabilidad social diseñado por Griselda Carñel, Patricia Costa y col. (UNER 2013), está conformado por los siguientes indicadores: cobertura de salud, precariedad de la vivienda y NBI por lo que resulta complementario con el nivel de ingreso que determinó nuestra encuesta. Los datos del IVS son analizados a nivel fracción y radio censal, extraídos del Plan Estratégico de Concepción del Uruguay (2009), elaborado en gran parte por los datos del INDEC, Censo 2001. 


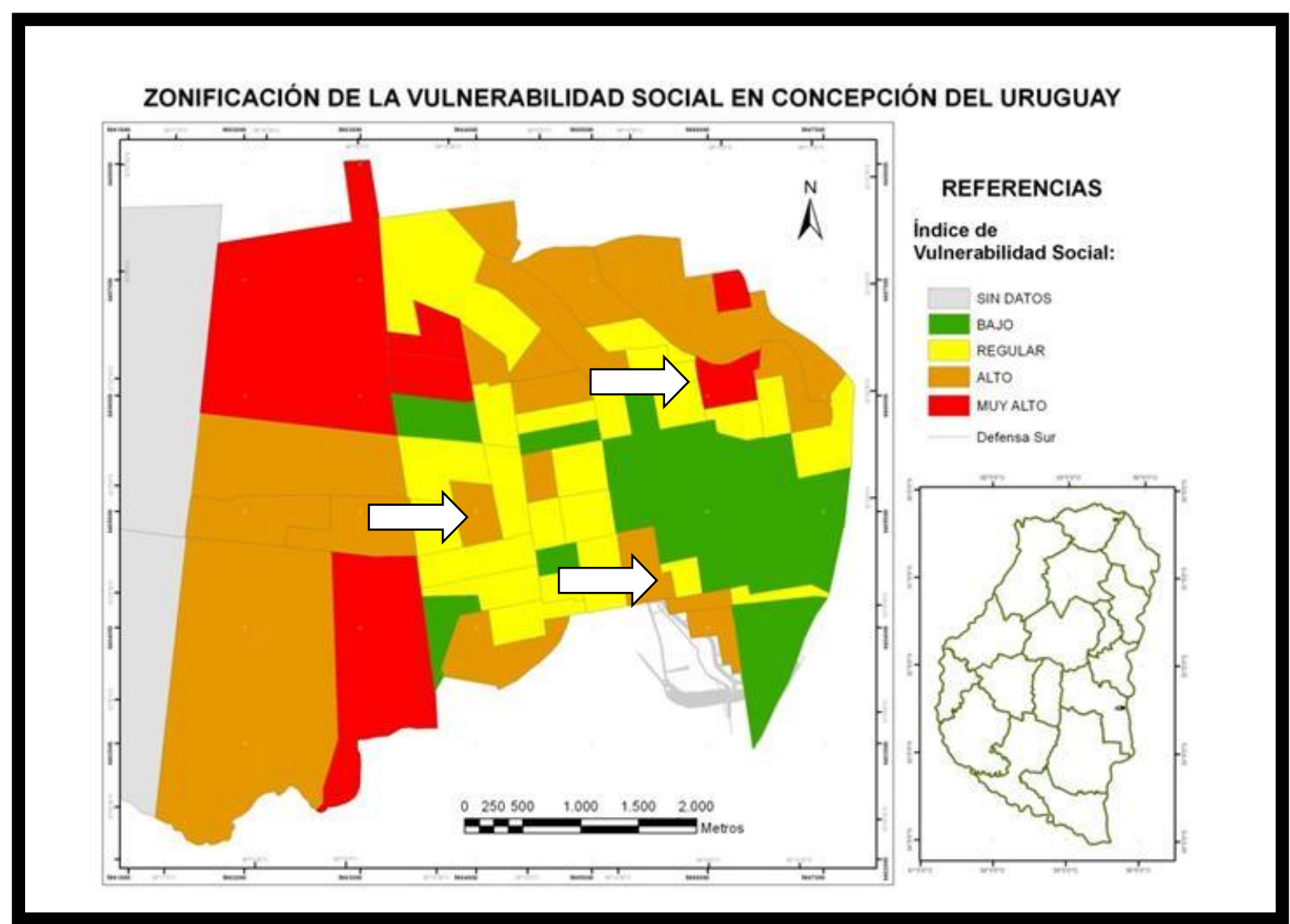

Modificado del Mapa elaborado por Carñel G, Costa Patricia et al. "Caracterización espacial por riesgo ambiental en la ciudad de Concepción del Uruguay con herramientas TIGs" Informe final PID-UNER 10053. 2013

Si se evalúa el riesgo de asma infantil según el índice de vulnerabilidad social muy alta, sumando todas las familias en ese nivel sin diferenciar por zonas inundables el resultado no demuestra una asociación clara:

\begin{tabular}{|c|c|c|c|c|}
\hline \multicolumn{4}{|c|}{ Tabla 8.8 Índice de vulnerabilidad social y riesgo de asma } \\
\hline & casos & controles & total & $\%$ \\
\hline VS muy alta & 24 & 70 & 94 & 18 \\
\hline otros niveles & 102 & 333 & 435 & 82 \\
\hline total & 126 & 403 & 529 & 100 \\
\hline OR 1,12 & $\mathrm{IC} 0,67 / 1,87$ & $\mathrm{X} 2: 0,18$ & $\mathrm{P}: 0,66$ & \\
\hline
\end{tabular}

Este resultado reforzaría la hipótesis de que la pobreza o la indigencia no influyen fuertemente en el resultado tan positivo de las zonas inundables. Un trabajo cooperativo realizado en niños cubanos $^{351}$, tampoco halló relación entre el nivel socioeconómico bajo y el riesgo de asma. 
Si bien se halló una OR 1,8 para la mayor presencia de esporas fúngicas en las viviendas de terrenos inundables, el IC y las pruebas de significado fueron negativas para reforzar esta asociación insinuada, que a priori parece bastante obvia.

Fracción de riesgo atribuible a la localización de la vivienda en zonas inundables

Si bien son altas tanto la odds ratio $(4,46)$, como el riesgo relativo para expuestos durante 5 años $(1,86)$ y la incidencia acumulada de expuestos en los primeros 5 años de vida (41\%), la fracción de riesgo atribuible en la población es relativamente baja (8\%) porque solo el $10 \%$ de los uruguayenses viven en estas zonas inundables. 


\section{Conclusiones y propuestas}

\section{Contrastación de hipótesis planteadas.}

Luego de la profundización en el conocimiento de trabajos experimentales y epidemiológicos y de haber ensayado diversas posibilidades explicativas con los resultados de la presente investigación epidemiológica poblacional, se puede afirmar frente a cada hipótesis establecida al inicio del proyecto:

La primera hipótesis se refería a que "la mayor exposición a riesgos ambientales domésticos inespecíficos (irritantes como el humo del tabaco y otros emisores de formaldehido, uso de insecticidas, etc....) se asocia positivamente con la severidad del asma".

Pudo demostrarse la utilidad de un indicador de contaminación fisicoquímica del aire doméstico con formaldehido, que combine adecuadamente las potencialidades emisoras de distintos materiales, con sus correspondientes procesos y entornos. Como se ha explicado anteriormente con este indicador se miden efectos del humo de tabaco, de la combustión del kerosene, gas y maderas y la presencia de tablas MDF emisoras en muebles, paredes, pisos y techos. Se asocia fuertemente al riesgo de asma infantil aunque no a la severidad.

Como en general los insecticidas no emiten formaldehido y de por si generan efectos dudosos en relación con el asma, asociarlos en un solo indicador debilita su interpretación y utilidad. Lo mismo puede decirse de otros potenciales factores inespecíficos de riesgo. La exploración de resultados combinando todos los posibles factores inespecíficos de riesgo en el aire interior no arrojó resultados concluyentes ni se logró elaborar un indicador basado en emisiones, concentraciones y efectos demostrados. Por lo tanto se descartó su presentación para evitar interpretaciones equívocas.

La segunda hipótesis se refería a que "la mayor exposición a hongos aerógenos en el dormitorio se asocia con el riesgo de asma, con la consecuencia empírica de que "la mayor cantidad de UFC/cápsula abierta en las respectivas habitaciones de casos y controles se asocia positivamente con el asma $\left(\chi^{2}, O R\right)^{\prime \prime}$. 
No pudo demostrarse la asociación mencionada, por lo que no habría un efecto inespecífico irritante o tóxico que conduzca a la aparición de asma infantil. La presencia aumentada de esporas fúngicas sería causa de asma solo en quienes tienen IgE específica contra esos antígenos, que en función de la práctica clínica local y las diversas publicaciones relevadas es de prevalencia relativamente baja.

La tercera hipótesis planteaba que "Las instalaciones portuarias y otras vinculadas al depósito y secado de soja y demás fuentes emisoras de contaminantes atmosféricos generan un área de mayor riesgo asociado con la distancia de viviendas y escuelas y los vientos predominantes".

Aparece un riesgo elevado para quienes viven en una franja ubicada entre los $500 \mathrm{y}$ los 1000 metros de los frigoríficos, que podrían estar afectados por una trayectoria de los contaminantes aéreos que pasarían a un nivel más elevado hasta los 500 metros de distancia. La emisión al aire de estas industrias, algunas de ellas de gran volumen de trabajo, se genera en chimeneas que conducen el humo desde las calderas, conteniendo productos de la combustión de hidrocarburos. Habitualmente funcionan en forma continua todo el año.

No pudo demostrarse una relación clara entre la cercanía a las fuentes emisoras de partículas de soja, arroz y otros granos con una mayor prevalencia del asma. Entre las posibles explicaciones a este hallazgo pueden plantearse:

- La densidad de contaminantes producidos no superó el umbral necesario para causar efectos mecánicos o químicos irritantes inespecíficos

- Los casos de asma solo se manifiestan en quienes están genéticamente determinados para reaccionar en forma específica mediante IgE como podría ser con el polvo de soja y por lo tanto el impacto es más selectivo.

La cuarta hipótesis se refería a "La ubicación de las viviendas en terrenos de poca altura y aledaños a arroyos, con mayor humedad relativa se asocia a mayor riesgo de asma". La subhipótesis con derivaciones prácticas planteaba: "Las viviendas ubicadas por debajo de la cota $8,25 \mathrm{~m}$. aledaños a cursos de agua se asocian a mayor presencia de asmáticos". 
Esta hipótesis fue corroborada claramente por el análisis de los datos relevados: OR: 4,46, IC 95\% 1,13/17,62, $\chi^{2}: 5,38, \operatorname{Pr}>\chi^{2} 0,02$.

\section{Aspectos más destacables de lo hallado}

En esta ciudad, con prevalencia alta de asma infantil, se halla un $16 \%$ de niños compatibles con el fenotipo de asma intrínseco muy temprano transitorio, con endotipo Th2 bajo, generalmente asociado a bronquiolitis y otras virosis respiratorias severas en los primeros meses de vida. En general no son alérgicos, aunque la mitad puede tener antecedentes familiares y tienden a mejorar hasta permanecer asintomáticos luego de los 5 años de edad, pero continúan con hiperirritabilidad bronquial acentuada el $38 \%$ de ellos, con respuestas a desencadenantes físicos en un porcentaje similar. Si se tiene en cuenta la hipotética evolución hacia una enfermedad pulmonar obstructiva crónica (EPOC) en la adultez, deberían encarar una actitud preventiva más cuidadosa en cuanto a higiene respiratoria.

Un grupo mayor (24\%), corresponde al fenotipo de asma infantil alérgica de perfil endotípico Th2 alto, genotipo atópico. El comienzo es anterior a los 5 años, habiéndose registrado antecedentes de sibilantes en ese período en el 95\% de los casos (OR 57 IC95\% 24/135). Predominan los cuadros leves (70\%) y se halló un 15\% de severos. Se asocian a Rinitis y Dermatitis atópicas. La mayoría no tiene un diagnóstico explícito de Asma y es tratada por los pediatras sin enfocar terapéuticas específicas de su alergia ni entregar instrucciones claras de manejo preventivo.

Según la percepción familiar, los desencadenantes inespecíficos (cambios climáticos, aire frío o acondicionado, humo de cigarrillo, olores fuertes, perfumes y aerosoles varios, emociones, llantos y risa) muestran una OR muy alta que supera a las probables virosis y los alérgenos como desencadenantes.

Los niños asmáticos o no, con hiperreactividad bronquial alta o media, tienen cinco veces más riesgo de presentar sibilantes frente a desencadenantes inespecíficos, lo que es coherente con la hipótesis del bajo umbral de excitabilidad bronquial como predisponente para la respuesta a los estímulos inespecíficos de tipo físico o químico, con efecto irritativo que seguiría la vía neurogénica.

Los llamados factores ambientales "inespecíficos" de riesgo generan en muchos casos respuestas "específicas" y en otros ejercen efectos sinérgicos o sumatorios en el 
caso de compartir moléculas como sucede con los emisores de formaldehido. También pueden actuar como factores contribuyentes movilizando alérgenos polínicos, fúngicos y de polvos diversos, sobre todo en los cambios climáticos.

La exposición al formaldehido genera un riesgo elevado, duplicando la probabilidad de presentar Asma. Es importante para estimar el riesgo tener en cuenta todos los posibles emisores en proporción a su capacidad de generar la contaminación aérea. La asociación con el asma es claramente más fuerte en los niños no atópicos.

Puede destacarse, como un resultado sorprendente, que el tabaquismo pasivo solo se insinúa como factor de riesgo ambiental, porque los intervalos de confianza de la OR no permiten inferir con más seguridad su influencia en la aparición de casos. El tabaquismo pasivo no parece afectar el riesgo de presentar síntomas de atopia, pero en el $17 \%$ de atópicos expuestos que evolucionaron como casos de Asma es posible que haya una proporción importante de alérgicos al tabaco.

Planteo como hipótesis a comprobar en investigaciones complementarias que en el caso del tabaquismo y posiblemente de la mayoría de los factores llamados inespecíficos, las investigaciones epidemiológicas deben diferenciar a los casos e incluso a los controles según sus diferentes genotipos y endotipos, para poder hallar resultados más claros.

Las esporas fúngicas no parecen asociarse a mayor riesgo de asma, lo que refuerza la hipótesis de que solo juegan un rol importante como alérgenos para quienes están predeterminados a reaccionar con respuesta tipo I a sus determinantes antigénicos.

No se pudo demostrar que los insecticidas sean un claro factor de riesgo de asma infantil aunque si duplican la posibilidad de que la HRB este aumentada cuando el uso es intenso.

Algunos elementos presentes en el dormitorio como las alfombras, las manchas de humedad, el uso de desodorantes de ambientes, la presencia de vegetación en el interior de la vivienda, la cercanía a talleres y depósitos, la percepción de partículas en suspenso en la vivienda, la quema de basuras o podas en el entorno tampoco se 
muestran como factores claros de riesgo. El trapo húmedo como método de limpieza del dormitorio tiene un efecto protector.

La cercanía a emisores de contaminantes atmosféricos vinculados a la emisión de partículas de soja y otros cultivos, no genera un riesgo aumentado de asma infantil. Por el contrario, la población que vive en una franja entre 500 y 1000 metros de distancia de los frigoríficos presentan una mayor probabilidad de casos de asma infantil.

Vivir en zonas inundables representa un evidente factor de riesgo de asma infantil.

Puede plantearse como síntesis conclusiva que si bien la mayoría de los elementos ambientales inespecíficos investigados no tienen una relación clara como causales del asma infantil, tanto la exposición alta al formaldehido en aire como la ubicación de las viviendas en zonas bajas de inundación frecuente, son factores causales inespecíficos evidentes, aunque ni suficientes ni necesarios. Pero deben tenerse en cuenta en la toma de decisiones tanto clínicas como sanitarias para mejorar las posibilidades de prevención en sus tres niveles. Surge entonces una pregunta interesante: ¿Cuál sería el impacto en Salud en Concepción del Uruguay si se lograra reducir ambos factores? El cálculo de la fracción de riesgo atribuible puede aportar en este sentido.

\section{Riesgo atribuible}

Para estimar los posibles beneficios preventivos que podrían lograrse actuando sobre algunos de los factores detectados como de mayor importancia, se exponen en la tabla siguiente las proporciones de los factores que presentaron una OR o RR significativo.

\begin{tabular}{|l|c|c|}
\hline \multicolumn{1}{|c|}{ Factor } & $\begin{array}{c}\text { Fracción de Riesgo } \\
\text { atribuible en la muestra } \\
\text { de expuestos }\end{array}$ & $\begin{array}{c}\text { Proporción de Riesgo } \\
\text { atribuible poblacional }\end{array}$ \\
\hline Zonas inundables & $46 \%$ & $8 \%$ \\
\hline formaldehido & $9,7 \%$ & $2 \%$ \\
\hline tabaquismo pasivo & $6 \%$ & \\
\hline & & \\
\hline
\end{tabular}


No se calculó el riesgo poblacional para el formaldehido por carecer de la información necesaria para evaluar la proporción poblacional de expuestos. Dada la aparentemente muy difundida utilización de los materiales emisores de esta sustancia, es probable que el riesgo atribuible en la muestra pueda extrapolarse al universo de la ciudad, por lo que el impacto sanitario de su evitación podría alcanzar hasta un $10 \%$ de reducción de casos de Asma infantil. Si se lograra el traslado de las familias a zonas no inundables (ampliamente disponibles) la reducción podría rondar el 8\% de los casos a los 6 años de edad. 


\section{Propuesta de investigaciones complementarias}

Para revisar las conclusiones de esta Tesis deberían realizarse algunas investigaciones complementarias, entre las que pueden destacarse:

1. Cohorte desde nacimiento (incluyendo últimos dos meses de embarazo) hasta los 10 años para calcular la incidencia de asma y la asociación a los factores de riesgo involucrados en el aire contaminado con humo de tabaco, en los emisores de formaldehido, en el hábitat con inundaciones frecuentes $y$ en los contaminantes del aire exterior, relevando también las variables endógenas de control y la reactividad específica (respuesta IgE frente a tabaco, hipotética IgE específica frente a formaldehido, respuesta IgE específica contra piretro, piretrinas y frente a partículas del aire exterior como soja y otras). El tamaño de la muestra debería superar los mil niños para potenciar el análisis estadístico, medir variables cuantitativas y aplicar el análisis multinivel. Su realización en un trabajo cooperativo multicéntrico en dos o tres ambientes diferentes enriquecería las posibilidades de plantear conclusiones más sólidas y lo haría más factible. Es necesario vincular lo planteado con la propuesta 2 que se enuncia a continuación.

2. Determinación en el aire doméstico y en el exterior de las partículas y gases considerados de riesgo para el Asma tanto como factores causales como contribuyentes o irritantes, en un monitoreo que abarque al menos varias mediciones en un período anual con relevamiento simultáneo de las fuentes productoras y sus respectivas actividades emisoras, así como las variables meteorológicas. Debería complementarse con un registro de exacerbaciones en una muestra de niños seleccionada al azar, por conglomerados representativos de la densidad poblacional y de la distribución territorial. 


\section{Recomendaciones sanitarias.}

\section{Aspectos de atención a las personas}

\section{Autocuidado familiar}

- Evitar el tabaquismo activo o pasivo en las embarazadas

- Educar y promover la percepción temprana de síntomas compatibles con asma y consultas de control pediátrico.

\section{Atención médica}

- Diagnóstico precoz de asma muy temprano infantil

- Tratamiento oportuno y orientado etiopatogénicamente

- Actualización en la formación pediátrica sobre los diversos genotipos, fenotipos y endotipos de asma infantil y sus respectivas orientaciones terapéuticas

- Enfoque preventivo del asma infantil en la mujer embarazada con asma 352

- Consulta oportuna al Especialista en Alergia e Inmunología, al Neumólogo y al Otorrinolaringólogo según el caso, acordando mecanismos eficientes de referencia y contrarreferencia

- Entregar recomendaciones escritas a las familias para guiar las conductas preventivas, con monitoreo de síntomas y sin exagerar en las restricciones 


\section{Aspectos de salud ambiental}

Se mencionan las principales medidas dirigidas a los tres factores de riesgo ambiental inespecífico hallados en esta investigación: formaldehido, insecticidas y vivienda en zona inundable.

\section{Prevención en el ambiente doméstico}

Para disminuir la exposición respiratoria a formaldehido en el aire interior, deben reducirse los principales emisores:

- Evitar el tabaquismo en la casa y en los automóviles, aún en horarios que no están los niños

- Evitar los sistemas abiertos de calefacción o cocina que implican combustión de hidrocarburos (gas o kerosene), de maderas y carbones (braseros, estufas $u$ hogares de leña, salamandras), que emitan humos, partículas y gases al ambiente interior.

- Evitar o disminuir al máximo posible el uso de placas de madera comprimida y reconstituida (MDF, fórmica, etc...) para mobiliario, paredes, pisos y techos sobre todo las de alta y media emisión o no controladas y sin cobertura hermética.

- Mantener, durante todo el día, una adecuada ventilación del dormitorio y otros ambientes que puedan contener los emisores mencionados y otros como pegamentos de papeles en pared y alfombras.

- Prelavar las vestimentas y otras telas nuevas que hayan sido tratadas con formaldehido (aprestos y planchado permanente).

Para disminuir el riesgo de aumento de hiperirritabilidad bronquial (no solo en asmáticos) que produce el uso intenso y frecuente de insecticidas en el dormitorio, deberían desarrollarse otro tipo de medidas de control de insectos como mosquiteros, repelentes, descacharrización y control de humedales en los espacios aledaños a la vivienda, que sean propicios para la multiplicación de los mosquitos. 


\section{Ordenamiento territorial}

- Evitar la instalación de nuevas viviendas en zonas inundables (por debajo de las cotas máximas de inundación)

- Diseñar un Programa de progresiva erradicación de las ya instaladas en zonas inundables, que incluya una respuesta adecuada tanto en la calidad de la vivienda como en las características de la nueva localización.

- Parquización de las zonas inundables con flora autóctona y equipamiento urbano de bajo costo o trasladable.

- Vigilancia para evitar nuevas radicaciones de viviendas en las áreas incorporadas al Programa

\section{Epílogo.}

Al comenzar esta Tesis se plantean algunas preguntas introductorias. Luego de haber transitado un largo período de estudio sobre el estado de la cuestión y haber recolectado, procesado y analizado una serie numerosa y variada de datos, puedo responder a aquellos interrogantes.

Considero de gran interés estudiar la epidemiología del Asma infantil en escenarios urbanos y rurales diversos ya que los factores ambientales inespecíficos, por estar algo menos vinculados a la genética, variarán de acuerdo a muy diferentes circunstancias. Es recomendable desde el punto de vista sanitario y clínico el conocimiento de las situaciones locales.

Hay múltiples y contradictorias posiciones sobre los factores de riesgo, causales, predisponentes y desencadenantes, basadas en argumentaciones científicas, clínicas y epidemiológicas. Es necesario, desde un enfoque complejo y sistémico, buscar la articulación descriptiva de la interacción entre los diferentes genotipos, endotipos y fenotipos con el ambiente interior y exterior. Parafraseando a Edgard Morin, el teórico de la Complejidad, se podría decir que, estudiando el asma navegamos en un océano de incertidumbres pero debemos hallar los islotes de certezas que nos permitan aportar para una mejor calidad de vida de tantos niños asmáticos. Creemos haber aportado para 
la ubicación y consolidación de algunos de esos deseables islotes y para evitar la desorientación provocada por concepciones no demostrables.

Logrando aquella articulación y el conocimiento de las realidades locales, se podrán realizar aportes de interés para la acción sanitaria y la atención clínica de una de las enfermedades crónicas infantiles de mayor prevalencia en el mundo. 


\section{Bibliografía}

1. Abbate E y Crisci C. Consideraciones generales. Definición y fisiopatogenia. Módulo 1 del Curso de actualización a distancia en Asma. Estrategia global para el manejo y la prevención del Asma. 1998-99. INTERASMA, GINA, Facultad de Ciencias médicas de la Universidad Nacional de Rosario. Argentina.

2. Agencia para Sustancias Tóxicas y el Registro de Enfermedades. "Desencadenantes ambientales del asma". CDC. Centros para el Control y la Prevención de Enfermedades. 1600 Clifton Rd Atlanta, GA 30333 USA. 2008

3. Agrawal, $\mathrm{S}$ et al Biopsia bronquial y lavado bronquioalveolar en el diagnóstico del asma en niños. Role of periostin, FENO, IL-13, lebrikzumab, other IL-13 antagonist and dual IL-4/IL-13 antagonist in asthma. Rev. Expert Opinion on Biological Therapy 2014 Vol. 14 Nro. 2 Página: 165 - 81

4. Anandan C et al. Is the prevalence of asthma declining? Systematic review of epidemiological studies. Allergy 2010. 65:152-167.

5. Ardusso L. Crisci C, Codina R, Lockey R et al, Asociación entre exposición a polvo de soja, sensibilidad alérgica y perfil de síntomas respiratorios. MEDICINA (Buenos Aires) 2000; 61: 1-7

6. Armentia A, et al. El tabaco como alérgeno en enfermedad bronquial obstructiva. Estudio preliminar. Alergol Inmunol Clin 2005; 20: 14-27

7. Asher MI, Keil U, Anderson HR, Beasley R, y otros. Internacional Study of Asthma and Allergies in Childhood (ISAAC): Rationale and methods. Eur Resp J 1995; 8:483491

8. Baena-Cagnani C. y Gené R. Factores de riesgo. Módulo 3 del Curso de actualización a distancia en Asma. Estrategia global para el manejo y la prevención del Asma. 1998-99. INTERASMA, GINA, Facultad de Ciencias médicas de la Universidad Nacional de Rosario. Argentina

9. Balanzat A, Urrutigoity J. Consenso de Asma bronquial. 2007. Arch Argent Pediatr 2008; 106(1): 61-68.

10. Barnes Ch et al. Frequency of Fungi in Homes of Pediatric Allergy Patients. Allergy Clin Immunol Int. 18/5 (2006) 
11. Barnes P, Grunstein M, Leff A, Woolcock A. Asthma. Lippincott Raven Publishers, Philadelphia. 1997

12. Barrett EG, Wilder JA, March TH, Espindola T, Bice DE: Cigarette smoke-induced airway hyperresponsiveness is not dependent on elevated immunoglobulin and eosinophilic inflammation a mouse model of allergic airway disease. Am J Repir Cir Care Med 2002, 165:1410-1418.

13. Beasley R y otros (The International Study of Asthma and Allergies in Chilhood (ISAAC) Steering Committee. Worldwide variation in prevalence of symptoms of asthma, allergic rhinoconjunctivitis and atopic eczema: ISAAC. The Lancet. Vol 351. 1998

14. Beasley R y otros. "International time trends in Asthma mortality". Cap. de Asthma: a link between Environment, Immunology and the Airways. Editors: Neffen H., Baena Cagnani C. y otros. Hogrefe \& Huber publishers, Buenos Aires, 1999.

15. Bedolla-Barajas Martín et al. Asthma in Mexican school-age children is not associated with passive smoking or obesity. http://dx.doi.org/10.5415/apallergy.2013.3.1.42 Asia Pac Allergy 2013;3:42-49

16. Blythe M. Some aspects of the ecological study of the house dust mites. Brit.J.Dis. Chest (1976) 70, 3

17. Bradberry SM Poisoning due to pyrethroids. Toxicol Rev. 2005;24 (2):93-106.

18. Bukstein Don y Strunk R. Problemas clínicos en asma y alergia. Ed. Salvat. 1988. Buenos Aires.

19. Bush, Robert K. MD and Portnoy Jay M., MD. The role and abatement of fungal allergens in allergic diseases. J ALLERGY CLIN IMMUNOL vol 107, number 3. $3 / 2001$

20. Caffarelli $\mathrm{C}$ et al. Anafilaxia inducida por ejercicio y en relación con la ingestión de múltiples alimentos. Allergy and Asthma proceedings, vol XII n 1.1998

21. Çaliskan $M$, et al. Rhinovirus wheezing illness and genetic risk of childhood-onset asthma. N Engl J Med. 2013; 368: 1398-407

22. Carlsen K. Asthma and Allergy in Sportsmen. ACI Internacional13/4 2001 
23. Carñel G, Costa Patricia et al. "Caracterización espacial por riesgo ambiental en la ciudad de Concepción del Uruguay con herramientas TIGs" Informe final PID-UNER 10053. 2013

24. Castro-Rodriguez JA, Holberg CJ, Wright AL, Martinez FD. A clinical index to define risk of asthma in young children with recurrent wheezing. Am J Respir Crit Care Med 2000; 162:1403-6.

25. Caudri D, Wijga A, Schipper CM, Hoekstra M, Postma DS, Koppelman GH, et al. Predicting the long-term prognosis of children with symptoms suggestive of asthma at preschool age. J Allergy Clin Immunol 2009; 124:903-10, e1-7.

26. Cedrato Angel, De Lellis R., Greiding L, Grinstein M. Progresos en Alergia e Inmunología pediátrica. Ed. Celcius. 1984. Buenos Aires.

27. Chalmers, G.W.; MacLeod, K.J.; Thomson, L.; Little, S.A.; McSharry, C.; Thomson, N.C Smoking and airway inflammation in patients with mild asthma CHEST Vol. 120 Nr. 6 Página: 1917 - 1922 Fecha de publicación: 01/12/2001

28. Chew, G.L. et al. Mold and endotoxin levels in the aftermath of Hurricane Katrina: A pilot project of homes in New Orleans undergoing renovation Environmental Health Perspectives Vol. 114 Nr. 12 Página: 1883 - 1889 01/12/2006

29. Chiappero M et al. Variación anual de la micoflora en la ciudad de San Juan y en hogares de pacientes con patología respiratoria IgE dependiente. Arch Arg Al e IC. Vol 27. 1996

30. Churg Andrew, et al "Cigarette Smoke Drives Small Airway Remodeling by Induction of Growth Factors in the Airway Wall", American Journal of Respiratory and Critical Care Medicine, Vol. 174, No. 12 (2006), 1327-1334

31. Cockcroft D, et al. Airways hyperresponsiveness. Am Rev Resp Dis 1990. 142:497500

32. Cook DG, Strachan D. Health effects of passive smoking - 3. Parental smoking and prevalence of respiratory symptoms and asthma in school age children Thorax $1997 ; 52: 1081-1094$

33. Cook DG, Strachan DP. Health effects of passive smoking: 3. Parental smoking and prevalence of respiratory symptoms and asthma in school age children. Thorax $1997 ; 52: 1081-94$ 
34. Cook DG, Strachan DP. Health effects of passive smoking: 3. Parental smoking and prevalence of respiratory symptoms and asthma in school age children. Thorax 1997;52:1081-94

35. Custovic Adnan, Chapman Martin. "Indoor allergens as a Risk Factor for Asthma". cap de Asthma, edited by Barnes, Grunstein, Leff and Woolcock. Lippincott-Raven Publisher, Philadelphia. 1997.

36. Dae Yong Kim et al. Cigarette smoke exacerbates mouse allergic asthma through Smad proteins expressed in mast cells. Respiratory Research 2011, 12:49

37. Dales R, Raizenne M. Residential exposure to volatile organic compounds and asthma. J Asthma. 2004 Jan;41(3):259-70.

38. Davies R. The role of Air Pollution on Allergic Airways Disease. Cap. de Asthma: a link between Environment, Immunology and the Airways. Editors: Neffen H., Baena Cagnani C. y otros. Hogrefe \& Huber publishers, Buenos Aires, 1999.

39. de la Iglesia Huerta Antonio, PLAGUICIDAS: Neurotoxicidad y vigilancia de la salud. Centro Nacional de Medios de Protección. Sevilla-INSHT. http://www.insht.es

40. Del Campo Sánchez Ana et al. Modificaciones del hábito tabáquico en familias de niños asmáticos. Aten Fam 2010; 17(2):38-44

41. Eco informe Sector Muebles AIDIMA 2009 http://www.eco-diseño.net

42. Edmonson D et al. "Allergy and "toxic mold síndrome". Annals of Allergy \& Clinical Immunology. Vol 4. 2/2005

43. Eisner MD. Environmental tobacco smoke and adult asthma. Clin Chest Med 2002;23:749-61

44. Environmental Protection Agency Methoprene R.E.D. Fact Sheet June 2001 Update of the March 1991

45. Epler G. Occupational Lung Diseases. "Clinics in Chest Medicine". Ed. Saunders. Philadelphia. 1997.

46. Espinosa González Jaime. Productos Químicos Peligrosos de Uso en Domicilios: Informe Final Proyecto: MINSA/REPAMAR/CEPIS/OPS-OMS/GTZ PN 98.2073.9001.00 Panamá, Marzo del 2000

47. Fernández Camacho Rocío. Origen y características de las partículas finas y ultrafinas en el aire ambiente de Huelva. Tesis doctoral. Centro de Investigación en Química Sostenible (CIQSO), Universidad de Huelva, 2011 
48. Fuertes J, et al. Prevalencia actual de asma, alergia e hiperrespuesta bronquial en niños de 6-8 años. An Esp Pediatr 2001;54:18-26.

49. Gordis Leon. Epidemiología 3ạ ed. Elsevier España. 2005

50. Gruzieva Olena, et al. Meta-analysis of air pollution exposure association with allergic sensitization in European birth cohorts. J ALLERGY CLIN IMMUNOL march 2014

51. Hallas T. The biology of mites. Allergy, 1991, 46, Suppl. 11, 6-9. Copenhagen

52. Hallas T. The biology of mites. Allergy. 1991, 46, Suppl 11, 6-9.

53. Harper DS, et al. Tobacco hypersensitivity and environmental tobacco smoke exposure in a paediatric population. Ann Allergy Asthma Immunol 2001; 86: 59-61.

54. Heraud MC, Herbelin-Wagner ML. Risk factors: environment, tobacco smoke. Arch Pediatr 2002;9(Suppl 3):377-83.

55. Howell J. Obstrucción de la vía aérea, cap de Cecil Loeb. Tratado de Medicina interna. 13 ed. Nueva Editorial Interamericana, 1972

56. Hudson, N.L et al. Characteristics and magnitude of acute pesticide-related illnesses and injuries associated with pyrethrin and pyrethroid exposures-11 states, 2000-2008 American Journal of Industrial Medicine Vol. 57 Nr. 1. p 15 - 30. $01 / 2014$

57. Intoxicación aguda por plaguicidas, piretrinas y piretroides http://www.bvsde.org.ni/Web textos/CIES/Cies0002/capitulo5.pdf

58. Jean-Pastor M, Vervloet $\mathrm{D}$ et al. Destrucción de los ácaros en el polvo doméstico: eficacia y tolerancia de un nuevo acaricida en aerosol. Revue francaise d' Allergologie. 3 1986. 125-129

59. Jimenez Diaz Carlos. El Asma y otras enfermedades alérgicas. Ed. España. 1932. Madrid.

60. Just J, et al. Wheeze phenotypes in young children have different courses during the preschool period. Ann Allergy Asthma Immunol 2013;111:256-61

61. Kageyama M. y otros. Manual de muestreo poblacional. Aplicaciones en Salud ambiental. OPS-OMS, 1997

62. Karpati Adam et al. Pesticide Spraying for West Nile Virus Control and Emergency Department Asthma Visits in New York City, 2000 Environmental Health Perspectives VOLUME 112 | NUMBER 11 | August 20041183 
63. Kobayashi, Yoshiki et al. Passive smoking impairs histone deacetylase-2 in children with severe asthma. Chest. Sep. 13, 2013

64. Korsgaard J et al. Epidemiology of house dust mite allergy. Allergy. 1991, 46, Suppl. 11 14-18

65. Kurlat David. Alergia en Pediatría. Ed Panamericana. Buenos Aires, 1974.

66. Larsen, S.Tet al. Ozone Increases Airway Hyperreactivity and Mucus Hyperproduction in Mice Previously Exposed to Allergen JOURNAL OF TOXICOLOGY AND ENVIRONMENTAL HEALTH - PART A Vol. 73 Nr. 11 Página: 738 - 747 01/2010

67. Lehrer SB, Stankus RP, Salvaggio JE. Tobacco smoke sensitivity: a results of allergy? Ann Allergy 1986; 56: 369-377.

68. Llop, Sabrina, et al. "Prenatal and postnatal residential usage of insecticides in a multicenter birth cohort in Spain". Science of the Total Environment 445-446 (2013) 273-280.

69. Lugauskas A et al. Airborne fungi in industrial environments. Potential agents of respiratory diseases. Ann Agric Environ Med 2004, 11,19-25

70. Macan J, et al. Health effects of pyrethrins and pyrethroids Arh Hig Rada Toksikol. 2006 Jun; 57 (2): 237-43.

71. Mangiaterra Magdalena. Aeromicología. Instituto de Medicina Regional. UNNE. 2011 (nota en Universia)

72. Marcó Leandro et al. Evolución de la prevalencia del asma infantil. "Archivos de Alergia e Inmunología clínica", Vol 37, sup 2 año 2006, ISSN 1515-9825.

73. Martel Marie-Josée et al. Determinants of the Incidence of Childhood Asthma: A Two-Stage Case-Control Study Am. J. Epidemiol. 169: 195-205. 2007.

74. Martínez, Vercelli. Asma. Lancet 382: 1360-72 2013

75. Mata Fernández C., Fernández-Benítez M., Pérez Miranda M., Guillén Grima F.. Validation of the Spanish version of the Phase III ISAAC questionnaire on asthma. J Invest Allergol Clin Immunol 2005; Vol. 15(3): 201-210

76. Mathov Enrique. Curso práctico de Alergia e Inmunología. Tomos 1 y 2. Ed. Publicaciones médicas argentinas. 1973. Buenos Aires.

77. Mazzáfero V y colaboradores. "Medicina en Salud Pública". Ed. El Ateneo. Buenos Aires, 1987. 
78. Melgert BN, Postma DS, Geerlings M, Luinge MA, Klok PA, van der Strate BW, Kerstjens HA, Timens W, Hylkema MN: Short-term smoke exposure attenuates ovalbumin-induced airway inflammation in allergic mice. Am J Respir Cell Mol Biol 2004, 30:880-885.

79. Min Xie and Sally E. Wenzel A global perspective in asthma: from phenotype to endotype Chin Med J 2013;126 (1)

80. Mitchell EA, Stewart AW; ISAAC Phase One Study Group. International Study of Asthma and Allergy in Childhood (ISAAC). Eur J Epidemiol 2001;17:667-73

81. Moretto, A. Indoor spraying with the pyrethroid insecticide lambda-cyhalothrin: Effects on spraymen and inhabitants of sprayed houses. Bull WHO 69(5):591-594; 1991

82. Muñoz Lopez F. Asma bronquial infantil. (monografías de la Cátedra de Pediatría de Barcelona). Ed. Espaxs. 1974. Barcelona.

83. Murray CS, Woodcock A et al. Pediatr Pulmonol. Tobacco smoke exposure, wheeze, and atopy. 2004 Jun; 37(6):492-8.

84. Neffen H, Patiño C. Epidemiología. Módulo 2 Curso de actualización a distancia en Asma. Estrategia global para el manejo y la prevención del Asma. 1998-99.

INTERASMA, GINA, Facultad de Ciencias médicas de la Universidad Nacional de Rosario. Argentina.

85. Neffen y Baena Cagnani. Asthma mortality in Latin America. Cap. de Asthma: a link between Environment, Immunology and the Airways. Editors: Neffen H., Baena Cagnani C. y otros. Hogrefe \& Huber publishers, Buenos Aires, 1999.

86. Ning Song, Prevalence, severity and risk factors of asthma, rhinitis and eczema in a large group of Chinese schoolchildren J Asthma, 2014; 51(3): 232-242

87. O'Byrne Paul, Chair (McMaster University Canada) et al. Iniciativa global para el asma. (GINA) Reporte 2006. Versión en español de GINA Mesoamérica.

88. O'Byrne Paul, Estrategia global para el manejo y la prevencion del asma. GINA Report 06 (http://www.ginasthma.org). McMaster University Hamilton, Canada. GINA

89. Osimitz, T.G et al. Human exposure to insecticide products containing pyrethrins and piperonyl butoxide (2001-2003) FOOD AND CHEMICAL TOXICOLOGY Vol. 47 Nr. 7 Página: 1406 - 1415. 07/2009 
90. Patiño C. y Neffen H. "Adaptación a la realidad local". Módulo 2 Curso de actualización a distancia en Asma. Estrategia global para el manejo y la prevención del Asma. 1998-99. INTERASMA, GINA, Facultad de Ciencias médicas de la Universidad Nacional de Rosario. Argentina.

91. Peat JK, Li J., Reversing the trend: reducing the prevalence of asthma. J. Allergy Clin. Immunol. 1999; 103: 1-10. (citado en Holgate S. Asthma: challenge for the next millennium).

92. Perez Lozano A. Asma bronquial. Ed. Mediterráneo. 1965 España.

93. Piédrola Gil Gonzalo y otros. "Medicina preventiva y Salud Pública". 9a edición. Ed. Masson-Salvat. Barcelona, España. 1991.

94. Poole Alex, et al. Dissecting childhood asthma with nasal transcriptomics distinguishes subphenotypes of disease. J Allergy Clin Immunol 2014;133:670-8

95. Portnoy J et al. Health effects of indoor fungi. Annals of Allergy, Asthma \& Immunology. Vol 94, 3/2005.

96. Prescott G. Woodruff, et al. "T-helper Type 2-driven Inflammation Defines Major Subphenotypes of Asthma", American Journal of Respiratory and Critical Care Medicine, Vol. 180, No. 5 (2009), pp. 388-395.

97. Romero Palacios P. Asma y humo de tabaco Arch Bronconeumol 2004; 40(9):4148

98. Rylander R et al Airways Inflammation, Atopy, and (1 $\left.{ }^{\circledR} 3\right)-b-D-G l u c a n$ Exposures in Two Schools AMERICAN JOURNAL OF RESPIRATORY AND CRITICAL CARE MEDICINE VOL 1581998

99. Saint-laurent Julie. Atteinte des voies respiratoires par différents irritants chimiques et environnementaux: Étude de l'influence du tabac et du chlore sur la muqueuse bronchique. Thèse du Programme de doctorat en médecine expérimentale pour l'obtention du grade de Philosophiae Doctor (Ph.D.) Médecine expérimentale Faculté de Médecine. Université Laval. Québec 2009.

100.Salmún N y otros. "Incidencia del Asma bronquial en la población escolar argentina. Estudio multicéntrico". Revista Archivos Argentinos de Alergia e Inmunología, vol. 25 no 6 de 1994. Buenos Aires, Argentina.

101.Salmún N y otros. "Prevalence of Asthma in Argentine children. A multicenter study". Revista: Allergy \& Clinical Inmunology. May/june 1999, vol. 11 № 3. 
(Organo oficial de la Asociación Internacional de Alergología e Inmunología Clínica y de Interasma. Ed. Medical University of South Caroline, USA

102. Salvaggio J et al. Mold-induced Asthma. J. Allergy Clin Immunol. Vol. 68, n 5. Nov 1981

103.Samet J. Asthma Epidemiology: Old and news issues. Cap. de Asthma: a link between Environment, Immunology and the Airways. Editors: Neffen H., Baena Cagnani C. y otros. Hogrefe \& Huber publishers, Buenos Aires, 1999.

104.Samet J. Involuntary smoking and Asthma. Cap. de Asthma: a link between Environment, Immunology and the Airways. Editors: Neffen H., Baena Cagnani C. y otros. Hogrefe \& Huber publishers, Buenos Aires, 1999.

105.Samet Jonathan et al. Health Effects and Sources of Indoor Air Pollution. Part 1. State of Art. AM REV RESPIR DIS 1987; 136:1486-1508

106.San Martin Hernan y col. "Salud y Enfermedad". 4ạ ed. Ed. La Prensa Médica Mexicana. México. 1981.

107.San Román M., et al. Intoxicación por piretrinas: una causa singular de convulsiones en el lactante. BOL PEDIATR 2003; 43: 284-289

108.Sánchez Caraballo Jorge. Características fisicoquímicas de los gases y partículas contaminantes del aire. Su impacto en el asma. latreia Vol. 25 (4): 369-379, octubre-diciembre 2012

109.Scheffer A, Bousquet J y otros. Informe del consenso internacional sobre el Diagnóstico y Tratamiento del Asma. Instituto Nacional del Corazón, Pulmón y Sangre, Departamento de Salud y Servicios Humanos, Servicio de Salud Pública, Instituto Nacional de Salud de los Estados Unidos de América. Publicación n $92-$ 3091, Maryland, USA. 3/1992. (Participaron expertos invitados de diversos países).

110.Schwela D. Air pollution and health in urban areas. Rev Environ Health. 2000 JanJun; $15(1-2): 13-42$.

111.Sears M. Natural History of Asthma. McMaster University, Canada. Cap de Asthma: a link between Environment, Immunology and the Airways. Editors: Neffen H., Baena Cagnani C. y otros. Hogrefe \& Huber publishers, Buenos Aires, 1999. 
112.Shah Ashok. Allergic Bronchopulmonary Aspergillosis. Allergy Clin Immunol Int - J. World Allergy Org 17/5 (2005)

113.Shahon H. Compendio de Alergia clínica. Ed. Librería Hachette. 1943. Buenos Aires.

114.Siroux V, Pin I, Oryszczyn MP, Le Moual N, Kauffmann F. Relationships of active smoking and asthma severity in the EGEA study. Epidemiological study on the Genetics and Environment of Asthma. Eur Respir J 2000;15:470-7.

115. Sneller $\mathrm{M}$ et al. Incidence o fungal spores at the homes of allergic patients in an agricultural community. 12 month study in and out doors. Annals of Allergy. Vol 43 1979

116.Sonis Abraam y col. "Medicina sanitaria y administración de Salud". 3 ed. Tomo 1. Ed. El Ateneo. Barcelona, España. 1982

117.Sterk P. et al. Asthma phenotyping: $T_{H} 2$-high, $T_{H} 2-l o w$, and beyond. The Journal of Allergy and Clinical Immunology Volume 133, Issue 2, Pages 395-396, February 2014

118.Strachan DP, Cook DG. Health effects of passive smoking: 1. Parental smoking and lower respiratory illness in infancy and early childhood Thorax 1997;52:905-914

119.Strachan DP, Cook DG. Health effects of passive smoking: 5. Parental smoking and allergic sensitisation in children. Thorax 1998;53:117-123

120.Strachan DP, Cook DG. Health effects of passive smoking: 6. Parental smoking and childhood asthma: longitudinal and case-control studies. Thorax 1998;53:204-12

121.Szefler S., Advances in pediatric asthma in 2013: Coordinating asthma care J ALLERGY CLIN IMMUNOL. MARCH 2014

122. Teper A y Máspero J. Mecanismos del asma. Mod 4 del Curso de actualización en Asma. Estrategia global para el manejo y la prevención del Asma. 1998-99. INTERASMA, GINA, Facultad de Ciencias médicas de la Universidad Nacional de Rosario. Argentina.

123.Urbach Erich. Alergia. Ed. Salvat. 1950. Barcelona.

124.van der Werff SD et al. Prediction of Asthma by Common Risk Factors: A Follow-up Study in Cuban Schoolchildren. J Investig Allergol Clin Immunol 2013; Vol. 23(6): $415-420$ 
125.VandenDriessche, K.S.J. et al Anaphylaxis in an Airplane After Insecticide Spraying Journal of travel Medicine Vol. 17 Nr. 6 Página: 427 - 429. 11/2010

126.Varela Fuentes B. y otros. Alergia en la práctica clínica. Ed. Espasa-Calpe. 1946. Buenos Aires.

127.Warner J. The prediction and prevention of childhood asthma. Cap. de Asthma: a link between Environment, Immunology and the Airways. Editors: Neffen $\mathrm{H}$., Baena Cagnani C. y otros. Hogrefe \& Huber publishers, Buenos Aires, 1999.

128.Wijga A et al. "Are children at high familial risk of developing allergy born into a low risk environment?" The PIAMA Birth Cohort Study. Clinical and Experimental Allergy, 2001. Vol 31, 576-581.

129.Win-Shwe, Tin-Tin, et al. Indoor Volatile Organic Compounds and Chemical Sensitivity Reactions. Clinical and Developmental Immunology. Volume 2013. 130.Wolff, P.T. et al. Spirometric reference values in urban children in Madagascar: Poverty is a risk factor for low lung function. Pediatric Pulmonology Vol. 49 Nr. 1 Página: $76-832014$

131.Yañez A y Balanzat A. Asma: diagnóstico y clasificación. Mod. 5 del Curso de actualización a distancia en Asma. Estrategia global para el manejo y la prevención del Asma. 1998-99. INTERASMA, GINA, Facultad de Ciencias médicas de la Universidad Nacional de Rosario. Argentina. 


\section{Citas y Notas}

${ }^{1}$ Martínez, Vercelli. Asma. "Los resultados de varios ensayos refutan la afirmación que el uso crónico de
corticoesteroides inhalados (ICS) pueda bloquear el curso natural del asma y el desarrollo de la limitación
del flujo aéreo. Cuatro años de tratamiento dos veces por día con ICS en los niños en edad escolar con
asma no tuvieron efecto en la función pulmonar o en los resultados clínicos 4 años después de retirar el
tratamiento. En los niños preescolares con sibilancias, la administración de ICS por varios años y con
diferentes métodos no tuvo efecto a largo plazo en los resultados relacionados con asma". Lancet 382: 1360-72 2013

2 Sears M. Natural History of Asthma. McMaster University, Canada. Cap de Asthma: a link between Environment, Immunology and the Airways. Editors: Neffen H., Baena Cagnani C. y otros. Hogrefe \& Huber publishers, Buenos Aires, 1999.

${ }^{3}$ Modificado de: Baena-Cagnani C. y Gené R. Factores de riesgo. Módulo 3 del Curso de actualización a distancia en Asma. Estrategia global para el manejo y la prevención del Asma. 1998-99. INTERASMA, GINA, Facultad de Ciencias médicas de la Universidad Nacional de Rosario. Argentina.

${ }^{4}$ Peat JK, Li J., Reversing the trend: reducing the prevalence of asthma. J. Allergy Clin. Immunol. 1999; 103:1-10. (citado en Holgate S. Asthma: challenge for the next millennium).

${ }^{5}$ Trends in adult current asthma prevalence and contributing risk factors in the United States by state: 2000-2009 BMC Public Health 2013;Vol 13(12):1156

${ }^{6}$ Beasley R y otros (The International Study of Asthma and Allergies in Chilhood (ISAAC) Steering Committee. Worldwide variation in prevalence of symptoms of asthma, allergic rhinoconjunctivitis and atopic eczema: ISAAC. The Lancet. Vol 351. 1998

7 Samet J. Asthma Epidemiology: Old and news issues. Cap. de Asthma: a link between Environment, Immunology and the Airways. Editors: Neffen H., Baena Cagnani C. y otros. Hogrefe \& Huber publishers, Buenos Aires, 1999.

${ }^{8}$ D’Amato G, Liccardi G, D’Amato M, Cazzola M. Outdoor airpollution, climatic changes and allergic bronchial asthma. EurRespir J 2002;20:763-776.

9 Perzanowski, Ro"nmark, Platts-Mills, et al.: Effect of Cat and Dog Ownership on Asthma in Children AMERICAN JOURNAL OF RESPIRATORY AND CRITICAL CARE MEDICINE VOL 1662002

10 Perez Lozano A. Asma bronquial. Ed. Mediterráneo. 1965 España.

${ }^{11}$ El Prof. Dr. Bernardo Manzino mencionaba en sus clases de Clínica Médica de la FCM UNLP (1976), cinco tipos de disnea por sus orígenes: respiratoria, circulatoria, tisular (acidosis y uremia), sanguínea (anemias) y nerviosa (neurosis respiratoria).

12 Muñoz Lopez F. Asma bronquial infantil. (monografías de la Cátedra de Pediatría de Barcelona). Ed. Espaxs. 1974. Barcelona.

13 Dres. Lin-Shien Fu, Ming-Chin Tsai Una revisión práctica. Exacerbación del asma en niños Pediatr Neonatol. 2013 Nov 6. <http://dx.doi.org/10.1016/i.pedneo.2013.07.004>

${ }^{14}$ Mathov, E Alergia (Méx.);29(4):123-42, 1982.

15 Wiesch D, Samet J.(1998) citado en Samet J. Asthma Epidemiology: Old and news issues. Cap. de Asthma: a link between Environment, Immunology and the Airways. Editors: Neffen $\mathrm{H}$., Baena Cagnani C. y otros. Hogrefe \& Huber publishers, Buenos Aires, 1999.

16 Investigación escocesa (1962-1987) citada por Sears M. Natural History of Asthma. McMaster University, Canada. Cap de Asthma: a link between Environment, Immunology and the Airways. Editors: Neffen H., Baena Cagnani C. y otros. Hogrefe \& Huber publishers, Buenos Aires, 1999. 
17 Sears M. Natural History of Asthma. McMaster University, Canada. Cap de Asthma: a link between Environment, Immunology and the Airways. Editors: Neffen H., Baena Cagnani C. y otros. Hogrefe \& Huber publishers, Buenos Aires, 1999.

18 Datos del Instituto nacional de Epidemiología "E. Coni” citados por Neffen y Baena Cagnani en Asthma mortality in Latin America. Cap. de Asthma: a link between Environment, Immunology and the Airways. Editors: Neffen H., Baena Cagnani C. y otros. Hogrefe \& Huber publishers, Buenos Aires, 1999.

$19 *$ Wenzel SE. Asthma phenotypes: the evolution from clinical to molecular approaches. Nat Med 2012; 18: 16-725. * Min Xie and Sally E. Wenzel A global perspective in asthma: from phenotype to endotype Chin Med J 2013;126

${ }^{20}$ Scheffer A, Bousquet J y otros. Informe del consenso internacional sobre el Diagnóstico y Tratamiento del Asma. Instituto Nacional del Corazón, Pulmón y Sangre, Departamento de Salud y Servicios Humanos, Servicio de Salud Pública, Instituto Nacional de Salud de Estados Unidos de América. Pub. n 92-3091, Maryland, USA.3/1992. (Participaron expertos invitados de diversos países).

${ }^{21}$ Abbate E y Crisci C. Consideraciones generales. Definición y fisiopatogenia. Módulo 1 del Curso de actualización a distancia en Asma. Estrategia global para el manejo y la prevención del Asma. 1998-99. INTERASMA, GINA, Facultad de Ciencias médicas de la Universidad Nacional de Rosario. Argentina.

22 Salmún N y otros. "Prevalence of Asthma in Argentine children. A multicenter study". Allergy \& Clinical Inmunology. May/june 1999, vol. 11 no 3. (Organo oficial de la Asociación Internacional de Alergología e Inmunología Clínica y de Interasma. Ed. Medical University of South Caroline, USA.

${ }^{23}$ International Study of Asthma and Allergies in childhood. Estudio multicéntrico mundial comenzado en 1989 que en su fase I ha desarrollado un cuestionario estandardizado para medir prevalencia del Asma y se ha probado en numerosos países incluída la Argentina y Concepción del Uruguay en particular.

${ }^{24}$ Koner, citado en Surós J. Semiología médica y técnica exploratoria. Salvat Editores, Barcelona, 1975.

${ }^{25}$ Sterch, citado en Surós J. Semiología médica y técnica exploratoria. Salvat Editores, Barcelona, 1975.

${ }^{26}$ Asher MI, Keil U, Anderson HR, Beasley R, y otros. Internacional Study of Asthma and Allergies in Childhood (ISAAC): Rationale and methods. Eur Resp J 1995; 8:483-491

${ }^{27}$ Caudri D, Wijga A, Schipper CM, Hoekstra M, Postma DS, Koppelman GH, et al. Predicting the long-term prognosis of children with symptoms suggestive of asthma at preschool age. J Allergy Clin Immunol 2009; 124:903-10, e1-7.

${ }^{28}$ Castro-Rodriguez JA, Holberg CJ, Wright AL, Martinez FD. A clinical index to define risk of asthma in young children with recurrent wheezing. Am J Respir Crit Care Med 2000;162:1403-6.

${ }^{29}$ Poole Alex, et al. Dissecting childhood asthma with nasal transcriptomics distinguishes subphenotypes of disease. J Allergy Clin Immunol 2014;133:670-8

${ }^{30}$ Pearce $\mathrm{N}$ et al. Self-reported prevalence of asthma symptoms in children in Australia, England, Germany and New Zealand: an international comparison using the ISAAC protocol. Eur Resp J 1993. 6: 1455-1461

${ }^{31}$ Burney PGJ et al. Validity and repeatability of the IUATLD (1984) Bronchial Symptoms Questionnaire: an international comparison. Eur Resp J 1989. 2:940-945.

32 Mata Fernández C., Fernández-Benítez M., Pérez Miranda M., Guillén Grima F. Validation of the Spanish version of the Phase III ISAAC questionnaire on asthma. J Invest Allergol Clin Immunol 2005; Vol. 15(3): 201-210

${ }^{33}$ Martinez FD et al. Asthma and wheezing in the first six years of life. New England Journal of Medicine. 332:3:133-138 1995.

34 Johansson et al. Revised Nomenclature for Allergy for Global Use: Report of the Nomenclature Review Committee of the World Allergy Organization2003. J Allergy Clin Immunol vol $113 \mathrm{n}^{\circ} 5$

${ }^{35}$ Citado en Warner J. The prediction and prevention of childhood asthma. Cap. de Asthma: a link between Environment, Immunology and the Airways. Editors: Neffen H., Baena Cagnani C. y otros. Hogrefe \& Huber publishers, Buenos Aires, 1999. 
${ }^{36}$ Yañez A y Balanzat A. Asma: diagnóstico y clasificación. Mod. 5 del Curso de actualización a distancia en Asma. Estrategia global para el manejo y la prevención del Asma. 1998-99. INTERASMA, GINA, Facultad de Ciencias médicas de la Universidad Nacional de Rosario. Argentina.

${ }^{37}$ Martinez FD et al. Initial airway function is a risk factor for recurrent wheezing respiratory illness during the first 3 years of life. Am Rev Resp Dis 1991; 143:312-316.

38 Papi A, et al. Rhinovirus infection causes steroid resistance in airway epithelium through nuclear factor kB and c-Jun N-terminal kinase activation. J Allergy Clin Immunol 2013;132:1075-85. (citado en Szefler S., Advances in pediatric asthma in 2013: Coordinating asthma care J ALLERGY CLIN IMMUNOL MARCH 2014) 39 Just J, et al. Wheeze phenotypes in young children have different courses during the preschool period. Ann Allergy Asthma Immunol 2013;111:256-61

40 Stick E et al (1991) citado en Warner J. The prediction and prevention of childhood asthma. Cap. de Asthma: a link between Environment, Immunology and the Airways. Editors: Neffen H., Baena Cagnani C. y otros. Hogrefe \& Huber publishers, Buenos Aires, 1999.

${ }^{41}$ Balanzat A, Urrutigoity J. Consenso de Asma bronquial. 2007. Arch Argent Pediatr 2008; 106(1): 61-68.

42 Howell J. Obstrucción de la vía aérea, cap de Cecil Loeb. Tratado de Medicina interna. 13 ed. Nueva editorial interamericana, 1972.

${ }^{43}$ Sterk P. et al. Asthma phenotyping: $T_{H} 2$-high, $T_{H} 2-l o w$, and beyond. The Journal of Allergy and Clinical Immunology Volume 133, Issue 2 , Pages 395-396, February 2014

44 Prescott G. Woodruff, Barmak Modrek, David F. Choy, Guiquan Jia, Alexander R. Abbas, Almut Ellwanger, Joseph R. Arron, Laura L. Koth, and John V. Fahy "T-helper Type 2-driven Inflammation Defines Major Subphenotypes of Asthma", American Journal of Respiratory and Critical Care Medicine, Vol. 180, No. 5 (2009), pp. 388-395.

45 Prescott G. Woodruff, Barmak Modrek, David F. Choy, Guiquan Jia, Alexander R. Abbas, Almut Ellwanger, Joseph R. Arron, Laura L. Koth, and John V. Fahy "T-helper Type 2-driven Inflammation Defines Major Subphenotypes of Asthma", American Journal of Respiratory and Critical Care Medicine, Vol. 180, No. 5 (2009), pp. 388-395.

46 Beasley R y otros. "International time trends in Asthma mortality". Cap. de Asthma: a link between Environment, Immunology and the Airways. Editors: Neffen H., Baena Cagnani C. y otros. Hogrefe \& Huber publishers, Buenos Aires, 1999.

47 Salmún $\mathrm{N}$ y otros. "Incidencia del Asma bronquial en la población escolar argentina. Estudio multicéntrico". Revista Archivos Argentinos de Alergia e Inmunología, vol. 25 no 6 de 1994. Buenos Aires, Argentina.

Salmún N y otros. "Prevalence of Asthma in Argentine children. A multicenter study". Revista: Allergy \& Clinical Inmunology. May/june 1999, vol. 11 no 3. (Organo oficial de la Asociación Internacional de Alergología e Inmunología Clínica y de Interasma. Ed. Medical University of South Caroline, USA.

48 Salmún N y otros. "Incidencia del Asma bronquial en la población escolar argentina. Estudio multicéntrico". Revista Archivos Argentinos de Alergia e Inmunología, vol. 25 no 6 de 1994. Buenos Aires, Argentina.

${ }^{49}$ Marcó Leandro y otros. Evolución de la prevalencia del asma infantil. "Archivos de Alergia e Inmunología clínica", Vol 37, sup 2 año 2006, ISSN 1515-9825

50 Samet J. Asthma Epidemiology: Old and news issues. Cap. de Asthma: a link between Environment, Immunology and the Airways. Editors: Neffen H., Baena Cagnani C. y otros. Hogrefe \& Huber publishers, Buenos Aires, 1999.

${ }^{51}$ Anandan $\mathrm{C}$ et al. Is the prevalence of asthma declining? Systematic review of epidemiological studies. Allergy 2010. 65:152-167.

52 Galvez Vargas R. y otros. Estudios de cohortes. Cap. 9 de Piédrola Gil y otros, "Medicina Preventiva y Salud Pública", $9^{\circ}$ ed. Ed. Científicas y técnicas (Masson-Salvat). Barcelona, España. 1991. 
53 Modificado de: Baena-Cagnani C. y Gené R. Factores de riesgo. Módulo 3 del Curso de actualización a distancia en Asma. Estrategia global para el manejo y la prevención del Asma. 1998-99. INTERASMA, GINA, Facultad de Ciencias médicas de la Universidad Nacional de Rosario. Argentina.

${ }^{54}$ Modificado de: Baena-Cagnani C. y Gené R. Factores de riesgo. Módulo 3 del Curso de actualización a distancia en Asma. Estrategia global para el manejo y la prevención del Asma. 1998-99. INTERASMA, GINA, Facultad de Ciencias médicas de la Universidad Nacional de Rosario. Argentina.

55 Jones AC et al. 1996 citado en Warner J. The prediction and prevention of childhood asthma. Cap. de Asthma: a link between Environment, Immunology and the Airways. Editors: Neffen H., Baena Cagnani C. y otros. Hogrefe \& Huber publishers, Buenos Aires, 1999.

56 Warner J. The prediction and prevention of childhood asthma. Cap. de Asthma: a link between Environment, Immunology and the Airways. Editors: Neffen H., Baena Cagnani C. y otros. Hogrefe \& Huber publishers, Buenos Aires, 1999.

${ }^{57}$ Baena-Cagnani C. y Gené R. Factores de riesgo. Módulo 3 del Curso de actualización a distancia en Asma. Estrategia global para el manejo y la prevención del Asma. 1998-99. INTERASMA, GINA, Facultad de Ciencias médicas de la Universidad Nacional de Rosario. Argentina

58 Crisci C. Genética del asma. Cap del mod 1del Curso de actualización a distancia en Asma. Estrategia global para el manejo y la prevención del Asma. 1998-99. INTERASMA, GINA, Facultad de Ciencias médicas de la Universidad Nacional de Rosario. Argentina

${ }^{59}$ Çaliskan M, et al. Rhinovirus wheezing illness and genetic risk of childhood-onset asthma. N Engl J Med. 2013; 368: 1398-407

${ }^{60}$ Coppioli J. Presentación en Congreso de AAAeIC. 8-2013 Buenos Aires.

61 Jaakkola JJ, Nafstad P, Magnus P. Environmental tobacco smoke, parental atopy, and childhood asthma. Environ Health Perspect 2001;109:579-82

62 Sears M. Natural History of Asthma. McMaster University, Canada. Cap de Asthma: a link between Environment, Immunology and the Airways. Editors: Neffen H., Baena Cagnani C. y otros. Hogrefe \& Huber publishers, Buenos Aires, 1999.

63 Armentia A, et al. El tabaco como alérgeno en enfermedad bronquial obstructiva. Estudio preliminar. Alergol Inmunol Clin 2005; 20: 14-27

${ }^{64}$ ARDUSSO L. CRISCI C, LOCKEY R et al, Asociación entre exposición a polvo de soja, sensibilidad alérgica yperfil de síntomas respiratorios MEDICINA (Buenos Aires) 2000; 61: 1-7

${ }^{65}$ Çaliskan M, et al. Rhinovirus wheezing illness and genetic risk of childhood-onset asthma. N Engl J Med. 2013; 368: 1398-407.

${ }^{66}$ Welliver RC, Wong DT, Sun M, et al. Parainfluenza virus bronchiolitis: epidemiology and pathogenesis. Am J Dis Child 1986;140:34-40

${ }^{67}$ Romero Palacios P. Asma y humo de tabaco Arch Bronconeumol 2004; 40(9):414-8

68 Warner J. The prediction and prevention of childhood asthma. Cap. de Asthma: a link between Environment, Immunology and the Airways. Editors: Neffen H., Baena Cagnani C. y otros. Hogrefe \& Huber publishers, Buenos Aires, 1999.

69 Lewis et al (1996) citado en Warner J. The prediction and prevention of childhood asthma. Cap. de Asthma: a link between Environment, Immunology and the Airways. Editors: Neffen H., Baena Cagnani C. y otros. Hogrefe \& Huber publishers, Buenos Aires, 1999.

${ }^{70}$ Nagel G, Koenig W, et al. Associations of adipokines with asthma, rhinoconjunctivitis, and eczema in German schoolchildren. Pediatr Allergy Immunol 2009;20:81-8.

${ }^{71}$ Bedolla-Barajas Martín et al. Asthma in Mexican school-age children is not associated with passive smoking or obesity. http://dx.doi.org/10.5415/apallergy.2013.3.1.42 Asia Pac Allergy 2013;3:42-49

72 Baena-Cagnani C. y Gené R. Factores de riesgo. Módulo 3 del Curso de actualización a distancia en Asma. Estrategia global para el manejo y la prevención del Asma. 1998-99. INTERASMA, GINA, Facultad de Ciencias médicas de la Universidad Nacional de Rosario. Argentina 
${ }^{73}$ Baena-Cagnani C. y Gené R. Factores de riesgo. Módulo 3 del Curso de actualización a distancia en Asma. Estrategia global para el manejo y la prevención del Asma. 1998-99. INTERASMA, GINA, Facultad de Ciencias médicas de la Universidad Nacional de Rosario. Argentina

${ }^{74}$ Holloway JW, Beghe B, Holgate ST. The genetic basis of atopic asthma. Clin ExpAllergy 1999;29(8):102332. Citado en Global Initiative for Asthma (GINA). Papeles de trabajo preparatorios de la revisión 2006.

${ }^{75}$ Spooner Ch. Air measurements of dust, chemicals and fumes. Occupational Lung diseases.Clinic in chest diseases. Vol 132 1992. Ed Saunders USA.

${ }^{76}$ Aerosol: Suspensión de partículas sólidas o líquidas en el aire.

${ }^{77}$ Hargreave F. En Small airways in health and disease. Proceedings of Symposium Copenhagen, 1979.Pág. 143.

78 Hornung V, Bauernfeind F, Halle A, et al. Silica crystals and aluminum salts activate the NALP3 inflammasome through phagosomal destabilization. Nat Immunol. 2008;9:847-856.

${ }^{79}$ Behrendt $\mathrm{H}$ et al. Interaction between aeroallergens and airborne particulate matter. Int Arch Allergy Inmmunol 1992; 99:425-428

80 Davies R. The role of Air Pollution on Allergic Airways Disease. Cap. de Asthma: a link between Environment, Immunology and the Airways. Editors: Neffen H., Baena Cagnani C. y otros. Hogrefe \& Huber publishers, Buenos Aires, 1999.

${ }^{81}$ Oyarzún M. Contaminación atmosférica y asma bronquial Rev Chil Enf Respir 2000; 16: 142-7.

82 Granum B, et al. IgE adjuvant effect caused by particles - immediate and delayed effects. Toxicology. 2001 Jan 2;156(2-3):149-59.

83 Sánchez Caraballo Jorge. Características fisicoquímicas de los gases y partículas contaminantes del aire. Su impacto en el asma. latreia Vol. 25 (4): 369-379, octubre-diciembre 2012

84 Davies R. The role of Air Pollution on Allergic Airways Disease. Cap. de Asthma: a link between Environment, Immunology and the Airways. Editors: Neffen H., Baena Cagnani C. y otros. Hogrefe \& Huber publishers, Buenos Aires, 1999.

85 Trabajo de Diaz Sanchez comentado por Davies R. The role of Air Pollution on Allergic Airways Disease. Cap. de Asthma: a link between Environment, Immunology and the Airways. Editors: Neffen H., Baena Cagnani C. y otros. Hogrefe \& Huber publishers, Buenos Aires, 1999.

${ }^{86}$ Basha 1994 citado en Davies R. The role of Air Pollution on Allergic Airways Disease. Cap. de Asthma: a link between Environment, Immunology and the Airways. Editors: Neffen H., Baena Cagnani C. y otros. Hogrefe \& Huber publishers, Buenos Aires, 1999.

87 Peden (1995) citado en Davies R. The role of Air Pollution on Allergic Airways Disease. Cap. de Asthma: a link between Environment, Immunology and the Airways. Editors: Neffen H., Baena Cagnani C. y otros. Hogrefe \& Huber publishers, Buenos Aires, 1999.

${ }^{88}$ Sandström, citado en Davies R. The role of Air Pollution on Allergic Airways Disease. Cap. de Asthma: a link between Environment, Immunology and the Airways. Editors: Neffen H., Baena Cagnani C. y otros. Hogrefe \& Huber publishers, Buenos Aires, 1999.

${ }^{89}$ D'Amato G, Liccardi G, D'Amato M, Cazzola M. Outdoor air pollution, climatic changes and allergic bronchial asthma. Eur Respir J 2002; 20: 763-76.

${ }^{90}$ Sánchez Caraballo Jorge. Características fisicoquímicas de los gases y partículas contaminantes del aire. Su impacto en el asma. latreia Vol. 25 (4): 369-379, octubre-diciembre 2012

91 Perez Laura et al. Chronic burden of near-roadway traffic pollution in 10 European cities (APHEKOM network). Eur Respir J erj00311-2012; published ahead of print 2013,

92 Committee on the assessment of asthma and indoor air. Division of Health Promotion and Disease Prevention, Institute of Medicine. Indoor chemical exposure. Clearing the Air: Asthma and Indoor Air Exposure. Washington, DC: National Academy Press, 2000:223.

93 Bello A, Quinn MM, Perry MJ, Milton DK. Quantitative assessment of airborne exposures generated during common cleaning tasks: a pilot study. Environ Health. 2010 Jan;9:76

94 Citado en Dales $R$, Raizenne M. Residential exposure to volatile organic compounds and asthma. J Asthma. 2004 Jan;41(3):259-70 
95 US Department of Health Education and Welfare. The health consequences of smoking. A report of the Surgeon General . (DHEW Publication n. HSM 73-8704). Washington, DC: US Government Printing Office, 1971

${ }^{96}$ Harlap S, Davies AM. Infant admissions to hospital and maternal smoking. Lancet 1974; i:529-32.

${ }^{97}$ Colley JR, Holland WW, Corkhill RT. Influence of passive smoking and parental phlegm on pneumonia and bronchitis in early childhood. Lancet 1974;ii:1031-4.

${ }^{98}$ Tager IB, Weiss ST, Rosner B, Speizer FE. Effect of parental cigarette smoking on the pulmonary function of children. Am J Epidemiol1979;110:821-8

${ }^{99}$ Ministerio de Salud de la Nación. Encuesta nacional de factores de riesgo de 2005 (año en que se realizó la encuesta de nuestra investigación sobre asma). Para 2009 había descendido a 30,1\%.

100 Romero Palacios P. Asma y humo de tabaco Arch Bronconeumol 2004; 40(9):414-8

${ }^{101}$ Fase Argentina de la Encuesta Mundial de Tabaquismo. Ministerio de Salud de la Nación. 5/2013.

102 Romero Palacios P. Asma y humo de tabaco Arch Bronconeumol 2004; 40(9):414-8

103 Gené Ricardo. Importancia del tabaco en el asma bronquial. Módulo 6 del Curso de actualización a distancia en Asma. Estrategia global para el manejo y la prevención del Asma. 1998-99. INTERASMA, GINA, Facultad de Ciencias médicas de la Universidad Nacional de Rosario. Argentina.

104 Women and Smoking: A Report of the Surgeon General. Office on Smoking and Health (US). Atlanta (GA): Centers for Disease Control and Prevention (US); 2001 Mar.

105 http://www.msal.gov.ar/tabaco

${ }^{106}$ Romero Palacios P. Asma y humo de tabaco. Arch Bronconeumol 2004; 40(9):414-8 415

107 Pirkle JL, Flegal KM, Bernert JT, Brody DJ, Etzel RA, Maurer KR. Exposure of the US population to environmental tobacco smoke: the Third National Health and Nutrition Examination Survey, 1988-91. JAMA 1996;275:1322-40.

${ }^{108}$ Rylander E, Pershagen G, Eriksson M, et al. Parental smoking, urinary cotinine, and wheezing bronchitis in children. Epidemiology 1995;6:289-93

109 Strachan DP, Cook DG. Health effects of passive smoking: 1. Parental smoking and lower respiratory illness in infancy and early childhood Thorax 1997;52:905-914

110 Jimenez Diaz Carlos. El Asma y otras enfermedades alérgicas. Ed. España. 1932.

111 Prof. Dr. Alberto Quirantes Hernández. Profesor de Medicina y Jefe del Servicio de Endocrinología Hospital Docente "Dr. Salvador Allende" La Habana - Cuba. http://www.nnc.cubaweb.cu/mayo 2011

112 Shahon H. Compendio de Alergia clínica. Ed. Librería Hachette. 1943. Buenos Aires.

${ }^{113}$ Varela Fuentes B. y otros. Alergia en la práctica clínica. Ed. Espasa-Calpe. 1946. Buenos Aires.

114 Urbach Erich. Alergia. Ed. Salvat. 1950. Barcelona.

${ }^{115}$ Vaughan W. Practice of Allergy. Mosby, St Louis, 1939.

116 Pipes D. Ann Allergy, 3, 277(1945).

${ }^{117}$ Citado en Urbach Erich. Alergia. Ed. Salvat. 1950. Barcelona.

118 Mathov Enrique. Curso práctico de Alergia e Inmunología. Tomos 1. Ed. Publicaciones médicas argentinas. 1973. Buenos Aires.

119 Kurlat David. Alergia en Pediatría. Ed. Panamericana. Buenos Aires, 1974

${ }^{120}$ Bukstein Don y Strunk R. Problemas clínicos en asma y alergia. Ed. Salvat. 1988. Buenos Aires.

${ }^{121}$ Lehrer SB, Stankus RP, Salvaggio JE. Tobacco smoke sensitivity: a results of allergy? Ann Allergy 1986; 56: 369-377.

${ }^{122}$ Abate E. Comentarios de: Cockcroft D, Hiperreactividad de la vía aérea: implicancias terapéuticas. Nuevas perspectivas en Asma. Buenos Aires, 1989

${ }^{123}$ Harper DS, Cox R, Summers D, Butler W, Hagan L. Tobacco hypersensitivity and environmental tobacco smoke exposure in a paediatric population. Ann Allergy Asthma Immunol 2001; 86: 59-61.

${ }^{124}$ Armentia A, et al. El tabaco como alérgeno en enfermedad bronquial obstructiva. Estudio preliminar. Alergol Inmunol Clin 2005; 20: 14-27 
125 Barrett EG, Wilder JA, March TH, Espindola T, Bice DE: Cigarette smoke-induced airway hyperresponsiveness is not dependent on elevated immunoglobulin and eosinophilic inflammation a mouse model of allergic airway disease. Am J Repir Cir Care Med 2002, 165:1410-1418.

${ }^{126}$ Melgert BN, Postma DS, Geerlings M, Luinge MA, Klok PA, van der Strate BW, Kerstjens HA, Timens W, Hylkema MN: Short-term smoke exposure attenuates ovalbumin-induced airway inflammation in allergic mice. Am J Respir Cell Mol Biol 2004, 30:880-885.

127 Dae Yong Kim et al. Cigarette smoke exacerbates mouse allergic asthma through Smad proteins expressed in mast cells. Respiratory Research 2011, 12:49

${ }^{128}$ Churg Andrew, et al "Cigarette Smoke Drives Small Airway Remodeling by Induction of Growth Factors in the Airway Wall", American Journal of Respiratory and Critical Care Medicine, Vol. 174, No. 12 (2006), 1327-1334.

${ }^{129}$ Chalmers, G.W.; MacLeod, K.J.; Thomson, L.; Little, S.A.; McSharry, C.; Thomson, N.C Smoking and airway inflammation in patients with mild asthma CHEST Vol. 120 Nr. 6 Página: 1917 - 1922 Fecha de publicación: 01/12/2001

${ }^{130}$ Curiosamente este investigador menciona en su publicación que Chalmers halla bajo el número de los eosinófilos en los asmáticos fumadores coincidiendo con su hallazgo, mientras que la publicación del mencionado dice: "Sputum eosinophils and ECP levels were higher in both nonsmoking and smoking asthmatics than in healthy nonsmokers".

131 Floreani AA, Rennard SI. The role of cigarette smoke in the pathogenesis of asthma and as a trigger for acute symptoms. Curr Opin Pulm Med 1999;5:38-46.

132 Kobayashi, Yoshiki et al. Passive smoking impairs histone deacetylase-2 in children with severe asthma Chest. Sep. 13, 2013

${ }^{133}$ ACT. Cuestionario simple para autoevaluar la situación del asmático, con versión adaptada para niños. Evaluado favorablemente por la American Thoracic Association

${ }^{134}$ sustancia P: neurokinina 1 (NK1-R), sustancia K: neurokinina A (NK2-R) y CGRP: calcitonin gen-related peptide.

${ }^{135}$ Kraan, J., H. Vink-Klooster, and D. S. Postma. "The NK-2 Receptor Antagonist SR 48968C Does Not Improve Adenosine Hyperresponsiveness And Airway Obstruction In Allergic Asthma." Clinical \& Experimental Allergy 31.2 (2001): 274-278

136 Teper A y Máspero J. Mecanismos del asma. Mod 4 del Curso de actualización en Asma. Estrategia global para el manejo y la prevención del Asma. 1998-99. INTERASMA, GINA, Facultad de Ciencias médicas de la Universidad Nacional de Rosario. Argentina.

137 Heraud MC, Herbelin-Wagner ML. Risk factors: environment, tobacco smoke. Arch Pediatr 2002;9(Suppl 3): 377-83.

138 Gilliland FD et al. Effects of glutation S-transferase M1, maternal smoking during pregnancy, and environmental tobacco smoke on asthma and wheezing in children. Am J Respir Crit Care Med 2002;166:457-63

139 Larsson L. Incidence of asthma in Swedish teenagers: relation to sex and smoking habits. Thorax 1995; 50:260-4.

140 Cook DG, Strachan DP. Health effects of passive smoking: 3. Parental smoking and prevalence of respiratory symptoms and asthma in school age children. Thorax 1997;52:1081-94

${ }^{141}$ Strachan DP, Coook DG. Health effects of passive smoking: 6. Parental smoking and childhood asthma: longitudinal and case-control studies. Thorax 1998;53:204-12

142 Eisner MD. Environmental tobacco smoke and adult asthma. Clin Chest Med 2002;23:749-61

${ }^{143}$ Mitchell EA, Stewart AW; ISAAC Phase One Study Group. International Study of Asthma and Allergy in Childhood (ISAAC). Eur J Epidemiol 2001;17:667-73

${ }^{144}$ Collins $\mathrm{MH}$, et al. Fetal lung hypoplasia associated with maternal smoking: a morphometric analysis. Pediatr Res 1985;19:408-12 citado en ROMERO PALACIOS PJ. ASMA Y HUMO DE TABACO Arch Bronconeumol 2004; 40(9):414-8 415 
145 Ponsonby $\mathrm{AL}$, et al. The relation between infant indoor environment and subsequent asthma. Epidemiology 2000;11:128-35.

146 Plaschke PP, et al. Onset and remission of allergic rhinitis and asthma and the relationship with atopic sensitization and smoking. Am J Respir Crit Care Med 2000;162:920-4

${ }^{147}$ Siroux V, Pin I, Oryszczyn MP, Le Moual N, Kauffmann F. Relationships of active smoking and asthma severity in the EGEA study. Epidemiological study on the Genetics and Environment of Asthma. Eur Respir J 2000;15:470-7.

${ }^{148}$ Galván Fernández C, Suárez López de Vergara RG, Oliva Fernández C, Domenech Martínez E. Patología respiratoria en los jóvenes y hábito tabáquico. Arch Bronconeumol 2000; 36:186-90.

149 Gené R. Consideraciones sobre tabaquismo pasivo y asma bronquial. Módulo 3 del Curso de actualización a distancia en Asma. Estrategia global para el manejo y la prevención del Asma. 1998-99. INTERASMA, GINA, Facultad de Ciencias médicas de la Universidad Nacional de Rosario. Argentina

${ }^{150}$ Romero Palacios P. Asma y humo de tabaco Arch Bronconeumol 2004; 40(9):414-8

151 Cook DG, Strachan DP. Health effects of passive smoking: 3. Parental smoking and prevalence of respiratory symptoms and asthma in school age children. Thorax 1997;52:1081-94

${ }^{152} \mathrm{Si}$ se equipara la interpretación de valores de OR a la tabla de interpretación de Riesgos relativos (RR) propuesta por el Prof. Dr. Galvez Vargas de la Universidad de Granada, sería un riesgo débil para los valores entre 1,2 y 1,74. Galvez Vargas et al. Estudio de cohortes. Cap 9 de Piédrola Gil Gonzalo y otros.

"Medicina preventiva y Salud Pública". 9a edición. Ed. Masson-Salvat. Barcelona, España. 1991.

153 Palmieri M, Longobardi G, Napolitano G, et al. Parental smoking and asthma in childhood. Eur J Pediatr 1990; 149:738-40.

${ }^{154}$ DiFranza JR, Lew RA. Morbidity and mortality in children associated with the use of tobacco products by other people. Pediatrics 1996;97:560-8.

155 Strachan DP. Epidemiology. In: Silverman M, ed. Childhood asthma and other wheezing disorders. London: Chapman \& Hall, 1995: 7-31.

156 Palmieri M, Longobardi G, Napolitano G, et al. Parental smoking and asthma in childhood. Eur J Pediatr 1990;149:738-40.

157 Strachan DP, Coook DG. Health effects of passive smoking: 5. Parental smoking and allergic sensitization in children. Thorax 1998;53:117-23

158 Barrett EG, Wilder JA, March TH, Espindola T, Bice DE: Cigarette smoke-induced airway hyperresponsiveness is not dependent on elevated immunoglobulin and eosinophilic inflammation a mouse model of allergic airway disease. Am J Repir Cir Care Med 2002, 165:1410-1418.

159 Chalmers, G. et al. Smoking and airway inflammation in patients with mild asthma. Chest 120:19171922. 2001.

${ }^{160}$ Godden DJ et al. Outcome of wheeze in childhood. Symptoms and pulmonary functions 25 years later. Am J Respir Crit Care Med 1994. 149: 106-12

161 Murray CS, Woodcock A et al. Pediatr Pulmonol. Tobacco smoke exposure, wheeze, and atopy. 2004 Jun; 37(6):492-8.

162 Clasificaron como atópicos a los niños con antecedentes rinitis de tipo alérgico o eccema.

${ }^{163}$ Chen Y, Rennie DC, Dosman JA. Influence of environmental tobacco smoke on asthma in nonallergic and allergic children. Epidemiology 1996;7:536-9.

${ }^{164}$ Murray AB, Morrison BJ. It is children with atopic dermatitis who develop asthma more frequently if the mother smokes. J Allergy Clin Immunol 1990;86:732-9.

${ }^{165}$ Strachan DP, Coook DG. Health effects of passive smoking: 6. Parental smoking and childhood asthma: longitudinal and case-control studies. Thorax 1998;53:204-12

${ }^{166}$ Floreani AA, Rennard SI. The role of cigarette smoke in the pathogenesis of asthma and as a trigger for acute symptoms. Curr Opin Pulm Med 1999;5:38-46.

167 Strachan DP, Coook DG. Health effects of passive smoking: 6. Parental smoking and childhood asthma: longitudinal and case-control studies. Thorax 1998;53:204-12

168 O’Connell EJ, Logan GB. Parental smoking in childhood asthma. Ann Allergy 1974;32:142-5. 206 
169 Bedolla-Barajas Martín et al. Asthma in Mexican school-age children is not associated with passive smoking or obesity. http://dx.doi.org/10.5415/apallergy.2013.3.1.42 Asia Pac Allergy 2013;3:42-49

170 Ning Song, Prevalence, severity and risk factors of asthma, rhinitis and eczema in a large group of Chinese schoolchildren J Asthma, 2014; 51(3): 232-242

${ }^{171}$ Brunekreef B. et al. PIAMA study group. "Indoor smoking is adequately reported by parents of 3 months old infants as assessed by nicotine measurements in indoor air: the PIAMA birth cohort study" Epidemiology 2000. 11:350-2.

172 Cook DG, Strachan DP. Health effects of passive smoking: 3-Parental smoking and prevalence of respiratory symptoms and asthma in school age children. Thorax 1997;52: 1081-94.

173 Department of Health Committee on the Medical Effects of Air Pollutants. Asthma and outdoor air pollution. London: HMSO, 1995: 85-176.

${ }^{174}$ Salvaggio J et al. Mold-induced Asthma. J. Allergy Clin Immunol. Vol. 68, n 5. Nov 1981

175 Bush, Robert K. MD and Portnoy Jay M., MD. The role and abatement of fungal allergens in allergic diseases. J ALLERGY CLIN IMMUNOL vol 107, number 3. 3/2001

${ }^{176}$ Salvaggio J et al. Mold-induced Asthma. J. Allergy Clin Immunol. Vol. 68, n 5. Nov 1981

177 *Barnes Ch et al. Frequency of Fungi in Homes of Pediatric Allergy Patients. Allergy Clin Immunol Int. 18/5 (2006).

**Gergen $\mathrm{P}$ et al. The association of individual allergen reactivity with respiratory disease in a national sample: Data from the second National Health and Nutrition Examination Survey, 1976-80 (NHANES II) J Allergy Clin Immunol 1992; 90:579-588. ***Halonen $\mathrm{M}$ et al. Alternaria as a major allergen for Asthma in children raised in a desert environment. Am J Respir Crit Care Med 1997; 155:1356-1361.

178 Edmonson D et al. Allergy and "toxic mold síndrome". Annals of Allergy \& Clinical Immunology. Vol 4. 2/2005

179 Jaakola $\mathrm{M}$ et al. Indoor dampness and molds and development of adult-onset asthma: a population based incident case-control study. Environ Health Perspect. 2002; 110:543-547

${ }^{180}$ Burge H. Fungi: toxic killer or unavoidable nuisances? Ann Allergy Asthma Immunol. 2001; 2001, 87 (Suppl 3): 52-56

181 Jossen R. Sensibilización a cucarachas, ácaros y hongos en asmáticos del centro de Santa Fe. Presentado en el Congreso sudamericano de Alergia y Asma de Córdoba 2011.

182 Fili $\mathrm{N}$ et al Alergenos sensibilizantes más frecuentes en niños asistidos en hospital público de Salta. Presentado en el Congreso sudamericano de Alergia y Asma de Córdoba 2011.

${ }^{183}$ Casuística del Prof. Dr. Carlos Baena-Cagnani en Córdoba, Argentina.

${ }^{184}$ Bush, Robert K. MD and Portnoy Jay M., MD. The role and abatement of fungal allergens in allergic diseases. J ALLERGY CLIN IMMUNOL vol 107, number 3. 3/2001

${ }^{185}$ Gergen $\mathrm{P}$, Turkeltaub P, Kovar M. The prevalence of skin test reactivity to eight common aeroallergens in the U.S. population: results from the second National Health and Nutrition Examination Survey. J Allergy Clinlmmunol 1987;80:669-79.

${ }^{186}$ Aas K, Leegaard J, Aukrust L. Immediate type hypersensitivity to common moulds. A comparison of different diagnostic materials. Allergy 1980;35:443-51

187 Shah Ashok. Allergic Bronchopulmonary Aspergillosis. Allergy Clin Immunol Int - J. World Allergy Org $17 / 5$ (2005)

188 * Shah A et al. Allergic bronchopulmonary aspergillosis with cubbing and cavitation. Indian Pediatric 1993. 30:248-251. **Imbeau SA et al. Allergic bronchopulmonary aspergillosis in infants. Am J Dis Child 1977. 131: 1127-1130.

189 Portnoy J et al. Health effects of indoor fungi. Annals of Allergy, Asthma \& Immunology. Vol 94, 3/2005. 190 Edmonson D et al. Allergy and "toxic mold síndrome". Annals of Allergy \& Clinical Immunology. Vol 4. 2/2005

${ }^{191}$ Edmonson D et al. Allergy and "toxic mold síndrome". Annals of Allergy \& Clinical Immunology. Vol 4. 2/2005

192 Entiendo más adecuado llamarlo así y no "síndrome del edificio enfermo", que se me ocurre describe una cuestión propia de arquitectos e ingenieros de construcción. 
193 Johanning E. et al. Health and immunology study following exposure to toxicgenic fungi (Stachibotrys chartarum) in a water damage office environment. Int Arch Occup Environ Health 1996; 68: 207/218

194 Martínez, Vercelli. Asma. Lancet 382: 1360-72 2013

195 Rylander R et al. Airways inflammation, atopy and (1->3)-6-D-glucan exposures in two schools. Am J Respir Crit CareMed. 1998; 158 (5 pt 1): 1685-1687.

196 Portnoy J et al. Health effects of indoor fungi. Annals of Allergy, Asthma \& Immunology. Vol 94, 3/2005.

197 Portnoy J et al. Health effects of indoor fungi. Annals of Allergy, Asthma \& Immunology. Vol 94, 3/2005.

${ }^{198}$ Edmonson D et al. "Allergy and "toxic mold síndrome". Annals of Allergy \& Clinical Immunology. Vol 4. 2/2005

199 Samet J M, Marbury M C, Spengler J D. Health effects and sources of indoor air pollution (Part I \& 2). Am Rev Respir Dis 1987; 136: 1486-508 y 137: 221-42. [ [ Links ]

${ }^{200}$ Agencia para Sustancias Tóxicas y el Registro de Enfermedades, 4770 Buford Hwy NE, Atlanta, USA http://www.atsdr.cdc.gov/

201 Informe Técnico AIDIMA. España. http://www.xn--eco-diseo-s6a.net/ Ecoinforme Muebles 2009.

202 Citado en Agencia para Sustancias Tóxicas y el Registro de Enfermedades. "Desencadenantes ambientales del asma". CDC. Centros para el Control y la Prevención de Enfermedades. 1600 Clifton Rd Atlanta, GA 30333 USA. 2008

203 (Dykewicz et al. 1991; Grammar et al. 1990; Kramps et al. 1989; Wantke et al. 1996a, 1996b). (Wantke et al. 1996a). (citados en Health effects. Formaldehyde. Agencia para Sustancias Tóxicas y el Registro de Enfermedades, 4770 Buford Hwy NE, Atlanta, USA http://www.atsdr.cdc.gov/ 2008

204 (citado en HEALTH EFFECTS. Formaldehyde. Agencia para Sustancias Tóxicas y el Registro de Enfermedades , 4770 Buford Hwy NE, Atlanta, USA http://www.atsdr.cdc.gov/ 2008

205 (citado en HEALTH EFFECTS. Formaldehyde. Agencia para Sustancias Tóxicas y el Registro de Enfermedades , 4770 Buford Hwy NE, Atlanta, USA http://www.atsdr.cdc.gov/ 2008

206 Thrasher et al. (1987); Wantke et al. 1996b; (citados en HEALTH EFFECTS. Formaldehyde. Agencia para Sustancias Tóxicas y el Registro de Enfermedades, 4770 Buford Hwy NE, Atlanta, USA http://www.atsdr.cdc.gov/ 2008

207 Division of Toxicology and Environmental Medicine. Formaldehyde. Dep. of Health and Human Services, Public Health Service. Agency for Toxic Substances and Disease Registry. www.atsdr.cdc.gov/ USA 2008

${ }^{208}$ Eco informe Sector Muebles AIDIMA 2009 http://www.eco-diseño.net

${ }^{209}$ Agencia para Sustancias Tóxicas y el Registro de Enfermedades , 4770 Buford Hwy NE, Atlanta, USA http://www.atsdr.cdc.gov/

${ }^{210}$ Agencia para Sustancias Tóxicas y el Registro de Enfermedades Atlanta, USA

${ }^{211}$ Agencia Internacional para la Investigación del Cáncer, Organización Mundial de la Salud; http://www.iarc.fr/ 2004.

212 Li, Q.; Mei, Q.; Huyan, T.; Xie, L.; Che, S.; Yang, H.; Zhang, M.; Huang, Q. Effects of formaldehyde exposure on human NK cells in vitro. Environmental Toxicology and Pharmacology Vol. 36 Nr. 3 Página: 948 - 955 Fecha de publicación: 01/11/2013

213 Citado en Dales R, Raizenne M. Residential exposure to volatile organic compounds and asthma. J Asthma. 2004 Jan;41(3):259-70

${ }^{214}$ HEALTH EFFECTS. Formaldehyde. Agencia para Sustancias Tóxicas y el Registro de Enfermedades , 4770 Buford Hwy NE, Atlanta, USA http://www.atsdr.cdc.gov/ 2008

215 Administración Nacional de Medicamentos, Alimentos y Tecnología médica. http://www.anmat.gov.ar/listados/Listado Insecticidas Raticidas 2013.pdf

${ }^{216}$ Espinosa González Jaime. Productos Químicos Peligrosos de Uso en Domicilios: Informe Final Proyecto: MINSA/REPAMAR/CEPIS/OPS-OMS/GTZ PN 98.2073.9-001.00 Panamá, Marzo del 2000

${ }^{217}$ Efecto, Saeta, Carrefour, Caracol, Great value, Alto poder, Magnífico, Gladiador, Escudo, Leader price, el Buda y For fait

${ }^{218}$ de la Iglesia Huerta Antonio, PLAGUICIDAS: Neurotoxicidad y vigilancia de la salud. Centro Nacional de Medios de Protección. Sevilla-INSHT. http://www.insht.es 
${ }^{219}$ Varela Fuentes B. y otros. Alergia en la práctica clínica. Ed. Espasa-Calpe. 1946. Buenos Aires.

${ }^{220}$ Kurlat David. Alergia en Pediatría. Ed Panamericana. Buenos Aires, 1974.

${ }^{221}$ Citado en Perez Lozano A. Asma bronquial. Ed. Mediterráneo. 1965 España.

222 Mitchell J. Allergic contact dermatitis from pyrethrum (chrysanthemum spp.) The roles of pyrethrosin, a sesquiterpene lactone, and of pyrethrin II. British Journal of Dermatology Volume 86, Issue 6, 568-573 June 1972

223 Darsow Ulf et al. Immunoglobulin E-Mediated Allergy Plays a Role in Atopic Eczema as Shown in the Atopy Patch Test. WAO Journal \& Volume 1, Number 3, March 2008

${ }^{224}$ Macan J, et al. Health effects of pyrethrins and pyrethroids Arh Hig Rada Toksikol. 2006 Jun; 57 (2): 237-43.

225 Intoxicación aguda por plaguicidas, piretrinas y piretroides

http://www.bvsde.org.ni/Web textos/CIES/Cies0002/capitulo5.pdf

${ }^{226}$ Karpati Adam et al. Pesticide Spraying for West Nile Virus Control and Emergency Department Asthma Visits in New York City, 2000 Environmental Health Perspectives VOLUME 112 | NUMBER 11 | August 20041183

227 Moretto, A. Indoor spraying with the pyrethroid insecticide lambda-cyhalothrin: Effects on spraymen and inhabitants of sprayed houses. Bull WHO 69(5):591-594; 1991.

${ }^{228}$ Karpati Adam et al. Pesticide Spraying for West Nile Virus Control and Emergency Department Asthma Visits in New York City, 2000 Environmental Health Perspectives VOLUME 112 | NUMBER 11 | August 20041183

229 VandenDriessche, K.S.J. et al Anaphylaxis in an Airplane After Insecticide Spraying LOURNAL OF TRAVEL MEDICINE Vol. 17 Nr. 6 Página: 427 - 429 Fecha de publicación:01/11/2010

${ }^{230}$ Bradberry SM Poisoning due to pyrethroids. Toxicol Rev. 2005;24 (2):93-106.

231 SAN ROMÁN M., et al. Intoxicación por piretrinas: una causa singular de convulsiones en el lactante. BOL PEDIATR 2003; 43: 284-289

232 Hudson, N.L Characteristics and magnitude of acute pesticide-related illnesses and injuries associated with pyrethrin and pyrethroid exposures-11 states, 2000-2008 AMERICAN JOURNAL OF INDUSTRIAL MEDICINE Vol. 57 Nr. 1 Página: 15 - 30. 01/2014

233 Citado en Dales R, Raizenne M. Residential exposure to volatile organic compounds and asthma. J Asthma. 2004 Jan;41(3):259-70.

${ }^{234}$ National Pesticide Information Center - Piperonyl Butoxide General Fact Sheet USA

235 Jean-Pastor M, Vervloet $\mathrm{D}$ et al. Destrucción de los ácaros en el polvo doméstico: eficacia y tolerancia de un nuevo acaricida en aerosol. Revue francaise d' Allergologie. 3 1986. 125-129

236 Osimitz, T.G et al. Human exposure to insecticide products containing pyrethrins and piperonyl butoxide (2001-2003) FOOD AND CHEMICAL TOXICOLOGY Vol. 47 Nr. 7 Página: 1406 - 1415. 07/2009

${ }^{237}$ Environmental Protection Agency. Methoprene R.E.D. Fact Sheet. June 2001 Update of the March 1991

${ }^{238}$ Korsgaard J et al. Epidemiology of house dust mite allergy. Allergy. 1991, 46, Suppl. 11 14-18.

239 Bush, Robert K. MD and Portnoy Jay M., MD. The role and abatement of fungal allergens in allergic diseases. J ALLERGY CLIN IMMUNOL vol 107, number 3. 3/2001

${ }^{240}$ Sastre H. et al. Factores de riesgo no genéticos en el desarrollo de asma bronquial. Neumosur 2007; 19, 1: $17-18$

${ }^{241}$ Strachan DP. Hay fever, hygiene and household size. Br Med J 1994; 308:1259-60

242 http://www.aq.upm.es/Departamentos/Fisica/UD-instalaciones/Paginas\%2010-11.pdf

243 Fuentes Freixanet V. Cálculos de Ventilación Natural.- Universidad autónoma metropolitana. México 2004

${ }^{244}$ http://www.bvsde.paho.org/arquitectura/clase43/clase43.htm\#aberturas

${ }^{245}$ Comunidad. Valenciana, España. Norma HD 91 que exige que todas las habitaciones (excepto baños, pasillos, trasteros....) tengan una superficie de ILUMINACIÓN de al menos el $10 \%$ de su superficie y al menos $1 / 3$ de la superficie de iluminación, debe ser practicable para proporcionar VENTILACION.

${ }^{246}$ Bornehag $G$ et al. Dampness in buildings and health: Nordic interdisciplinary review of the scientific evidence on association between exposure to "dampness" in building and Health effects (NORDAMMP). Indoor Air. 2001; 11:72-86. 
247 Barnes Ch et al. Frequency of Fungi in Homes of Pediatric Allergy Patients. Allergy Clin Immunol Int. 18/5 (2006)

248 Bush, Robert K. MD and Portnoy Jay M., MD. The role and abatement of fungal allergens in allergic diseases. J ALLERGY CLIN IMMUNOL vol 107, number 3. 3/2001

${ }^{249}$ En mi casuística personal, no publicada aún, con más de 3.000 pacientes testificados en esta zona, las reacciones positivas intensas superan el $75 \%$ para las diversas especies de ácaros, principalmente Dermatofagoides pteronissimus y farinae y Blomia tropicalis.

250 Hallas T. The biology of mites. Allergy, 1991, 46, Suppl. 11, 6-9. Copenhagen

251 Modificado de Agencia para Sustancias Tóxicas y el Registro de Enfermedades. "Desencadenantes ambientales del asma".CDC. Centros para el Control y la Prevención de Enfermedades. 1600 Clifton Rd Atlanta, GA 30333 USA.

252 Arshad SH. Primary prevention of asthma and allergy. J Allergy Clin Immunol 2005;116(1):3-14.

253 Agencia para Sustancias Tóxicas y el Registro de Enfermedades. "Desencadenantes ambientales del asma”.

CDC. Centros para el Control y la Prevención de Enfermedades. 1600 Clifton Rd Atlanta, GA 30333 USA.

254 O'Byrne Paul, Estrategia global para el manejo y la prevencion del asma. Report 06 (http://www.ginasthma.org). McMaster University Hamilton, Canada. GINA

255 Sánchez Caraballo Jorge. Características fisicoquímicas de los gases y partículas contaminantes del aire. Su impacto en el asma. latreia Vol. 25 (4): 369-379, octubre-diciembre 2012

${ }^{256}$ Dales R, Raizenne M. Residential exposure to volatile organic compounds and asthma. J Asthma. 2004 Jan;41(3):259-70

257 Trabajos de Diaz Sanchez comentados por Davies R. The role of Air Pollution on Allergic Airways Disease. Cap. de Asthma: a link between Environment, Immunology and the Airways. Editors: Neffen H., Baena Cagnani C. y otros. Hogrefe \& Huber publishers, Buenos Aires, 1999

258 Oyarzún M. Contaminación atmosférica y asma bronquial Rev Chil Enf Respir 2000; 16: 142-7

259 Sánchez Caraballo Jorge. Características fisicoquímicas de los gases y partículas contaminantes del aire. Su impacto en el asma. latreia Vol. 25 (4): 369-379, octubre-diciembre 2012

${ }^{260}$ Gruzieva Olena, et al. Meta-analysis of air pollution exposure association with allergic sensitization in European birth cohorts. J ALLERGY CLIN IMMUNOL march 2014.

261 Oftedal B, et al Residential outdoor air pollution and allergen sensitization in schoolchildren in Oslo, Norway. Clin Exp Allergy 2007;37:1632-40.

${ }^{262}$ Ardusso L. Crisci C, Lockey R et al, Asociación entre exposición a polvo de soja, sensibilidad alérgica y perfil de síntomas respiratorios MEDICINA (Buenos Aires) 2000; 61: 1-7

263 Ardusso L. Crisci C, Lockey R et al, Asociación entre exposición a polvo de soja, sensibilidad alérgica y perfil de síntomas respiratorios MEDICINA (Buenos Aires) 2000; 61: 1-7

${ }^{264}$ Carñel G, Costa Patricia et al. "Caracterización espacial por riesgo ambiental en la ciudad de Concepción del Uruguay con herramientas TIGs" Informe final PID-UNER 10053. 2013

265 Perez Lozano A. Asma bronquial. Ed. Mediterráneo. 1965, España.

${ }^{266}$ Citados en Korsgaard J et al. Epidemiology of house dust mite allergy. Allergy. 1991, 46, Sup11 14-18.

${ }^{267}$ Está prohibida la construcción bajo esta cota por ser área inundable, según Ordenanza № 4110 del año 1996, mediante la cual declara "Zona de no innovar sujeta a expropiación"al sector inundable ubicado al norte de la traza de la defensa hasta la curva de nivel cota $+8.25 \mathrm{mts}$ " (referida a la escala del puerto local).

268 Se consideran factores ambientales inespecíficos aquellas variables no endógenas que actúan por mecanismos no mediados por IgE (alergia tipo I).

${ }^{269}$ Asher MI, Keil U, Anderson HR, Beasley R, y otros. Internacional Study of Asthma and Allergies in Childhood (ISAAC): Rationale and methods. Eur Resp J 1995; 8:483-491

270 Burney PGJ et al. Validity and repeatability of the IUATLD (1984) Bronchial Symptoms Questionnaire: an international comparison. Eur Resp J 1989. 2:940-945. 
271 Mata Fernández C., Fernández-Benítez M., Pérez Miranda M., Guillén Grima F.. Validation of the Spanish version of the Phase III ISAAC questionnaire on asthma. J Invest Allergol Clin Immunol 2005; Vol. 15(3): 201-210

272 Pearce $N$ et al. Self-reported prevalence of asthma symptoms in children in Australia, England, Germany and New Zealand: an international comparison using the ISAAC protocol. Eur Resp J 1993. 6: 1455-1461

${ }^{273}$ Fuertes J, et al. Prevalencia actual de asma, alergia e hiperrespuesta bronquial en niños de 6-8 años. An Esp Pediatr 2001;54:18-26.

274 GINA Iniciativa global para el Asma. NHLBI. OMS 2006.http://www.ginasthma.org).

275 Está prohibida la construcción bajo esta cota por ser área inundable, según Ordenanza № 4110 del año 1996, mediante la cual declara "Zona de no innovar sujeta a expropiación", "al sector inundable ubicado al norte de la traza de la defensa hasta la curva de nivel cota +8.25 m" (referida a la escala del puerto local). Sin embargo numerosas familias se siguen instalando en estos terrenos y si alguna de ellas lo desocupa, otras construirán su vivienda, generalmente muy precaria.

${ }^{276}$ Burney PGJ et al. Validity and repeatability of the IUATLD (1984) Bronchial Symptoms Questionnaire: an international comparison. Eur Resp J 1989. 2:940-945.

277 Mata Fernández C., Fernández-Benítez M., Pérez Miranda M., Guillén Grima F.. Validation of the Spanish version of the Phase III ISAAC questionnaire on asthma. J Invest Allergol Clin Immunol 2005; Vol. 15(3): 201-210

278 Pearce N et al. Self-reported prevalence of asthma symptoms in children in Australia, England, Germany and New Zealand: an international comparison using the ISAAC protocol. Eur Resp J 1993. 6: 1455-1461

${ }^{279}$ Scheffer A, Bousquet J y otros. Informe del consenso internacional sobre el Diagnóstico y Tratamiento del Asma. Instituto Nacional del Corazón, Pulmón y Sangre, Departamento de Salud y Servicios Humanos, Servicio de Salud Pública, Instituto Nacional de Salud de los Estados Unidos de América. Publicación $\mathrm{n}^{\circ}$ 92-3091, Maryland, USA. 3/1992. (Participaron expertos invitados de diversos países)

$280 \mathrm{P}$ basada en la prevalencia de la investigación anterior realizada en la ciudad.

${ }^{281}$ Galvez Vargas R. y otros. Estudios de cohortes. Cap. 9 de Piédrola Gil y otros, "Medicina Preventiva y Salud Pública", $9^{\circ}$ ed. Ed. Científicas y técnicas (Masson-Salvat). Barcelona, España. 1991

282 Gordis Leon. Epidemiología 3a ed. Elsevier España. 2005

283 Gordis Leon. Epidemiología 3 ed. Elsevier España. 2005

${ }^{284}$ United States. Department of Health, Education and Welfare: Smoking and Health: Report of the Advisory Committee to the Surgeon General. Washington, DC. Public Health Service, 1964. (Citado en Gordis Leon. Epidemiología 3a ed. Elsevier España. 2005).

285 Los porcentajes se refieren al total que respondió por si o por no a la pregunta respectiva, situación que varió en cada una de ellas.

${ }^{286}$ Marcó Leandro et al. Evolución de la prevalencia del asma infantil. Revista: "Archivos de Alergia e Inmunología clínica", Vol 37, sup 2 año 2006, ISSN 1515-9825.

287 Acordamos con lo resaltado por los investigadores Cook y Strachan (1998) sobre la creciente importancia de la tos como manifestación de asma, incluso sin sibilantes, tal como lo plantean Ninan et al en Persistent nocturnal cough in childhood: a population based study. Arch Dis 112 Child 1995;73:4037 y Wright et al, en Recurrent cough in childhood and its relation to asthma. Am J Respir Crit Care Med 1996;153:1259-65

${ }^{288}$ Ver procedimiento en Material y métodos la tabla de Operacionalización de las variables

${ }^{289}$ Kurlat David. Alergia en Pediatría. Ed. Panamericana. Buenos Aires, 1974.

290 encuesta 2 a muestra 2 de casos y controles en familias que aceptaron realizar el cuestionario asistido y la visita domiciliaria. $(\mathrm{n}=140)$

${ }^{291}$ Clough J et al. The profile and spectrum of bronchial responsiveness and its relationship to atopy and wheeze in 7 and 8 years old children with respiratory symptoms. Arch Dis Child 1992, 67 514-579

292 Cockcroft DW, et al. Bronchial reactivity to inhaled histamine: a method and clinical survey. Clin Allergy $1977 ; 7: 235-243$. 
${ }^{293}$ Caudri D, Wijga A, Schipper CM, Hoekstra M, Postma DS, Koppelman GH, et al. Predicting the long-term prognosis of children with symptoms suggestive of asthma at preschool age. J Allergy Clin Immunol 2009; 124:903-10, e1-7.

294 Martel Marie-Josée et al. Determinants of the Incidence of Childhood Asthma: A Two-Stage CaseControl Study Am. J. Epidemiol. 169: 195-205. 2007

295 Baena-Cagnani C. y Gené R. Factores de riesgo. Módulo 3 del Curso de actualización a distancia en Asma. Estrategia global para el manejo y la prevención del Asma. 1998-99. INTERASMA, GINA, Facultad de Ciencias médicas de la Universidad Nacional de Rosario. Argentina.

${ }^{296}$ Holberg CJ, Wright AL, Martinez FD, et al. Child day care, smoking by caregivers, and lower respiratory tract illness in the first 3 years of life. Group Health Medical Associates. Pediatrics 1993;91:885-92.

297 Gordis Leon. Epidemiología 3a ed. Elsevier España. 2005

298 Gordis Leon. Epidemiología 3a ed. Elsevier España. 2005

299 Esta actividad fue realizada en el marco de esta investigación en el Laboratorio del Programa Salud para todos de la FCS-UNER, bajo la conducción del Dr. Dante Bueno, Microbiólogo con experiencia en Hongos y un equipo de becarios colaboradores (Bidal, Chichi, Costa).

${ }^{300}$ Gordis Leon. Epidemiología 3 $\underline{a}$ ed. Elsevier España. 2005

${ }^{301}$ Wijga A et al. "Are children at high familial risk of developing allergy born into a low risk environment? The PIAMA Birth Cohort Study. Clinical and Experimental Allergy, 2001. Vol 31, 576-581.

302 Está prohibida la construcción bajo esta cota por ser área inundable, según Ordenanza № 4110 del año 1996, mediante la cual declara "Zona de no innovar sujeta a expropiación", "al sector inundable ubicado al norte de la traza de la defensa hasta la curva de nivel cota $+8.25 \mathrm{~m}$ " (referida a la escala del puerto local). Sin embargo numerosas familias se siguen instalando en estos terrenos y si alguna de ellas lo desocupa, otras construirán su vivienda, generalmente muy precaria.

303 Situación de los años 2004/5 en que se desarrollo la recolección básica de datos para la investigación. Con posterioridad este basural fue desactivado parcialmente.

${ }^{304}$ Chichi Gabriel. Evaluación de Impacto Ambiental de la Empresa CALIMBOY S.A. C. del Uruguay E Ríos.

${ }^{305}$ Carñel G, Costa Patricia y col. "Caracterización espacial por riesgo ambiental en la ciudad de Concepción del Uruguay con herramientas TIGs" Informe final PID-UNER 10053. 2013

306 Proyectado según Censo Nacional de Población, Hogares y Viviendas 2001. Censo 2001. F01. Radios censales 08-

307 Encuesta citada en Carñel G, Costa Patricia et al. "Caracterización espacial por riesgo ambiental en la ciudad de Concepción del Uruguay con herramientas TIGs" Informe final PID-UNER 10053. 2013

${ }^{308}$ Carñel G, Costa Patricia et al. "Caracterización espacial por riesgo ambiental en la ciudad de Concepción del Uruguay con herramientas TIGs" Informe final PID-UNER 10053. 2013

${ }^{309}$ Radios censales. 02, 03, 06, 07. Proyectado desde el Censo Nacional de Población, Hogares y Viviendas 2001.

310 Wijga A et al. "Are children at high familial risk of developing allergy born into a low risk environment? The PIAMA Birth Cohort Study. Clinical and Experimental Allergy, 2001. Vol 31, 576-581.

${ }^{311}$ Dales R, Raizenne M. Residential exposure to volatile organic compounds and asthma. J Asthma. 2004 Jan;41(3):259-70.

312 Silva SI. Epidemiología del cáncer; principios y métodos. Lyon: Agencia Internacional de Investigación sobre el Cáncer; 1999.IARC. Epidemiología del cáncer; principios y métodos.

${ }^{313}$ Fuertes J, Meriz J, Isanta C, Pardos C, López V, González E. Factores de riesgo de asma, alergia e hiperreactividad bronquial en niños de 6 a 8 años. An Esp Pediatr 2001;55:205-12

${ }^{314}$ Fuertes J, et al. Prevalencia actual de asma, alergia e hiperrespuesta bronquial en niños de 6-8 años. An Esp Pediatr 2001;54:18-26.

315 Martel Marie-Josée et al. Determinants of the Incidence of Childhood Asthma: A Two-Stage CaseControl Study Am. J. Epidemiol. 169: 195-205. 2007

${ }^{316}$ van der Werff SD et al. Prediction of Asthma by Common Risk Factors: A Follow-up Study in Cuban Schoolchildren. J Investig Allergol Clin Immunol 2013; Vol. 23(6): 415-420 
317 Marcó Leandro et al. Incidencia del asma infantil en Concepción del Uruguay, Argentina. Factores de riesgo y protección. Presentado en Congreso Sudamericano de Alergia y Asma. Córdoba 2011.

${ }^{318}$ Armentia A, et al. El tabaco como alérgeno en enfermedad bronquial obstructiva. Estudio preliminar. Alergol Inmunol Clin 2005; 20: 14-27

${ }^{319}$ Wijga A et al. "Are children at high familial risk of developing allergy born into a low risk environment? The PIAMA Birth Cohort Study. Clinical and Experimental Allergy, 2001. Vol 31, 576-581.

320 O'Byrne Paul, Estrategia global para el manejo y la prevencion del asma. GINA Report 06 (http://www.ginasthma.org). McMaster University Hamilton, Canada. GINA

${ }^{321}$ Chiappero $\mathrm{M}$ et al. Variación anual de la micoflora en la ciudad de San Juan y en hogares de pacientes con patología respiratoria IgE dependiente. Arch Arg Al e IC. Vol 27. 1996

322 Lugauskas A et al. Airborne fungi in industrial environments. Potential agents of respiratory diseases. Ann Agric Environ Med 2004, 11,19-25.

323 Li D, Kendrick B. Indoor aeromycota in relation to residential characteristics and allergic symptoms. Mycopathologia 1995;131:149-57.

${ }^{324} \mathrm{Li} \mathrm{C}$, Hsu L. Airborne fungus allergen in association with residential characteristics in atopic and control children in a subtropical region. Arch Environ Health 1997;52:72-9.

325 Hulin, M. et al. "Positive associations between respiratory outcomes and fungal index in rural inhabitants of a representative sample of French dwellings". International Journal of Hygiene and Environmental Health. Available online 30 March 2012,

326 Martel Marie-Josée et al. Determinants of the Incidence of Childhood Asthma: A Two-Stage CaseControl Study Am. J. Epidemiol. 169: 195-205. 2007

${ }^{327}$ Edmonson D et al. "Allergy and "toxic mold síndrome". Annals of Allergy \& Clinical Immunology. Vol 4. 2/2005

328 Pirhonen I, Nevalainen A, Husman T, Pekkanen J. Home dampness, moulds and their influence on respiratory infections and symptoms in adults in Finland. Eur Respir J 1996;9:2618-22.

${ }^{329}$ Ver cap 3: formaldehido.

330 Harving $\mathrm{H}$, et al. Pulmonary function and bronchial reactivity in asthmatics during low-level formaldehyde exposure. Lung 1990; 168:15-21.

331 B D Ostro, M J Lipsett, J K Mann, M B Wiener, and J Selner "Indoor air pollution and asthma. Results from a panel study." American Journal of Respiratory and Critical Care Medicine, Vol. 149, No. 6 (1994), pp. 1400-6.

332 (citado en HEALTH EFFECTS. Formaldehyde. Agencia para Sustancias Tóxicas y el Registro de Enfermedades , 4770 Buford Hwy NE, Atlanta, USA http://www.atsdr.cdc.gov/

333 Thrasher et al. (1987); Wantke et al. 1996b; (citados en HEALTH EFFECTS. Formaldehyde. Agencia para Sustancias Tóxicas y el Registro de Enfermedades, 4770 Buford Hwy NE Atlanta USA http://www.atsdr.cdc.gov

${ }^{334}$ HEALTH EFFECTS. Formaldehyde. Agencia para Sustancias Tóxicas y el Registro de Enfermedades , 4770 Buford Hwy NE, Atlanta, USA http://www.atsdr.cdc.gov/

335 Dales R, Raizenne M. Residential exposure to volatile organic compounds and asthma. J Asthma. 2004 Jan;41(3):259-70.

${ }^{336}$ Agencia para Sustancias Tóxicas y el Registro de Enfermedades. HEALTH EFFECTS. Formaldehyde. Atlanta, USA http://www.atsdr.cdc.gov/ 2008

${ }^{337}$ Riesgo ajustado por ventilación del dormitorio. Ver Cap. 7, Formaldehido de esta Tesis.

338 Agencia para Sustancias Tóxicas y el Registro de Enfermedades. HEALTH EFFECTS. Formaldehyde. Atlanta, USA http://www.atsdr.cdc.gov/ 2008

${ }^{339}$ Agencia para Sustancias Tóxicas y el Registro de Enfermedades. HEALTH EFFECTS. Formaldehyde. Atlanta, USA http://www.atsdr.cdc.gov/ 2008

${ }^{340}$ Llop Sabrina, et al. "Prenatal and postnatal residential usage of insecticides in a multicenter birth cohort in Spain". Science of the Total Environment 445-446 (2013) 273-280.

${ }^{341}$ Martel Marie-Josée et al. Determinants of the Incidence of Childhood Asthma: A Two-Stage CaseControl Study Am. J. Epidemiol. 169: 195-205. 2007 
342 Volkmer RE, Ruffin RE, Wigg NR, et al. The prevalence of respiratory symptoms in South Australian preschool children. II. Factors associated with indoor air quality. J Paediatr ChildHealth. 1995;31(2):116120.

${ }^{343}$ Levesque B, Lajoie P, Rhainds M, et al. Enquete sociale et de sante de 1998 au Quebec: divers determinants des maladies chroniques respiratoires. Can J Public Health. 2001;92(3): 228-232.

344 Pirhonen I, Nevalainen A, Husman T, Pekkanen J. Home dampness, moulds and their influence on respiratory infections and symptoms in adults in Finland. Eur Respir J 1996;9:2618-22.

${ }^{345}$ Chew, G.L. et al. Mold and endotoxin levels in the aftermath of Hurricane Katrina: A pilot project of homes in New Orleans undergoing renovation ENVIRONMENTAL HEALTH PERSPECTIVES Vol. 114 Nr. 12 Página: 1883 - 1889 01/12/2006

${ }^{346}$ Blythe M. Some aspects of the ecological study of the house dust mites. Brit.J.Dis. Chest (1976) 70, 3

${ }^{347}$ Hallas T. The biology of mites. Allergy. 1991, 46, Suppl 11, 6-9.

348 Martel Marie-Josée et al. Determinants of the Incidence of Childhood Asthma: A Two-Stage CaseControl Study Am. J. Epidemiol. 169: 195-205. 2007

$349 *$ Rona RJ. Asthma and poverty. Thorax. 2000;55(3):239-244. * Ernst P, Demissie K, Joseph L, et al. Socioeconomic status and indicators of asthma in children. Am J Respir Crit Care Med. 1995;152(2):570575 .

* Sin DD, Svenson LW, Cowie RL, et al. Can universal access to health care eliminate health inequities between children of poor and nonpoor families? A case study of childhood asthma in Alberta. Chest. 2003; 124(1):51-56. (citados por Martel Marie-Josée et al. Determinants of the Incidence of Childhood Asthma: A Two-Stage Case-Control Study Am. J. Epidemiol. 169: 195-205. 2007

${ }^{350}$ Wolff, P.T. et al. Spirometric reference values in urban children in Madagascar: Poverty is a risk factor for low lung function. PEDIATRIC PULMONOLOGY Vol. 49 Nr. 1 Página: 76 - 832014

${ }^{351}$ van der Werff SD et al. Prediction of Asthma by Common Risk Factors: A Follow-up Study in Cuban Schoolchildren. J Investig Allergol Clin Immunol 2013; Vol. 23(6): 415-420

352 Tegethoff M, Olsen J, Schaffner E, Meinlschmidt G. Asthma during pregnancy and clinical outcomes in offspring: a national cohort study. Pediatrics 2013; 132:483-91. Citado en Szefler S., Advances in pediatric asthma in 2013: Coordinating asthma care J ALLERGY CLIN IMMUNOL MARCH 2014 


\section{Anexo.}

- Formulario de Encuesta 1

- Mapas del área de estudio 